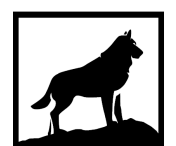

Michigan Technological

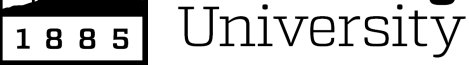

Michigan Technological University

Digital Commons @ Michigan Tech

\title{
ANALYZING THE LIFE-CYCLE OF UNSTABLE SLOPES USING APPLIED REMOTE SENSING WITHIN AN ASSET MANAGEMENT FRAMEWORK
}

El Hachemi Y. Bouali

Michigan Technological University, eybouali@mtu.edu

Copyright 2018 El Hachemi Y. Bouali

\section{Recommended Citation}

Bouali, EI Hachemi Y., "ANALYZING THE LIFE-CYCLE OF UNSTABLE SLOPES USING APPLIED REMOTE SENSING WITHIN AN ASSET MANAGEMENT FRAMEWORK", Open Access Dissertation, Michigan Technological University, 2018.

https://doi.org/10.37099/mtu.dc.etdr/649

Follow this and additional works at: https://digitalcommons.mtu.edu/etdr

Part of the Geological Engineering Commons, Geology Commons, Geomorphology Commons, Geotechnical Engineering Commons, and the Urban Studies and Planning Commons 


\title{
ANALYZING THE LIFE-CYCLE OF UNSTABLE SLOPES USING APPLIED REMOTE SENSING WITHIN AN ASSET MANAGEMENT FRAMEWORK
}

\author{
By \\ El Hachemi Y. Bouali \\ A DISSERTATION \\ Submitted in partial fulfillment of the requirements for the degree of \\ DOCTOR OF PHILOSOPHY \\ In Geology
}

\section{MICHIGAN TECHNOLOGICAL UNIVERSITY 2018}

(C) 2018 El Hachemi Y. Bouali 
This dissertation has been approved in partial fulfillment of the requirements for the Degree of DOCTOR OF PHILOSOPHY in Geology.

Department of Geological and Mining Engineering and Sciences

Dissertation Advisor: Dr. Thomas Oommen

Committee Member: Dr. Stanley Vitton

Committee Member: $\quad$ Dr. Donald Atwood

Committee Member: $\quad$ Dr. Rüdiger Escobar-Wolf

Department Chair: $\quad$ Dr. John Gierke 


\section{TABLE OF CONTENTS}

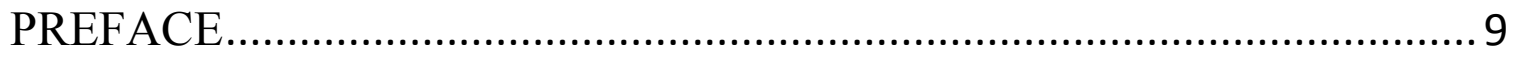

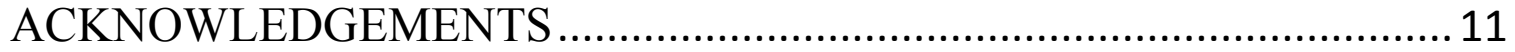

LIST OF ABBREVIATIONS .............................................................. 12

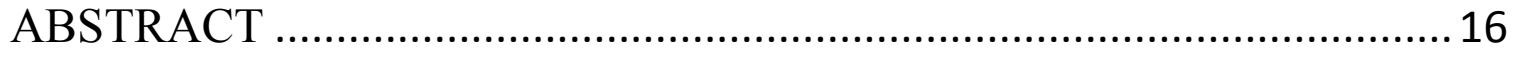

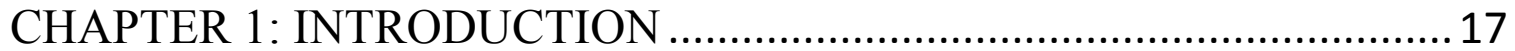

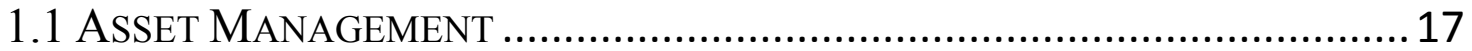

1.2 CuRRENT Practices In ASSET MANAGEMENT ...................................19

1.2.1 FHWA Generic Asset Management Framework .........................2 21

1.2.2 AASHTO Asset Management Plan .............................................. 23

1.2.3 Risk-based Approach Framework............................................. 27

1.2.4 Bridge Management System ..................................................29

1.2.5 Long-Term Bridge Performance Program ................................... 30

1.2.6 Maintenance Rating Program ................................................... 31

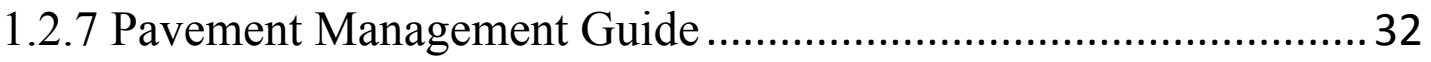

1.2.8 Unstable Slope Management Programs ........................................ 34

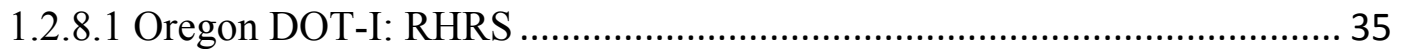

1.2.9 Asset Management of Embankments: United Kingdom................ 37

1.3 Limitations of CurRent Asset Management Plans ......................38

1.4 PURPOSE OF THIS STUDY …........................................................ 42

CHAPTER 2: ROCKFALL HAZARD RATING SYSTEM: BENEFITS OF UTILIZING REMOTE SENSING …................................................ 44

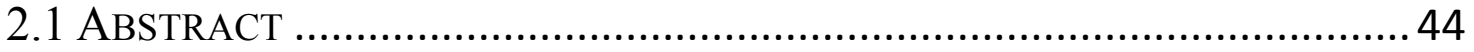

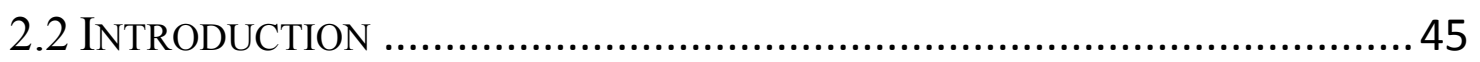

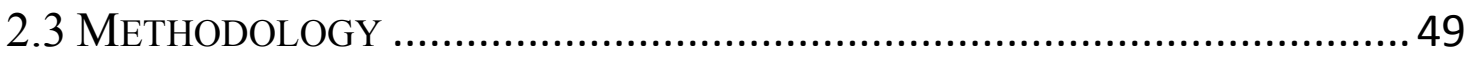

2.3.1 Preliminary Slope Rating (RHRS Step 2)..................................50

2.3.2 Detailed Slope Rating (RHRS Step 3) ....................................... 51

2.3.3 Yearly Reviews and Updates (RHRS Step 6) ..............................52

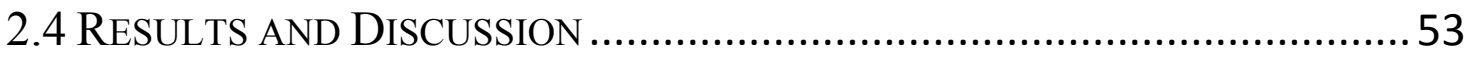

2.4.1 Preliminary Slope Rating (RHRS Step 2) ...................................53 
2.4.2 Detailed Slope Rating (RHRS Step 3) ....................................... 55

2.4.3 Yearly Reviews and Updates (RHRS Step 6) ...............................59

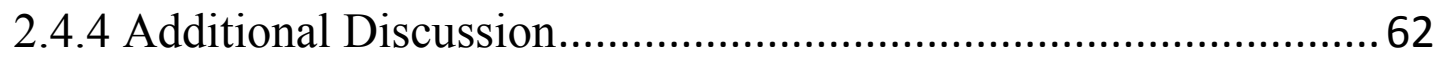

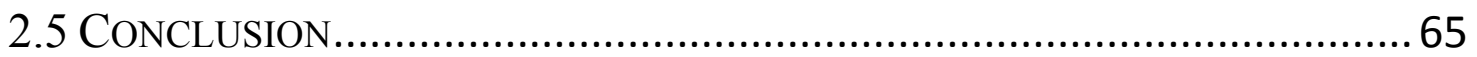

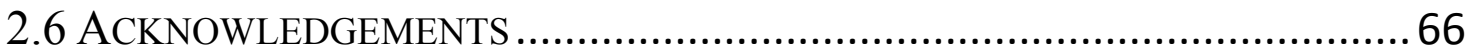

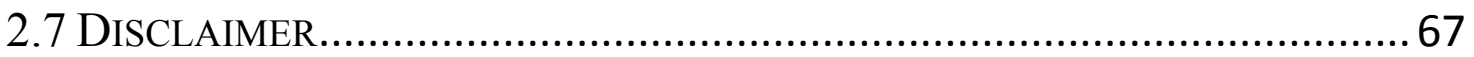

CHAPTER 3: INTERFEROMETRIC STACKING TOWARD GEOHAZARD IDENTIFICATION AND GEOTECHNICAL ASSET

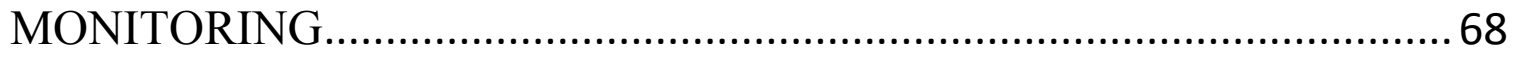

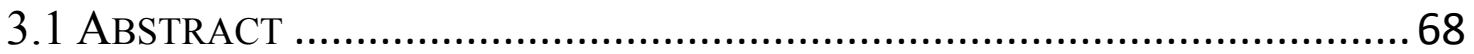

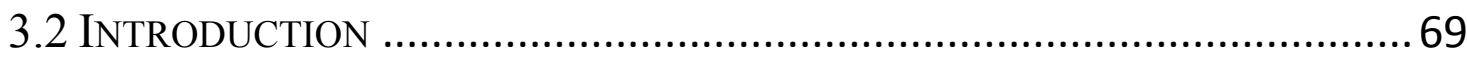

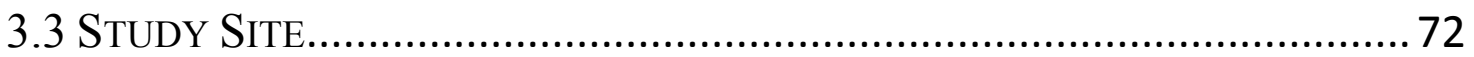

3.4 RADAR IMAGERY DATA SET AND METHODOLOGY ............................... 77

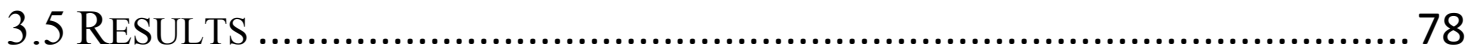

3.5.1 Local-Scale: Spatial and Temporal Geohazard Monitoring.......... 78

3.5.2 Regional-Scale: Identification of Geohazard Locations ............... 82

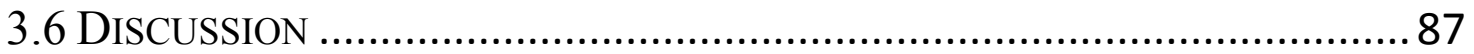

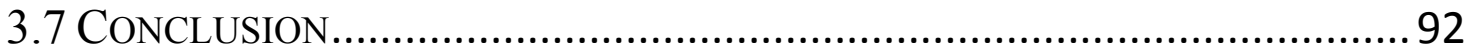

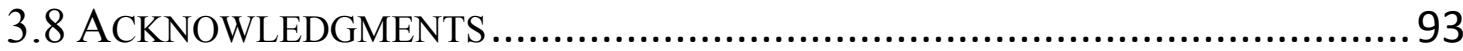

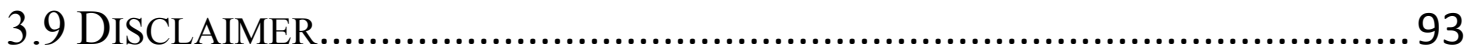

CHAPTER 4: STRUCTURE MAPPING THROUGH SPATIAL AND TEMPORAL DEFORMATION MONITORING USING PERSISTENT SCATTERER INTERFEROMETRY AND GEOGRAPHIC INFORMATION SYSTEMS..............................................................94

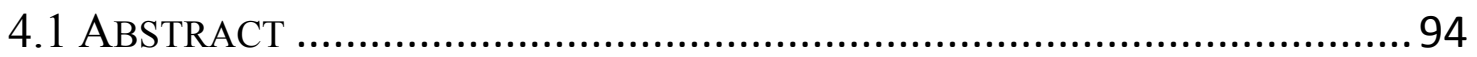

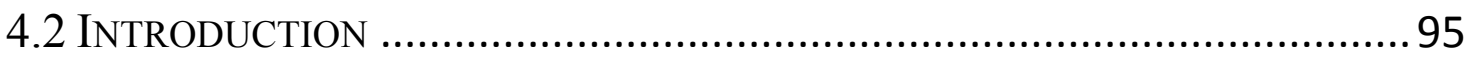

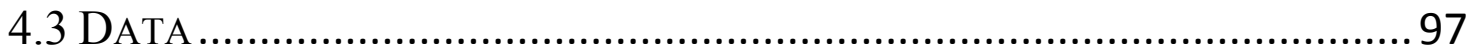

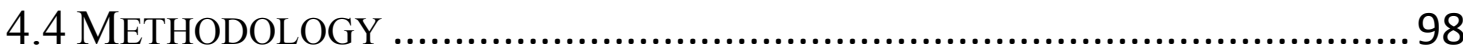

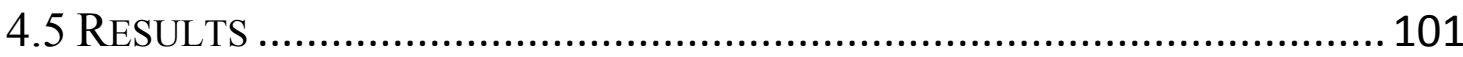

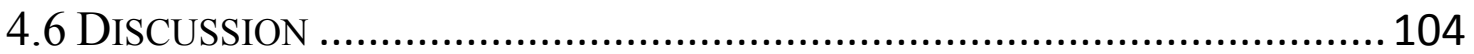

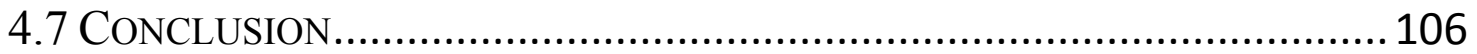

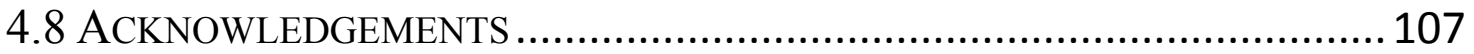

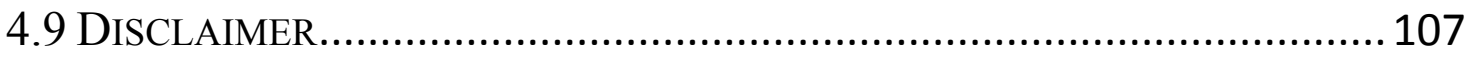


CHAPTER 5: MONITORING INDIA'S DAMS FROM SPACE: A COSTEFFECTIVE APPROACH USING SENTINEL-1 RADAR IMAGES ..... 108

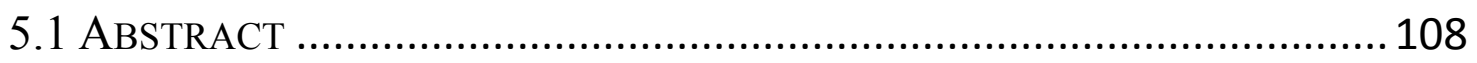

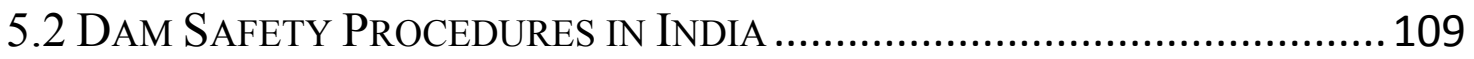

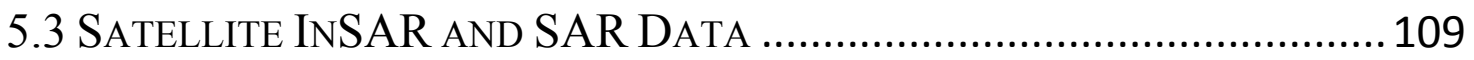

5.4 CASE Studies: THREE DAMS IN SoUTHERn INDIA ............................ 110

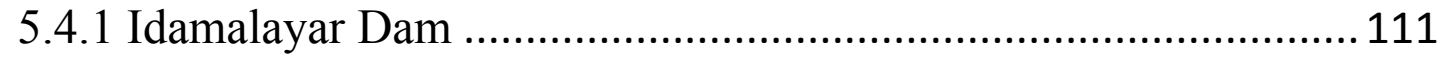

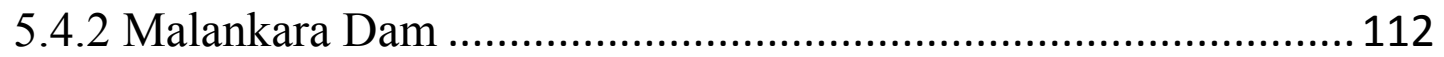

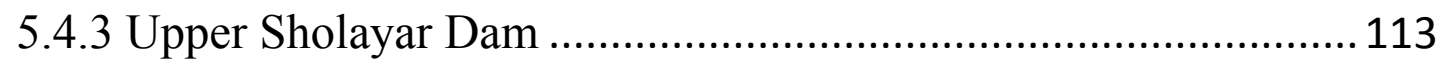

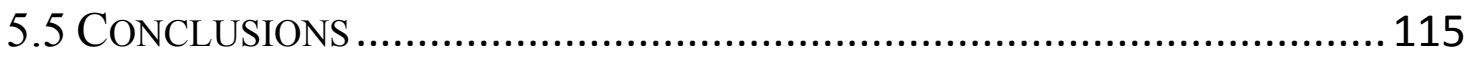

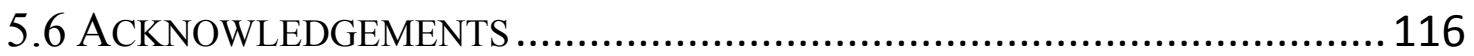

CHAPTER 6: MONITORING THE CASITAS DAM IN VENTURA COUNTY, CALIFORNIA WITH SATELLITE INSAR ..........................117

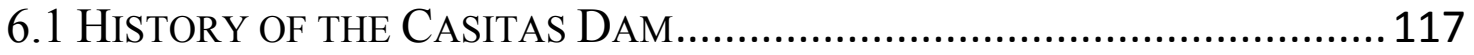

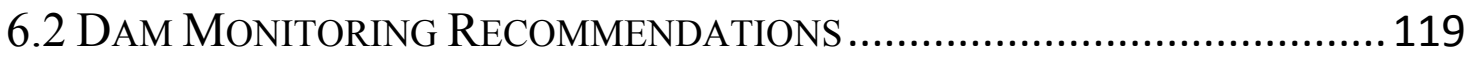

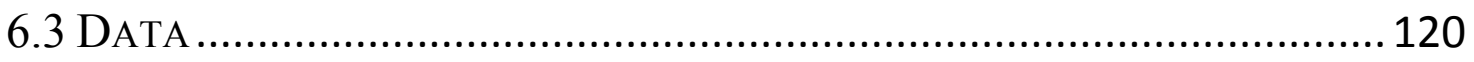

6.4 LONG-TERM MONITORING RESULTS AND DiSCUSSION ...................... 120

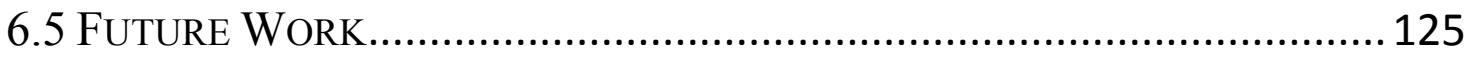

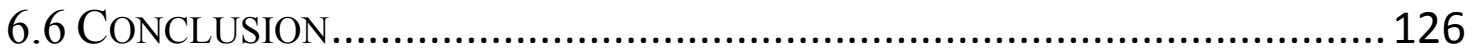

CHAPTER 7: MAPPING OF SLOW LANDSLIDES ON THE PALOS VERDES PENINSULA USING THE CALIFORNIA LANDSLIDE INVENTORY AND PERSISTENT SCATTERER INTERFEROMETRY

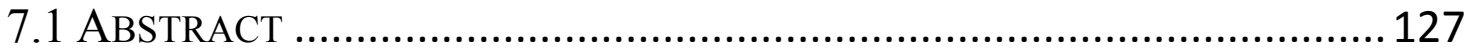

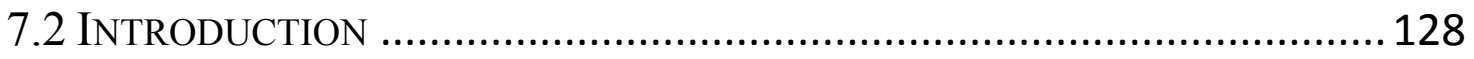

7.3 STUDY SITE

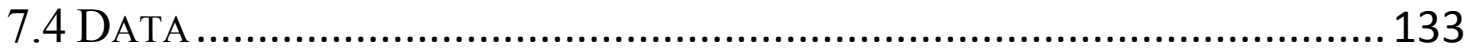

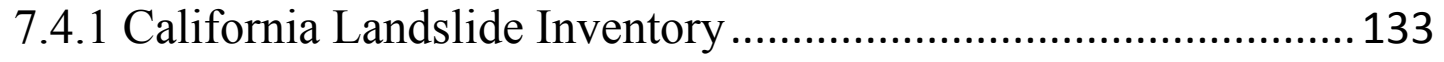

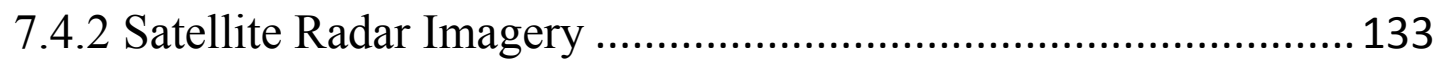

7.4.3 Direction and Magnitude of Deformation Rate ......................... 137

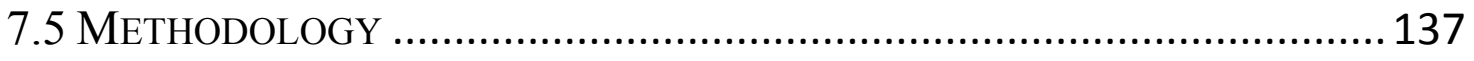

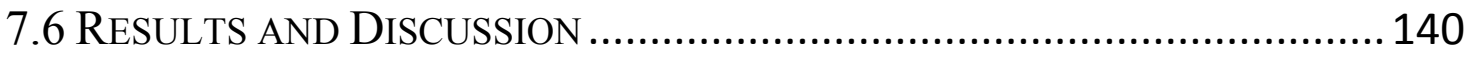

7.6.1 PSI Limitations for Landslide Mapping ................................... 149

7.6.2 PSI Advantages for Landslide Mapping .................................... 150 
7.7 CONCLUSION. 151

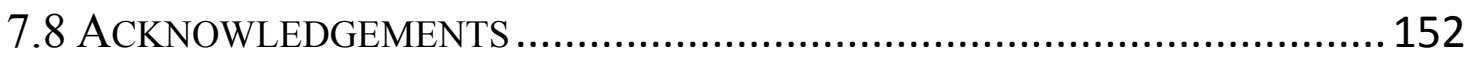

7.9 COMPLIANCE WITH ETHICAL STANDARDS ....................................... 152

CHAPTER 8: EVIDENCE OF INSTABILITY IN PREVIOUSLYMAPPED LANDSLIDES AS MEASURED USING GPS, OPTICAL, AND RADAR DATA BETWEEN 2007 AND 2017: A CASE STUDY IN THE PORTUGUESE BEND LANDSLIDE COMPLEX, CALIFORNIA.........154

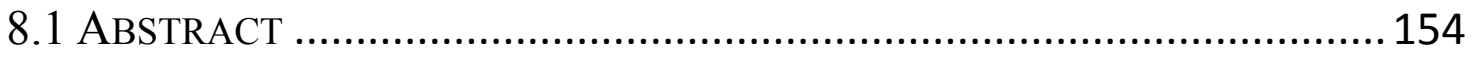

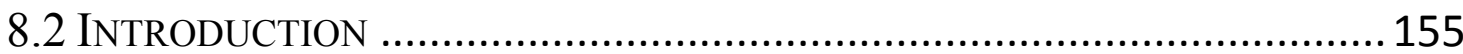

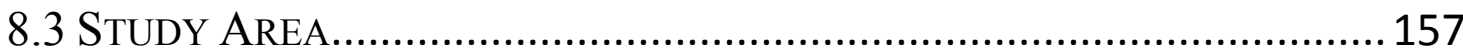

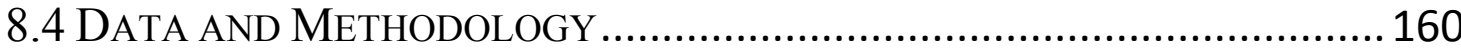

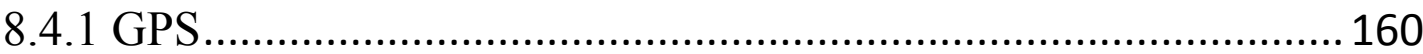

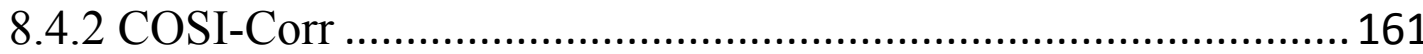

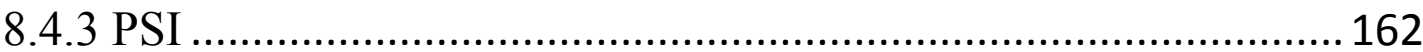

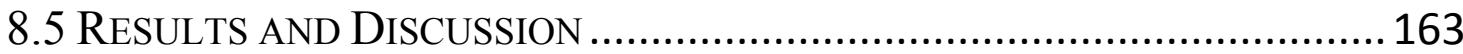

8.6 FINAL LANDSLIDE DEFORMATION MAP............................................. 171

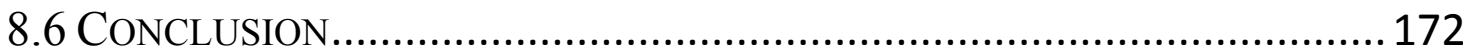

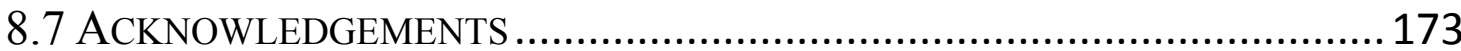

CHAPTER 9: FUTURE WORK IN LANDSLIDE PREDICTION............174

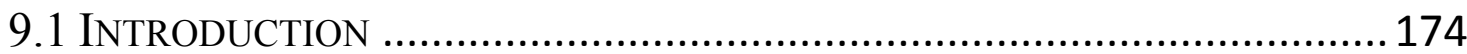

9.2 FutURE WORK IN LANDSLIDE PREDICTION ..................................... 175

9.3 PreLIMINARY RESUltS IN LANDSLIDE PREDICTION ..........................179

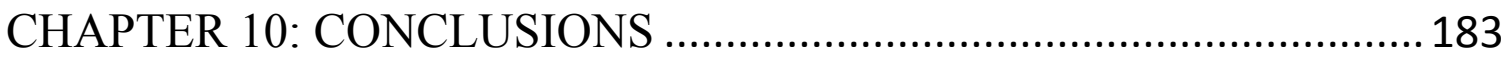

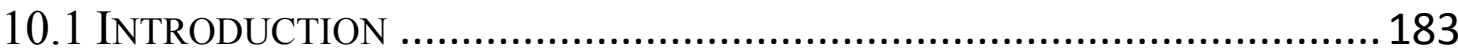

10.2 SYNTHETIC APERTURE RADAR SENSORS ....................................... 183

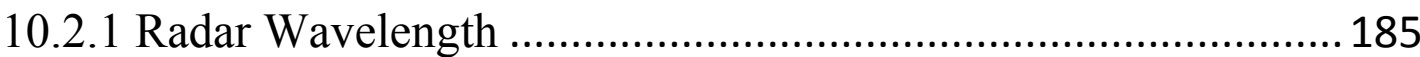

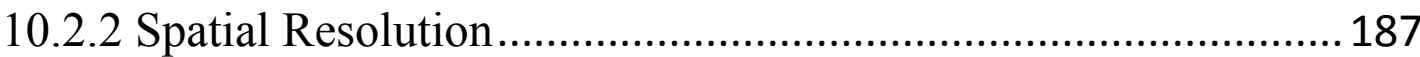

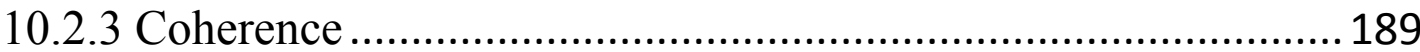

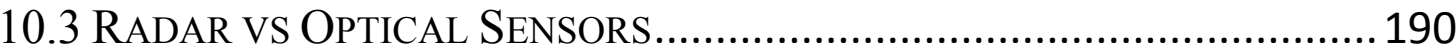

10.3.1 Rockfall Hazard Rating System and Geotechnical Asset

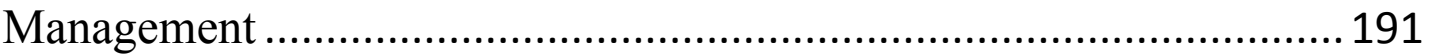

10.3.2 Landslide Mapping and Monitoring …................................... 192

10.4 COMBINING RADAR, OPTICAL, AND GPS ...................................... 193

10.4.1 Difficulty with Comparing Radar, Optical, and GPS Results ... 193 
10.4.2 How to Resolve LOS and Magnitude Differences.................... 194

10.5 UtILIZING UNMANNED AERIAL VEHICLES (UAVs).........................196

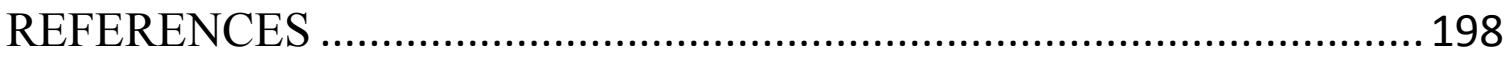

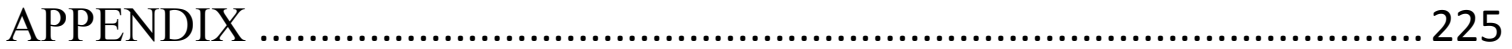

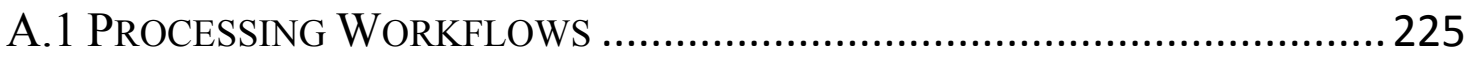

A.2 AbStracts For ConfEREnCE PreSEnTAtions ............................... 227

A.2.1 An Application of Interferometric Synthetic Aperture Radar in a

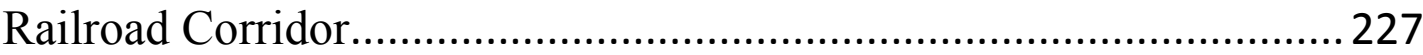

A.2.2 Interferometric Synthetic Aperture Radar Applied to Geotechnical Asset Management in Transportation Environments ...........................228

A.2.3 Field Verification of Satellite-based Velocity Data ....................2229

A.2.4 Can We Extract Information Regarding Transportation Asset

Condition from Satellite-based Radar Interferometric Data? ............. 230

A.2.5 A Multi-Sensor Approach to Monitor Slope Displacement ....... 231

A.2.6 Monitoring Slope Instability and Ground Deformation across the

Palos Verdes Peninsula with COSMO-SkyMed Satellite Radar Imagery

A.2.7 Rockfall Hazard Analysis using Satellite, UAV, and Field Data: A Comparison of Techniques and RHRS Results 233

A.2.8 Comparing the California Landslide Inventory to Ground Motion

Detected by the COSMO-SkyMed Satellite across the Palos Verdes

Peninsula

A.2.9 Utilizing PSInSAR to Monitor Transportation Asset Conditions to Maintain Mobility Efficiency .... 235

A.2.10 Evaluating the Integrity of Railway Corridor Using Remote Sensing

A.2.11 Monitoring the Casitas Dam in Ventura County, California with Satellite InSAR

A.2.12 Slow Landslide Identification using InSAR to Update the California Landslide Inventory on the Palos Verdes Peninsula... 237 A.2.13 Landslide Life-Cycle Monitoring and Failure Prediction using Satellite Remote Sensing ..... 238 A.2.14 Satellite InSAR as an Initial Health Assessment Tool for Dams and Reservoirs 239 
A.2.15 Landslide Monitoring at Three Orders of Magnitude: PSI, COSICorr, and GPS Measurements at the Portuguese Bend Landslide Complex in Southern California ...................................................... 240

A.3 COPYRIGHT PERMISSION ............................................................... 242 


\section{PREFACE}

Each chapter contains, or is entirely composed of, material that has been published in peer-reviewed academic journals. Below are listed the citations for material found in each chapter.

Chapter 1. Portions of this chapter can be found in the literature review sections of the following reports written for a project funded by the US Department of Transportation entitled Sustainable Geotechnical Asset Management along the Transportation Infrastructure Environment using Remote Sensing.

Escobar-Wolf R, Bouali EH, Cerminaro D, Oommen T, Brooks C, Vitton S, Lautala P, and Cunningham K (2014) Deliverable 1-A: Requirements for Remote Sensing Based Geotechnical Asset Management System including Types of Geotechnical Assets and their Conditions that need to be Assessed in Different Transportation Environments. Michigan Technological University, USDOT Cooperative Agreement No. RITARS-14-H-MTU, 28 p.

Escobar-Wolf R, Bouali EH, Justice S, Cerminaro D, Oommen T, and Vitton S (2015) Deliverable 4-A \& B: Report \& Demonstration of Performance Rating of Geotechnical Assets using Remotely Measured Displacement. Michigan Technological University, USDOT Cooperative Agreement No. RITARS-14-H-MTU, 61 p.

Escobar-Wolf R, Bouali EH, Leonarduzzi D, and Oommen T (2016) Deliverable 7-A: Implementation Framework of the Key Project Tasks for State DOTs/Operators/Owners, and 7-B: Outreach Activities. Michigan Technological University, USDOT Cooperative Agreement No. RITARS14-H-MTU, 37 p. 
Escobar-Wolf R, Bouali EH, Oommen T, Dobson R, Vitton S, Brooks C, and Lautala P (2016) Final Report: Sustainable Geotechnical Asset Management along the Transportation Infrastructure Environment Using Remote Sensing. Michigan Technological University, USDOT Cooperative Agreement No. RITARS-14-H-MTU, 152 p.

Chapter 2. Bouali EH, Oommen T, Vitton S, Escobar-Wolf R, and Brooks C (2017) Rockfall hazard rating system: benefits of utilizing remote sensing. Environmental and Engineering Geoscience, 23(3):165-177.

Chapter 3. Bouali EH, Oommen T, and Escobar-Wolf R (2016) Interferometric stacking toward geohazard identification and geotechnical asset monitoring. Journal of Infrastructure Systems, 22(2):05016001.

Chapter 4. Bouali EH, Oommen T, and Escobar-Wolf R (2017) Structure mapping through spatial and temporal deformation monitoring using Persistent Scatterer Interferometry and Geographic Information Systems. Geotechnical Frontiers 2017, 509-519.

Chapter 5. Bouali EH, Oommen T, and Sajinkumar KS (2018) Monitoring India's dams from space: a cost-effective approach using Sentinel-1 radar images. International Dam Safety Conference, 23-24 January, Thiruvananthapuram, Kerala, India.

Chapter 6. This is a work in preparation for future publication.

Chapter 7. Bouali EH, Oommen T, and Escobar-Wolf (2018) Mapping of slow landslides on the Palos Verdes Peninsula using the California landslide inventory and Persistent Scatterer Interferometry. Landslides, 15(3):439-452.

Chapter 8. This is a work in preparation for future publication. 


\section{ACKNOWLEDGEMENTS}

The work presented here was supported and funded in part by the following sources: US Department of Transportation (2014-2016), Michigan Space Grant Consortium Fellowship (2015 and 2016), and NASA Earth and Space Science Fellowship (2016-2018). Additional support came from the Association of Environmental \& Engineering Geologists and the AEG Foundation, the North-Central Section of the Geological Society of America, the Graduate Student Government at Michigan Technological University, and the NASA Earth and Space Science Fellowship for travel support, enabling me to share my research at regional and national conferences. Data were provided by a variety of sources, including the Alaska Satellite Facility, California Department of Conservation, California Geological Survey, City of Rancho Palos Verdes, Delft Institute for Earth-oriented Space Research, Digital Globe, Esri, European Space Agency, Google, Italian Space Agency, Jet Propulsion Laboratory, NASA, TRE Canada Inc., UNAVCO, Union Pacific Railroad, and the USGS. I would like to thank my advisor, Thomas Oommen, for his unwavering support, guidance, and assistance with my research, scholarship, and academic progress. I would like to thank my committee members, Stanley Vitton, Donald Atwood, and Rüdiger Escobar-Wolf. I would also like to my coauthors and those who assisted with research and field work: Scott Anderson, Adrian Bohane, Colin Brooks, Daniel Cerminaro, Zachary Champion, Keith Cunningham, David Dean, Richard Dobson, Caleb Douglas, Richard Endres, Alex Flannery, Ben Hart, Vicky Hsiao, Pasi Lautala, Devin Leonarduzzi, Samantha Justice, Richard Pohana, KS Sajin Kumar, Mike San Angelo, Caesar Singh, and Frank Wuttig. I would like to thank my family for their never-ending love and support, especially my mother Suzanne LeBlanc, my sister Sarah Bouali, and my grandparents Monique and Roland LeBlanc. I would also like to thank Sarah VanderMeer, for the support and the time spend together making memories, and the whole VanderMeer family. 


\section{LIST OF ABBREVIATIONS}

$\begin{array}{ll}\text { AASHTO } & \text { American Association of State Highway and Transportation } \\ \text { AC } & \text { Officials } \\ \text { AcPB } & \text { Abalone Cove } \\ \text { ADTT } & \text { Active Portuguese Bend } \\ \text { AFS } & \text { Average Daily Truck Traffic } \\ \text { ALOS } & \text { Away From the Satellite } \\ \text { AnPB } & \text { Advanced Land Observing Satellite } \\ \text { ASAR } & \text { Ancient Portuguese Bend } \\ \text { ASI } & \text { Advanced Synthetic Aperture Radar } \\ \text { ASTER } & \text { Italian Space Agency } \\ \text { BAM } & \text { Advanced Spaceborne Thermal Emission Reflection Radiometer } \\ \text { BC } & \text { Bridge Asset Management } \\ \text { BCMoT } & \text { Beach Club } \\ \text { BMS } & \text { British Columbia Ministry of Transportation } \\ \text { CGS } & \text { Bridge Management System } \\ \text { CLI } & \text { California Geological Survey } \\ \text { COSI-Corr } & \text { California Landslide Inventory } \\ \text { COSMO-SkyMed } & \text { Co-registration of Optically Sensed Images and Correlation } \\ & \text { Constellation of small Satellites for the Mediterranean basin } \\ \text { CWC } & \text { Observation } \\ \text { DAMA } & \text { Central Water Commission } \\ \text { DDSI } & \text { Data Management Association } \\ \text { DEM } & \text { Division of Dam Safety and Inspections } \\ \text { DOT } & \text { Digital Elevation Model } \\ \text { DRIP } & \text { Department of Transportation } \\ \text { DS } & \text { Distributed Scatterer } \\ \text { DSI } & \\ & \text { Distributed Scatterer Interferometry } \\ \text { ASehabilitation and Improvement Project } \\ \text { A }\end{array}$




\begin{tabular}{|c|c|}
\hline DSInv & Digital Structure Inventory \\
\hline DSS & Decision Support System \\
\hline EAM & Embankment Asset Management \\
\hline ENVISAT & Environmental Satellite \\
\hline ERS-1 & European Remote-Sensing Satellite 1 \\
\hline ERS-2 & European Remote-Sensing Satellite 2 \\
\hline ESA & European Space Agency \\
\hline FDOT & Florida Department of Transportation \\
\hline FERC & Federal Energy Regulatory Commission \\
\hline FHWA & Federal Highway Administration \\
\hline FT & Flying Triangle \\
\hline GAM & Geotechnical Asset Management \\
\hline GAMF & Geotechnical Asset Management Framework \\
\hline GCP & Ground Control Point \\
\hline GIS & Geographical Information Systems \\
\hline GPS & Global Positioning System \\
\hline ILI & InSAR Landslide Inventory \\
\hline InSAR & Interferometric Synthetic Aperture Radar \\
\hline ISTEA & Intermodal Surface Transportation Efficiency Act \\
\hline $\mathrm{KC}$ & Klondike Canyon \\
\hline LA CBO & Los Angeles Countywide Building Outlines \\
\hline LAR-IAC & Los Angeles Region Imagery Acquisition Consortium \\
\hline LiDAR & Light Detection and Ranging \\
\hline LOS & Line of Sight \\
\hline LTBP & Long-Term Bridge Performance \\
\hline LTS & Long-Term Slide \\
\hline MAP-21 & Moving Ahead for Progress in the $21^{\text {st }}$ Century \\
\hline MDOT & Michigan Department of Transportation \\
\hline MODOT & Montana Department of Transportation \\
\hline MRP & Maintenance Rating Program \\
\hline
\end{tabular}




\begin{tabular}{|c|c|}
\hline MTRI & Michigan Tech Research Institute \\
\hline MTU & Michigan Technological University \\
\hline NASA & National Aeronautics and Space Administration \\
\hline NBIS & National Bridge Inventory System \\
\hline NCHRP & National Cooperative Highway Research Program \\
\hline NCTA & North Carolina Turnpike Authority \\
\hline NED & National Elevation Dataset \\
\hline NHS & National Highway System \\
\hline NYSDOT & New York State Department of Transportation \\
\hline ODOT & Oregon Department of Transportation \\
\hline OGC & Office of Government Commerce \\
\hline OHDOT & Ohio Department of Transportation \\
\hline OST-R & Office of the Assistant Secretary for Research and Technology \\
\hline $\mathrm{P} 4$ & Parcel 4 \\
\hline PALSAR & Phased Array type L band Synthetic Aperture Radar \\
\hline PAM & Pavement Asset Management \\
\hline PAS & Potentially Active Slide \\
\hline PMS & Pavement Management System \\
\hline PS & Persistent Scatterer \\
\hline PSI & Persistent Scatterer Interferometry \\
\hline PVHLC & Palos Verdes Hills Landslide Complex \\
\hline RDT & Regional Downward Trend \\
\hline RHRS & Rockfall Hazard Rating System \\
\hline RSS & Relatively Stable Slope \\
\hline SA & Slope Aspect \\
\hline SAM & Slope Asset Management \\
\hline SAR & Synthetic Aperture Radar \\
\hline $\mathrm{SfM}$ & Structure from Motion \\
\hline SLC & Single Look Complex \\
\hline SNR & Signal-to-Noise Ratio \\
\hline
\end{tabular}




$\begin{array}{ll}\text { SqueeSAR } & \text { Squeezed Synthetic Aperture Radar } \\ \text { SRTM } & \text { Shuttle Radar Topography Mission } \\ \text { TAM } & \text { Transportation Asset Management } \\ \text { TDOT } & \text { Tennessee Department of Transportation } \\ \text { TRB } & \text { Transportation Research Board } \\ \text { TS } & \text { Towards the Satellite } \\ \text { UAV } & \text { Unmanned Aerial Vehicle } \\ \text { UDOT } & \text { Utah Department of Transportation } \\ \text { UESS } & \text { Unmapped Extremely Slow Slide } \\ \text { UPRR } & \text { Union Pacific Railroad } \\ \text { USBR } & \text { United States Bureau of Reclamation } \\ \text { USDOT } & \text { United States Department of Transportation } \\ \text { USGS } & \text { United States Geological Survey } \\ \text { USM } & \text { Unstable Slope Management } \\ \text { VVG } & \text { Valley View Graben } \\ \text { WSDOT } & \text { Washington State Department of Transportation }\end{array}$




\section{ABSTRACT}

An asset management framework provides a methodology for monitoring and maintaining assets, which include anthropogenic infrastructure (e.g., dams, embankments, and retaining structures) and natural geological features (e.g., soil and rock slopes). It is imperative that these assets operate efficiently, effectively, safely, and at a high standard since many assets are located along transportation corridors (highways, railways, and waterways) and can cause severe damage if compromised. Assets built on or around regions prone to natural hazards are at an increased risk of deterioration and failure. The objective of this study is to utilize remote sensing techniques such as InSAR, LiDAR, and optical photogrammetry to identify assets, assess past and current conditions, and perform long-term monitoring in transportation corridors and urbanized areas prone to natural hazards. Provided are examples of remote sensing techniques successfully applied to various asset management procedures: the characterization of rock slopes (Chapter 2), identification of potentially hazardous slopes along a railroad corridor (Chapter 3), monitoring subsidence rates of buildings in San Pedro, California (Chapter 4), and mapping displacement rates on dams in India (Chapter 5) and California (Chapter 6). A demonstration of how InSAR can be used to map slow landslides (those with a displacement rate $<16 \mathrm{~mm} /$ year and may be undetectable without sensitive instrumentation) and update the California Landslide Inventory on the Palos Verdes Peninsula is provided in Chapter 7. Long-term landslide monitoring using optical photogrammetry, GPS, and InSAR measurements is also used to map landslide activity at three orders of magnitude (meter to millimeter scales) in Chapter 8. Remote sensing has proven to be an effective tool at measuring ground deformation, which is an implicit indicator of how geotechnical asset condition changes (e.g., deteriorates) over time. Incorporating these techniques into a geotechnical asset management framework will provide greater spatial and temporal data for preventative approaches towards natural hazards. 


\section{Chapter 1: Introduction}

\subsection{Asset Management}

The term asset management is defined differently by everyone, yet essentially means the same thing. In general, any actions implemented to maintain, preserve, or to perpetuate an asset's optimal performance level throughout its lifespan fall under the asset management umbrella. Transportation agencies each have their own official term. In a report entitled Strategy for improving asset management practices, the Australian road transport and traffic agencies association (Austroads) defined asset management as "...a comprehensive and structured approach to the long-term management of assets as tools for the efficient and effective delivery of community benefits." (Austroads 1997). The Federal Highway Administration (FHWA) expanded on this definition two years later:

"[Asset management is] a systematic approach of maintaining, upgrading, and operating physical assets cost effectively. It combines engineering principles with sound business practices and economic theory, and it provides tools to facilitate a more organized, logical approach to decisionmaking. Thus, asset management provides a framework for handling both short- and long-range planning." (p8, FHWA 1999)

Iterations of the asset management definition have been produced since and include portions of the FHWA definition. For example, the Michigan Department of Transportation (MDOT) defines asset management as “...a process to strategically manage our transportation system in a cost-effective and efficient manner" (MDOT 2015); Flintsch \& Bryant, Jr. (2006) define it as "... a strategic approach to the optimal allocation of resources for the management, operation, maintenance, and preservation of transportation infrastructure"; the National Cooperative Highway Research Program (NCHRP) describe a portion of it as "...a strategic and systematic process of operating, maintaining, upgrading, and expanding physical assets effectively throughout their life cycle..." (Cambridge Systematics, Inc. et al. 2009). Regardless of the myriad of definitions and 
repetitive verbiage, everyone seems to agree that basic asset management requires the maintenance, management, and preservation of all assets along the transportation corridor.

Although many goals of asset management are included in the definition, the American Association of State Highway and Transportation (AASHTO) summarized the goals into three general statements (pS-1, Cambridge Systematics et al. 2002). The first goal is to "build, preserve, and operate facilities" in a manner that is more "cost-effective" and with an improvement in "asset performance." The second goal is to give consumers the "best value for the public tax dollar spent." The third goal, which is more political, is to "enhance the credibility and accountability of the transportation agency to its governing executive and legislative bodies." Of these three goals, methodologies towards accomplishing the first two goals have been studied in detail, as the third goal is a byproduct of the first two.

The United States was relatively late to the asset management game. Asset management programs were implemented in other countries (Canada, Australia, New Zealand, and across Europe) in the 1980s and 1990s. The first US-based seminar was held in the Washington, D.C., in 1996 with AASHTO and FHWA as hosts. The overwhelming positivity felt from this seminar lead to successive annual meetings, beginning in 1998 with the Asset Management National Conference in Scottsdale, Arizona. Then in 2000, the Transportation Research Board (TRB) joined AASHTO and FHWA to create an "AM [Asset Management] Task Force" (p8 Hawkins \& Smadi, 2013). Since then an increase in research and funding has gone towards many forms of asset management (e.g., pavement, transportation, bridge, geotechnical, tunnel, etc.) with the US Department of Transportation (USDOT) and many state DOTs including some sort of asset management protocol in their annual infrastructure budget. Then on July 6, 2012, law P.L. 112-141 the Moving Ahead for Progress in the 21st Century Act (MAP-21) was signed into law (USDOT 2015). MAP-21 requires the development of "a risk-based asset management plan for the National Highway System (NHS) to improve and preserve the condition of the assets and the performance of the system" (p1660, Stanley \& Pierson 2013). Transportation asset management (TAM) is the most widespread asset management plan, with at least 16 states having some sort of TAM plan currently in place (e.g., California, Colorado, 
Connecticut, Florida, Georgia, Indiana, Michigan, Minnesota, Missouri, Montana, New Jersey, North Carolina, Oregon, Pennsylvania, Utah, Virginia, and Washington - Lindquist $\&$ Wendt 2012). These TAM plans include some, but not all, of other various asset types (e.g., pavement, bridges, geotechnical, tunnels), as other asset types are usually separated into other management plans. For example, DOTs in Washington, Oregon, California, and many other western states have a separate rock fall/landslide hazard program. So, basically, for state DOTs with no existing asset management plan, the most difficult decision is how to start one; while for those states with existing TAM plans, the biggest problem is integrating all asset management plans into one system or network.

\subsection{Current Practices in Asset Management}

Current practices in asset management vary greatly by transportation agency and again by asset type. The initial asset management approach was to divide focus by asset type and then create individual asset management programs. This resulted in the generation of TAM, pavement asset management (PAM), bridge asset management (BAM), geotechnical asset management (GAM), slope asset management (SAM), embankment asset management (EAM), and so on and so forth. The obvious problem with this divideand-conquer approach is that separate management plans do not share data or information. This can pose a problem since a variety of assets share the same transportation corridor. For example, one slope failure could potentially affect assets categorized in all management programs listed above. Even worse, some types of asset management systems do not have standard procedure between states DOTs or transportation agencies. Vessely (2013) laments that “...there does not appear to be a standard of practice for geotechnical asset management $[\mathrm{GAM}]$ within state and federal transportation agencies in the United States" (p35). Therefore, the need for an integrated asset management approach is apparent and, according to Anderson \& Rivers (2013), recent recommendations have been made to change the focus from an "asset-by-asset approach to one that examines the entire corridor."

Differences by transportation agency and asset type notwithstanding, many DOTs and agencies have adopted a common asset management approach, which has been dubbed 
the worst-first approach. The approach is quite simple: assets that have failed or have degraded to the point of disrepair are either repaired or entirely replaced (FHWA 1999). There may be two reasons why a worst-first approach is more common than a preventative approach: (1) tight budgets and limited funding require addressing the most critical assets, a reactive approach due to safety concerns, as opposed to spending the money on proactive measures; (2) justification to the consumers for a proactive and preventative approach is difficult because the tax-payers essentially expect the assets in the worst condition are addressed first and that, essentially, preservation is interpreted as "fixing something that isn't broken" (p21, FHWA 1999).

In lieu of these reasons, the worst-first approach has been deemed unsustainable. The FHWA admits that "most states limit application of their management systems to monitoring conditions and then plan and program their projects on a worst-first basis" and that this approach is "tactical rather than strategic" (p16, FHWA 1999). Stanley \& Pierson (2013) go one step further and claim the worst-first approach "results in overall system degradation as no assets receive preventative maintenance in time to keep the investment optimized" (p1660). So, although a short-term fix of one failed asset may be cheaper, may receive more publicity, and is much easier to explain to the public ("It was fixed because it failed!'), it is more dangerous, and, on a longer timeframe, the worst-first approach is more time-consuming and costly than a preventative approach.

This understanding has led to the creation of many asset management procedures and workflows. The following sections describe two general asset management workflows (FHWA and AASHTO) and a risk-based approach framework (Mian et al. 2011) along with a handful of specific management systems, including: the Bridge Management System, the Long-Term Bridge Performance Program (FHWA), the Maintenance Rating Program, the Pavement Management Guide (AASHTO 2001), a few statewide DOT-based Unstable Slope Management Programs, and an Asset Management of Embankments program used in the United Kingdom (Glendinning et al. 2009). 


\subsubsection{FHWA Generic Asset Management Framework}

The FHWA created a generic asset management framework (Figure 1.1) to illustrate that all asset management plans should focus on strategy, a preventative approach, as opposed to tactics, a reactive approach. This flowchart aims to provide the foundation for an asset management procedure and can be applied on any scale: asset-by-asset, transportation corridor, or entire network.

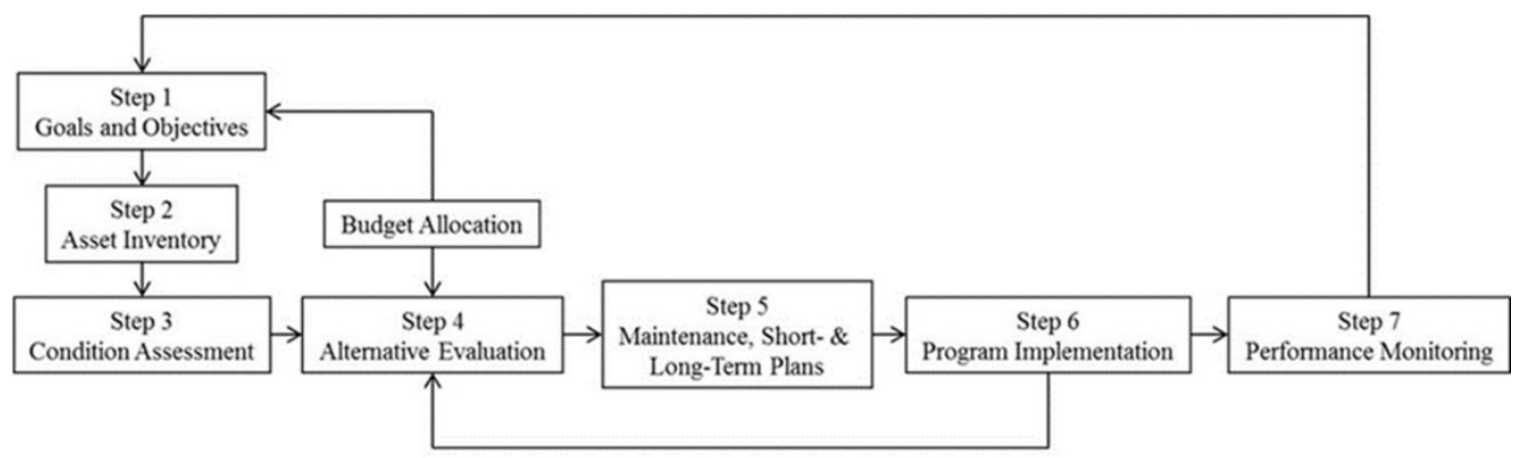

Figure 1.1: The seven steps, along with budget allocation, that comprise the generic asset management framework created by FHWA (recreated from FHWA 1999).

Step 1: Goals and Objectives. Goals and objectives, which may take the form of policies and laws, must first be addressed prior to any actions taken. These goals should align with realistic expectations for what the asset management program can accomplish. Factors such as available budget, resources, workforce, and logistics should be examined as potential limitations and considered. The result of Step 1 should include a full understanding of management goals and objectives, which should in some way reflect the constituents' needs, and intended targets should be set for the rest of the generic asset management framework.

Step 2: Asset Inventory. The construction of the asset inventory is a difficult and time-consuming step. Important questions must be answered before beginning the inventory, such as: (1) which assets should be included in, and excluded from, the inventory? (2) What information should be recorded for each asset (e.g., location, value, functions, services, condition, etc.)? (3) How will the asset information be recorded (e.g., 
spreadsheet, GIS geodatabase, etc.)? (4) How will field crews be trained to record subjective information in a consistent manner? The scope of constructing an asset inventory can be daunting, especially when considering scales of entire transportation networks on the state or federal level. Although initially time-consuming, the creation of an asset inventory would only need to be completed once and then updated as new assets are constructed or destroyed, and existing assets receive maintenance or upgrades.

Step 3: Condition Assessment. This step aims to identify the condition of each asset and apply forward modeling to predict asset condition change over time. An initial condition assessment may have been included in the asset inventory (Step 2). The type of assessment would vary drastically by asset type - it would not make sense to have the same criteria for tunnels as for bridges. The current asset condition as well as historical asset condition and performance assessments are recommended for adequate performance modeling. The goal of this step is to utilize "analytical tools and reproducible procedures [to] produce viable cost-effective strategies for allocating budgets to satisfy agency needs and user requirements, using performance expectations as critical inputs" (p18, FHWA 1999).

Step 4: Alternative Evaluation. Alternate choices and budget allocations are then reevaluated if necessary. Any ways to optimize the asset management program should also be considered. This step is a quality control measure.

Step 5: Maintenance with Short- and Long-Term Plans. Building on what was accomplished through Steps 2-4, short- and long-term maintenance plans are prepared based on the information gained. Short-term plans would include reactive measures such as repairing critically deteriorated assets, replacing assets that have failed, and addressing threats to public safety or substantial damage to assets in the transportation environment. Long-term plans would incorporate preventative measures using asset condition assessment criteria (e.g., risk-based or hazard-based) that identify assets in need of care via life-cycle monitoring.

Step 6: Program Implementation. This step is basic: the asset management program now begins. The importance of this step is that, depending on the asset 
management program performance, it can either lead back to Step 4, if the program requires additional optimization, or lead forward to Step 7.

Step 7: Performance Monitoring. The final step of the generic asset management framework is to assess the performance of the framework which, according to the FHWA, should be conducted annually. The framework becomes more flexible and dynamic with a repetitive self-evaluation mindset because external changes, such as varying budget and funding amounts, can be addressed in a timely fashion - or as stated by the FHWA: “... any Asset Management system should be flexible enough to respond to changes in any of these variables or factors [policies, goals, asset types and characteristics, budgets, State operating procedures, and business practices]" (p18, FHWA 1999).

\subsubsection{AASHTO Asset Management Plan}

AASHTO has also provided a list of eight components an asset management plan should include:

1. Data Management. As defined by the Data Management Association (DAMA), data management is "...the development, execution and supervision of plans, policies, programs and practices that control, protect, deliver and enhance the value of data and information assets" (p4, DAMA 2009). Management of data within an asset management plan would include the organization of data obtained from various technologies (e.g., handwritten field notes or data collected from the field in differing formats, asset pictures, computer spreadsheets, GPS data, etc.) as well as big data storage, access, and visualization (Vessely 2013), which may include compiling all data into a geodatabase.

2. Inventory and Condition Surveys. This component is identical to Steps 2 and 3 of the generic asset management framework (FHWA 1999). AASHTO (2013) does provide a list of specific information that should be provided for each asset:

a. Performance Measures

i. Current asset performance rating

ii. Current asset performance with respect to the entire network

iii. Trend analysis (historic asset performance) 
iv. Predictive analysis (potential future performance)

b. Geographic Location

c. Jurisdiction Data

d. Functional and Utilization Data

e. Performance Characteristics

f. Construction History and Historical Significance

g. Archive of Valuable Documents

3. Levels of Service: which are defined as "...classifications or standards that describe the quality of service offered to road users, usually by specific facilities or services against which service performance can be measured" (p21, AASHTO 2013). Levels of service are then divided into two groups: (1) customer, how the public interacts with the service, and (2) technical, what is required by the transportation agency or service provider.

4. Service Life. This is an understanding of how an asset's performance changes from deterioration over time. Service life is usually shown in plot-format, with a performance metric decreasing over time and a comparison between asset preservation and total asset deterioration (e.g., Figure 1.2). 


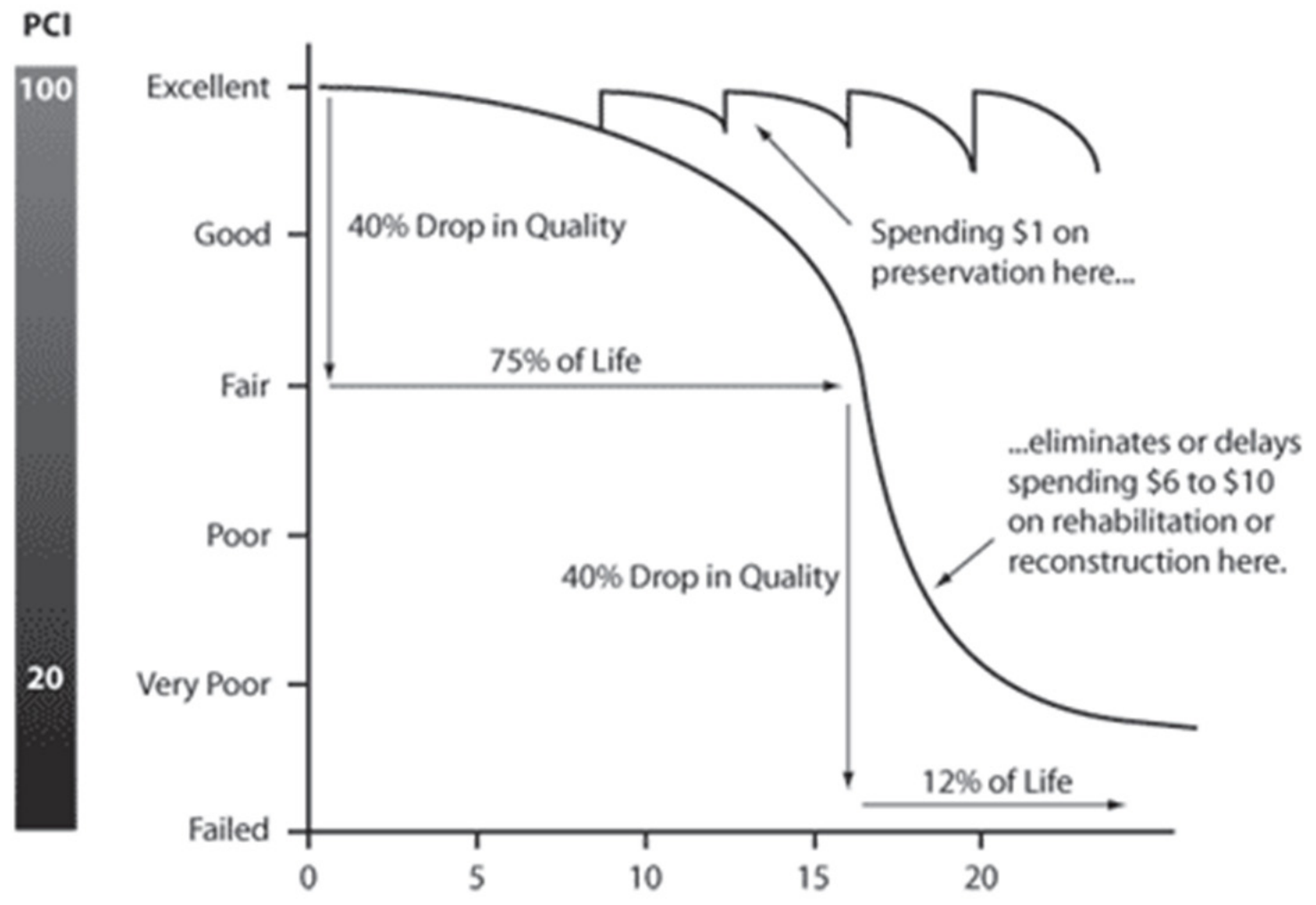

Figure 1.2: Hypothetical pavement deterioration curve plotting time the pavement condition index (PCI-y-axis) over time (x-axis). The saw-tooth curve displays the benefits of a preservation approach compared to the more common worst-first approach, which may lead to significant deterioration (main curve). Plot was taken from Galehouse et al. (2006).

5. Performance Measures (Outcome Measures) and Condition Indices. Performances measures quantify the successfulness of the asset management plan; these variables can also be used as a form of performance quality control. AASHTO's transportation asset management plan includes eight performance measure areas: (1) condition, (2) life-cycle cost, (3) safety, (4) mobility, (5) reliability, (6) customer measures, (7) externalities, and (8) risk (p16, AASHTO 2013). Seven performance measures included as goals in MAP-21 are: (1) safety, (2) infrastructure condition, (3) congestion reduction, (4) system reliability, (5) freight movement and economic 
vitality, (6) environmental sustainability, and (7) reduced project delivery delays (USDOT 2013).

6. Risk Management. Risk is defined as any threat to transportation infrastructure and operations regardless of cause (AASHTO 2013). Therefore, risk management is the practice of identifying, analyzing, and mitigating sources of risk. The generation of a risk-based approach framework (e.g., see Section 1.2.4 - Mian et al. 2011) where the frequency, likelihood, and/or probability of a risk occurrence is estimated, is the general goal.

7. Life Cycle and Cost-Benefit Analyses. A life cycle analysis examines the change in asset performance, cost, deterioration, and potential risk over an asset's lifespan. A cost-benefit analysis is a method of calculating the financial pros (benefits) and cons (costs) of an activity or function. In terms of asset management, benefits may include the savings acquired due to an asset's performance or the projected savings of asset preservation instead of total asset failure, while costs may include the actual expense of asset preservation. The value of an asset is determined by the cost of the asset subtracted from the benefit of the asset; an asset has positive value if the benefits are greater than the costs.

8. Decision Support System (DSS). A DSS addresses the following: (1) the needs of an asset management plan and potential solutions, (2) evaluation of options, and (3) an analysis of asset performance with respect to investment (AASHTO 2013). 


\subsubsection{Risk-based Approach Framework}

The framework for the risk-based approach presented by Mian et al. (2011) could be incorporated into the Condition Assessment (Step 3) and/or Alternative Evaluation (Step 4) of the FHWA generic asset management framework (FHWA 1999) or the Risk Management step of the AASHTO Asset Management Plan (AASHTO 2013). For the purposes of this framework, the definition of 'risk' provided by the Office of Government Commerce (OGC) of the United Kingdom is used, which states:

"Risk is an uncertain event or set of events that, should it occur, will influence the achievement of objectives. A risk is measured by a combination of the probability and the magnitude of its impact on objectives." (OGC 2007)

The framework consists of five steps (labeled Step 0-4 by Mian et al. 2011) which work to combine asset management with risk management.

- Step 0: Decision Scope - the scope is clearly defined and should include the following information:

○ Identification of "service aspect and level" (p2, Mian et al. 2011),

○ Duration of time the framework will be implemented, and

○ Geographic location(s) of assets, transportation corridor, and/or network. A determination between a proactive approach and a reactive approach must be decided upon as well. A proactive approach is one where incremental maintenance reduces the probability of unexpected repairs; a reactive approach, which may be less expensive on the short-term (and funding can be easier to justify to the public), increases the probability of incidental repairs and may conflict with performance measures (e.g., life-cycle cost, mobility, and safety - AASHTO, 2013; almost all listed in the MAP-21 guidelines - USDOT 2013). Basically, all asset management plans strive for a proactive approach.

- Step 1: Hazard Identification - a hazard is any "uncertain event or set of events" that lead to risk within the transportation environment. Hazards must be identified by: 
- Type,

○ Magnitude,

○ Cause, and

- Impact on service, goals, objectives, and performance measures.

- Step 2: Risk Estimation - the calculation of the "likelihood" and "consequence" of the risk event occurring, which yields a quantifiable output (Mien et al. 2011). Likelihood is defined as the probability that an event, that has already occurred, would result in a defined outcome. The consequence is the resultant negative impact, or severity (in magnitude), from a certain risk. Therefore:

$$
R=L \cdot C
$$

defines the relationship between risk (R), likelihood (L), and consequence (C) over a period (Woodruff 2005). An output could be in the form of a risk matrix (Figure 1.3). A risk matrix compares the likelihood (rows) and consequence/impact (columns) to calculate the risk event level. Risk matrices can be either qualitative or quantitative, with the latter being the preferred choice but also requires more data.

\begin{tabular}{|c|c|c|c|c|c|}
\hline \multirow{2}{*}{ Likelihood } & \multicolumn{5}{|c|}{ Impact } \\
\cline { 2 - 6 } & Insignilicant & Minor & Moderate & Major & Severe \\
\hline Almost certain & Moderate & High & High & Extreme & Extreme \\
\hline Likely & Moderate & Moderate & High & High & Extreme \\
\hline Possible & Low & Moderate & Moderate & High & Extreme \\
\hline Unlikely & Low & Moderate & Moderate & Moderate & High \\
\hline Rare & Low & Low & Moderate & Moderate & High \\
\hline
\end{tabular}

Figure 1.3: Example of a qualitative risk matrix (image taken from Lee Merkhofer Consulting 2014). 
- Step 3: Risk Evaluation - a two-fold step that defines the maximum risk threshold and mitigation. The maximum risk threshold is the greatest risk allowable for an asset to be considered 'safe' or not require mitigation. For example, if the maximum risk threshold were set to 'Low' in the risk matrix in Figure 3, then all assets with a 'Moderate,' 'High,' or 'Extreme' risk would require mitigation actions to be performed. According to Mien et al. (2011), mitigation may take three forms:

“... (1) essential intervention for critical risks, (2) intervention desirable but not essential, for moderate risks or (3) no intervention necessary for low risks. The middle category associated with 'moderate risks' is the one that requires the most detailed evaluation and where 'risk tolerance' [or maximum risk threshold] becomes an essential part of the decision making" ( $\mathrm{p} 4$, italics in original text).

- Step 4: Risk-based Decision Making - finally a decision should be made on what kind of mitigating action (if any) is required based on many factors, including the risk level, the assets at risk, the impact on performance measures, etc. The goal of this framework is to determine an acceptable risk tolerance at a given scale (asset, corridor, and network) and identify those assets that require further action. Since event risk changes through time, this framework should be repeated at an interval deemed sufficient for proper asset and risk management.

\subsubsection{Bridge Management System}

The Intermodal Surface Transportation Efficiency Act (ISTEA) of 1991 required every State DOT to adopt a Bridge Management System (BMS), which would incorporate (and replace) the National Bridge Inventory System (NBIS). Included in the NBIS were bridges or culverts greater than 20 feet in length and carried vehicular traffic. Additionally, each bridge was given an initial condition rating ranging from 0 - failed/closed - to 9 excellent condition (USDOT 1995). The FHWA sponsored the software PONTIS BMS in 1991 and was included in the AASHTOWare software suite in 1995 (FHWA 1999). PONTIS BMS allowed for the compilation of a detailed bridge asset inventory, the ability 
to model various maintenance/repair/mitigation strategies, and rank assets based on economic criteria (Gutkowski \& Arenella 1998; FHWA 1999).

The BMS and NBIS were good starting points for the further development of bridge and culvert management. The data collected from these programs would inspire the FHWA to develop the Long-Term Bridge Performance program, which was launched as a 20-year research program aimed to "collect, document, maintain, and study high-quality, quantitative performance data on a representative sample of bridges nationwide" (USDOT 2012).

\subsubsection{Long-Term Bridge Performance Program}

The Long-Term Bridge Performance (LTBP) program was created in 2008 after the FHWA created the NBIS and found that of the more than 600,000 bridges, tunnels, and culverts inventoried, approximately 151,497 were considered "structurally deficient or functionally obsolete" (FHWA 2014). The entire purpose of the LTBP program is to create an inventory comprised of numerical/quantitative data of bridges across the US; this purpose aligns with the Asset Inventory (Step 2) and Condition Assessment (Step 3) of the generic asset management framework (FHWA 1999) and the Inventory and Condition Surveys step of the Asset Management Plan (AASHTO 2013).

The LTBP asset inventory will be compiled through two data collection phases: (1) the developmental phase and (2) the long-term data collection phase. The developmental phase was a pilot study conducted on bridges in California, Florida, Minnesota, New Jersey, New York, Utah, and Virginia. The objective was three-fold: (1) to verify and substantiate the bridge management data collection procedures, (2) to solidify interests and bonds with state DOTs, and (3) to make sure enough information is gained to successfully complete the long-term data collection phase of the project. The long-term data collection phase - which began in March 2013 - is currently ongoing. As of March 2015, two announcements have been released by the FHWA to update the public on the progress of the second phase. The first announcement, published June 2013, identified 24 bridges in the Mid-Atlantic region of the US (New Jersey, Pennsylvania, Delaware, Maryland, and Virginia) that have been selected to be included in initial field 
investigations. The second announcement, also published in June 2013, was entitled Selection Procedure for Reference and Cluster Bridges and includes eight general steps for bridge selection. The eight steps are as follows (produced here verbatim from FHWA 2013):

1. Filter all bridges in the selected region using high level criteria.

2. Obtain State prioritization for remaining population.

3. Sort all remaining bridges into "Design of Experiments" subpopulations based on span length, age and Average Daily Truck Traffic (ADTT).

4. Compute the normalized distance measure for each bridge, which defines its experimental "power."

5. Rank the bridges within each subpopulation based on the distance measure.

6. Select bridges from each subpopulation based on the distance measure and a set of supplemental criteria.

7. Examine the distribution of secondary variables.

8. Iterate until a balance distance measure, supplemental criteria, and subpopulation variability is achieved.

See FHWA (2013) for a complete description of each step. Of particular interest is step 2, which requires input from the State DOT to prioritize bridges at low, medium, or high status, with high statuses assigned to the most critical bridges. State DOTs would ideally have an asset management plan in place (e.g., FHWA, AASHTO, etc.) to quantifiably identify bridges of highest priority.

\subsubsection{Maintenance Rating Program}

The Maintenance Rating Program (MRP), developed in 1985 by the Florida DOT (FDOT), is a highway asset condition assessment plan on the state level. At least once per year, State DOTs are tasked with assigning condition ratings to assets along state highway transportation corridors. Rated corridor elements include (USDOT 2007):

1. Roadway,

2. Roadside,

3. Vegetation and aesthetics, 
4. Traffic signs, and

5. Drainage.

The maximum rating for each category is 20 and, therefore, a perfect total rating of 100 is possible. An 80 was originally set as a passable grade by the FDOT, but since then other states have had the option to alter their target rating. For example, the North Carolina Turnpike Authority aims for an overall rating of 90/100 for the Triangle Expressway system (NCTA 2014).

Workers must undergo state-run MRP computer-based training and pass the MRP Handbook Exam (FDOT 2013). The goal is to develop a uniform asset rating style from State DOT employees so that all state's MRP ratings are consistent, while also dividing up the inventory rating work into smaller geographic regions.

Unfortunately, to date only six US states (Florida, Kentucky, North Carolina, Tennessee, Texas, and Virginia) and Taiwan (Chou et al. 2006) have (at least partially) adopted the MRP. Seven other US states (Illinois, Indiana, Michigan, Minnesota, Ohio, South Carolina, and Wisconsin) have published reports on the potential benefits of MRP or have expressed interest in developing a system but have not executed the program or have instead constructed a different plan. Although the MRP may work well at the statelevel, the immediate limitation is the lack of MRP acceptance among many states and, consequentially, little consistency for how assets are rated.

\subsubsection{Pavement Management Guide}

AASHTO released an official definition for Pavement Management System (PMS) in 1993:

"A pavement management system (PMS) is a set of tools or methods that assist decision-makers in finding optimum strategies for providing, evaluating, and maintaining pavements in a serviceable condition over a period of time." (AASHTO 1993)

In 2001, AASHTO released the Pavement Management Guide, which lists and describes the six elements required for pavement management (AASHTO 2001). The six elements are: 
1. Asset Inventory. The inventory “...includes information that defines the management sections and information about the location, limits, size, connectivity to other sections, number of traffic lanes, route designations, and functional classification for each management section" (p16, AASHTO 2001).

2. Condition Assessment. The condition of pavement assets is measured using the following variables: surface distress, structural capacity, roughness, surface friction, and skid resistance (Peterson 1987; AASHTO 2001).

3. Determination of Needs. Once the basic information has been compiled, a decision must be made on what work needs to be done (if any) for each pavement asset. Some sort of hazard rating scale is generally used, such as pavement condition index (PCI), which assigns a PCI value ranging from 0 to 100 (Figure 1.2 - FHWA 1991). 'Trigger values' are set to identify the level of maintenance (LOM) required. Default trigger values and LOM are as follows:
a. $0 \leq \mathrm{PCI}<25$
Heavy Rehabilitation/Reconstruction
b. $25 \leq \mathrm{PCI}<50$
Moderate Rehabilitation
c. $50 \leq \mathrm{PCI}<75$
Light Rehabilitation
d. $75 \leq \mathrm{PCI} \leq 100$
Preventative Maintenance

4. Prioritization of Projects Needing Maintenance and Rehabilitation. Prioritization of projects to complete is usually based on condition assessment, determination of needs, available funding, and logistics.

5. A Method to Determine the Impact of Funding Decisions. The goal here is to develop a methodology of determining the most economically efficient implementation of the program. Every funding agency wants optimal spending of their money.

6. A Feedback Process. Quality measures or a self-assessment rubric to grade the program's effectiveness and impact would help in making the pavement management plan more robust and sustainable. 
This pavement management procedure is basically the FHWA's generic asset management framework applied to a specific asset type and could be linked to other asset management procedures to create a corridor- or network-wide asset management plan.

\subsubsection{Unstable Slope Management Programs}

Unstable Slope Management (USM) programs have been developed by many State DOTs and aim to identify unstable slopes along transportation corridors before failures occur. These types of programs incorporate two general asset management steps: asset (slope) inventory and condition assessment.

The first USM program, implemented by the Oregon DOT (ODOT) and referred to as Oregon DOT-I or the Rockfall Hazard Rating System (RHRS), will be described in detail. Other state DOTs have created their version of the rating system, but since these were based on the original Oregon DOT-I they are compared in Table 1.1.

Table 1.1: Complete list of input parameters used in nine RHRSs: (1) ODOT-I, (2) ODOTII, an updated version by ODOT, (3) OHDOT - Ohio DOT, (4) NYSDOT - New York State DOT, (5) UDOT - Utah DOT, (6) WSDOT - Washington State DOT, (7) TDOT Tennessee DOT, (8) MODOT - Montana DOT, and (9) BCMoT - British Columbia Ministry of Transportation. This table is recreated from Huang et al. (2009).

\begin{tabular}{|c|c|c|c|c|c|c|c|c|c|}
\hline Parameters & ODOT-I & $\begin{array}{c}\text { ODOT- } \\
\text { II }\end{array}$ & ОНDОт & NYSDOT & UDOT & WSDOT & TDOT & MODOT & BCMoT \\
\hline $\begin{array}{c}\text { Annual } \\
\text { Averge Daily } \\
\text { Traffic }\end{array}$ & $\mathrm{X}$ & $\mathrm{X}$ & $\mathrm{X}$ & $\mathrm{X}$ & $\mathrm{X}$ & $\mathrm{X}$ & $\mathrm{X}$ & $\mathrm{X}$ & $X$ \\
\hline $\begin{array}{c}\text { Accident } \\
\text { History }\end{array}$ & & $X$ & $X$ & & & $X$ & & & \\
\hline $\begin{array}{c}\text { Annual } \\
\text { Maintenance } \\
\text { Frequency }\end{array}$ & & $\mathrm{X}$ & & & & & & & \\
\hline $\begin{array}{c}\text { Average } \\
\text { Vehicle Risk }\end{array}$ & $X$ & & $X$ & $X$ & $X$ & $X$ & $X$ & $X$ & $\mathrm{X}$ \\
\hline $\begin{array}{c}\text { Annual } \\
\text { Maintenance } \\
\text { Cost }\end{array}$ & & $\mathrm{X}$ & $\mathrm{X}$ & & & & & & \\
\hline $\begin{array}{l}\text { Backslope } \\
\text { Above Cut }\end{array}$ & & & & $\mathrm{X}$ & $\mathrm{X}$ & & & $\mathrm{X}$ & \\
\hline $\begin{array}{c}\text { Benefit-Cost } \\
\text { Ratio }\end{array}$ & & $\mathrm{X}$ & $\mathrm{X}$ & & & $\mathrm{X}$ & & & $\mathrm{X}$ \\
\hline $\begin{array}{c}\text { Block Size } \\
\text { Volume }\end{array}$ & $X$ & & & $X$ & $X$ & & $X$ & $X$ & $\mathrm{X}$ \\
\hline $\begin{array}{c}\text { Detour } \\
\text { Distance/Time }\end{array}$ & & & $\mathrm{X}$ & & & $\mathrm{X}$ & & & \\
\hline
\end{tabular}




\begin{tabular}{|c|c|c|c|c|c|c|c|c|c|}
\hline $\begin{array}{l}\text { Differential } \\
\text { Erosion }\end{array}$ & $X$ & & & $\mathrm{X}$ & $X$ & & $X$ & & $X$ \\
\hline $\begin{array}{l}\text { Discontinuity } \\
\text { Length }\end{array}$ & $X$ & & & & & & & & X \\
\hline $\begin{array}{c}\text { Discontinuity } \\
\text { Orientation }\end{array}$ & $\mathrm{X}$ & & & & & & $\mathrm{X}$ & $X$ & $\mathrm{X}$ \\
\hline $\begin{array}{c}\text { Discontinuity } \\
\text { Roughness }\end{array}$ & $X$ & & & $X$ & $X$ & & $X$ & $X$ & $X$ \\
\hline $\begin{array}{l}\text { Discontinuity } \\
\text { Weathering }\end{array}$ & & & & & & & & $X$ & \\
\hline $\begin{array}{c}\text { Ditch } \\
\text { Dimensions } \\
\end{array}$ & $X$ & & & $\mathrm{X}$ & $X$ & & $X$ & $X$ & $X$ \\
\hline $\begin{array}{c}\text { Expected } \\
\text { Damages or } \\
\text { Fatalities }\end{array}$ & & & $\mathrm{X}$ & & & $X$ & & & \\
\hline $\begin{array}{l}\text { Failure Zone } \\
\text { Length } \\
\end{array}$ & $\mathrm{X}$ & & $\mathrm{X}$ & $\mathrm{X}$ & $X$ & $X$ & $X$ & $X$ & \\
\hline $\begin{array}{c}\text { Freezing Period } \\
\text { or Freeze-Thaw } \\
\text { Cycle } \\
\end{array}$ & $X$ & & & & & & & & X \\
\hline Future Impact & & & $\mathrm{X}$ & & & $X$ & & & \\
\hline $\begin{array}{c}\text { Highway } \\
\text { Classification }\end{array}$ & & $X$ & & & & $X$ & & & \\
\hline $\begin{array}{l}\text { Impact to Road } \\
\text { Structure }\end{array}$ & & $X$ & $\mathrm{X}$ & & & $X$ & & & \\
\hline $\begin{array}{c}\text { Instability } \\
\text { Related to Rock }\end{array}$ & $X$ & $X$ & & $X$ & $X$ & $X$ & & $X$ & $\mathrm{X}$ \\
\hline $\begin{array}{c}\text { Instability } \\
\text { Related to Soil }\end{array}$ & & $X$ & & & & $X$ & & & \\
\hline $\begin{array}{c}\text { Instability } \\
\text { Related to Fill }\end{array}$ & & $X$ & & & & & & & \\
\hline $\begin{array}{c}\text { Percent } \\
\text { Decision Sight } \\
\text { Distance } \\
\end{array}$ & $X$ & & $\mathrm{X}$ & $X$ & $X$ & $X$ & $X$ & $X$ & $\mathrm{X}$ \\
\hline $\begin{array}{c}\text { Rate of } \\
\text { Movement }\end{array}$ & & $X$ & $\mathrm{X}$ & & & & & & \\
\hline $\begin{array}{l}\text { Roadway } \\
\text { Width }\end{array}$ & $X$ & & & & & & $X$ & & $\mathrm{X}$ \\
\hline $\begin{array}{l}\text { Rockfall//Slide } \\
\text { Frequency }\end{array}$ & & $X$ & $\mathrm{X}$ & & & & & & \\
\hline $\begin{array}{l}\text { Rockfall//Slide } \\
\text { History }\end{array}$ & $X$ & & & & & & $X$ & & X \\
\hline Slope Height & $X$ & & & & & & $X$ & $X$ & $X$ \\
\hline Slope Angle & & & $\mathrm{X}$ & $\mathrm{X}$ & $X$ & $X$ & & $X$ & \\
\hline Traffic Speed & $X$ & & $\mathrm{X}$ & & & $X$ & & & $\mathrm{X}$ \\
\hline $\begin{array}{c}\text { Vertical and } \\
\text { Horizontal } \\
\text { Displacement }\end{array}$ & & & $\mathrm{X}$ & & & & & & \\
\hline $\begin{array}{l}\text { Water on } \\
\text { Surface }\end{array}$ & $X$ & & & $\mathrm{X}$ & $X$ & $X$ & $X$ & $X$ & $\mathrm{X}$ \\
\hline
\end{tabular}

\subsubsection{Oregon DOT-I: RHRS}

The Rockfall Hazard Rating System was created by the ODOT in the 1980s. This system contains six main features (Pierson 1991):

1. A uniform method for slope inventory. 
2. A preliminary rating of all slopes. Slopes were initially rated based on the estimated potential for rock on the roadway and historical rock fall activity. In both categories, the slope would receive an " $A$ " rating if high, " $B$ " rating if moderate, and " $C$ " rating if low. "A" rated slopes then proceed to the detailed rating, while "B" rated slopes will be addressed if time permits and " $C$ " rated slopes discarded.

3. A detailed rating of all hazardous slopes. The detailed rating would assign a numerical value, from 1 to 100 , to each slope based on the following criteria:

a. Slope height - the vertical height of the slope from which a rock fall is expected.

b. Ditch effectiveness - the ability of roadside ditches to restrict falling rocks from reaching the roadway.

c. Average vehicle risk - the percentage of time that a vehicle will be present in the rock fall hazard zone.

d. Percent of decision sight distance - an estimation of the length of roadway, in feet, a driver must have to make a complex decision, based on vehicle speed, with respect to the actual length of roadway a driver would have to make the maneuver.

e. Roadway width - distance from edge of pavement on one side of the road to the edge of pavement on the opposite side.

f. Geologic character - attempts to describe slope characteristics based on geology.

g. Block size or quantity of rock fall per event - a representative estimation of size and amount of rock fall content per event.

h. Climate and presence of water on the slope.

i. Rockfall history - chosen from the following options: few falls, occasional falls, many falls, and constant falls.

A score is assigned to each of the variables listed above. The RHRS uses only four score options $-3,9,27,81$, with greater values indicating more hazardous slopes - although Pierson claims "... [these score values] are representative scores of a continuum of points from 1 to 100” (p3, Pierson 1991). 
4. A preliminary design and cost estimate for more serious sections.

5. Project identification and development. Pierson (1991) identifies four ways the results from the Rockfall Hazard Rating System may be used to determine projects for construction.

a. Slopes are chosen based on the rating score.

b. Slopes are chosen based on the rating score relative to the construction cost.

c. Adjacent slopes that require similar mitigation procedures are grouped together and chosen based on areal extent.

d. Slopes are chosen based on the rating score and proximity to important transportation infrastructure.

6. Annual review and update.

Eight other USM plans were constructed based on the Rockfall Hazard Rating System of Pierson (1991) and ODOT described above. Table 1.1 compares the input parameters used in each USM system, illustrating that not one system incorporates all possible input parameters and that there are pros and cons to using any USM program.

\subsubsection{Asset Management of Embankments: United Kingdom}

The embankment management framework described by Glendinning et al. (2009) and Perry et al. (2003) begin with a risk assessment flowchart and includes a strategic level and a tactical level. The strategic level examines all the slopes in the transportation network and includes steps like the construction of an asset inventory, slope prioritization based on risk analysis, maintenance, and asset monitoring. The tactical level focuses on individual slopes and includes steps such as condition assessment, potential mitigating actions needed, risk analysis, cost-benefit analysis, and short- and long-term planning.

Some specifications to the framework were given in Glendinning et al. (2009). Regular inspections of the assets are performed to assess the current condition of the asset and placed in an inventory (asset register). Risk analysis is performed by combining the current condition assessment information with "...historical information in some sort of

database... [t]he history plus the current condition provides information on the possible 
potential for failure" (p111, Glendinning et al. 2009) and coupling that information with a risk matrix approach (Figure 1.3) where "...the consequences of failure including safety and commercial risks... [such as] volume of traffic, value of the route, diversionary route availability and its strategic importance to the movement of freight" (p111). Funding and resources are directed where they are most required and, therefore, maintenance, monitoring, and remediation are performed if and where necessary.

\subsection{Limitations of Current Asset Management Plans}

Many limitations exist with either (1) the current asset management plans, or (2) implementation shortcomings of current asset management plans by state or federal DOTs. Below are listed eleven limitations, challenges, or areas within the asset management field that require more research concentration.

1. State-wide inventories are massive. Steps to collect inventory information on new asset classes, assess the existing condition, and rate new assets is "...such a large undertaking that... some states (e.g., Colorado and Washington) recently cut back on plans to inventory and assess retaining walls because of the cost of implementation and uncertainty in the payoff from the investment" ( $p 11$, Anderson \& Rivers 2013).

2. Incomplete inventories. No state has completed an inventory and initial condition rating for these assets: pavement, bridges, walls, culverts, slopes, embankments, and drainages (Anderson \& Rivers 2013). State DOTs have focused on specific asset types based on hazard. For example, states in the western US (Washington, Oregon, California, and Colorado) focus on rock and soil slope management due to landslide risks, while states in the Midwest (Michigan, Wisconsin, Ohio, and Pennsylvania) focus on pavement and bridge management due to deterioration from freeze/thaw cycles and heavy salt use.

3. Different asset types require different methods for measuring condition. "The expectation of the frequency of [a] rock fall from a rock cut, the long-term settlement of a bridge approach, movement of an anchored wall, or corrosion of steel reinforcements in mechanically stabilized earth are all areas in which the 
profession has not established or has not developed means for measuring or recording in consistent ways" (p13, Anderson \& Rivers 2013).

4. Condition variation in time is difficult to predict. The challenge that has had the least attention "is the need for predicting how performance changes through time and identification of the most advantageous times for investment for long-term level or service optimization" (p14, Anderson \& Rivers 2013).

5. There exists no good method for predicting large failures from observed deterioration. "Someday it will be possible, for example, to identify the deterioration of the [150-ft high side-hill] embankment on I-75 in Tennessee [which failed in May 2012] and take timely steps to improve drainage, and thereby the level of service, without such a large negative impact on performance" (p14, Anderson \& Rivers 2013).

6. Geotechnical asset management programs are minimal in scope. "Many agencies have rock fall management programs that could be classified as geotechnical asset management efforts; however, the number of programs for other geotechnical features... is limited" (p24, Vessely 2013). The author provides a list of possible geotechnical assets that could be monitored with a comprehensive asset management program: tunnels; retaining walls; earth retaining structures; embankments; modified native slopes or cut slopes; slopes, both stable and those displaying deformation, such as rock fall, rockslides, landslides, and even avalanche sites; road subgrade, rail subgrade, and transportation ground improvements; culverts; quarry and other material excavation sites.

7. Geotechnical asset life-cycle is poorly understood. Since geotechnical asset management is relatively new compared to other asset management programs (e.g., pavement, bridges, and highways), the complete life cycle of many geotechnical assets is not well understood. "There is a general lack of understanding and published data about the life cycles of most geotechnical assets" (p1659, Stanley \& Pierson 2013).

8. Future spending estimates are based on present asset deterioration models - actual spending varies greatly when assets do not deteriorate as projected (asset life-cycle 
is poorly understood). "Current approaches are based on maintaining a balance between the cost of spending now and spending in the future, versus consequences of failure... In this case [of an embankment failure that destroyed a rail subgrade], failure to recognize the transient nature of the embankment behavior has led to increased costs of having to mobilize twice to instigate repair. Historically, however, there has been very limited information about the future performance of the asset" (p117, Glendinning et al. 2009).

9. The sundry of asset management programs implemented on many levels, by many agencies/organizations with individual performance measures, results in incompatible datasets. "Data integration and sharing for asset management involve bringing in data from various sources. Most transportation agencies have large quantities of variable, heterogeneous data. Data heterogeneity usually results from the presence of internal legacy systems that have diverse structures and formats. The challenge is to create a framework that incorporates all of the data items needed to perform the desired asset management business functions, addresses the disparities in data sources and formats, and responds flexibly to changing data requirements when new business functions are introduced or when existing processes are modified" (p9, USDOT 2007).

10. There are problems experienced by local governments that need to be addressed. According to the Asset Management Overview released by the USDOT (2007), local governments described nine problems they encountered during the implementation of asset management programs. The general themes of these problems are listed below:

a. Commitment by management and staff is important.

b. Building and maintaining an asset inventory must be accomplished first but may also be performed progressively from many sources.

c. Asset condition assessment need not always be performed at the highest sophistication level to be a valuable decision-making tool.

d. Data formats may range from field notes to spreadsheets to geodatabases. 
e. Monitoring of the asset inventory and asset condition assessment is vital in keeping the asset management program relevant.

f. Decision-making based on the comparison of different asset types can be accomplished with an asset management program.

g. Asset condition standards are subjective and may vary between local governments, transportation agencies, and federal agencies and may vary by asset type.

h. Interdepartmental data sharing saves time and money.

i. The simpler the asset management tools, the more likely they will be accepted and widely used - "the tools need to be easily understandable, adaptable to the user's specific interests, and easy to operate without entailing lengthy, tedious activities for data entry, formatting, and other routine operations" (p19, USDOT 2007).

11. There are areas that need additional research. In 2005, a panel discussion focused on research needs and strategies for meeting them. The panel identified the following research needs (p24, USDOT 2007):

a. Data collection and integration

i. Maintaining databases of condition data

ii. Metadata standards

iii. Improving data quality

iv. Automated data collection

b. Condition assessment

i. Condition assessment processes for hidden infrastructure

ii. Using remote sensing capabilities

iii. Better warning systems

iv. Linking condition assessment with decision-making processes

c. Performance modeling

i. Capturing the effect of routine maintenance in life-value

ii. Modeling preventative maintenance

iii. Enhanced modeling techniques 
iv. Defining performance measures

d. Analysis

i. Tradeoffs in the decision-making process

ii. Asset valuation methodologies

iii. Risk analysis and cost of failure

iv. Treatment selection methods

e. Big picture issues

i. Documenting the benefits of asset management

ii. Infrastructure security

iii. Applications of emerging technologies

iv. Sustainable development

f. Teaching infrastructure management

i. Clearinghouse for infrastructure management course materials

ii. Translating research into course materials

\subsection{Purpose of this Study}

The work in this dissertation builds upon the geotechnical asset management framework to demonstrate the capabilities of applied remote sensing for unstable slope lifecycle analyses. Remote sensing techniques utilize optical, LiDAR, and radar sensors from various platforms (e.g., terrestrial, aerial, and satellite). The purpose of this study is to show how these techniques can be applied to asset management steps - specifically asset inventory (Step 2), condition assessment (Step 3), and performance monitoring (Step 5) from Figure 1.1 - on unstable slopes, which include rock slopes, soil/sediment slopes, and embankments (e.g., roadcuts and dams). The following chapters are placed in order by asset type and management steps; Table 1.2 shows the contents of each chapter based on asset, geotechnical asset management steps, and remote sensing technique used. 
Table 1.2: Focus of each chapter based on asset type, management steps, and remote sensing techniques.

\begin{tabular}{|c|c|c|c|}
\hline Chapter & Asset Type(s) & $\begin{array}{l}\text { Geotechnical Asset Management } \\
\text { Step(s) and/or Other System(s) }\end{array}$ & $\begin{array}{c}\text { Remote Sensing } \\
\text { Technique(s) }\end{array}$ \\
\hline 2 & $\begin{array}{l}\text { Rock Slope; } \\
\text { Railroad } \\
\text { Assets }\end{array}$ & $\begin{array}{c}\text { Asset Inventory; } \\
\text { Condition Assessment; } \\
\text { Performance Monitoring; } \\
\text { Rockfall Hazard Rating System }\end{array}$ & $\begin{array}{l}\text { Optical } \\
\text { Photographs; } \\
\text { LiDAR }\end{array}$ \\
\hline 3 & $\begin{array}{l}\text { Rock Slope; } \\
\text { Railroad } \\
\text { Assets } \\
\end{array}$ & $\begin{array}{c}\text { Asset Inventory; } \\
\text { Condition Assessment; } \\
\text { Performance Monitoring }\end{array}$ & InSAR \\
\hline 4 & Building & $\begin{array}{c}\text { Asset Inventory; } \\
\text { Condition Assessment; } \\
\text { Geographic Information Systems }\end{array}$ & InSAR \\
\hline 5 & Dam & Condition Assessment & InSAR \\
\hline 6 & Dam & $\begin{array}{l}\text { Condition Assessment; } \\
\text { Performance Monitoring }\end{array}$ & InSAR \\
\hline 7 & $\begin{array}{c}\text { Rock and Soil } \\
\text { Slopes }\end{array}$ & Asset Inventory & $\begin{array}{l}\text { InSAR; } \\
\text { GPS }\end{array}$ \\
\hline 8 & $\begin{array}{l}\text { Rock and Soil } \\
\text { Slopes }\end{array}$ & $\begin{array}{l}\text { Condition Assessment; } \\
\text { Performance Monitoring }\end{array}$ & $\begin{array}{c}\text { Optical Correlation; } \\
\text { InSAR; } \\
\text { GPS } \\
\end{array}$ \\
\hline
\end{tabular}




\title{
Chapter 2: Rockfall Hazard Rating System: Benefits of Utilizing Remote Sensing ${ }^{1}$
}

\author{
El Hachemi Bouali²; Thomas Oommen, Ph.D. ${ }^{3}$; Stanley Vitton, Ph.D. ${ }^{4}$; \\ Rüdiger Escobar-Wolf, Ph.D. ${ }^{5}$; and Colin Brooks ${ }^{6}$
}

\subsection{Abstract}

Transportation corridor slopes have the potential to be hazardous to adjacent assets. Rockfall Hazard Rating System (RHRS) is a stepwise process designed to identify potentially hazardous slopes by assigning a hazard rating that determines the order to mitigate and remediate slopes. A traditional RHRS approach is field-based: observations are made by a field crew who convert observations into slope ratings (preliminary and detailed). The purpose of this study is to examine the benefits of utilizing remote sensing techniques on 14 slopes within a 24-km railroad corridor in southeastern Nevada. Remote sensing allows for data acquisition in difficult-to-reach locations from various view angles. Images and data from three remote sensing technique-platform combinations are examined: optical imagery acquired via satellite, optical imagery acquired via unmanned aerial vehicle (UAV), and light detection and ranging (LiDAR) data acquired from a stationary sensor. Detailed RHRS slope ratings from both sets of optical images are

${ }^{1}$ The material contained in this chapter was previously published in Environmental and Engineering Geoscience.

2 Department of Geological and Mining Engineering and Sciences, Michigan Technological Univ., 1400 Townsend Dr., Houghton, MI 49931 (corresponding author). E-mail: eybouali@mtu.edu

3 Department of Geological and Mining Engineering and Sciences, Michigan Technological Univ., 1400 Townsend Dr., Houghton, MI 49931. E-mail: toommen@mtu.edu

4 Department of Civil and Environmental Engineering, Michigan Technological Univ., 1400 Townsend Dr., Houghton, MI 49931. E-mail: vitton@mtu.edu

5 Department of Geological and Mining Engineering and Sciences, Michigan Technological Univ., 1400 Townsend Dr., Houghton, MI 49931. E-mail: rpescoba@mtu.edu

6 Michigan Tech Research Institute, 3600 Green Court, Suite 100, Ann Arbor, MI 48105. Email: cnbrooks@mtu.edu 
compared to two types of field-based ratings: (1) initial field observations performed using a traditional RHRS approach, and (2) average detailed rating scores from six participants (geologists and geotechnical engineers) who were given field notes of the ten rating criteria

for the 14 slopes. Terrestrial LiDAR is capable of monitoring slow slope deformation, with an accuracy of approximately 1-2 cm/year, and identifying areas of rapid deformation. Remote sensing techniques should not replace traditional field methods entirely. Instead, developing an approach that combines the advantages of field- and remote sensing-based methodologies will enable transportation agencies to ensure a more robust, efficient, and time-effective RHRS approach.

\subsection{Introduction}

Rockfall Hazard Rating System (RHRS) is a procedure used to analyze and prioritize slopes along transportation corridors (roadways and railways) based on the potential hazard of rockfall occurrence. A train derailment in British Columbia, Canada in the early 1970s was the impetus for the development of RHRS, which is commonly used today (Brawner and Wyllie 1975). Rating criteria based on geometric and geologic conditions of the railroad-slope environment were created to determine future rockfall mitigation and remediation efforts. Slopes were categorized by greatest potential hazard (A) to least hazardous (E). This novel approach was expanded (Wyllie et al. 1979; Wyllie 1980; Wyllie 1987) with development of an exponential scoring system to better categorize slopes from A to E. The practicality of this proactive approach was realized and adopted by many transportation agencies in the early 1990s when state agencies collaborated to develop initial RHRS instructions (Pierson 1991; Pierson 1992; Pierson and Van Vickle 1993; Brawner 1994). Since then some transportation agencies have further refined slope hazard rating criteria (Huang 2009). RHRS procedures described by Pierson and Van Vickle (1993) will be used in this paper, since this version is incorporated in most recent RHRS approaches.

The full RHRS procedure requires completion of six steps: (1) slope inventory, (2) preliminary slope rating, (3) detailed slope rating, (4) project design and cost estimation, (5) project identification and development, and (6) yearly reviews and updates. Data 
collected in these six steps are then inputted into a geodatabase that incorporates locations of slopes adjacent to relevant transportation corridors (Step 1). The preliminary slope rating (Step 2) classifies slopes into three hazard categories - A (high), B (moderate), and C (low) - based on past rockfall activity and potential for future rockfall activity. A detailed slope rating (Step 3) further classifies high-risk slopes (from the preliminary slope rating) by assigning a score based on ten rating criteria that include (1) slope height, (2) ditch effectiveness, (3) average vehicle risk, (4) decision sight distance, (5) roadway width, (6) structural condition, (7) rock friction (hard rock) or differential erosion rates (soft rock), (8) block size/volume, (9) climate and water presence, and (10) rockfall history. Scores range from one (lowest hazard) to 100 (highest hazard) per rating criteria. The detailed rating for each slope is the summation of all ten rating criteria scores. Project design and cost estimation (Step 4) is considered prior to project implementation. Pierson and Van Vickle (1993) offer a variety of methods for project identification and development based on the RHRS procedure. The purpose of Step 5 is to formulate the best approach for rockfall mitigation and remediation construction, while Step 6 recommends rated slopes be reviewed on an annual basis. Therefore, depending on the outcome of Step 6, changes to information recorded in Steps 1-5 may be required for relevant slopes.

Implementation of the RHRS procedure can be time-consuming and expensive due to the amount of data acquisition and analysis (preliminary and detailed slope ratings) required, which increases drastically with scale (e.g., state-wide transportation networks), and need for annual reviews and updates. Transportation agencies have tried using different types of non-traditional data acquisition techniques to minimize these difficulties. Traditional data acquisitions are in situ measurements and/or field observations; the instrument and the user need to be on site. Non-traditional data acquisitions are remote sensing-based; active or passive sensors mounted upon moving or stationary platforms receive information in the form of electromagnetic waves (e.g., aerial photography). The use of remote sensing data acquisition for RHRS purposes - such as slope characterization, feature identification, and surficial change and displacement measurements - has evolved over the last 15 years. Data sources include state highway video logs (Maerz et al. 2005; Youssef et al. 2007; Youssef and Maerz 2012), optical photography and photogrammetry 
(Di Crescenzo and Santo 2007; Lucieer et al. 2014), terrestrial laser scanning (Bauer et al. 2005; Abellán et al. 2009; Abellán et al. 2010), and light detection and ranging (LiDAR) technologies (Strouth and Eberhardt 2007; Lato et al. 2009; Lan et al. 2010; Lato et al. 2012). Terrestrial remote sensing techniques allow for detailed observations and accurate surficial measurements of slopes. Platforms in motion, such as satellites, airplanes, terrestrial vehicles, and unmanned aerial vehicles (UAVs), allow for data acquisition that covers relatively large areas (potentially multiple slopes at once) at various vantage points in repeatable fashion.

A 24-km section of railroad corridor in southeastern Nevada (Figure 2.1) was chosen to test the efficacy of applying two remote sensing methods-optical photogrammetry and LiDAR, with instruments located on different platforms and viewing angles (Table 2.1) — to develop an RHRS rating for slopes within the corridor. The railroad corridor follows the valley floor of a canyon system that cuts through volcanic rock consisting of rhyolite, tuff, and welded breccia, with approximately $33 \%$ of railroad tracks within $30 \mathrm{~m}$ of a slope with height $>50 \mathrm{~m}$. Approximately $2.5 \%$ of the $24-\mathrm{km}$ track passes through five tunnels.

The railroad corridor was studied by Justice (2015), who utilized a multi-level approach through the application of the RHRS procedure. The multi-level approach, which used local- and regional-scale hazard assessments, was performed using satellite orthophotography and point-cloud images generated from a terrestrial LiDAR survey on three slopes within the railroad corridor. Bouali et al. (2016a) used a satellite-based remote sensing technique, interferometric synthetic aperture radar (InSAR), to measure surficial displacement rates across the railroad corridor between 1992 and 2010; this study included all three slopes from the Justice (2015) study. One slope exhibited downslope displacement rates $>10 \mathrm{~mm} /$ year and five additional slopes were identified as potentially hazardous based on slope distance from railroad track, slope height, slope angle, downslope displacement rate (velocity), and total displacement. 


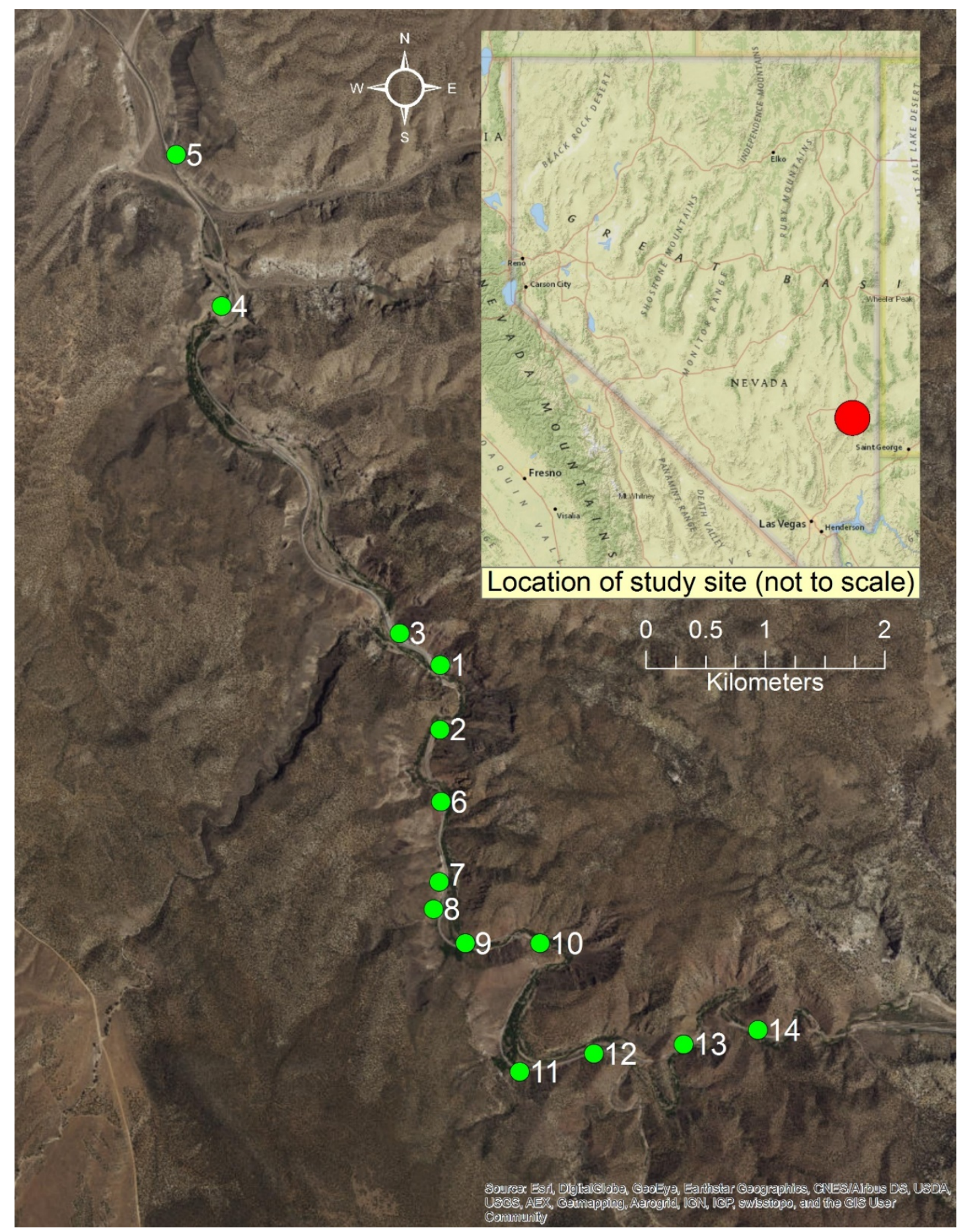

Figure 2.1: 24-km segment of railroad corridor located in southeastern Nevada (inset). 14 slopes (green circles) are identified by number (Slope 1, Slope 2, etc.). Background imagery was generated in ArcGIS software by Esri. 
Table 2.1: Types of remote sensing platforms, sensors, and output data used for this study.

\begin{tabular}{|c|c|c|c|c|}
\hline Platform & Sensors & $\begin{array}{c}\text { Sensor } \\
\text { Type }\end{array}$ & Motion & Output Data \\
\hline Satellite & $\begin{array}{c}\text { Landsat 7, } \\
\text { WorldView 1 \& 2 }\end{array}$ & Optical & Polar Orbit & $\begin{array}{c}\text { Photographic } \\
\text { Images }\end{array}$ \\
\hline UAV & $\begin{array}{c}\text { Nikon D800 }(50 \mathrm{~mm}) \\
\text { mounted on Bergen } \\
\text { Hexacopter }\end{array}$ & Optical & $\begin{array}{c}\text { Remote Controlled } \\
\text { by Operator }\end{array}$ & $\begin{array}{c}\text { Photographic } \\
\text { Images, 3-D } \\
\text { Point Clouds }\end{array}$ \\
\hline Terrestrial & RIEGL LMS-Z210ii & LiDAR & Stationary & $\begin{array}{c}\text { 3-D Point } \\
\text { Clouds }\end{array}$ \\
\hline
\end{tabular}

This study will focus on 14 slopes (named Slope 1, Slope 2, .., Slope 14) that meet three geometric criteria: (1) slope toe is located within $15 \mathrm{~m}$ of the railroad track, (2) slope is at least $15 \mathrm{~m}$ tall, and (3) a dip greater than $25^{\circ}$ towards the railroad tracks is measured on the slope face. The purpose of this study is to investigate the effectiveness of using remote sensing techniques to assess RHRS values compared to a traditional field-based method. Although some state transportation agencies continuously monitor and rate their highest priority slopes (e.g., through video logs), a synergistic field- and remote sensingbased approach will allow for measurements undetectable or not within view from transportation corridor heights, such as identification of rockfall source areas and unstable blocks, small-scale rock displacement detection (mm-scale), and identification of potential future hazardous slopes. Specifically, additional advancements in the usage of remote sensing techniques for preliminary slope ratings, detailed slope ratings, and annual rating reviews and updates would supplement repetitive site visits yet complement the traditional RHRS field-based approach. A long-term monitoring approach that updates slope ratings in near real-time would be beneficial and incorporating remote sensing techniques into RHRS procedures can accomplish this goal.

\subsection{Methodology}

The application of remote sensing techniques in acquiring information for Step 2 (preliminary slope rating), Step 3 (detailed slope rating), and Step 6 (yearly reviews and updates) can aid in the efficacy of the RHRS procedure discussed in Pierson and Van 
Vickle (1993). Preliminary slope ratings can be assigned to slopes based on relatively low resolution, vertical photography acquired from optical sensors on satellites, airplanes, and UAVs. The process of assigning detailed slope ratings to "A" level slopes, traditionally conducted by an on-site field crew, can be improved by data obtained from terrestrial LiDAR (at ground-level) and oblique-angle, high resolution photographs from UAVs. The yearly RHRS review and update can further use remote sensing datasets to reduce review time and cost. A description of an approach using traditional field methods and remote sensing techniques to provide a synergistic RHRS approach is discussed below.

\subsubsection{Preliminary Slope Rating (RHRS Step 2)}

The preliminary slope rating classifies a slope based on the "estimated potential for rockfall on roadway" and "historical rockfall activity" using a three-tiered class system: "A" for high, "B" for moderate, and "C" for low (p18, Pierson and Van Vickle 1993). Eight factors are considered when performing the preliminary rating. Of these eight factors, four potential rockfall factors can be estimated using remote sensing. These are (1) size of rockfall material, (2) quantity of material, (3) amount available, and (4) ditch effectiveness. The four historical rockfall activity factors can also be estimated using remote sensing data if these data were acquired after the rockfall event and prior to remediation. This study will examine the four potential rockfall factors; a similar approach can be applied to historical rockfall activity factors if relevant data were acquired.

Optical photography, acquired by satellite, airplane, or UAV fly-overs, can directly aid in quantification of factors that indicate a potential for future rockfall events that impact the adjacent transportation corridor. All four factors are area measurements (rock size, material quantity, material amount, and ditch coverage) and, therefore, can be estimated using optical photographs in a GIS database. Two acquisition variables that dictate the effectiveness of using optical photographs are image resolution and view angle. Coarse resolution (m-scale) images are widely available and sufficient for identifying large unstable blocks, but there are likely to be sub m-scale rocks that can cause damage and will be undetectable at such coarse resolutions. It is therefore important to obtain optical photographs at a resolution greater than (lower in magnitude) the smallest sized rock 
deemed dangerous to traffic within the transportation corridor, most likely from images with $\mathrm{cm}$-scale resolution. The view angle from which images are acquired is also important, as a different vantage point gives more information on the slope. For situations where the top of the slope is not viewable from transportation corridor (ground) level, a vertical view angle allows for better estimations of material quantity and amount of material available, as well as identification of potential large unstable blocks previously unobservable.

\subsubsection{Detailed Slope Rating (RHRS Step 3)}

Slopes with a preliminary "A" rating are of highest priority, requiring detailed slope ratings be conducted on these slopes first (Pierson and Van Vickle 1993). The detailed slope rating assigns a numerical value between one (lowest hazard) and 100 (highest hazard) for the ten rating criteria previously discussed. Five rating criteria are quantitative, with the function $y=3^{\mathrm{x}}$ used as the basis of the scoring system, with discrete formulae for the exponent (x) provided for slope height, average vehicle risk, sight distance, roadway width, and block size/volume (p29, Pierson and Van Vickle 1993). The other five rating criteria (ditch effectiveness, structural condition, rock friction or differential erosion, climate and presence of water, and rockfall history) are more qualitative; scores are assigned based on observations rather than numerical measurements. The sum of scores for the ten rating criteria equal the total hazard score for a slope, ranging from ten (no hazard) to 1,000 (immediate hazard). Since total hazard scores are subjective and relative, it is important to maintain consistency when assigning detailed slope ratings along transportation corridors. Further, transportation agencies use the total hazard score as an input variable when assigning priority for mitigation and remediation strategies (Step 5).

To assess the subjectivity of the detailed slope rating RHRS step, field notes of the ten rating criteria for each of the 14 slopes were given to six participants (geologists and geotechnical engineering faculty and graduate students at Michigan Technological University). Participants, who were not given any additional information of the railroad corridor, were asked to convert the field notes (text and numeric data) into detailed slope ratings for all 14 slopes. The purpose of this exercise is to quantify, albeit simplistically, variance of field-based detailed rating scores and, under the assumption that field-based 
RHRS procedure is the baseline, to determine the accuracy of different remote sensing techniques.

Remote sensing can only be beneficial if acquired images capture enough detail to identify slope features and characteristics. Image resolution must be on par with what can be observed in the field. Additionally, remote sensing techniques can supplement fieldbased observations by acquiring images from various view angles in hard-to-reach locations on a slope (e.g., top of slope, tall vertical cliff faces, areas considered dangerous due to rockfall or unstable materials, etc.). High resolution (cm-scale) UAV images, acquired at oblique angles, allow for additional observations at higher elevations along the slope. The combination of multiple remote sensing techniques, especially with data acquired from several types of sensors and locations, provides the ability to quantify rating criteria from the detailed slope rating procedure.

\subsubsection{Yearly Reviews and Updates (RHRS Step 6)}

Transportation agencies are required to maintain optimum safety throughout the transportation network. One way of doing this, in terms of hazards posed by unstable slopes, is to perform an annual review of every "A"-rated slope (RHRS Step 3). This provides a long-term monitoring procedure that is focused on the most hazardous slopes. Furthermore, any preliminarily-rated slope (regardless of tiered rating: A, B, or C) that has undergone any changes (construction, maintenance, displacement, etc.) should be reassessed and the slope rating reassigned.

A major benefit of utilizing remote sensing techniques in assessing RHRS parameters is the capability of monitoring slope changes over prolonged periods. Multiple acquisitions of LiDAR and optical photogrammetry can qualitatively monitor changes as well as quantitatively measure deformation rates on and around each slope. Annual-scale qualitative observations may include noting (1) change of talus sizes at the bottom of slopes, (2) weathering condition and erosion locations on the slope face, and (3) presence of water in planes of weakness (faults, joints, and bedding planes), among others. Quantitatively, LiDAR and optical photogrammetric techniques such as Structure from Motion (SfM) and three-dimensional point cloud change detection allow for the calculation 
of surficial deformation between image pairs by measuring the change in slope surface location, between two different acquisition dates, in three-dimensional space.

\subsection{Results and Discussion}

Examples of remote sensing data analyses applied to the RHRS procedure are organized by RHRS step. The effectiveness of optical satellite and UAV photography are examined in Section 2.4.1 Preliminary Slope Rating (RHRS Step 2). Those two techniques are compared to two field-based approaches - an initial field examination and a participant survey-in Section 2.4.2 Detailed Slope Rating (RHRS Step 3). Long-term remote sensingbased slope monitoring approach are discussed in Section 2.4.3 Yearly Review and Update (RHRS Step 6), with a LiDAR change detection example given of Slope 1.

\subsubsection{Preliminary Slope Rating (RHRS Step 2)}

Preliminary slope ratings were assigned to all 14 slopes via both traditional fieldbased observations and using optical satellite images (Table 2.2). The field approach identified three "A"-rated slopes, nine "B"-rated slopes, and two "C"-rated slopes. The satellite imagery approach identified one "A"-rated slope, seven "B"-rated slopes, and six "C"-rated slopes. An underestimation of preliminary slope ratings using optical satellite imagery is probably due to the use of coarse resolution imagery (m-scale). Sub m-scale details are unobservable and blurry at coarse resolutions, resulting in hazardous features (e.g., moderate-sized loose rocks, adverse joint orientations, and other evidence of displacement) going undetected. This underestimation issue is addressed more fully in Section 2.4.2 Detailed Slope Rating (RHRS Step 3). Although small-scale details may be unobservable with coarse resolution imagery, other steps within the RHRS procedure can be made easier when supplemented with optical satellite imagery. Coarse satellite imagery can be obtained free of charge and in near real-time, which can aid in large-scale rockfall detection and monitoring. 
Table 2.2: Preliminary slope ratings for each slope using field-based observations and optical satellite imagery.

\begin{tabular}{|l|c|c|c|c|c|c|c|c|c|c|c|c|c|c|}
\hline Slope \# & 1 & 2 & 3 & 4 & 5 & 6 & 7 & 8 & 9 & 10 & 11 & 12 & 13 & 14 \\
\hline Field & A & B & B & C & C & B & A & B & B & B & B & A & B & B \\
\hline Satellite & A & B & B & C & C & B & B & C & B & C & C & B & B & C \\
\hline
\end{tabular}

Vertical optical imagery can greatly assist in the preliminary slope rating RHRS step. Figure 2.2 shows Slope 1 - the only slope where historic rockfalls have blocked and disrupted rail traffic - from three vantage points: (A) ground-level near the railroad tracks, (B) near-vertical optical image acquired via satellite, and (C) vertical optical image acquired via UAV. Many slope features were identified with satellite and UAV imagery that were undetected from ground-level. Features identified using satellite imagery include at least three large blocks at the top of the slope and the presence of the main scarp (Figure 2.2B: red dashed oval; Figure 2.2C), although an accurate measurement as to the size of the main scarp was difficult to obtain. Aperture of the main scarp was estimated using UAV images (and confirmed by field work) to be about $8 \mathrm{~m}$ wide. Additional features detected with UAV imagery include presence of a secondary scarp, located downslope from the main scarp, and large blocks and piles of loose rock (also downslope from the main scarp). 

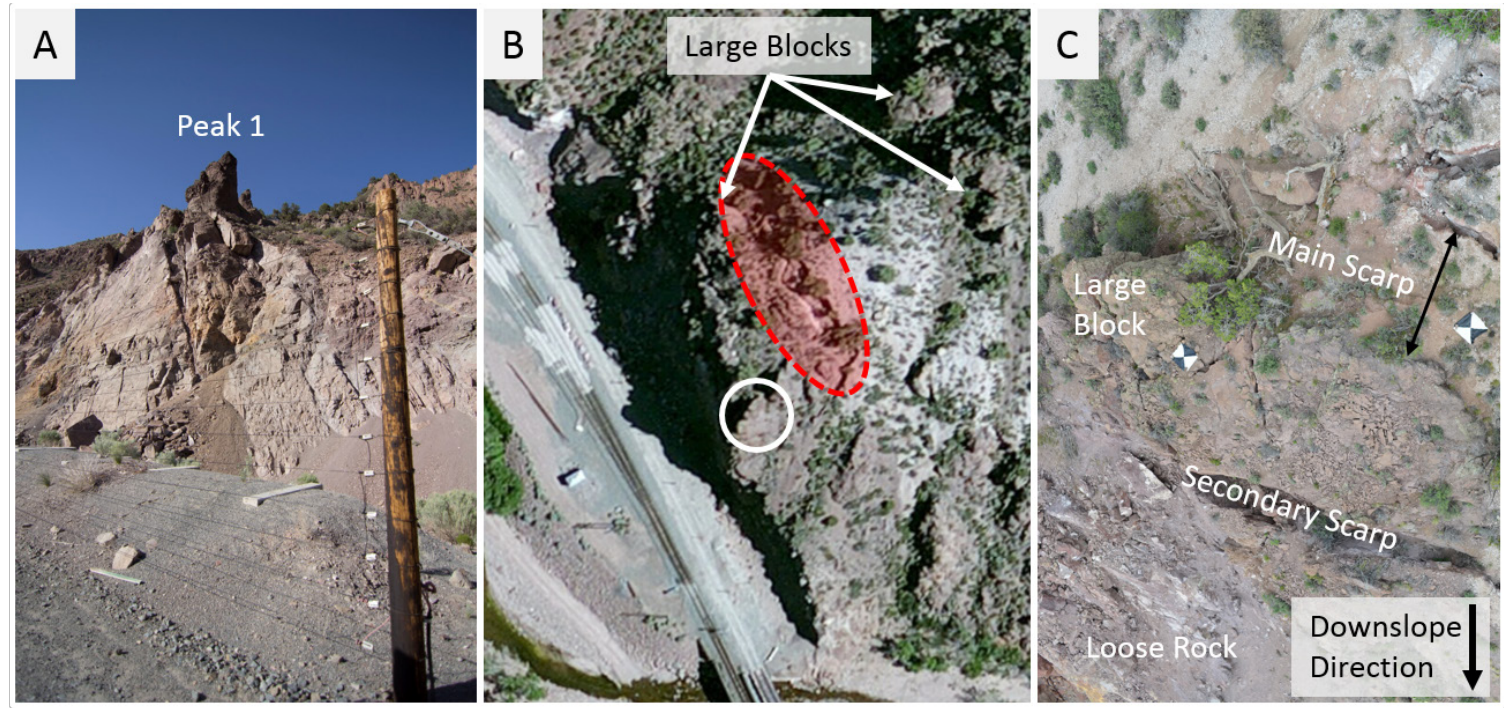

Figure 2.2: Slope 1. (A) Photo taken from ground-level near the railroad tracks. (B) Nearvertical optical satellite image. Peak 1 from (A) is shown in white circle. Slope features that aid in preliminary slope rating include three large blocks and the main scarp (red dashed oval). (C) Vertical UAV image that details the main scarp (up to 8 meters wide) and a previously-undetected secondary scarp, a large block also identified in (B), and piles of loose rock.

\subsubsection{Detailed Slope Rating (RHRS Step 3)}

A detailed slope rating is normally performed on slopes that receive an "A" rating in the preliminary slope rating step. This is usually due to the sheer quantity of slopes that may be classified as "A" level, especially when dealing with statewide transportation networks (Pierson and Van Vickle 1993). However, since the areal extent of this project is relatively small, all slopes were given a detailed slope rating regardless of preliminary slope rating. This allows for a direct comparison of how preliminary slope ratings translate into detailed slope rating hazard scores and how remote sensing datasets can assist in slope prioritization and future decision-making. Table 2.3 shows preliminary and detailed ratings, as well as values for rating criteria, for each slope. Slope 1 received a preliminary slope rating (field/satellite) of $\mathrm{A} / \mathrm{A}$ and a detailed slope rating of 506, making it the most hazardous slope in the railroad corridor. Slopes that received an A/B preliminary slope 
rating corresponded to a 427-467 detailed slope rating, B/B corresponded to 325-334, B/C corresponded to $308-350$, and $\mathrm{C} / \mathrm{C}$ corresponded to 250-269. There is a clear distinction between slopes with an $\mathrm{A} / \mathrm{A}$ or $\mathrm{A} / \mathrm{B}$ rating $(\geq 427)$, slopes with a $\mathrm{B} / \mathrm{B}$ or $\mathrm{B} / \mathrm{C}$ rating (308-350), and slopes with a $\mathrm{C} / \mathrm{C}$ rating $(\leq 269)$.

Table 2.4 displays information for all field-based detailed rating scores. The initial score is the detailed rating score obtained by the original field crew. The minimum and maximum participant scores illustrate the range in detailed rating scores assigned based on the same set of textual and numerical field notes. Initial score and participants scores were generally in agreement: the initial score fell into the participant scores range for nine slopes (Slopes 2, 4, 5, 7, 8, 9, 11, 12, and 14); initial score was greater than the participant scores range for Slopes 1 and 3; initial score was less than the participant scores range for Slopes 6, 10, and 13. Participant scores ranges were within 72 for every slope except Slope 14. Discrepancies in detailed rating scores were usually due to interpretation of subjective, textual rating criteria, especially when complex slope characteristics do not neatly compartmentalize into pre-assigned rating criteria scores. For example, structural condition of a rock slope is assigned a rating criterion score of three if there are "discontinuous joints, favorable orientation," nine if "discontinuous joints, random orientation," 27 if "discontinuous joints, adverse orientation," and 81 if "continuous joints, adverse orientation" (p26, Pierson and Van Vickle 1993). Subjectivity occurred when slopes were described as having "continuous joints, random orientation," which is not a predetermined category and, therefore, the value of structural condition rating criteria is left for the participant to decide. This type of subjective score assignment was required at multiple slopes because complex geology sometimes required uncategorized descriptions. 
Table 2.3: Preliminary slope ratings based on field observations and satellite imagery (also shown in Table 2.2). Detailed slope ratings based on initial field observations. Rating criteria listed by number: \#1 slope height, \#2 ditch effectiveness, \#3 average vehicle risk, \#4 decision sight distance, \#5 roadway width, \#6 structural condition, \#7 rock friction, \#8 block size/volume, \#9 climate and presence of water, and \#10 rockfall history. Shaded rating criteria were calculated using exponent formulae from Pierson and Van Vickle (1993).

\begin{tabular}{|c|c|c|c|c|c|c|c|c|c|c|c|c|c|c|c|}
\hline \multicolumn{2}{|c|}{ Slope \# } & 1 & 2 & 3 & 4 & 5 & 6 & 7 & 8 & 9 & 10 & 11 & 12 & 13 & 14 \\
\hline \multicolumn{2}{|c|}{$\begin{array}{c}\text { Preliminary } \\
\text { Slope } \\
\text { Ratings } \\
\text { (Field/ } \\
\text { Satellite) }\end{array}$} & $\begin{array}{c}\mathrm{A} / \\
\mathrm{A}\end{array}$ & $\begin{array}{l}\mathrm{B} / \\
\mathrm{B}\end{array}$ & $\begin{array}{l}\mathrm{B} / \\
\mathrm{B}\end{array}$ & $\begin{array}{l}\mathrm{C} / \\
\mathrm{C}\end{array}$ & $\begin{array}{l}\mathrm{C} / \\
\mathrm{C}\end{array}$ & $\begin{array}{l}\mathrm{B} / \\
\mathrm{B}\end{array}$ & $\begin{array}{c}\mathrm{A} / \\
\mathrm{B}\end{array}$ & $\begin{array}{l}\mathrm{B} / \\
\mathrm{C}\end{array}$ & $\begin{array}{l}\mathrm{B} / \\
\mathrm{B}\end{array}$ & $\begin{array}{l}\mathrm{B} / \\
\mathrm{C}\end{array}$ & $\begin{array}{l}\mathrm{B} / \\
\mathrm{C}\end{array}$ & $\begin{array}{c}\text { A/ } \\
\text { B }\end{array}$ & $\begin{array}{l}\text { B/ } \\
\text { B }\end{array}$ & $\begin{array}{l}\mathrm{B} / \\
\mathrm{C}\end{array}$ \\
\hline \multirow{10}{*}{ 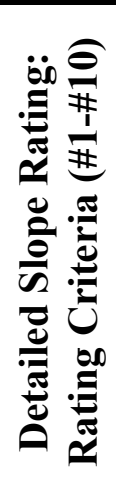 } & $\# 1$ & 100 & 100 & 100 & 16 & 10 & 76 & 100 & 71 & 15 & 100 & 62 & 81 & 100 & 13 \\
\hline & $\# 2$ & 27 & 3 & 9 & 81 & 81 & 81 & 70 & 70 & 81 & 70 & 27 & 27 & 81 & 81 \\
\hline & $\# 3$ & 1 & 1 & 1 & 1 & 1 & 1 & 1 & 1 & 1 & 1 & 1 & 1 & 1 & 1 \\
\hline & $\# 4$ & 0 & 1 & 0 & 0 & 13 & 24 & 8 & 8 & 1 & 1 & 0 & 27 & 1 & 0 \\
\hline & $\# 5$ & 100 & 100 & 100 & 100 & 100 & 100 & 100 & 100 & 100 & 100 & 100 & 100 & 100 & 100 \\
\hline & $\# 6$ & 81 & 72 & 81 & 58 & 36 & 69 & 81 & 81 & 81 & 63 & 81 & 81 & 70 & 63 \\
\hline & $\# 7$ & 81 & 62 & 3 & 8 & 3 & 21 & 22 & 3 & 27 & 27 & 27 & 27 & 21 & 81 \\
\hline & $\# 8$ & 47 & 2 & 9 & 9 & 5 & 9 & 100 & 0 & 9 & 47 & 27 & 16 & 9 & 2 \\
\hline & $\# 9$ & 7 & 7 & 7 & 7 & 7 & 7 & 7 & 7 & 7 & 7 & 7 & 7 & 7 & 7 \\
\hline & $\# 10$ & 62 & 9 & 3 & 3 & 3 & 5 & 3 & 3 & 3 & 3 & 27 & 66 & 3 & 14 \\
\hline \multicolumn{2}{|c|}{$\begin{array}{c}\text { Field-Based } \\
\text { Detailed } \\
\text { Slope } \\
\text { Rating } \\
\text { Scores } \\
\end{array}$} & 506 & 334 & 332 & 269 & 250 & 327 & 467 & 329 & 325 & 350 & 359 & 427 & 328 & 308 \\
\hline
\end{tabular}

Detailed slope ratings were also assigned using optical photography obtained from two platforms: satellite and UAV. The remote sensing-based RHRS detailed slope rating approach was conducted by downloading data (in the case of satellite images) or acquiring data (UAV images) and then identifying rating criteria from the images obtained of each slope within the study site. Measurements were made after importing images into a geographic information systems (GIS) geodatabase for analysis. 
Table 2.4: Detailed slope ratings. Initial score is identical to initial field-based observations found in Table 2.3. Statistics of participant scores (mean, standard deviation, minimum, and maximum) from the survey illustrate subjectivity of the RHRS procedure.

\begin{tabular}{|c|c|c|c|c|c|c|c|c|c|c|c|c|c|c|c|}
\hline \multicolumn{2}{|c|}{ Slope \# } & 1 & 2 & 3 & 4 & 5 & 6 & 7 & 8 & 9 & 10 & 11 & 12 & 13 & 14 \\
\hline \multicolumn{2}{|c|}{$\begin{array}{l}\text { Initial } \\
\text { Score }\end{array}$} & 506 & 334 & 332 & 269 & 250 & 327 & 467 & 329 & 325 & 350 & 359 & 427 & 328 & 308 \\
\hline \multirow{4}{*}{ 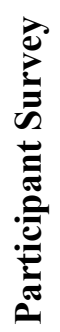 } & Mean & 452 & 357 & 313 & 283 & 259 & 402 & 492 & 344 & 325 & 419 & 359 & 433 & 393 & 362 \\
\hline & SD & 15 & 24 & 0 & 22 & 22 & 23 & 20 & 15 & 0 & 32 & 0 & 16 & 20 & 51 \\
\hline & Min. & 437 & 331 & 313 & 253 & 250 & 361 & 463 & 321 & 325 & 376 & 359 & 414 & 361 & 294 \\
\hline & Max. & 471 & 385 & 313 & 303 & 304 & 426 & 508 & 355 & 325 & 448 & 359 & 448 & 409 & 447 \\
\hline
\end{tabular}

Optical UAV photography were acquired using a Nikon D800 camera, with a 50-mm prime lens (collecting $35 \mathrm{MP}$ imagery at 2 frames/s at a speed of approximately 2 $\mathrm{m} / \mathrm{s}$ ) onboard a Bergen Hexacopter, for Slope 1 and Slope 2. Detailed rating scores are shown in Table 2.5. High resolution imagery (cm-scale), obtained from multiple UAV flyovers at different view angles (vertical and oblique), results in an overestimation of detailed rating scores when compared to both field-based methods and optical satellite photography usage. For example, vertical (Figure 2.3B) and oblique (Figure 2.3C) view angles of Slope 2 present a more complete picture of current slope conditions. A vertical view angle allows for the identification of source material for potential instabilities on top the slope, vegetation distribution (a vegetated region has not experienced a rockfall recently), and structural conditions such as weathering distribution and strike of joints/faults. An oblique view angle reveals more of the upper slope face, which is difficult to see from groundlevel. An overestimation of detailed rating scores was the result of more robust data. Table 2.6 shows the increase in UAV-based detailed rating scores compared to satellite-based detailed rating scores. Regarding Slope 2 (Figure 2.3), an increase in three rating criteria changed the detailed rating score from 331 (satellite) to 396 (UAV). An increase in the three rating criteria values - structural condition, rock friction, and block size/volumewas a direct result of better estimations due to higher resolution imagery. The use of sub- 
meter UAV imagery makes unstable rocks, ranging in size from tens of inches to $3 \mathrm{ft}$ (about $1 \mathrm{~m}$ ), visible; rocks of these sizes appear blurry in coarse resolution imagery. Details of structural condition and rock friction are also made clearer using high resolution UAV imagery, especially at an oblique view angle that reveals the slope face from the shadow zone sometimes observed from the vertical view angle (Figure 2.3).

Table 2.5: Detailed slope ratings based on field observations (initial scores and participant scores, also shown in Table 2.4), optical satellite imagery, and optical UAV imagery.

\begin{tabular}{|c|c|c|c|c|c|c|c|c|c|c|c|c|c|c|}
\hline Slope \# & 1 & 2 & 3 & 4 & 5 & 6 & 7 & 8 & 9 & 10 & 11 & 12 & 13 & 14 \\
\hline $\begin{array}{c}\text { Initial Field- } \\
\text { Based Scores }\end{array}$ & 506 & 334 & 332 & 269 & 250 & 327 & 467 & 329 & 325 & 350 & 359 & 427 & 328 & 308 \\
\hline $\begin{array}{c}\text { Mean Field- } \\
\text { Based } \\
\text { Participant } \\
\text { Scores }\end{array}$ & 452 & 357 & 313 & 283 & 259 & 402 & 492 & 344 & 325 & 419 & 359 & 433 & 393 & 362 \\
\hline $\begin{array}{c}\text { Optical } \\
\text { Satellite }\end{array}$ & 487 & 331 & 304 & 244 & 208 & 369 & 352 & 293 & 350 & 265 & 294 & 357 & 318 & 282 \\
\hline Optical UAV & 528 & 396 & $\mathrm{n} / \mathrm{a}$ & $\mathrm{n} / \mathrm{a}$ & $\mathrm{n} / \mathrm{a}$ & $\mathrm{n} / \mathrm{a}$ & $\mathrm{n} / \mathrm{a}$ & $\mathrm{n} / \mathrm{a}$ & $\mathrm{n} / \mathrm{a}$ & $\mathrm{n} / \mathrm{a}$ & $\mathrm{n} / \mathrm{a}$ & $\mathrm{n} / \mathrm{a}$ & $\mathrm{n} / \mathrm{a}$ & $\mathrm{n} / \mathrm{a}$ \\
\hline
\end{tabular}

\subsubsection{Yearly Reviews and Updates (RHRS Step 6)}

Repeat remote sensing acquisitions allow for the ability to calculate and monitor changes in slope geometry and displacement rates. A previous assessment of overall slope displacements across the railroad corridor was performed using Persistent Scatterer Interferometry (PSI) and Distributed Scatterer Interferometry (DSI), InSAR stacking techniques using radar images acquired via satellites, by Bouali et al. (2016a). In the case of a rural setting such as this railroad corridor, InSAR is capable of measuring displacement rates for a larger area, such as the general trend of slope movements over extended periods of time (which may aid in potential landslide detection), compared to smaller areas because output data can be spatially limited and detailed measurements may be lacking. Therefore, remote sensing techniques that provide high spatial data densities, such as LiDAR and optical photogrammetry, are preferred for monitoring complex and detailed changes within a slope. 

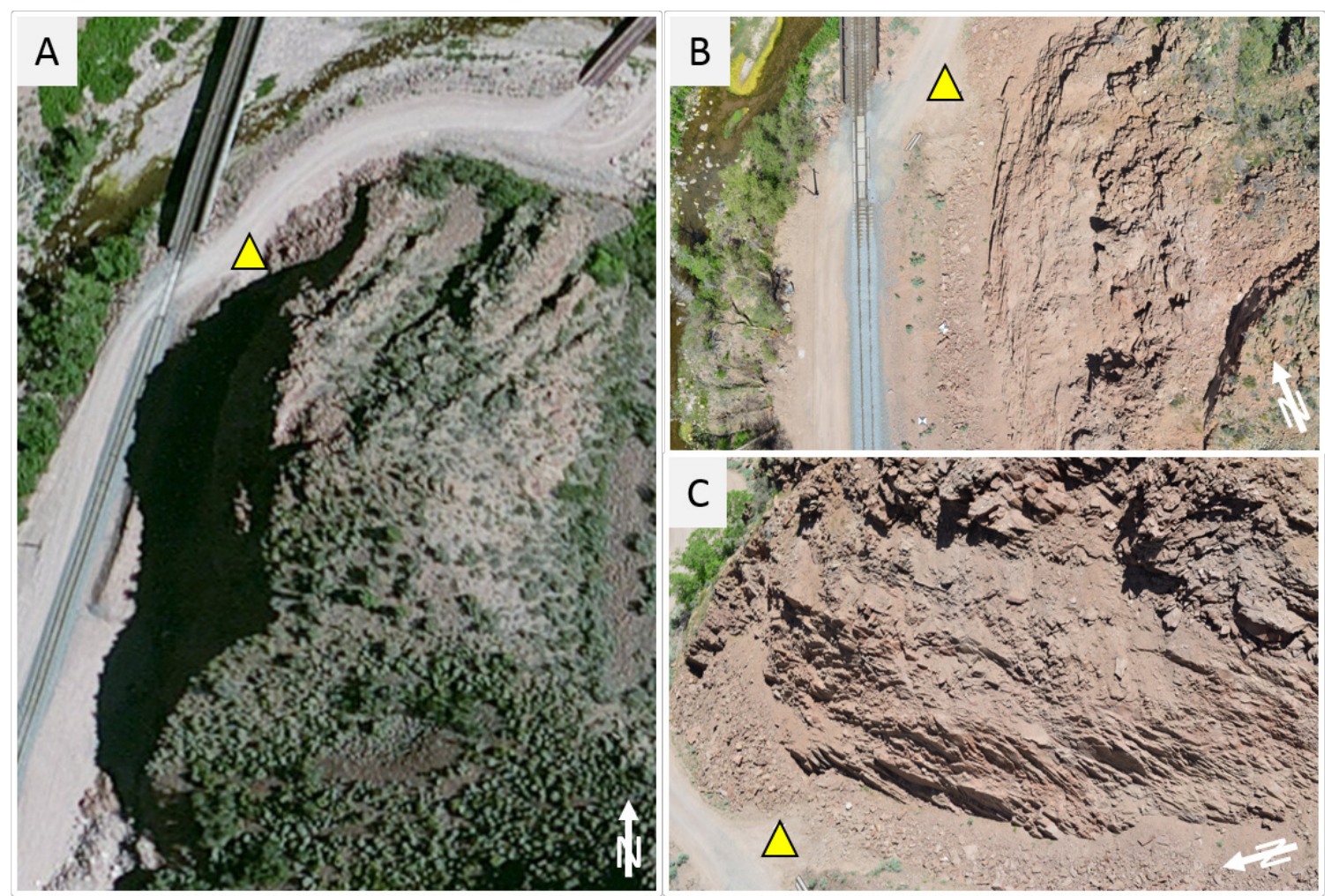

Figure 2.3: Images of Slope 2 taken from three view angles: (A) optical satellite image, (B) vertical optical UAV image, and (C) oblique optical UAV image. A yellow triangle is placed in each image for geographic reference.

Since Slope 1 was considered the most hazardous slope based on preliminary and detailed slope ratings (Tables 2.2-2.6), LiDAR point cloud data were acquired during each summer from 2011 to 2014 using a RIEGL LMS-Z210ii instrument, acquiring data at an angular resolution of $0.005^{\circ}$ and an accuracy of around $3 \mathrm{~cm}$. A detailed quantification of slope deformation was performed using a technique called 'change detection,' where threedimensional point clouds from two acquisitions are geometrically compared; a change, or difference, in point cloud location indicates the occurrence of measurable displacement. Figure 2.4 shows the surficial changes, occurring between 2011 and 2014, mapped on a three-dimensional digital elevation model (DEM) of Slope 1. Blue regions (negative change) show material loss and red regions (positive change) show material accumulation. 
Six individual rockfalls occurred on the Slope 1 face between 2011 and 2014 (numbered values in Figure 2.4), with substantial accumulation of material occurring at the central toe region.

Detailed change detection measurements, along with similar techniques called SfM, which utilizes optical photogrammetry to create three-dimensional point clouds (Westoby et al. 2012), and InSAR can assist in the yearly review process. By capitalizing on advancements in remote sensing technologies - such as increased spatial and temporal resolution, wider variety of view angles, more accurate sensors, and a growing variety of clever data processing techniques - transportation agencies can monitor potentially hazardous slopes with a more robust, efficient, and time-effective RHRS approach.

Table 2.6: Comparison of satellite- and UAV-derived values for rating criteria and detailed slope rating score.

\begin{tabular}{|c|c|c|c|c|}
\hline \multirow{2}{*}{$\begin{array}{l}\text { Rating } \\
\text { Criteria }\end{array}$} & \multicolumn{2}{|c|}{ Slope 1} & \multicolumn{2}{|c|}{ Slope 2} \\
\hline & Satellite & UAV & Satellite & UAV \\
\hline$\# 1$ & 100 & 100 & 100 & 100 \\
\hline$\# 2$ & 9 & 27 & 3 & 3 \\
\hline$\# 3$ & 1 & 1 & 1 & 1 \\
\hline \#4 & 0 & 0 & 0 & 0 \\
\hline$\# 5$ & 100 & 100 & 100 & 100 \\
\hline$\# 6$ & 81 & 81 & 27 & 50 \\
\hline$\# 7$ & 27 & 50 & 3 & 27 \\
\hline$\# 8$ & 81 & 81 & 9 & 27 \\
\hline$\# 9$ & 7 & 7 & 7 & 7 \\
\hline$\# 10$ & 81 & 81 & 81 & 81 \\
\hline $\begin{array}{l}\text { Detailed Slope } \\
\text { Rating Score }\end{array}$ & 487 & 528 & 331 & 396 \\
\hline
\end{tabular}




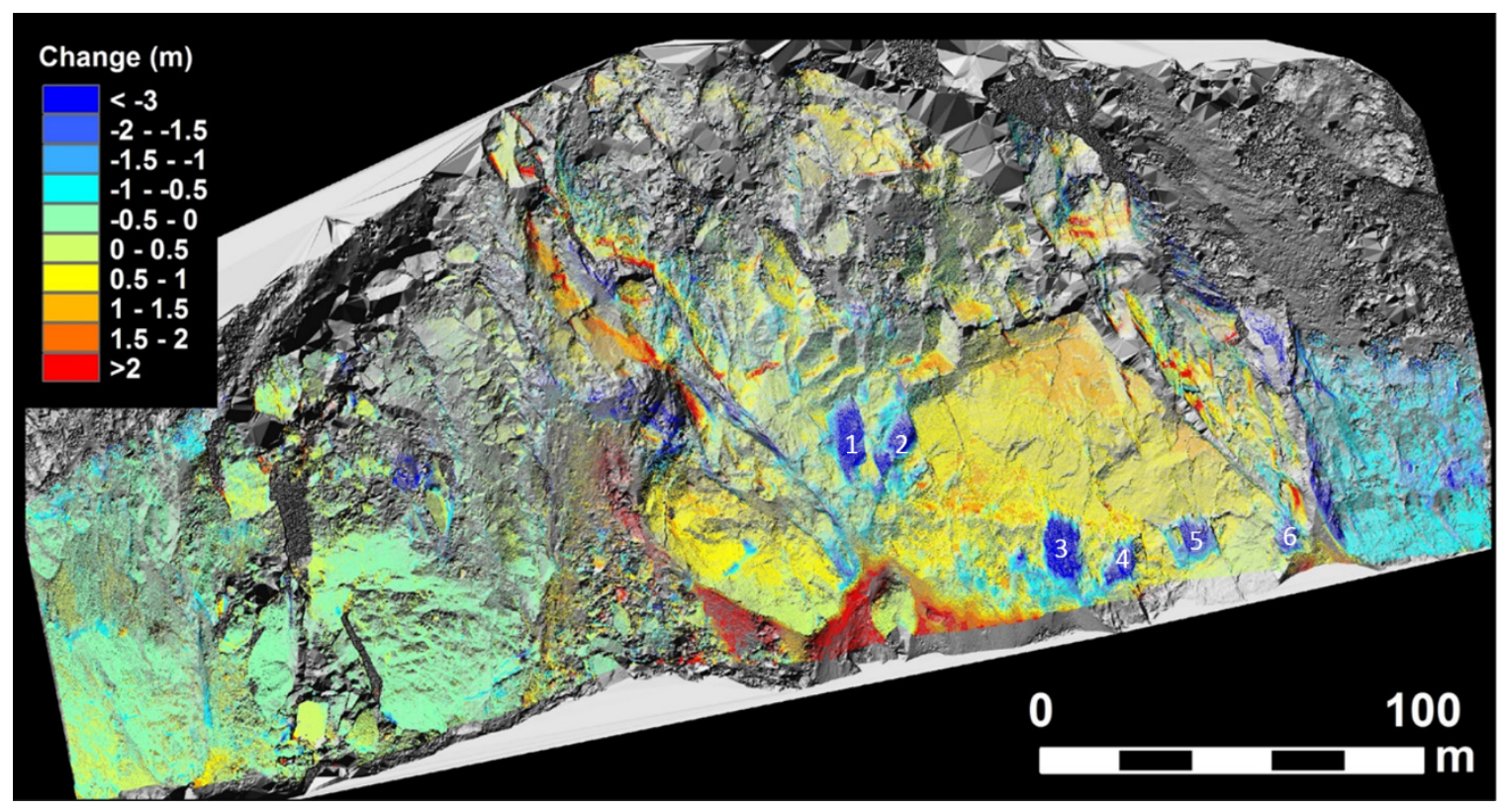

Figure 2.4: Change detection map of Slope 1 between 2011 and 2014. Negative change (blue) indicates material loss and positive change (red) indicates material accumulation. Six rockfall events, numbered by location, are detectable and occurred in the three-year span. Slope $13 D$ DEM was generated from the 2014 three-dimensional point cloud.

\subsubsection{Additional Discussion}

The three RHRS steps discussed in detail were Preliminary Slope Rating (Step 2), Detailed Slope Rating (Step 3), and Yearly Review and Update (Step 6). Remote sensing techniques can also play a secondary role in information collection and analyses in the other three RHRS steps. Step 1, Slope Inventory, can be aided by analyzing DEMs generated from satellite/aerial optical or radar images (e.g., NASA's Shuttle Radar Topography Mission, German Aerospace Center's TerraSAR-X and TanDEM-X, etc.). DEMs can assist in cataloging and digitizing the spatial extent of slopes adjacent to the transportation corridor. Step 4, Project Design and Cost Estimate, may benefit from detailed models derived from three-dimensional point clouds obtained from optical photogrammetry or LiDAR techniques. These models can help determine remediation designs and techniques that need to be constructed. Step 5, Project Identification and Development, is a management step that utilizes information gained from Steps 1-4 to 
determine necessary remediation projects for choice slopes. Pierson and Van Vickle (1993) provide four project identification methods: (1) score - priority given to slopes with highest detailed slope rating; (2) ratio - priority given to slopes with greatest score-to-cost ratio; (3) remedial - slopes with similar designs can be placed in a single project, which will alter slope prioritization; (4) proximity - slopes closest to rockfall sites are given highest priority. Each of these project identification methods can use remote sensing data, directly or indirectly. Thus, remote sensing techniques are practical supplementary tools to the traditional field-based approach for RHRS.

Using remote sensing has its advantages and limitations. Advantages include:

1. Acquires data over hard-to-reach or inaccessible terrain.

2. Spatial coverage over geographic scales spanning several orders of magnitude, ranging from local-scale (one geotechnical asset like an unstable slope) to regionalscale (segment of a transportation network like the railroad corridor).

3. Multiple acquisitions over the same area allow for the measurement of surficial changes over long periods of time.

4. Field-based techniques can be supplemented or eliminated and replaced with remote sensing data.

5. An offering of a wide array of sensors acquiring data over different swaths of the electromagnetic spectrum at different spatial resolutions from various view angles.

6. The ability to create a large library of historical, archival datasets that can be used with future data products.

7. Sensors can acquire one image that can be processed in a variety of ways.

8. Provides a noninvasive approach that does not disturb targets within a study area. Limitations include:

1. Shadow zones caused by mountainous topography, complex surficial geometry, or clouds (for optical images) result in a loss of data that cannot be recovered.

2. May not be cost-effective if used improperly. For example, acquiring high resolution data (e.g., cm-scale LiDAR point clouds) for preliminary slope ratings over a statewide transportation network would not be economical. 
3. Data acquired from remote sensing techniques contain factors that affect the receiving sensors such as noise introduced by interfering phenomena (e.g., water vapor affects two-way travel time of radar waves). Further, non-uniqueness, the idea that an outcome can be achieved through many different combinations of input factors, is a significant issue that must be considered when modeling remote sensing data.

4. Some acquisition and data processing techniques require training and may include a steep learning curve.

The traditional field-based RHRS approach is a more robust method, compared to remote sensing techniques. The field-based RHRS method allows field crews to interact and observe slopes in person; if only a few slopes are of interest then the field-based approach is much simpler. If, however, a transportation agency is tasked with monitoring a transportation corridor or an entire transportation network (e.g., local, regional, statewide), then a remote sensing-based RHRS approach, using high resolution optical imagery, may be preferable. For the remote sensing-based RHRS estimation, high resolution imagery acquired from different view angles is critical. The spatial resolution and view angles obtained from satellite imagery are coarser, more limited, and often result in significant underestimation of preliminary and detailed slope rating scores. However, an approach integrating rapidly-deployable UAV platforms with high resolution terrestrial LiDAR provides a readily-available toolset for collecting imagery that can be used for RHRS interpretation. UAV- and LiDAR-based data collections provide much higher spatial resolution and can easily obtain multiple view angles compared to satellite-based data. Detailed slope rating scores from UAV data shows promise to be used as an alternate approach for field-based RHRS measurements when monitoring transportation corridors. In addition, imagery collected using UAVs will provide a more methodical documentation of the site condition for the transportation agency compared to field-based data collection. Coupled with other remote sensing techniques (e.g., InSAR and optical photogrammetry), transportation agencies would benefit from a supplementary and complimentary remote sensing RHRS approach. 


\subsection{Conclusion}

RHRS is a procedure developed by Brawner and Wyllie (1975), and further expanded by geological engineers and transportation agencies (Wyllie et al. 1979; Wyllie 1980; Wyllie 1987; Pierson 1991; Pierson 1992; Pierson and Van Vickle 1993; Brawner 1994), to analyze slopes adjacent to transportation corridors and prioritize those most likely to experience damaging rockfalls. The traditional RHRS approach is to use personnel to acquire field-based measurements, especially for Step 1, Step 2, and Step 3. Video logs are also commonly used for data analysis for Step 3 and slope monitoring in Step 6. The purpose of this study, however, is to show the benefits of remote sensing data acquisition (optical satellite imagery, optical UAV imagery, and terrestrial LiDAR) and analyses for a more robust, efficient, and time-effective RHRS approach. Other remote sensing techniques, such as optical photogrammetry and InSAR, are also discussed and referenced. These remote sensing methods have a place as a supplemental data acquisition approach alongside the traditional field-based approach.

Observations from remote sensing imagery were compared to field-based observations (used as the baseline) for the preliminary and detailed slope rating steps. Fourteen slopes along a railroad corridor in southeastern Nevada were studied. In general, observations using optical satellite imagery provided an underestimation of preliminary and detailed slope ratings. This is most likely due to the coarse resolution imagery used (m-scale). It was therefore concluded that high resolution imagery is a requirement because consistent rating score underestimations may potentially lead to undetected future rockfall events, which is unacceptable. When using higher resolution imagery acquired from the UAV (cm-scale), an overestimation of preliminary and detailed slope rating scores occurred (when compared to satellite- and field-based approaches). This result is probably due to the combination of high resolution - small slope features and characteristics that can be observed - and various view angles - more information about the top of the slope is available (when compared to field-based approaches limited to ground-level).

Terrestrial LiDAR change detection successfully monitored rockfall events on Slope 1. Two three-dimensional point clouds, which map the location of the slope face surface, were geometrically differenced to calculate the amount of surface change (slope 
deformation) that occurred between the summers of 2011 and 2014. Evidence of surficial displacement include six locations of rock mass loss and an overall accumulation of material at the slope toe. Displacements up to 2-3 $\mathrm{m}$ in both directions (towards and away from the LiDAR sensor) were measured over the three-year span. Change detection, and other similar techniques (e.g., SfM and InSAR stacking), enable measurements of dynamic events that occur rapidly (e.g., rockfalls) or very slowly (e.g., landslide creep) over any length of time (e.g., daily, monthly, annually, etc.).

Every slope within or adjacent to a transportation corridor has the potential to pose hazards that may affect the performance and quality of transportation assets and the safety of its users. The traditional RHRS procedure attempts to identify and prioritize the most hazardous slopes through a robust field-based rating system. The use of remote sensing techniques has proved beneficial by providing more information, expanding the observable study area, archiving historical datasets, and allowing for detailed analysis otherwise unavailable to field crews. By combining remote sensing techniques to traditional fieldbased approaches, transportation agencies can build a more robust, efficient, and timeeffective RHRS procedure that can assist in the achievement of slope life-cycle performance goals along an entire transportation network.

\subsection{Acknowledgements}

This project was funded by the US Department of Transportation (USDOT) through the OST-R (Cooperative Agreement No. RITARS-14-H-MTU). The authors would like to express their utmost gratitude to the railroad company that allowed us access to the study site and the on-site employees who kept us safe. The authors would also like to thank Michigan Tech Research Institute's Richard Dobson, Ben Hart, and David Dean and Michigan Technological University's Zachary Champion for their contributions to field data acquisition, and the six Michigan Technological University participants for providing input with the RHRS survey. Additional thanks are extended to the organizations that provided the background images used in this research study, specifically the US Geological Survey, NASA, Google, and Digital Globe. 


\subsection{Disclaimer}

The views, opinions, findings, and conclusions reflected in this paper are the responsibility of the authors only and do not represent the official policy or position of the USDOT/OST-R or any State or other entity. 


\title{
Chapter 3: Interferometric Stacking toward Geohazard Identification and Geotechnical Asset Monitoring ${ }^{7}$
}

\author{
El Hachemi Bouali ${ }^{8}$; Thomas Oommen, Ph.D., A.M.ASCE'; \\ and Rüdiger Escobar-Wolf, Ph.D. ${ }^{10}$
}

\subsection{Abstract}

Geotechnical assets are those found along transportation environments and are made up of or supported by earth materials. A geotechnical asset management program aims to achieve life-cycle performance goals by maintaining the geotechnical assets in a safe, cost-effective, and timely manner. Interferometric synthetic aperture radar, a remote sensing technique that derives ground deformation information from satellite-based radar data, is proposed as a monitoring method in the context of geotechnical asset management. A total of 90 ERS-1, ERS-2, and ENVISAT radar images, acquired from 1992 through 2010, are processed using two interferometric stacking techniques to measure ground deformation along a railroad corridor. A local-scale study was first conducted over a known slide (S-1) where total displacements up to $6 \mathrm{~cm}$ were measured. Then a regional-scale study was performed to locate hazard zones. Six potential geohazard zones were identified along the railroad corridor based on five criteria: slope distance, slope height, slope angle, average downslope velocity, and total downslope displacement. Interferometric stacking is

7 The material contained in this chapter was previously published in the Journal of Infrastructure Systems.

8 Department of Geological and Mining Engineering and Sciences, Michigan Technological Univ., 1400 Townsend Dr., Houghton, MI 49931 (corresponding author). E-mail: eybouali@mtu.edu

9 Department of Geological and Mining Engineering and Sciences, Michigan Technological Univ., 1400 Townsend Dr., Houghton, MI 49931. E-mail: toommen@mtu.edu

10 Department of Geological and Mining Engineering and Sciences, Michigan Technological Univ., 1400 Townsend Dr., Houghton, MI 49931. E-mail: rpescoba@mtu.edu 
shown to be quite useful for geotechnical asset management, as this remote sensing technique allows for an indirect method of quantifying asset condition and allows for longterm monitoring of geotechnical assets that a management program aims to achieve.

\subsection{Introduction}

The purpose of asset management is to achieve and maintain performance goals over the lifespan of assets within the transportation environment. Measurable performance goals may include safety, mobility, preservation, environmental impacts, and economic aspects, among other variables (AASHTO 2011; Cambridge Systematics et al. 2002). Geotechnical assets, which are assets made up of or greatly supported by earth materials (soil, sediment, and rock), have normally not received much attention within the transportation environment setting (Sanford Bernhardt et al. 2003; Stanley and Pierson 2013). Current geotechnical asset management (GAM) practices target asset repairs based on priority levels: first rebuild all assets that have failed, then repair assets in dire condition, and finally perform upkeep and preventative care (budget-permitting). This practice is known as the worst-first approach, where assets in the worst condition are given first attention (highest priority). Although this approach is politically understandable-it is difficult to convince the general public because the taxpayer expects the assets in the worst condition are addressed first and that preservation is "fixing something that isn't broken" (FHWA 1999) - it has been shown to be costly, time-consuming, quite dangerous (Jonsson 2010; Sanford Bernhardt et al. 2003), and it “...results in overall system degradation as no assets receive preventative maintenance in time to keep the investment optimized" (Stanley and Pierson 2013).

In 1999, the Federal Highway Administration (FHWA) created a geotechnical asset management framework (GAMF, Figure 3.1) as their response to the need for a preventative asset management procedure. This GAMF can be used as a template for any kind of asset management, including transportation asset management (TAM), pavement asset management (PAM), and GAM, with the latter two being specific applications of the general TAM framework. According to the American Association of State Highway Transportation Officials (AASHTO), TAM is defined as “.... a strategic and systematic 
process of operating, maintaining, upgrading and expanding physical assets effectively throughout their lifecycle" (AASHTO 2013). The overall purpose of any asset management system is to generate a cost-effective, intelligent, and efficient system that can manage assets at all life-cycle points (from newly constructed to deteriorated/failed), within any transportation environment with, preferably, as minimal impact to the public as possible.

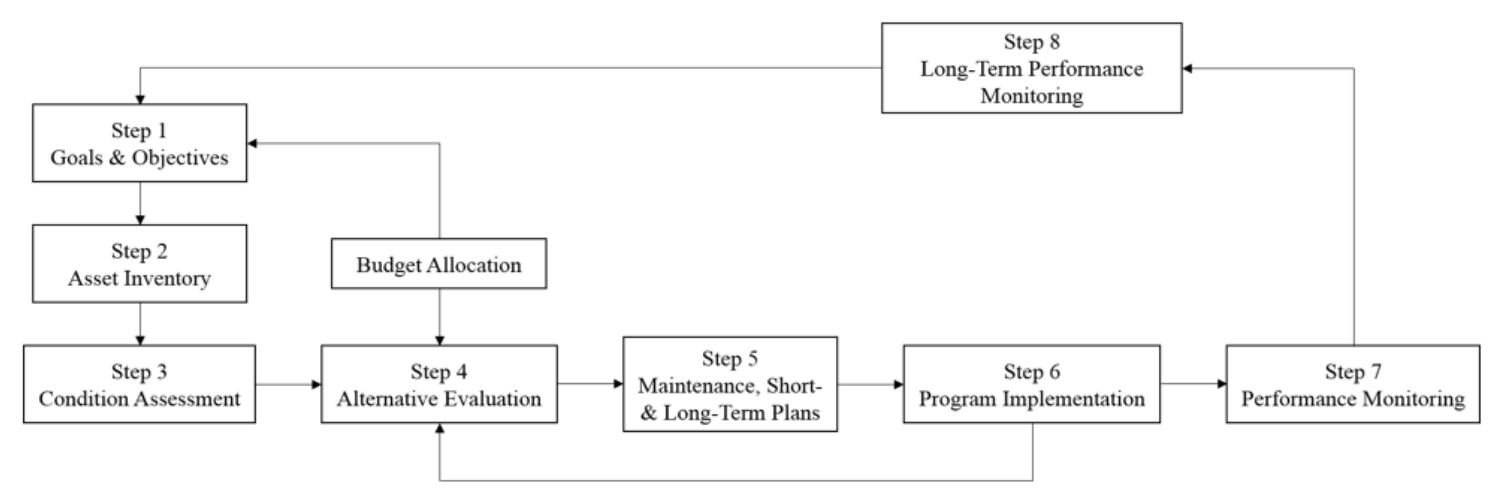

Figure 3.1: The FHWA GAMF framework: Steps 1-7 and the budget allocation (modified from FHWA 1999) as well as the proposed Step 8: Long-Term Performance Monitoring

The FHWA GAMF is composed of seven steps (Figure 3.1). The first three steps are initial assessment and budgetary-planning steps, where clearly-defined goals and objectives are created (Step 1), all assets within the relevant transportation environment(s) are identified and documented (Step 2), and initial conditions of each asset is somehow quantified, usually subjectively (Step 3). Alternative evaluation procedures are examined (Step 4) based on these first three steps. The last three steps are for project implementation, where short-term and long-term plans are decided (Step 5), the program is then implemented in the field (Step 6), and performance of the asset management program is monitored (Step 7). The authors suggest the addition of an eighth step, performance monitoring of the assets themselves, to the GAMF as this will aid in future condition assessment and maintenance plans. The framework allows for program revisions as asset management is performed, with Step 6 looping back to Step 4 for minor revisions made in 
evaluation, maintenance, and planning stages, and Step 7 looping back to Step 1 for major revisions in the general asset management approach.

State Departments of Transportation (DOTs) and other transportation agencies are currently struggling with the geotechnical asset inventory and condition assessment steps (Anderson and Rivers 2013; Stanley and Pierson 2013; Vessely 2013). Most problems stem from the vastness of transportation networks on the state level: the amount of time and money required to transport field crews to every asset, and then create an inventory and perform an initial condition survey, is intimidating. Additionally, criteria for assessing asset condition must vary for each asset type (e.g., a set of criteria for rock slopes would not apply for soil slopes, retaining walls, or bridge abutments). The asset inventory and condition assessment steps are vitally important to the GAMF as they lay the foundation for all future decisions. Therefore, developing a methodology to work around the vastness of state transportation networks is key to the successful implementation of an asset management program.

The authors propose the use of satellite-based interferometric synthetic aperture radar (InSAR) techniques as a remote sensing tool that may be used for asset condition assessment (Step 3) as well as long-term performance monitoring (Step 8). A remote sensing approach would bypass the spatial difficulties of extensive transportation networks that need to be covered by field crews; instead, large swaths of transportation networks, viewable from the satellite line-of-sight (LOS), could be monitored. Small ground deformations may be observed, down to $1 \mathrm{~mm} /$ year using interferometric stacking techniques, and may assist with performance monitoring as small, cumulative displacements along assets can be observed over extended periods of time.

Of course, InSAR cannot directly measure asset condition. Instead, the authors propose a method of using velocity and cumulative displacement measurements obtained from InSAR stacking products to aid in the condition assessment and long-term performance monitoring steps of the GAMF. The overall goal of this research project is (1) to examine how well InSAR velocity/displacement measurements align with field observations on a failed rock slope within a railroad corridor at the local scale, and (2) to use generic slope hazard criteria combined with InSAR-derived measurements to identify 
additional locations of potential future hazard within the railroad corridor at the regional (or network) scale.

\subsection{Study Site}

The area of interest covers a $29-\mathrm{km}$ stretch of railway that runs through a canyon system in southeastern Nevada (Figure 3.2). The study area will be examined on two scales: local and regional. The local scale focuses on one slope, $\mathrm{S}-1$, which is an unstable slope located within the railroad corridor. The regional study area covers an area of approximately $194 \mathrm{~km}^{2}$, which includes the $29-\mathrm{km}$ railway segment. The railroad corridor was constructed upon volcanic rock of Tertiary age (Figure 3.2). Most of the slopes are composed of steeply dipping $\left(50^{\circ}-70^{\circ}\right)$ pyroclastic deposits and volcanic flows composed of rhyolite tuff, welded tuff breccias, or welded tuff; the plateaus at higher elevations are basalt-capped, with an angular unconformity separating the younger basalt from the older, steeply dipping volcanic flows.

S-1 can be divided into two structural zones: the unstable block and the more (relatively) stable block (Figures 3.3 and 3.4). As the name implies, a majority of the displacement observed on S-1 occurred in the unstable block and is defined as everything downslope from the main scarp (Figure 3.5). The unstable block has potentially undergone three types of slope movement: (1) rotational slide, (2) rock topple, and (3) rock fall. The slope face on the unstable block is dipping approximately $65^{\circ}$ from horizontal, reaching a height of $36.5 \mathrm{~m}$ above the railroad tracks; the slope toe is located $21 \mathrm{~m}$ from the tracks. Slope inclination decreases to approximately $20^{\circ}-30^{\circ}$ at the $36.5-\mathrm{m}$ height mark and remains at this inclination upslope. The main scarp is located approximately $6 \mathrm{~m}$ upslope from the point of change in slope inclination. The stable block is the mass upslope from the main scarp. Relatively small amounts of movement have been observed on the stable block - as there is evidence for a minor scarp upslope from the main scarp - but most of the observable movement has been shallow surficial erosion and runoff. 


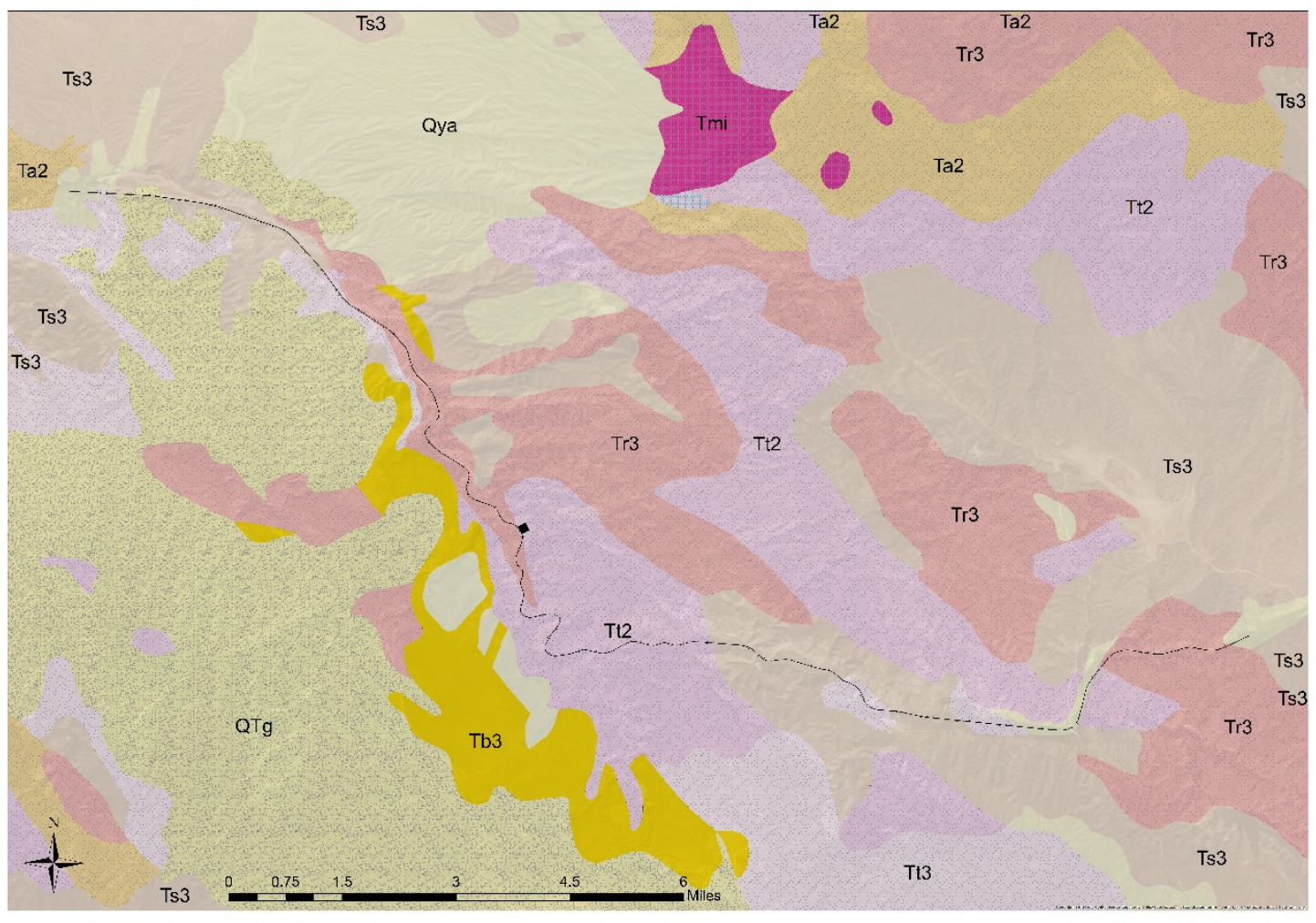

Figure 3.2: Full extent of the study area: the location of the S-1 slope (black polygon) and the 29-km railroad track segment (dashed line). Basic geology of the study area is shown (from Crafford 2007). Geologic units abbreviated as follows (youngest to oldest): Qyaalluvium; QTg-gravels; Ts3-tuffaceous sedimentary rocks; Tb3-basalt; Ta3-andesite and intermediate flows and breccias; Tt3 - silicic ash flow tuffs; Tr3 - rhyolitic flows and shallow intrusive rocks; Ta2 - intermediate andesite and flows and breccias; Tt2 intermediate silicic ash flow tuff; Tmi-mafic phaneritic intrusive rocks (Crafford 2007). 


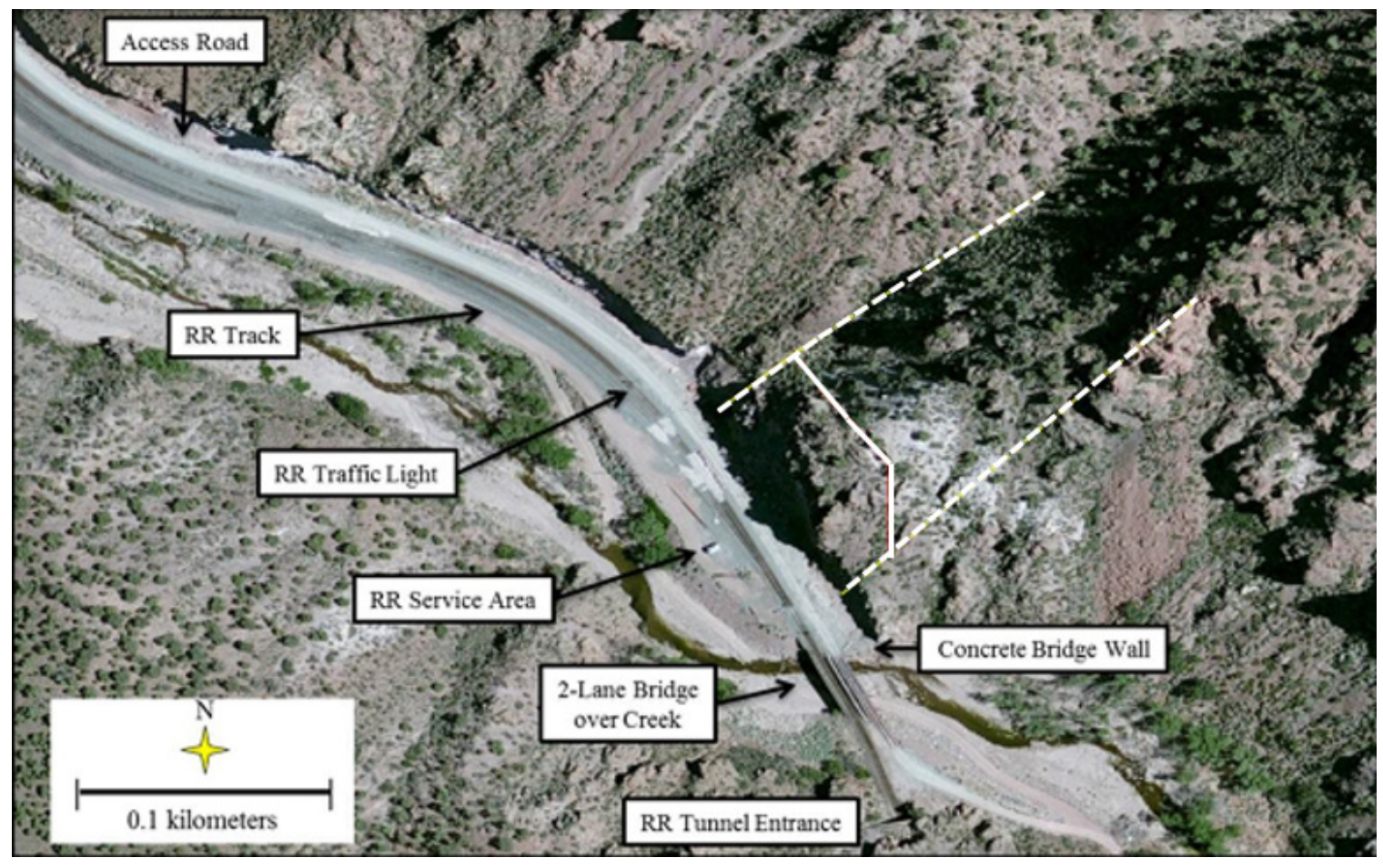

Figure 3.3: Location of select geotechnical and transportation assets around $S$-1. The solid line traces the main scarp and dashed lines trace locations of shear zones that define the active S-1 slope borders. Background imagery was generated in ArcGIS® software by Esri. 


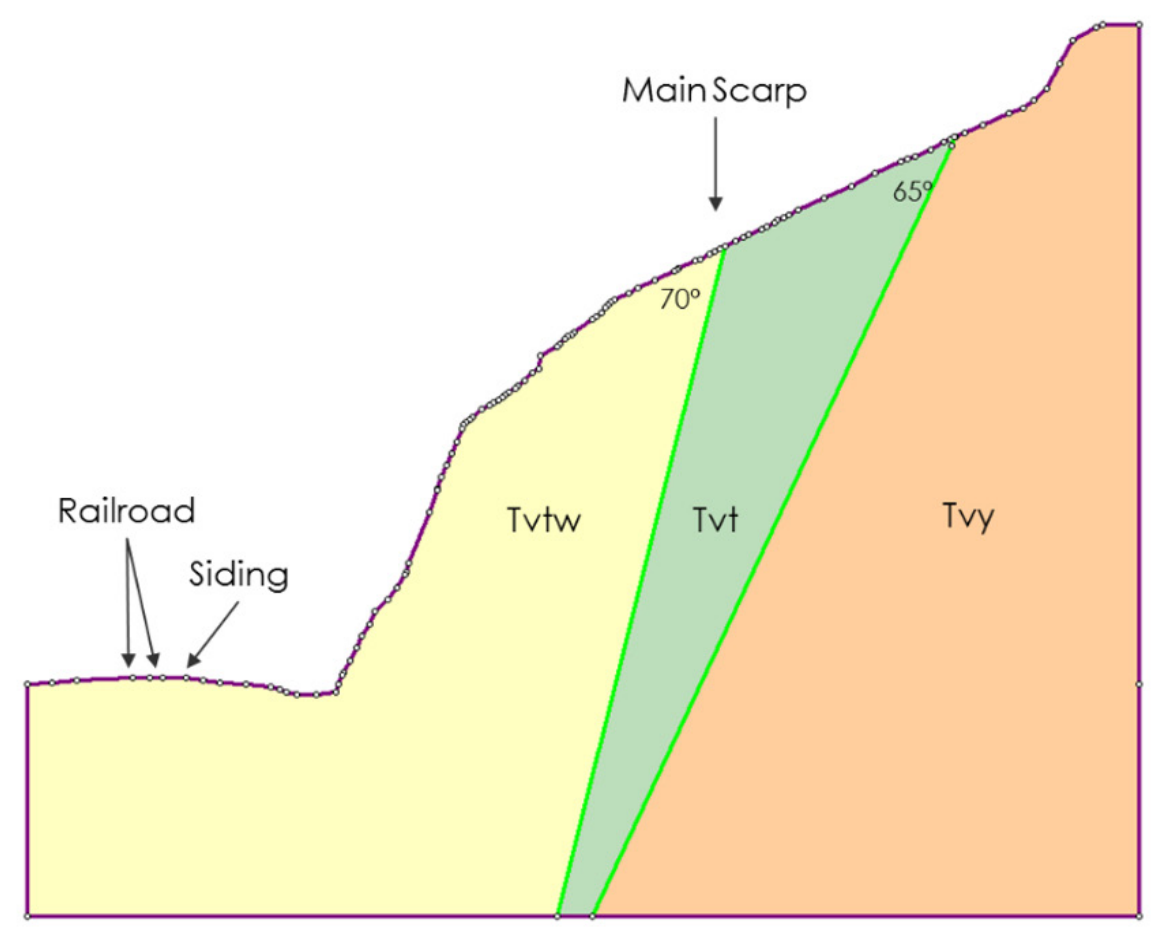

Figure 3.4: Simplified profile through the middle of the S-1 slope. The height of the model is 365 feet; the width of the model is 455 feet.

S-1 is composed of three volcanic rock units (youngest to oldest): rhyolitic welded tuff and breccias (Tvtw), tuff and tuffaceous sediments (Tvt), and undivided volcanic rocks (Tvy) - (Figure 3.4). Tvtw is reddish-gray, porphyritic, mostly welded (high strength), and with brecciated areas (low strength) where rock fragments are subangular and less than $2.5 \mathrm{~cm}$ in diameter. Tvt is a pinkish-white, aphanitic, crystalline tuff; the sequence is approximately $30 \mathrm{~m}$ thick. Tvy is a grouping of undifferentiated volcanic rocks that make up most of the base of S-1 and the eastern canyon wall. 

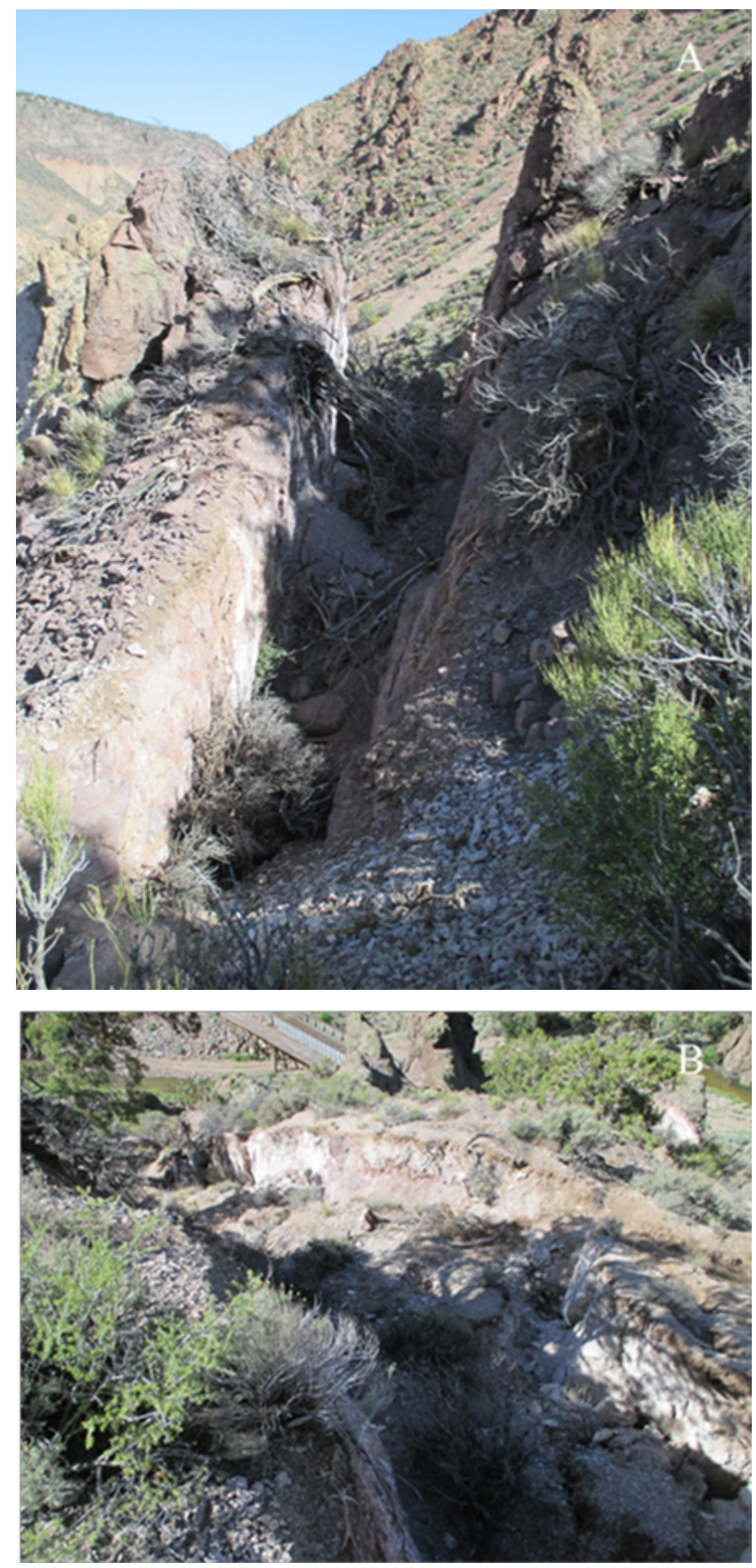

Figure 3.5: (A) Photo of the main scarp on $S$-1. Scarp width varies from $\sim 1.5 \mathrm{~m}$, as shown here, to about $4 \mathrm{~m}$, as shown in (B) 
The S-1 main scarp, where most displacement had been observed, is located at the Tvtw-Tvt unconformity boundary, which exhibits a dip of $70^{\circ}$ southwest (downslope direction-solid line in Figure 3.3). A minor scarp is located at the Tvt-Tvy unconformity, which outcrops upslope from the main scarp, with a dip of $65^{\circ}$ southwest. S-1 is bounded by two fault zones: (1) a sinistral, nearly vertical fault on the north side of the slope where recent rock fall activity has occurred, and (2) a shear zone on the south side of the slope (approximated by the dashed lines in Figure 3.3). Shear zones and faults have been identified within these lateral boundaries as well. The locations of some discontinuities are also cause for concern, especially within the heavily jointed Tvtw layer, where joint dip is parallel to the formation boundary $\left(70^{\circ}\right.$ downslope $)$ and joints are quite frequent, with $1 \mathrm{~m}$ average spacing; Tvt also shows jointing, but it is much more minor and closely spaced, less than $15 \mathrm{~cm}$ in most places.

\subsection{Radar Imagery Data Set and Methodology}

A total of 90 radar images between August 20, 1992, and August 15, 2010, were processed over the study area. Fifty images were acquired from the ERS-1 and ERS-2 satellites and 40 images from ENVISAT, which were equipped with C-Band synthetic aperture radar (SAR) antennae operating at $5.331 \mathrm{GHz}$ with approximately $20-\mathrm{m}$ resolution and horizontal-horizontal polarization. All images came from the same descending track, which had an LOS in the $\mathrm{N} 86^{\circ} \mathrm{W}$ azimuth direction and an incidence angle centered at $23^{\circ}$ from nadir.

These data were processed using two different interferometric stacking techniques: Persistent Scatterer Interferometry (PSI) and SqueeSAR. Both techniques require a stack of single look complex (SLC) SAR images, as well as a digital elevation model (DEM), as inputs. PSI searches the image stack for pixels with consistently high coherence values and calculates ground deformation based on measured phase shifts between the reference image and all other images within the stack (Ferretti et al. 2000; Ferretti et al. 2001). SqueeSAR combines PSI with Distributed Scatterer Interferometry (DSI). DSI searches the image stack for adjacent pixels that are statistically homogeneous (based on coherence) and calculates ground deformation in a comparable manner as PSI (Ferretti et al. 2011). The 
output products for both PSI and SqueeSAR are persistent scatterer (PS) and/or distributed scatterer (DS) points - spatially assigned at the radar image pixel-scale-where each PS/DS point contains a wealth of information (e.g., average ground velocity, displacement at each image acquisition with respect to the reference image, $\mathrm{x} / \mathrm{y} / \mathrm{z}$ information, coherence, and exact LOS angle/direction).

All 90 radar images were processed over the local scale using both PSI and SqueeSAR techniques. Only the 40 ENVISAT images were processed using PSI on the regional scale. A 10-m DEM from the United States Geological Survey (USGS) National Elevation Dataset (NED) was used as well (USGS 1999).

Ground deformation values may be positive of negative. Positive values indicate a shortening of the distance between the satellite and the ground, indicating ground deformation toward the satellite (TS). This may be due to uplift, accumulation of sediments/soils, or a lateral eastward movement. Negative values indicate an increase of satellite-to-ground distance, indicating ground deformation away from the satellite (AFS). This may be due to ground subsidence, downslope movement, erosion, or a lateral westward movement. Reminder: all measurements are made in the LOS direction (azimuth direction: $\mathrm{N} 86^{\circ} \mathrm{W}$, dip: $23^{\circ}$ ).

\subsection{Results}

\subsubsection{Local-Scale: Spatial and Temporal Geohazard Monitoring}

A local-scale InSAR study was conducted because the S-1 slope had been originally identified as a landslide hazard by the railroad company. In 2011, stationary ground-based LiDAR surveys began and have been conducted approximately twice per year since. All of these data sets, along with a geologic mapping and structural geology analysis performed in 2011, have allowed us to clearly define the portions of S-1 that are moving (Figure 3.3) as described previously. This allowed for general ground-truthing of InSAR results.

PSI results are shown in Figure 3.6. PSI yields few PS points on S-1, probably due to the strict high coherence criteria, vegetation, and slope geometry. The available PS 
points do show a similar trend to the field data: the unstable block exhibits the most average movement (-2.6 $\mathrm{mm} /$ year), minimal movement is measurable upslope from the main scarp along the more stable block $(-1.0 \mathrm{~mm} /$ year), and the adjacent slopes are basically stable (north adjacent: $-0.4 \mathrm{~mm} /$ year; south adjacent: $-0.2 \mathrm{~mm} /$ year) with the only exception being from locations of observable surface runoff areas (Figure 3.6). The bridge is the only anthropogenic geotechnical asset with PS points; some movement is measurable across the bridge. Figure 3.7 displays the results from the specialized InSAR stacking algorithm SqueeSAR, which combines PSI with DSI and yields a result containing both PS and DS points (Ferretti et al. 2011). A decrease in point density is apparent across the local study area, but more importantly, this technique can resolve more points along S-1, including on the geometrically complex slope face where there are three DS points and no PS points (the three DS points circled in Figure 3.7). SqueeSAR results show the same general trend, where the greatest slope displacement occur downslope from the main scarp, and the adjacent slopes are more stable. An unexpected result is the fact that zero PS and DS points were obtained along the bridge or any other anthropogenic geotechnical asset, except for one relatively stable DS point near the tunnel entrance $(-0.8 \mathrm{~mm} / \mathrm{year})$. 


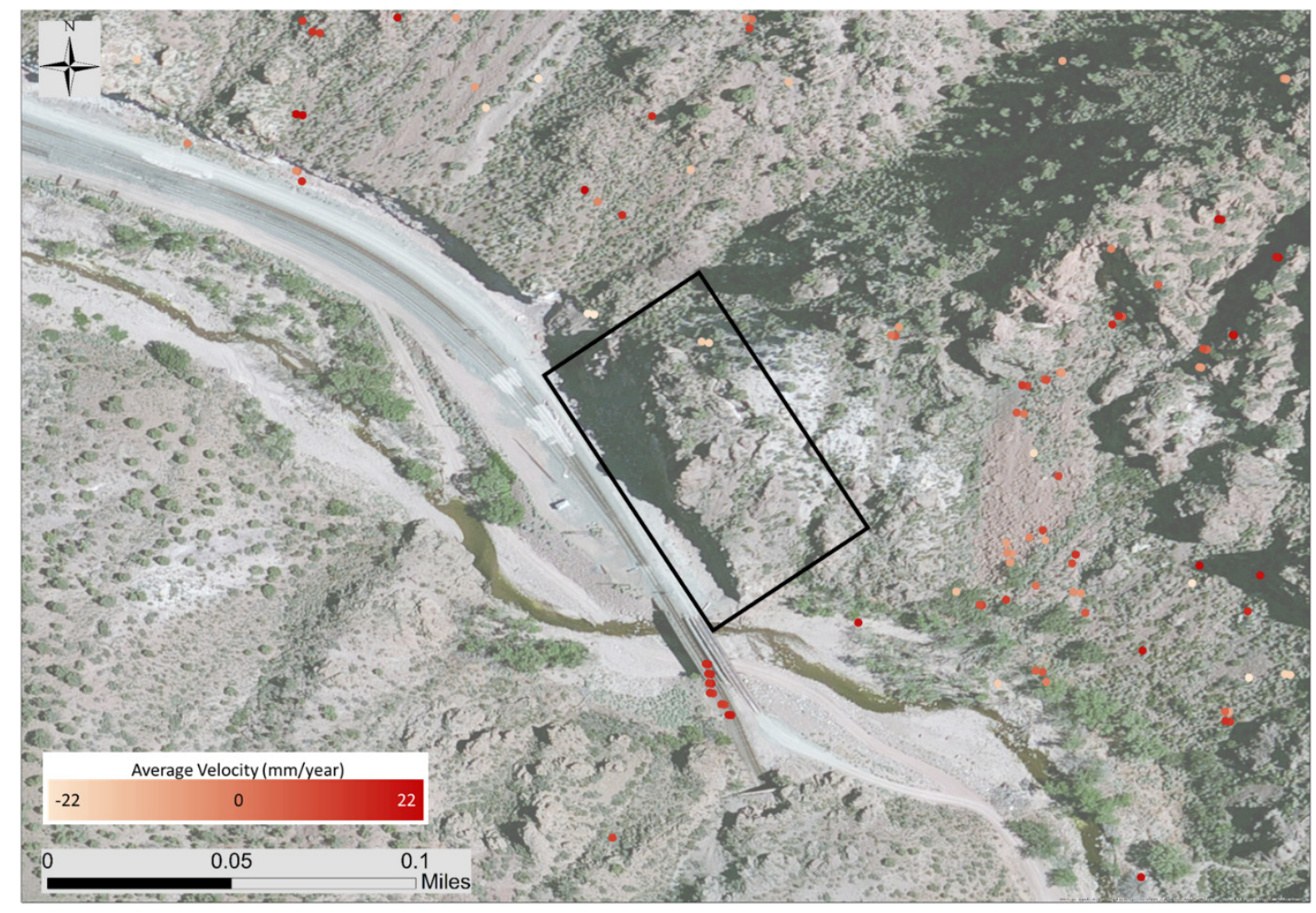

Figure 3.6: PSI average velocity (mm/year) along $S-1$ (polygon) and adjacent geotechnical and transportation assets. Background imagery was generated in ArcGIS® software by Esri. 


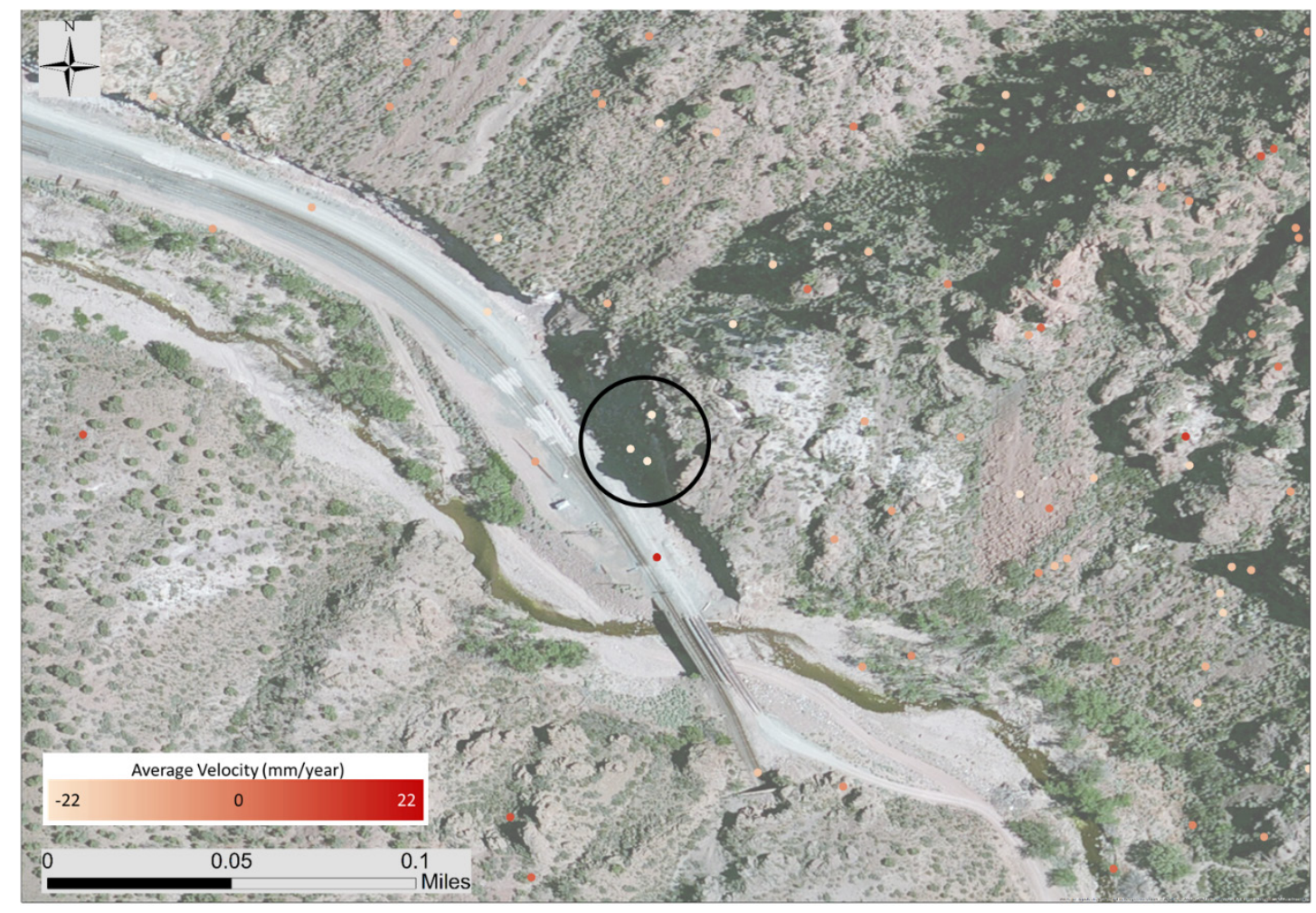

Figure 3.7: SqueeSAR ${ }^{\mathrm{TM}}$ average velocity (mm/year) over same area as Figure 3.6. Three $D S$ points (within circle) are measurable on the steep slope face; see Figure 3.8 for displacement time-series plot. Background imagery was generated in ArcGIS® software by Esri.

A closer examination of the three DS points on the S-1 slope yields additional supporting evidence of slope movement beginning in 2005. A displacement time-series plot of the three DS points is shown in Figure 3.8. All three time-series indicate S-1 was stable from 1992 to approximately January 2005, which coincides with reports from railroad personnel. In January 2005, after a devastating flood through the canyon, S-1 became unstable and has consequently been moving.

Since results from InSAR stacking procedures can replicate field observations - at the very least to the extent of where ground displacement is occurring - the PSI technique was applied as a reconnaissance method at the regional-scale. 
Displacement Time-Series of Three DS Points on S-1

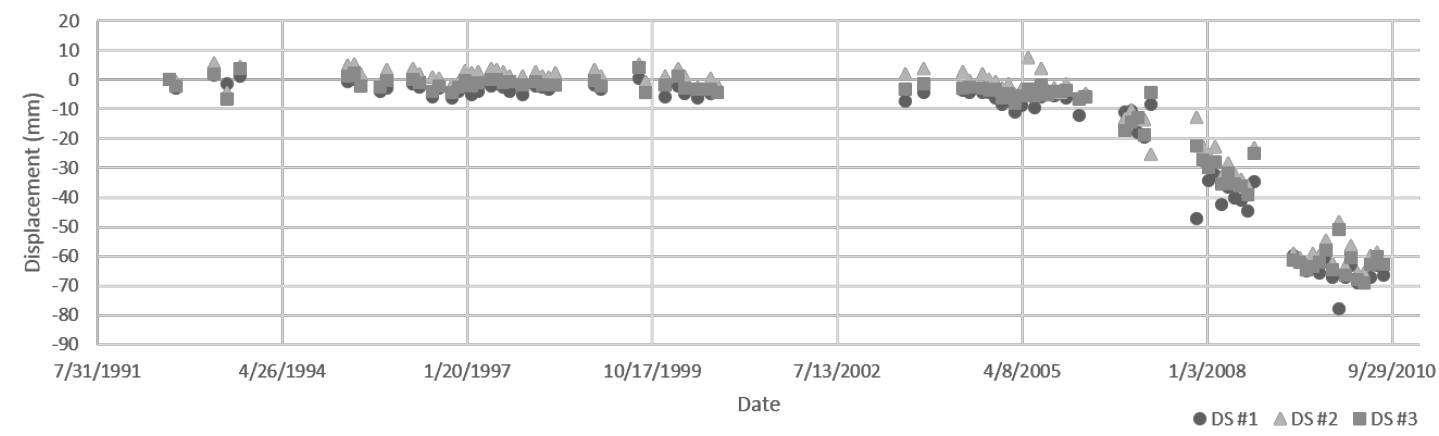

Figure 3.8: Displacement time-series for the 3 DS points on the slope face of S-1 (Figure 3.7, within circle). Each data point indicates the total displacement from first acquisition (August 20, 1992).

\subsubsection{Regional-Scale: Identification of Geohazard Locations}

Only the 40 ENVISAT radar images, spanning from July 13, 2003, to August 15, 2010, (identical ENVISAT images used in the local-scale study), were processed using PSI over an area of approximately $194 \mathrm{~km}^{2}$. The regional-scale study site includes $29 \mathrm{~km}$ of railway track, 28 railroad bridges, five tunnels, and one small town. PSI results are shown in Figure 3.9.

The regional-scale PSI analysis was performed to establish the potential for InSAR to be used as a monitoring tool for geohazard identification using remote sensing data sets - the ENVISAT radar images described above and a 10-m USGS NED DEM-based on the following five criteria:

1. Slope distance (railroad buffer area). A buffer zone of $100 \mathrm{~m}$ around the railroad track and adjacent access road was created to identify slopes with potential geohazards. This criterion essentially sets the window in which slopes with the remaining four characteristics must be located. 858 of the 13,446 PS points $(6.4 \%)$ met this criterion and are in the railroad corridor.

2. Slope height. The slope height is a geometric factor that measures the vertical distance between the railroad track elevation and the highest point on the slope 
within the buffer zone. A slope height of $15.25 \mathrm{~m}$ was used as the minimum threshold.

3. Slope angle. Slopes with an angle greater than $25^{\circ}$ were included. This value was chosen for two reasons. The first reason is that almost all slopes in the regional area of interest are composed of rhyolite tuff, which has an internal friction angle of approximately $30^{\circ}$. The second reason for this conservative value is due to DEM resolution: a relatively coarse resolution $(10 \mathrm{~m})$ measures all surface elevations within each pixel and assigns the average elevation as a value. Pixels that contain high-angled slopes also contain a greater variation of elevation values and, essentially, the measured (apparent) steepness of a slope will be less than the real steepness (observed in the field); apparent steepness is basically inversely proportional to DEM resolution.

4. Average velocity (displacement rate). Derived from PSI, the average velocity at each PS point measures the slope of the linear trend of the PS displacement over time. Figure 3.10 shows the average velocity distribution and classification statistics of the 13,446 PS points measured across the regional area of interest. Slopes with PS points exhibiting average velocities greater than (in the downslope direction) $-2.6 \mathrm{~mm} /$ year (equal to two standard deviations) were identified. A total of 486 PS points (3.6\%) showed measurable downslope (AFS) displacement rates greater than this threshold value.

5. Total displacement. Also derived from PSI, the total displacement measures the displacement at each PS point between the reference image (May 4, 2003) and the final image (July 11, 2010). Total displacement is important because if a PS point underwent nonlinear displacement, the total displacement value would differ significantly from the displacement calculated from the average velocity value. Figure 3.11 shows the total displacement classification statistics of the 13,446 PS points. Slopes with PS points exhibiting total displacements greater than $-18.6 \mathrm{~mm}$ (two standard deviations derived from the linear average velocity) were identified. A total of 1,207 PS points (9.0\%) showed total downslope (AFS) displacements greater than this threshold value. 


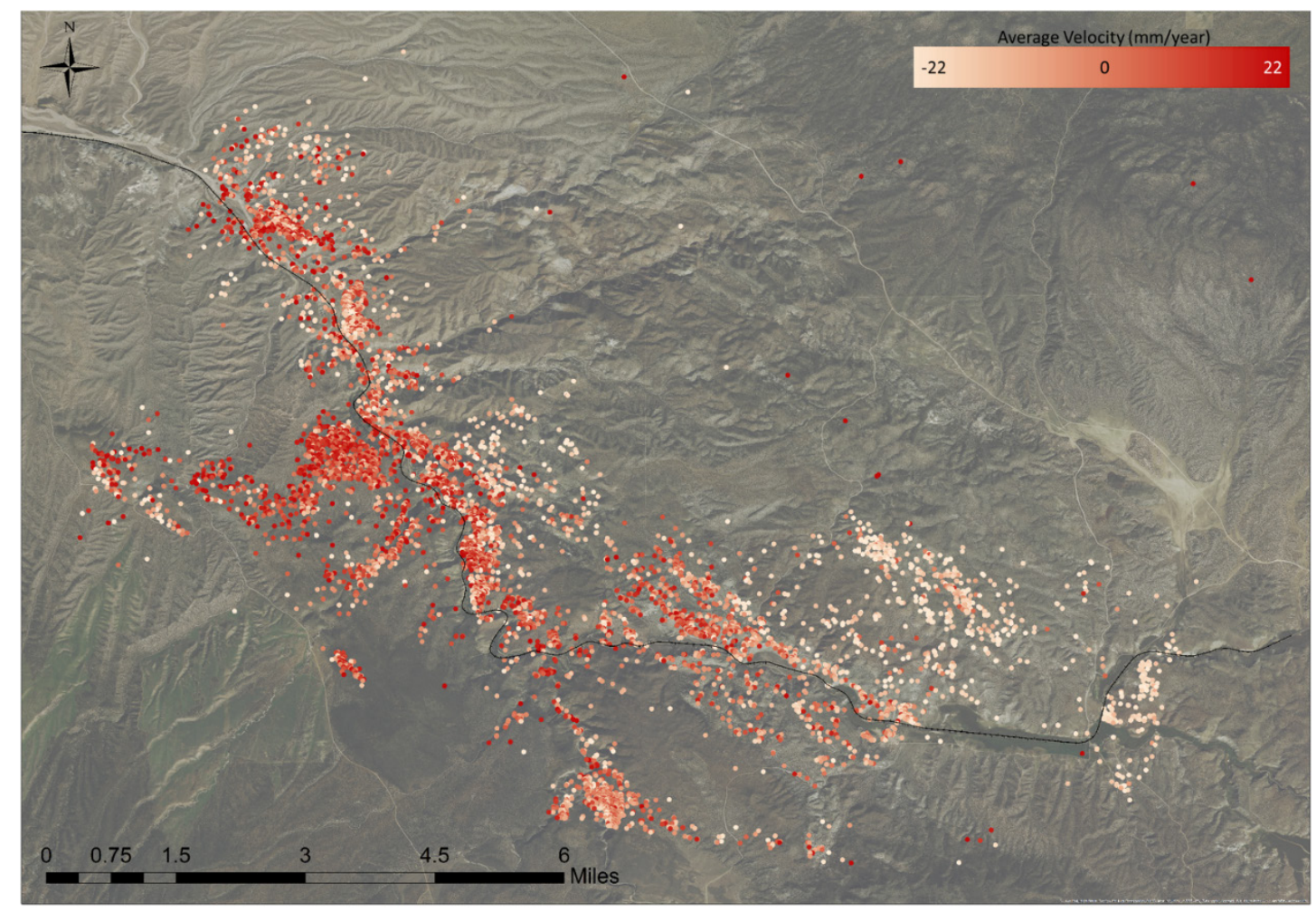

Figure 3.9: Regional-scale PSI average velocity (mm/year) results across the railroad corridor using 40 ENVISAT images (2003-2010). Background imagery was generated in ArcGIS® software by Esri. 


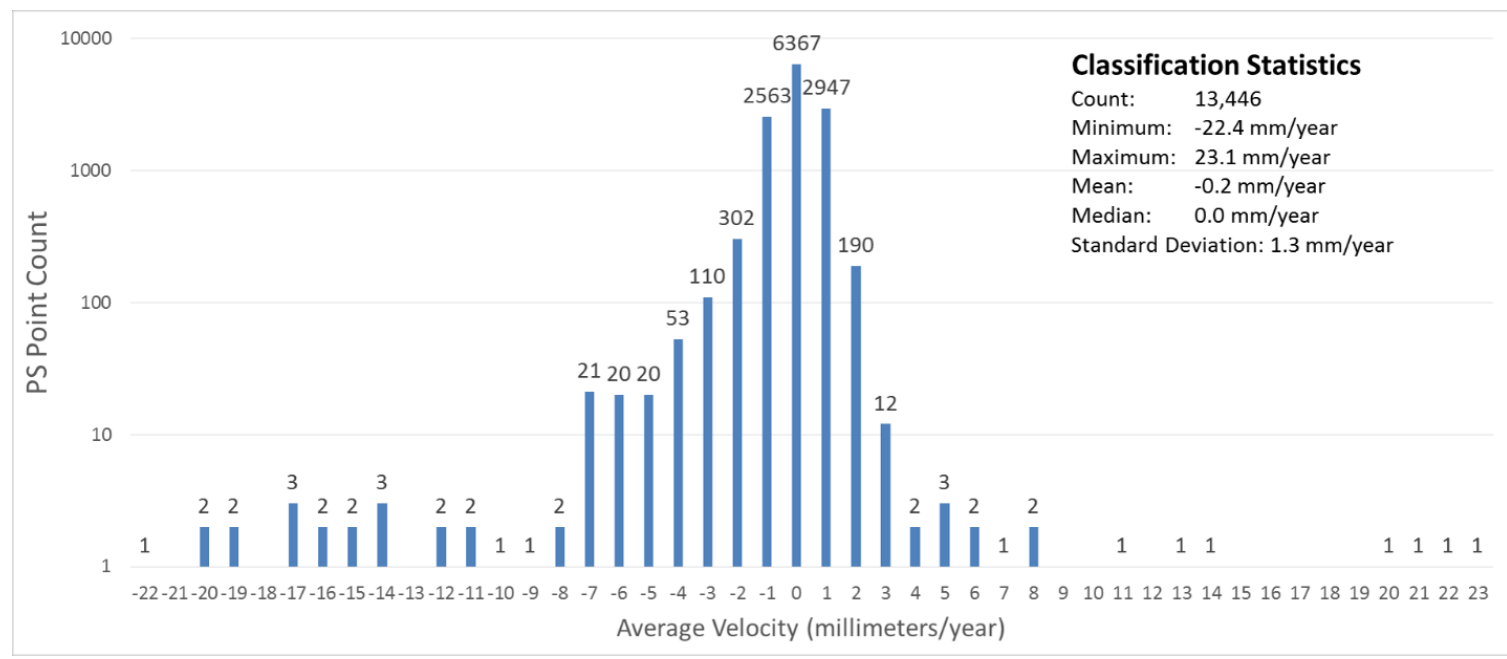

Figure 3.10: Distribution and classification statistics of average velocity measurements (rounded to the nearest $1.0 \mathrm{~mm} /$ year) for regional-scale PS points. Y-axis (PS Point Count) is shown in logarithmic scale.

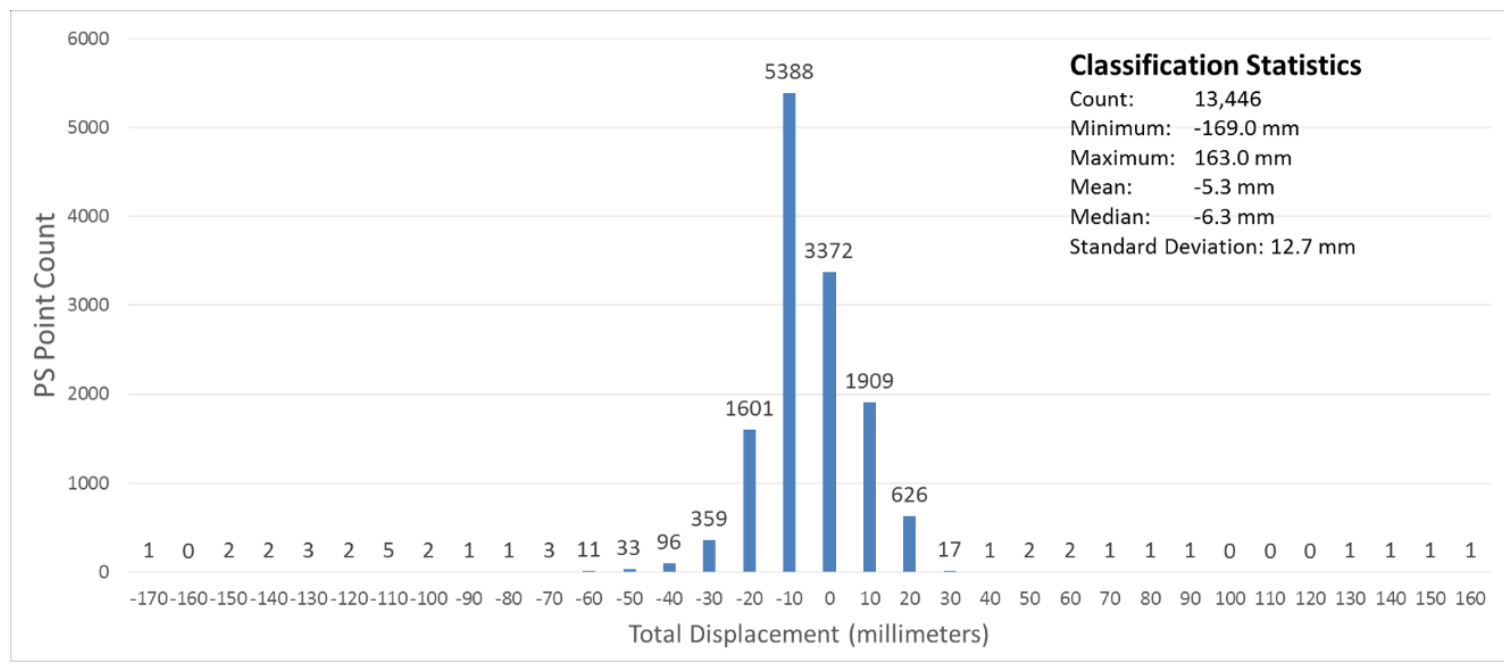

Figure 3.11: Distribution and classification statistics of total displacement measurements (rounded to the nearest $1.0 \mathrm{~cm}$ ) for the regional-scale PS points.

Only 292 PS points (2.2\%) met Criteria 4 and 5, which may indicate locations of geohazards of other sorts, such as subsidence or erosional features. Of these 292, a mere eight also met the remaining criteria, which means each of these PS points were located within $100 \mathrm{~m}$ of the railroad track, were located on slopes greater than $15.25 \mathrm{~m}$ in height 
at a slope angle greater than $25^{\circ}$, and exhibited the necessary minimum downslope displacement and velocity, indicating potential rock fall or landslide geohazard locations. This translates into six individual slopes (including S-1) that can be classified as potential geohazard locations based on these five criteria (Table 3.1 and Figure 3.12).

Table 3.1: Statistics for the 6 slopes that met the geo-hazard criteria.

\begin{tabular}{lrrrrrr}
\hline Slope \# & $\begin{array}{c}\text { Avg. Vel. } \\
(\mathrm{mm} / \text { year })\end{array}$ & $\begin{array}{l}\text { Max. Vel. } \\
(\mathrm{mm} / \text { year })\end{array}$ & $\begin{array}{c}\text { Avg. Tot. } \\
\text { Disp. } \\
(\mathrm{mm})\end{array}$ & $\begin{array}{c}\text { Max. Tot. } \\
\text { Disp. } \\
(\mathrm{mm})\end{array}$ & $\begin{array}{l}\text { Max. } \\
\text { Slope } \\
\text { Angle } \\
(\mathrm{deg})\end{array}$ & $\begin{array}{c}\text { Max. } \\
\text { Slope } \\
\text { Height } \\
(\mathrm{m})\end{array}$ \\
\hline 1 & 0.0 & -14.9 & -4.3 & -111.9 & 59.3 & 23.8 \\
2 & 0.2 & -2.7 & -1.3 & -32.5 & 60.9 & 51.5 \\
3 & 0.1 & -9.3 & -3.3 & -58.3 & 48.3 & 61.6 \\
4 & -0.6 & -5.9 & -10.2 & -49.8 & 46.2 & 78.9 \\
5 & -0.4 & -3.2 & -7.4 & -31.3 & 50.3 & 40.8 \\
6 & -1.7 & -3.7 & -18.2 & -32.9 & 28.3 & 16.5 \\
\hline
\end{tabular}




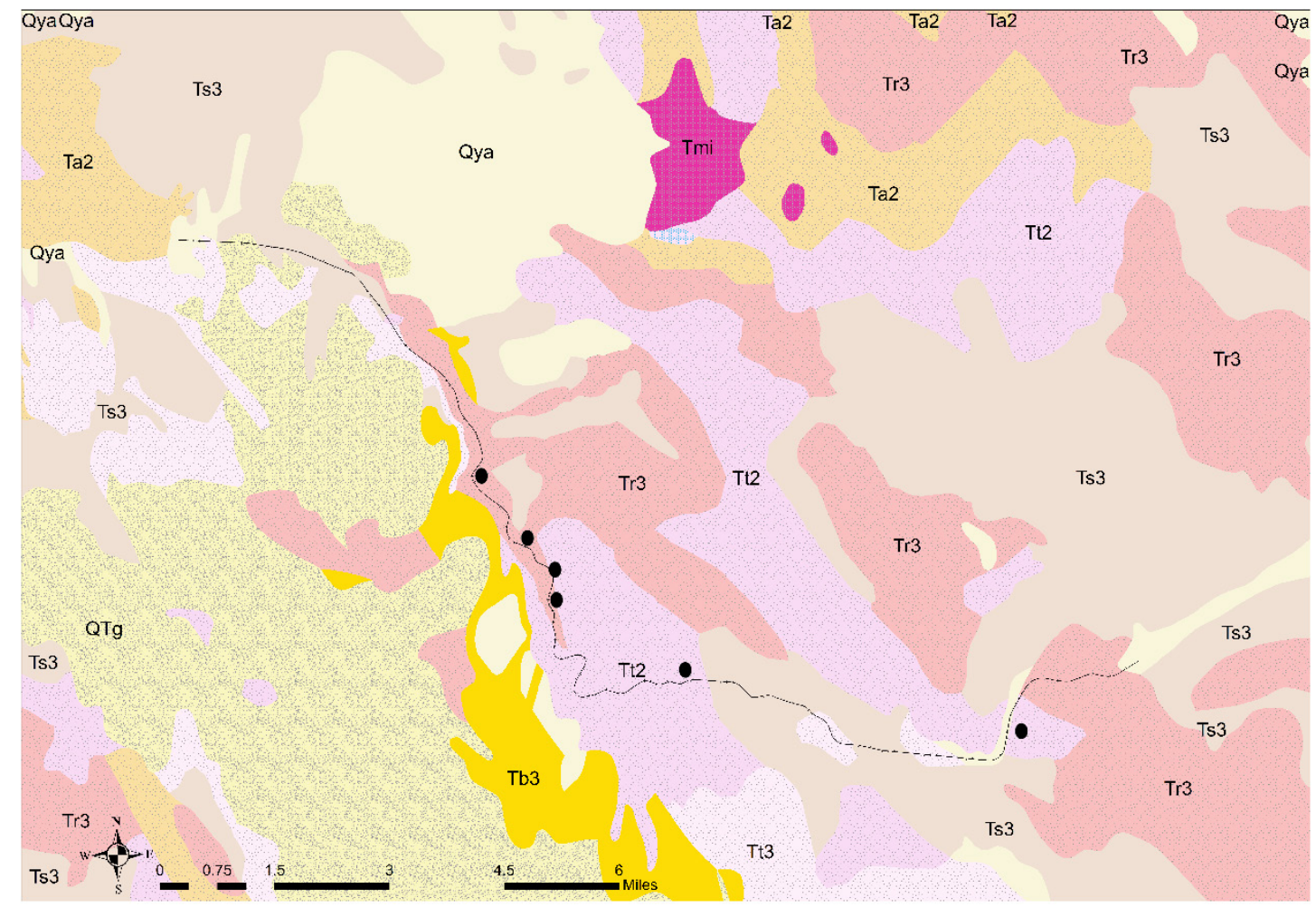

Figure 3.12: Locations of the 6 slopes deemed a potential geo-hazard based on the 5 criteria: slope distance, slope height, slope angle, average PS velocity, and total PS displacement. Geologic map reproduced from Crafford (2007) - see Figure 3.2 for geologic unit names.

\subsection{Discussion}

The local-scale results exhibit the capabilities of interferometric stacking techniques to monitor individual assets - in this case rock slopes - and to also differentiate between various displacement regimes. For example, greater downslope displacements and rates were observed on the unstable block $(-2.6 \mathrm{~mm} /$ year) while the adjacent slopes were much more stable. Geotechnical assets may be monitored both spatially and temporally using PSI and/or SqueeSAR. An integrated analysis of the spatial distribution of PS/DS points as well as temporal analysis (e.g., displacement time-series plots) reveals much more information about the geotechnical asset, including its historical displacement and its 
current deformation condition. The next step would be to develop further methods of analyzing the displacement throughout time and examine whether a displacement timeseries plot can indicate anything about an asset's present condition. Or, at the very least, temporal analyses may be developed to monitor an asset in real time and identify when the asset may be at risk of failure (e.g., exceeds a predefined deformation threshold). This may ameliorate the problem Anderson and Rivers (2013) have noticed: They hope that "[s]omeday it will be possible, for example, to identify the deterioration of the embankment on I-75 in Tennessee and take timely steps to improve drainage, and thereby the level of service, without such a large negative impact on performance" (p14). Spatial and temporal analyses of PS/DS points may address their goals.

The regional-scale application of PSI results illustrates how potential geohazards (e.g., rock falls or landslides) may be identified using a set of remote sensing-based criteria. Six slopes were identified as potential geohazard zones within the railroad corridor (Figure 3.12). The five criteria used in this regional application were a remote sensing version and loosely based on the RHRS used by Pierson et al. (1990) and the Oregon DOT. The aim was to show how a few simple remote sensing products-PSI results and a 10-m DEMcould be used to monitor viewable slopes within the satellite's LOS.

The criteria used in this paper were chosen to replicate moderately hazardous rock slope criteria from the RHRS. The original RHRS did not include ground deformation information as inputs (although subsequent versions have); minimum thresholds for average velocity and total displacement may be decided upon by the transportation agency or DOT, but the number of eligible PS points varies drastically based on the minimum thresholds set (Table 3.2; Figure 3.13).

As alluded to already, satellite-based InSAR has its advantages and limitations. Advantages of this remote sensing technique include: (1) the ability to cover a wide area within each interferometric stack (e.g., interferograms may be easily generated over areas as large as $10,000 \mathrm{~km}^{2}$ ); (2) the ability to accurately measure displacement rates to $1.0 \mathrm{~mm} /$ year, allowing for the monitoring of slower hazards that may not be easily perceptible; (3) a large archive of radar images allows for long-term monitoring of geotechnical assets. Some limitations include: (1) older satellites (launched pre-2010) 
acquired radar images with relatively coarse resolution (>10 m), so distinguishing smaller assets or individual elements of an asset may be difficult or impossible; (2) all measurements are made in the LOS direction; (3) only the assets within the satellite's LOS, and not within shadow or layover zones, may potentially be monitored; (4) the location of PS/DS points is unknown prior to processing; and (5) interferometric stacking techniques cannot measure relatively large movements occurring in short periods of time (Crosetto et al. 2010).

Table 3.2: Number of PS points that meet criteria 1-3 and various values for criteria 4 and 5 .

\begin{tabular}{l|ccccc}
\hline Total & \multicolumn{5}{|c}{ Average Velocity $(\mathrm{mm} /$ year) (Criteria 4) } \\
$\begin{array}{l}\text { Displacement } \\
\text { (mm) }\end{array}$ & 0 & -1 & -2 & -3 & -4 \\
(Criteria 5) & & & & & \\
\cline { 2 - 6 } 0 & 109 & 41 & 20 & 4 & 1 \\
-4 & 97 & 35 & 20 & 2 & 1 \\
-8 & 82 & 32 & 17 & 2 & 1 \\
-12 & 54 & 27 & 17 & 2 & 1 \\
-16 & 35 & 26 & 16 & 2 & 1 \\
-20 & 22 & 21 & 15 & 2 & 1 \\
-24 & 10 & 10 & 9 & 2 & 1 \\
-28 & 7 & 7 & 7 & 2 & 1 \\
-32 & 2 & 2 & 2 & 1 & 1 \\
\hline
\end{tabular}

InSAR is a remote sensing technique that has an enormous potential in assisting in GAM. Satellites with modest ground resolution $(20 \mathrm{~m})$ and wavelength (C-Band: $5.6 \mathrm{~cm})$ were used for this study, although radar image data from other satellites perform better under various situations. For example, TerraSAR-X allows for approximately $1 \mathrm{~m}$ resolution at $\lambda=33 \mathrm{~mm}$ and works well over urban areas, while ALOS PALSAR uses LBand radar waves $(\lambda=23.6 \mathrm{~cm})$ and can penetrate vegetation and yield ground information.

InSAR stacking techniques-PSI and SqueeSAR, among others - have been shown to be effective in asset condition assessment remotely, reducing the cost of expensive and time-consuming fieldwork. Total ground displacement and average velocity measurements 
for relatively large geotechnical assets, such as those that are many pixels in area, can be acquired using InSAR. With many more satellite missions scheduled, users will have their choice of radar specifications, which can be chosen based on the application. There exists short wavelength (e.g., X-Band) data sets, which are good for high resolution ground monitoring in urban settings. Longer wavelength data sets (e.g., L-Band or longer) can be used to penetrate vegetation and allows for greater displacement rate measurements. The many InSAR techniques - e.g., 2-4 pass interferometry for short-duration events, such as earthquakes, to stacking interferometry techniques for long-term events, such as subsidence and landslide creep - lends itself to be a useful tool that has been successfully applied toward GAM. 


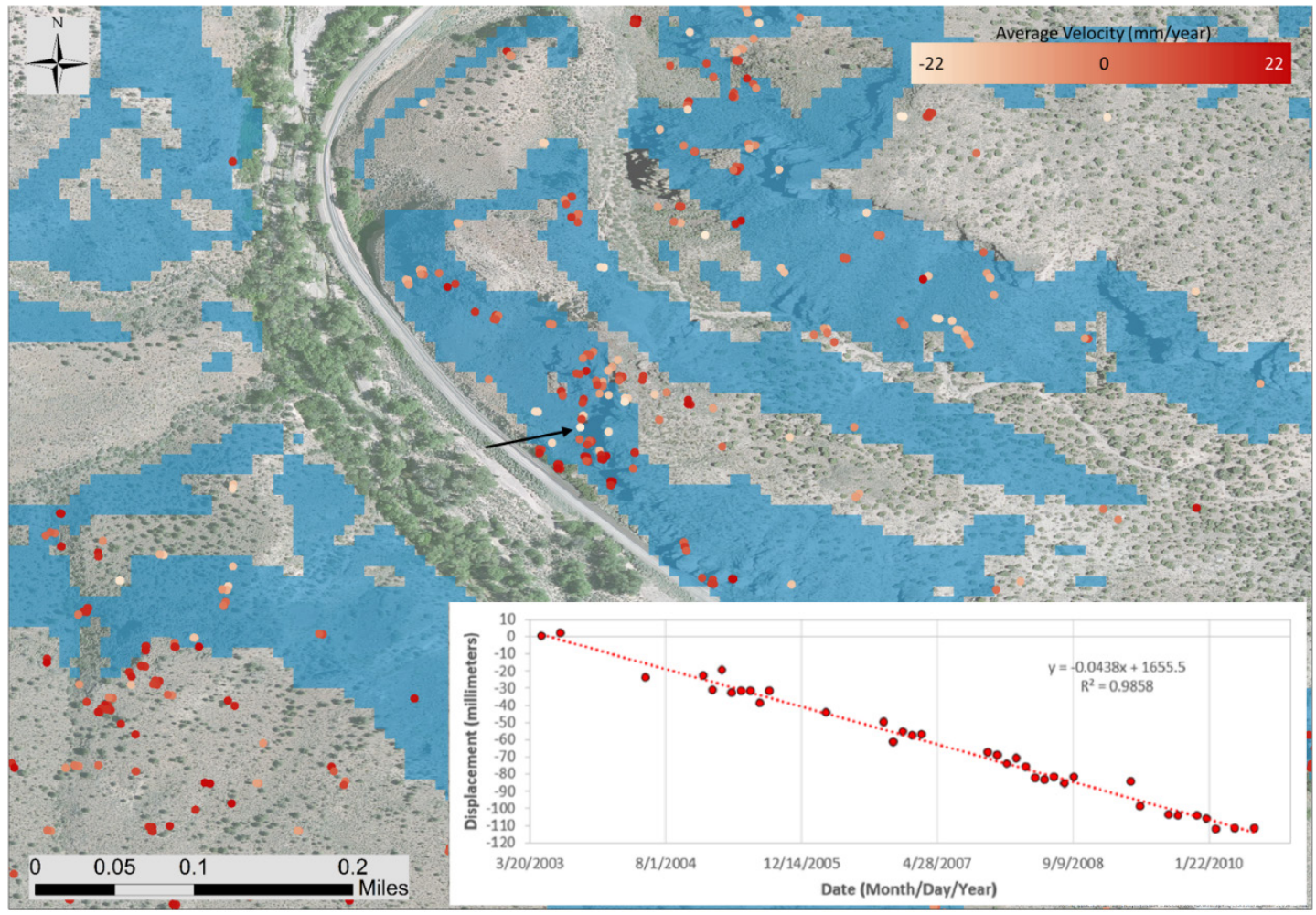

Figure 3.13: The arrow points to the location of the only PS point with an average velocity (mm/year) and total displacement (mm) substantially greater in the AFS direction than all other PS points within the railroad corridor. The PS point is located on a $26^{\circ}$ slope (dipping towards the corridor) with an average velocity of $-14.9 \mathrm{~mm} /$ year and a total displacement of $112 \mathrm{~mm}$. Shaded areas along the railroad corridor indicate slopes at or greater than an inclination of $25^{\circ}$. Background imagery was generated in ArcGIS® software by Esri. 


\subsection{Conclusion}

Satellite-based InSAR analysis is a practical approach toward measuring ground deformation of geotechnical assets. InSAR can be a valuable tool for asset condition assessment (Step 3). InSAR-derived results can also be used in short-term and long-term planning (Step 5) and asset performance monitoring (Steps 7 and 8). This approach is much more cost-effective and efficient than current GAM procedures, which require repeat field visits for updated site characterization and condition assessment.

Detailed displacement monitoring and interpretation was performed on the local scale. A detailed geologic investigation of the S-1 slope and an asset inventory covering $1.85 \mathrm{~km}$ of the railroad corridor were accomplished in one field visit. PSI and SqueeSAR processing yielded detailed information about the S-1 slope that allowed for the accurate division of the slope based on displacement rates and for the creation of displacement-time series plots. The displacement trend of the unstable block of S-1 shown in the time series parallels the records of the railroad company.

Further PSI processing was conducted on a regional scale, encompassing an area of approximately $194 \mathrm{~km}^{2}$ and including $29 \mathrm{~km}$ of railroad corridor. A total of 13,446 PS points was identified ( $\sim 60 \mathrm{PS}$ points $/ \mathrm{km}^{2}$ ) and a clear majority of them were located in and around the railroad corridor. A preliminary condition assessment was conducted by locating six potential landslide hazard zones based on five criteria (slope height, slope distance, slope angle, average downslope velocity, and total downslope displacement).

As stated previously, the purpose of any asset management program is to achieve and maintain performance goals over the lifespan of all assets within the transportation environment. InSAR is a remote sensing technique capable of monitoring individual assets (local scale) as well as asset networks (regional scale). Archival SAR data, as well as data available from present missions, allow for a robust data library for long-term deformation monitoring. These measurements can be used as input information for preliminary asset condition assessment. At the very least, ground deformation derived from InSAR techniques may target potential hazard zones, which may then be examined by field crews. The wide variety of planned upcoming missions adds to the future potential and promise of InSAR toward long-term geotechnical asset monitoring and, hopefully, condition 
assessment analyses that can be used for targeted preventative maintenance of vital geotechnical assets along transportation corridors.

\subsection{Acknowledgments}

This project was funded by the U.S. Department of Transportation (USDOT) through the Office of the Assistant Secretary for Research and Technology (Cooperative Agreement No. RI-TARS-14-H-MTU). Union Pacific Railroad (UPRR) granted the project team access to the study site. Satellite data were provided by the European Space Agency (Category 1 Proposal 18594). Precise orbits for the ERS-1/-2 and ENVISAT satellites were provided by the Delft Institute for Earth-oriented Space Research. Digital elevation models were provided by the Jet Propulsion Laboratory and the National Aeronautics and Space Administration via the Shuttle Radar Topography Mission. Data processing was performed using ENVI SARscape. The authors would also like to thank the following individuals for their contributions to the work described: Caesar Singh, USDOT and program manager; Caleb Douglas, UPRR; Adrian Bohane and Vicky Hsiao, TRE Canada, Inc.; Stanley Vitton, Michigan Technological University, Department of Civil and Environmental Engineering; Pasi Lautala, Michigan Tech Transportation Institute, Rail Transportation Program.

\subsection{Disclaimer}

The views, opinions, findings, and conclusions reflected in this paper are the responsibility of the authors only and do not represent the official policy or position of the USDOT/OST-R or any state or other entity. 


\title{
Chapter 4: Structure Mapping through Spatial and Temporal Deformation Monitoring using Persistent Scatterer Interferometry and Geographic Information Systems ${ }^{11}$
}

\author{
El Hachemi Bouali ${ }^{12}$; Thomas Oommen, Ph.D., A.M.ASCE ${ }^{13}$; \\ and Rüdiger Escobar-Wolf, Ph.D. ${ }^{14}$
}

\subsection{Abstract}

Many engineering professions have adopted asset management procedures to properly construct, monitor, maintain, and support physical assets through the full-service life-cycle of all assets within a network. All asset management programs, whether structural, geotechnical, or transportation, have one common goal: to achieve life-cycle performance goals (e.g., safety, preservation, economic and environmental sustainability, etc.) by cost-effectively managing physical structures. Monitoring deformation rates across an asset can be used as an indirect method of obtaining initial condition assessment information, which is vital for understanding an asset's current life-cycle stage. Persistent Scatterer Interferometry (PSI), an interferometric synthetic aperture radar (InSAR) remote sensing stacking technique, is capable of measuring displacement rates at $1 \mathrm{~mm} / \mathrm{year}$ accuracy on anthropogenic infrastructure not undergoing immediate, catastrophic failure.

11 The material contained in this chapter was previously published as a conference proceeding for Geotechnical Frontiers 2017.

12 Department of Geological and Mining Engineering and Sciences, Michigan Technological Univ., 1400 Townsend Dr., Houghton, MI 49931 (corresponding author). E-mail: eybouali@mtu.edu

13 Department of Geological and Mining Engineering and Sciences, Michigan Technological Univ., 1400 Townsend Dr., Houghton, MI 49931. E-mail: toommen@mtu.edu

14 Department of Geological and Mining Engineering and Sciences, Michigan Technological Univ., 1400 Townsend Dr., Houghton, MI 49931. E-mail: rpescoba@mtu.edu 
A Geographic Information System (GIS) allows storing, processing, analyzing, and displaying geographic data. By combining PSI and GIS capabilities, this paper will illustrate how these techniques can be utilized to spatially and temporally map deformation rates on a variety of assets, and how an initial condition assessment can be made on each asset. Structure mapping can be conducted in four steps: (1) digitization of geographic location for all structures; (2) processing of radar imagery, which results in displacement rate data for all viewable structures; (3) spatially analyzing displacement rates and assigning PS points to individual structures; (4) producing maps, including both spatial and temporal information (e.g., displacement-time series analyses). This procedure will be demonstrated using 40 COSMO-SkyMed satellite radar data, $3 \mathrm{~m}$ resolution images acquired between July 2012 and September 2014, over urban infrastructure in San Pedro, California.

\subsection{Introduction}

Asset management-broadly defined as a thorough approach to strategically construct, monitor, maintain, and support infrastructure at any level (e.g., a single asset, transportation corridor, entire network, etc.) throughout the full-service life-cycle in a timely and cost-effective manner-has been a goal for many agencies with large asset inventories. Transportation agencies strive to manage assets within the transportation corridor (Sanford Bernhardt et al. 2003; FHWA 2007), whether the focus is on earth retaining walls/structures (Anderson et al. 2009; Brutus et al. 2009; Vessely et al. 2015), unstable slopes (Huang et al. 2009; Stanley and Pierson 2013; Bouali et al. 2016a), or embankments (Glendinning et al. 2009). There are also asset management plans developed for bridges (TranSystems Co. 2011), pavement (Haas and Hudson 2015), utilities and vegetation (UAM 2013; Emmett et al. 2015), and buildings and structures (SSWD 2011; Mosman Council 2013), among many others. The purpose of this paper is to apply a technique called structure mapping to fulfill goals established by many asset management programs, specifically to inventory and monitor buildings and structures in an efficient and cost-effective manner. For the sake of simplicity, all building and structural assets will 
henceforth be referred to as structures; all methodologies, analyses, and discussions may be applied to other types of assets.

Structure mapping consists of four steps. The first step is to create a Digital Structure Inventory (DSInv). The second step is to acquire and import all necessary datasets into the GIS that will be mapped onto the spatial DSInv. The third step is to join the DSInv with the other datasets. The fourth step is to create a finalized map within the GIS. Structure mapping displays external data in a simplified form using a DSInv as a spatial template. This mapping approach can be useful for asset management purposes because it allows for spatial and temporal analysis of datasets: spatially with the DSInv and temporally with protracted external data acquisition, the latter of which is required for proper monitoring and maintenance of structures using an asset management program.

Calculating structural ground deformation can be an indirect condition assessment method and may aid in the understanding of a structure's present life-cycle stage. Ground deformation is measurable using a remote sensing technique called interferometric synthetic aperture radar (InSAR), which measures changes in the distance between the satellite sensor and the ground over time. Persistent Scatterer Interferometry (PSI), a specific InSAR image stacking technique developed in the late 1990s and made popular in the mid-2000s (Ferretti et al. 2000; Ferretti et al. 2001), optimizes InSAR over relativelystable anthropogenic structures by increasing measurement accuracy of deformation rates to $1 \mathrm{~mm} /$ year (Ferretti et al. 2001; Crosetto et al. 2009). PSI requires at least 20 radar images for acceptable results (stacking increases the signal-to-noise ratio). This capability is an advantage for asset management and structure mapping as it allows for long-term monitoring of structures in an urban setting.

San Pedro, California is a neighborhood-city located in southwestern Los Angeles (Figure 4.1). Considered a moderately-sized city, with a population of approximately 86,000 people, San Pedro includes many residential, commercial, and industrial neighborhoods, as well as a portion of the 17,000- $\mathrm{km}^{2}$ Port of Los Angeles (POLA 2012), offering a variety of urban structures to manage. This study site was chosen because of the long history of subsidence affecting local structures. The first anthropogenic-induced subsidence recorded in San Pedro began between 1940 and 1941 when a portion of 
Terminal Island (Figure 1), composed of artificial fill within the Port of Los Angeles, subsided by $40 \mathrm{~cm}$ due to oil extraction in the Los Angeles Basin (Mayuga and Allen 1970). Maximum subsidence due to oil extraction occurred in 1951 at around $71 \mathrm{~cm}$ and remediation programs reduced subsidence rates by 1968 (Mayuga and Allen 1970). Since then there have been some indications of potential subsidence due to groundwater extraction (CDWR 2014). The combination of complex ground deformation and widespread urban structures makes San Pedro a prime study site.

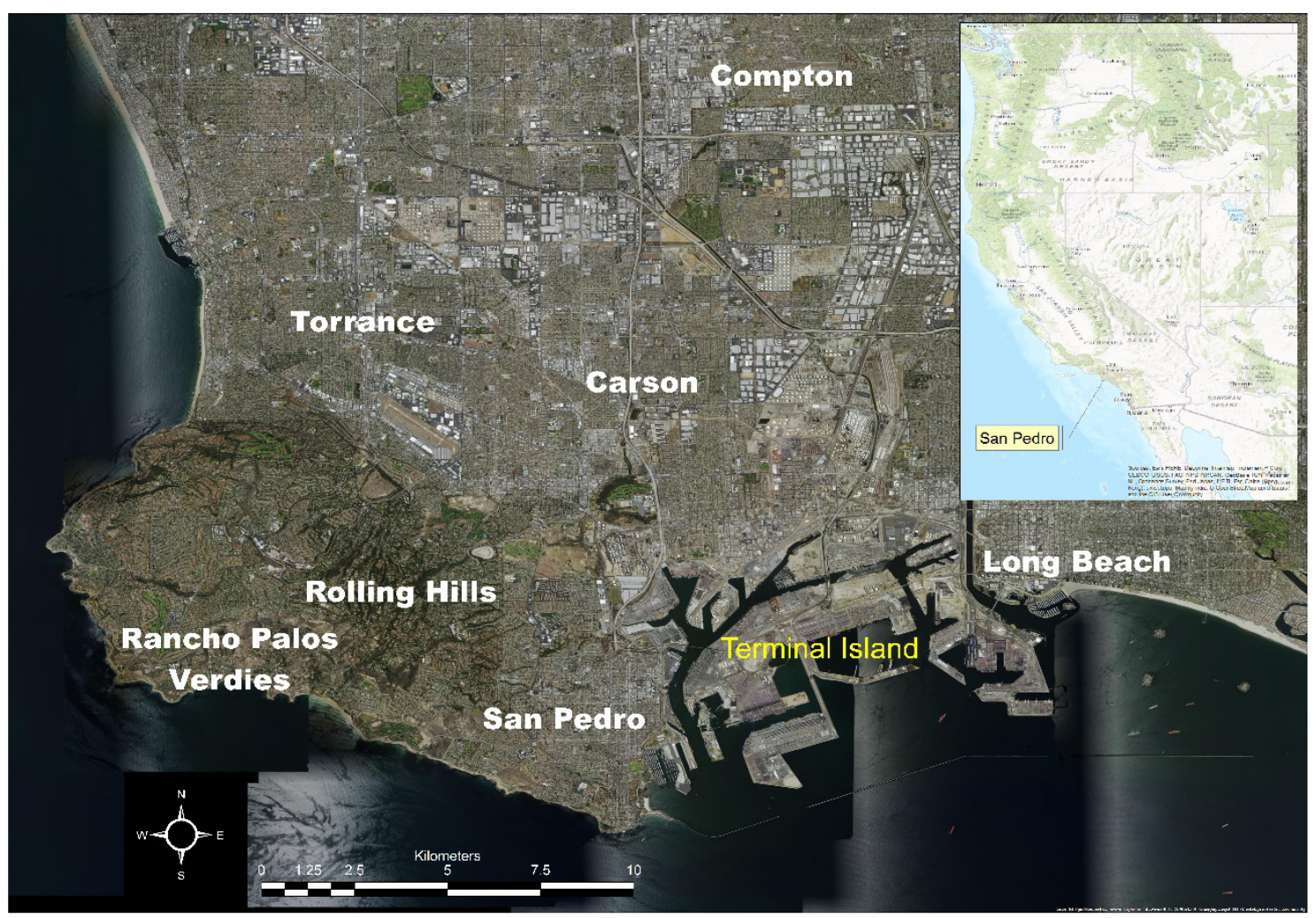

Figure 4.1: The study site of San Pedro, California is located on the Palos Verdes Peninsula, southwest of Los Angeles and within Los Angeles County.

\subsection{Data}

Structure mapping of San Pedro, California requires the use of optical and radar imagery. A combination of satellite and aerial optical imagery were used for the digitization of structures into a spatial DSInv. Satellite radar imagery were processed using 
PSI, which calculates LOS (near-vertical) ground deformation rates and were used for spatial and temporal deformation monitoring of structures. The optical imagery used in this study is the 'World Imagery' basemap, a preloaded option available in ArcMap 10.3.1 (an ArcGIS ${ }^{\circledR}$ software), provided by Esri et al. 2016a. 'World Imagery' is a global dataset, combining satellite and aerial imagery from many sources. The optical images used over San Pedro are aerial images acquired between 2009 and 2012 at 30-cm resolution, which cover the contiguous United States; they are provided by Digital Globe (Esri et al. 2016b). The radar imagery used in this study are 40 COSMO-SkyMed single look complex (SLC) synthetic aperture radar (SAR) images. The images were acquired between July 19, 2012 and September 27, 2014 in the Stripmap Himage mode, which transmits radar waves at a central frequency of $9.6 \mathrm{GHz}(\lambda=3.1 \mathrm{~cm})$ covering an aerial extent of $1,600 \mathrm{~km}^{2}$ (40 x $40 \mathrm{~km}$ ) with a resolution of $3 \mathrm{~m}$. The COSMO-SkyMed satellite is operated by the Italian Space Agency (ASI) and the single look complex SLC SAR images were provided by the European Space Agency (ESA).

\subsection{Methodology}

The workflow of all necessary procedures required to create a structure map of a study area is described in the paragraphs below.

Step 1: Structure Digitization. A DSInv may take two forms: non-spatial and spatial. Examples of non-spatial DSInvs include tables, charts, graphs, and work logs or workbooks. Examples of spatial DSInvs include geodatabases or collections of shapefiles within a GIS, which usually incorporates non-spatial data in the form of attributes and/or symbology. The Los Angeles Countywide Building Outlines (LA CBO) dataset, which contains over three million structures in Los Angeles County mapped from stereo imagery acquired in 2008, was used as the spatial DSInv (LAR-IAC 2008). The value of GIS spatial data is becoming more apparent; datasets like the LA CBO are available for free in the public domain.

Step 2: Data Processing. The purpose of this step is to acquire and import all necessary datasets into the GIS that will be mapped onto the spatial DSInv. These datasets are dependent on the purpose of spatial mapping. For example, the purpose of this paper is 
to monitor ground deformation, both spatially and temporally, across thousands of structures and, therefore, third-party datasets, such as the 40 COSMO-SkyMed SLC SAR images, were processed outside the GIS before the results were imported into the GIS. Processing of the 40 COSMO-SkyMed images, to yield ground deformation measurements across San Pedro between July 2012 and September 2014, was accomplished using the PSI technique (Ferretti et al. 2000; Ferretti et al. 2001) within the SARscape ${ }^{\circledR}$ software (Sarmap 2009). PSI outputs take the form of persistent scatterer (PS) points (Figure 4.2), where each PS point contains data assigned to a geographic location in space from a pixel in the original, slant-range radar image acquired by COSMO-SkyMed. All PSI average velocity, defined as the cumulative displacement rate in any direction over a period, results are shown using negative values to indicate subsidence, or overall downward motion, and positive results to indicate uplift, or overall upward motion. These data are imported into the GIS to be analyzed with the spatial DSInv. 


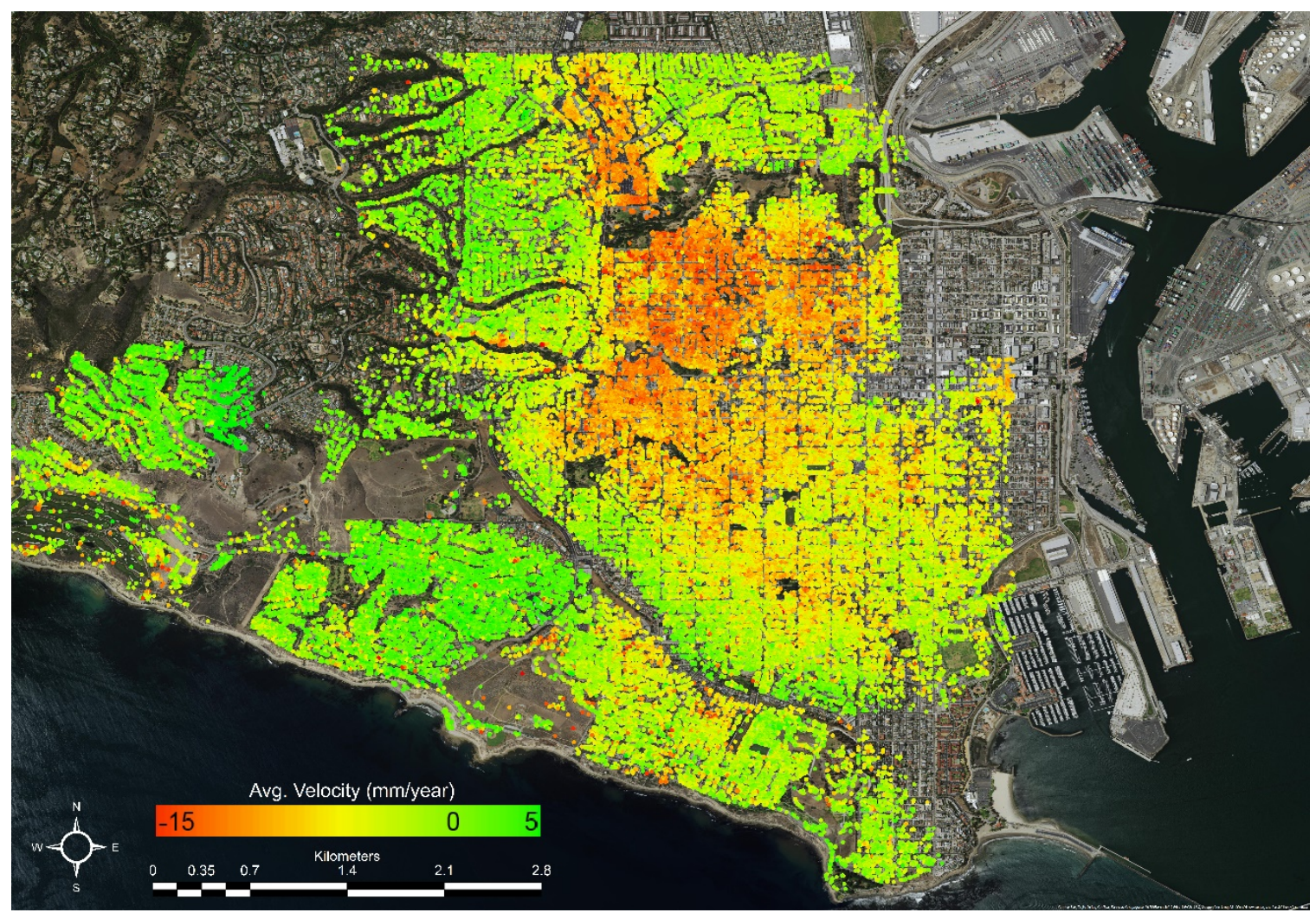

Figure 4.2: Average ground surface velocity results of 215,961 PS points in San Pedro, California by processing 40 COSMO-SkyMed SAR images (July 2012-September 2014) using the PSI technique. Negative average velocity values (red-orange-yellow) indicate subsidence (downward motion); positive values (green) indicate uplift (upward motion). The large red region in north-central San Pedro maps a measured subsidence 'bowl' and is the focus of spatial and temporal structure mapping in Figures 4.3 and 4.4, respectively.

Step 3: Spatial Analyzation. The third step is to join the DSInv with the other datasets, i.e. the other datasets will be mapped onto the spatial shapefiles that represent each structure. This step can accomplish several useful tasks, such as combining or averaging attributes from large datasets into a smaller dataset, which could reduce the number of attributes by orders of magnitude; spatially masking out, or excluding, extraneous data; creating an aesthetic map by reducing clutter caused by large datasets. The structures in San Pedro were joined with the PS points resulting from PSI processing. Variables contained within PS points, measuring ground deformation (displacement and 
velocity) and data quality (coherence), were joined with the DSInv. Spatial analyzation of ground deformation across San Pedro structures first requires the application of a spatial buffer (a fixed area surrounding each structure) and then the joining of PS points with the newly buffered polygons (map representations of structures). A spatial buffer of $3 \mathrm{~m}$ was deemed necessary because PS points that represent ground deformation on a structure may sometimes be assigned to a geographic location outside a structure's polygon due to either radar image resolution (which is $3 \mathrm{~m}$ for these COSMO-SkyMed imagery) or multiple radar bounces. Radar waves can sometimes reflect off multiple nearby targets in addition to the structure being mapped (trees, other structures, the ground, etc.). Multiple radar reflections (bounces) may result in PS points being mapped outside, but very near, a structure's spatial extent and, hence, the creation of buffered polygons representing the structures. The DSInv and PS point data were joined using the Join Data tool in ArcMap 10.3.1. This tool allows the user to join data based on spatial location. The displacement, velocity, and coherence data from each PS point was spatially joined with each buffered polygon. If a buffered polygon contained more than one PS point, all numerical PS point attributes will be summarized. For the purposes of this paper the displacement, velocity, and coherence attributes were averaged. Attributes may be displayed as count (or frequency), minimum, maximum, sum, standard deviation, and/or variance. The output of the Join Data tool is a new shapefile to be used in the map.

Step 4: Map Creation. The last step is the creation of a map that displays external data in a more simplified form. The map allows interested parties (e.g., transportation agencies, insurance companies, etc.) the ability to quickly and easily assimilate data about relevant structures and to make informed decisions for asset management procedures.

\subsection{Results}

A variety of data can be analyzed and displayed using structure mapping. This technique is beneficial because large or complicated datasets, which otherwise appear cluttered or messy in map format, can be observed on a structure-by-structure basis. Data derived from satellite radar imagery (40 COSMO-SkyMed images acquired between July 
2012 and September 2014) were combined with the structure mapping technique to create maps that illustrate the ground deformation history of San Pedro, California.

Spatial structure mapping results for the north-central region of San Pedro are shown in Figure 4.3. 2,570 structures were mapped for this example; only structures that spatially overlap measured PS points are used. As shown on the right of Figure 4.3, each structure is assigned an average value for all measurable PSI-related attributes. Other measurable attributes include total displacement, incremental displacement (displacement between first acquisition and all others), coherence (a data quality measure), the number of PS points per structure, geographic location for the structure, and radar LOS information. The example structure in Figure 4.3 is located at $33.754622^{\circ} \mathrm{N}, 118.308548^{\circ} \mathrm{W}$ at $94.62 \mathrm{~m}$ $(310.42 \mathrm{ft}$ ) above sea level with a total height of $8.11 \mathrm{~m}$, was experiencing downward displacement (subsidence) at an average rate of approximately $3.6 \mathrm{~mm} / \mathrm{year}$ between July 2012 and September 2014, and 274 PS points were measured on a structure with an area of $36,271 \mathrm{~m}^{2}$ (blue circle in Figure 4.3).

Temporal analysis of structure mapping results yields more complete information. Figure 4.4 displays the average velocity of structures in a neighborhood of San Pedro, as well as the displacement-time series (Figure 4.4 inset) - a graphical representation of incremental displacement at every image acquisition date with respect to the first acquisition date-for the structure (circled in red) that experienced relatively high subsidence rates compared to its neighbors. The exact cause of this subsidence is unknown, but the cyclical nature of the displacement-time series may indicate shrinking/swelling of clay-rich soils due to changes in water content (e.g., precipitation, sprinkler systems, absorption by vegetation, etc.). The displacement-time series illustrates that the average velocity measurement of this structure (at around $-8 \mathrm{~mm} /$ year) does not reveal all necessary information: this structure did not subside vertically at $-8 \mathrm{~mm} /$ year between July 2012 and September 2014. Instead, this structure experienced oscillatory (up and down) motion that resulted in a net displacement of approximately $-8 \mathrm{~mm}$. Additionally, a majority of the net displacement occurred between July 2012 and June 2013; the structure became relatively stable from June 2013 to September 2014, apart from 1 to $2 \mathrm{~mm}$ oscillations. These data can be manipulated and represented in GIS map format as well. Instead of spatially 
displaying average velocity values, for instance, the user can calculate displacement rates between selected dates - e.g., the user may be interested in ground displacement rates during a wet season (November 2013 to March 2014) - to show information in a manner relevant to the user. These types of detailed temporal measurements are applicable for every structure with available PS point data.

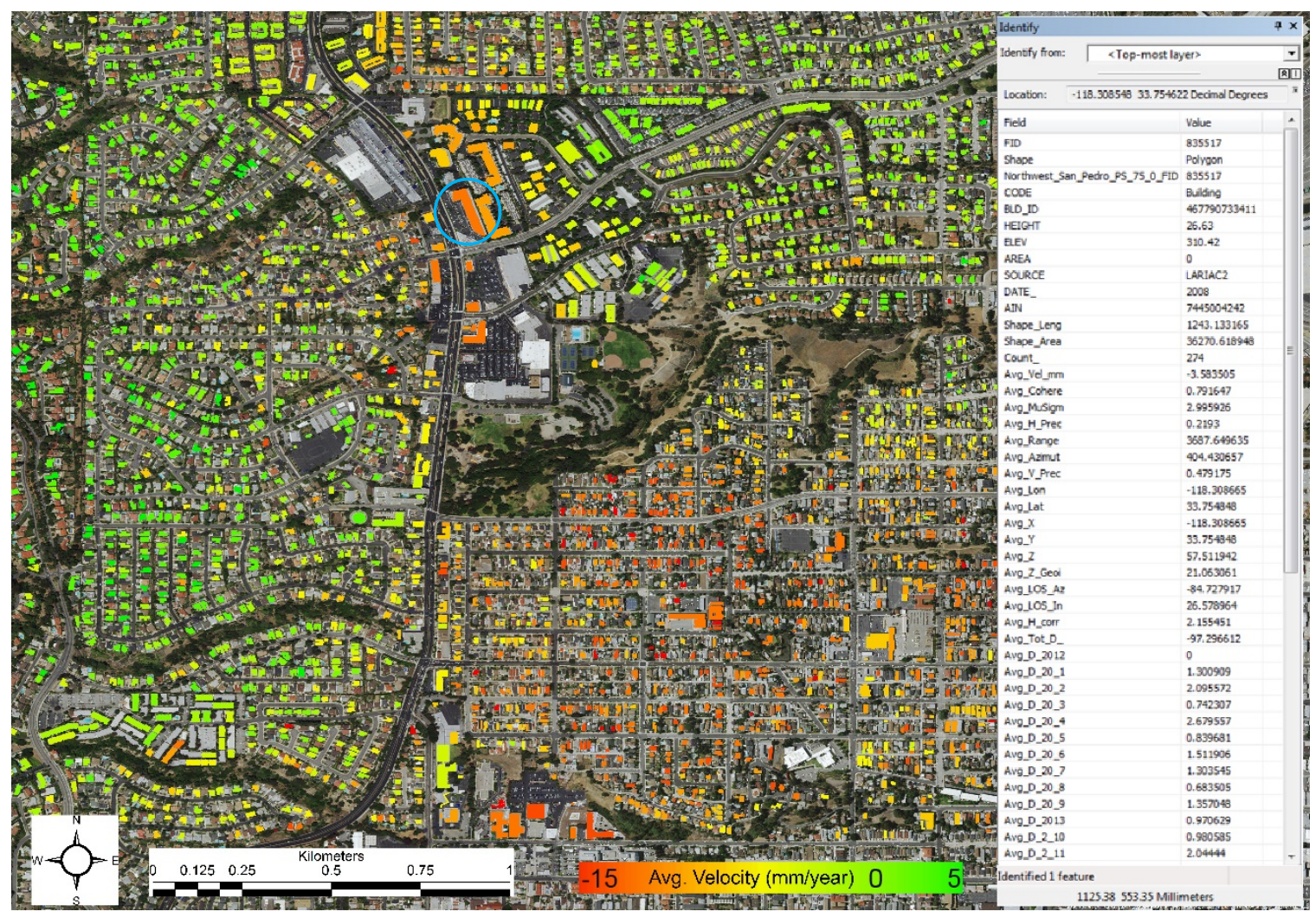

Figure 4.3: Spatial structure mapping in north-central region of San Pedro, California. The Identify inset shows an example of the amount of data contained within each structure polygon assigned to individual buildings (example structure shown in the blue circle). 


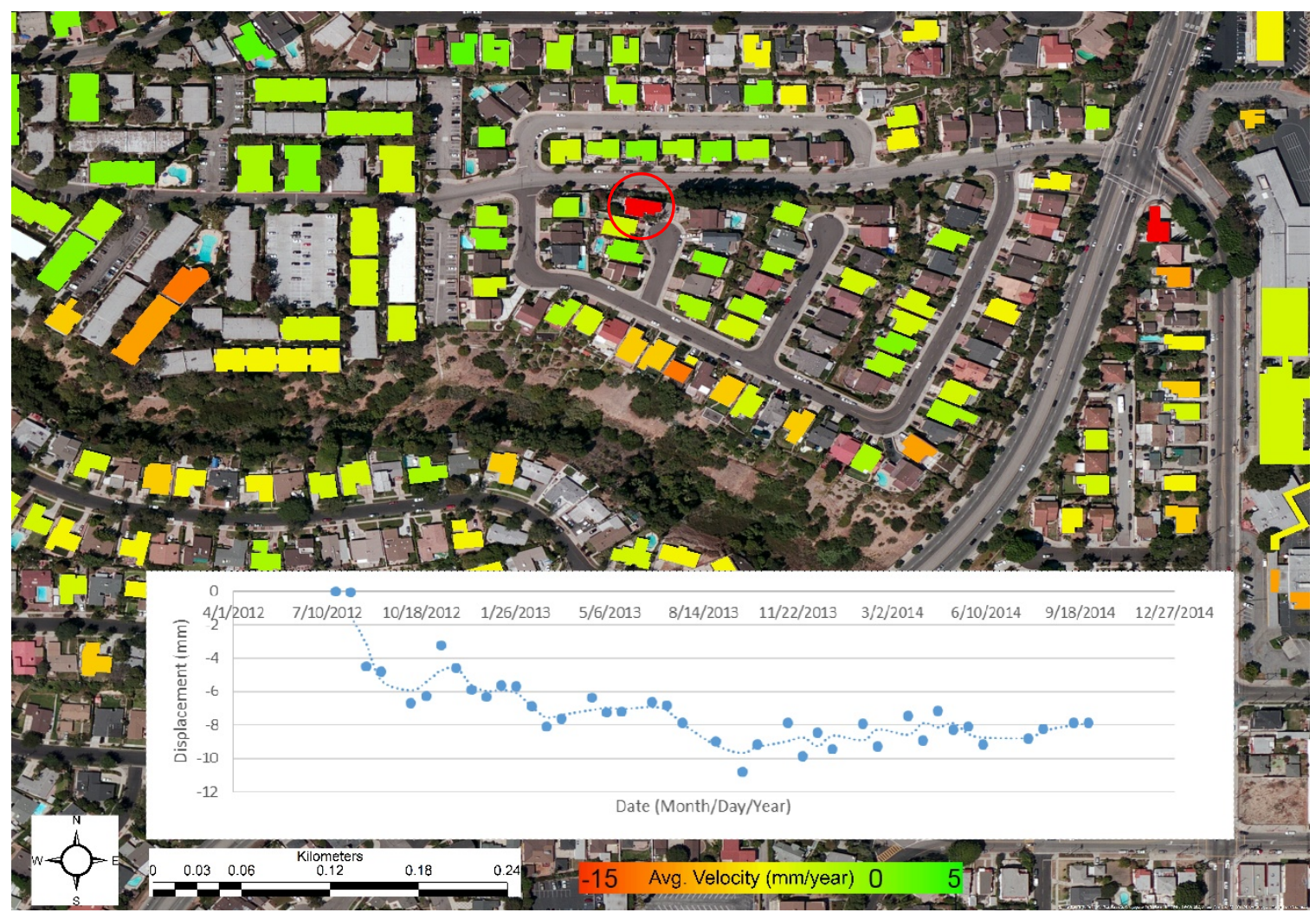

Figure 4.4: Average velocity map of a San Pedro neighborhood and displacement-time series (inset) of a structure (red circle) surrounded by structures that experienced less displacement. Average velocity magnitude is calculated by dividing all measured motion (upward and downward) by acquisition time. Average velocity direction is calculated by overall displacement trend (positive or negative). The displacement-time series shows the incremental displacement (points) at every image acquisition date with respect to the first acquisition date, as well as a three-image moving average (blue curve).

\subsection{Discussion}

Once the methodology has been completed and results are obtained, choosing how to display the data can be a difficult decision. As shown in the examples of Figures 4.3 and 4.4, conclusions drawn upon spatial and temporal ground deformation data may differ depending on the level of detail used for interpretation. Fortunately, the numerous ways to look at the data can aid in the understanding of structure movement; it is up to the user to decide the purpose of the structure mapping exercise. City-scale spatial information is 
beneficial when identifying regional trends, such as locating structures that may be at risk from variable ground deformation within a subsidence bowl (Figure 4.3). Neighborhoodscale spatial mapping can be useful when attempting to pinpoint local problem areas, like determining whether property damage from natural hazards is likely to occur based on surface deformation measurements (Figure 4.4). If deformation has occurred, investigating when (Figure 4.4 inset) and why deformation took place can aid in mitigation efforts and, hopefully, reduce or minimize future problems.

The structure mapping methodology map easily be applied to other assets, depending on the asset management approach of choice (e.g., geotechnical, transportation, etc.). In this case, building monitoring in San Pedro, California was chosen for multiple reasons: (1) a detailed, historic record of resource extraction exists for this area and using PSI to monitor recent subsidence rates is of great interest not just in San Pedro, but statewide, especially when coupled with the current drought; (2) PSI works well over urban areas where ground motion is measurable but not catastrophic (large ground motion results in de-correlation, or a drastic loss of coherence between radar images, making the technique unreliable, at best, or unusable, at worst); (3) a robust spatial DSInv of building locations in 2008 throughout Los Angeles County was created and made available by the Los Angeles Region Image Acquisition Consortium (LAR-IAC, with an updated 2014 version currently unavailable in the public domain). The results shown in Figures 4.2 through 4.4 can be directly used for asset management purposes. Ground deformation maps (Figures 4.2 and 4.3) can provide indirect measurements for initial asset condition assessment. For example, an asset experiencing high differential displacement (PS points indicate portions of the asset moving in different directions, possibly causing internal stress within the asset) may require further condition assessment by field crews. In the case of the San Pedro subsidence bowl (Figure 4.2), assets located along the perimeter of the bowl, where differential average velocity is present, may require long-term life-cycle monitoring, which may be accomplished through displacement-time series analyses (Figure 4.4). The PSI technique is a valuable tool for long-term ground deformation monitoring to indirectly assess anthropogenic assets. 
Structure mapping also aids in the creation and/or conversion of asset inventories into a spatial DSInv format, which can then be used for further processing. An advantage of structure mapping and additional GIS data analysis is the ability to perform bulk processing (e.g., multiple datasets may be spatially analyzed to an entire DSInv, which may include thousands of structure polygons) in a relatively quick manner (e.g., the spatial joining of 2,570 structure polygons to 215,961 PS points, each with about 60 attributes, took on the order of minutes to perform on a basic desktop computer). Limitations of structure mapping mirror the limitations inherent in the datasets used during Step 3: Spatial Analyzation. For example, processing 20-m resolution radar images (in Step 2: Data Processing) with the expectation of monitoring small-scale structures (such as fire hydrants) is not a promising endeavor. Therefore, limitations include spatial resolution of images, temporal resolution of the data (i.e., how often the data are acquired), spatial extent and density of the data, signal-to-noise ratio, and other general issues inherent in data acquisition. The limitations of structure mapping can be overcome through advancements of data gathering techniques. The capabilities of structure mapping will improve as technology improves, allowing for further synergy of data from many acquisition modes (subsurface-, terrestrial-, aerial-, and satellite-based) with GIS applications that will result in more robust data fusion.

\subsection{Conclusion}

Asset management programs are created in order to monitor, maintain, and achieve life-cycle performance goals, such as safety to the public and economic sustainability, for all assets within a network by managing physical structures. It was shown that the PSI technique is capable of monitoring ground deformation rates across the urban study site of San Pedro, California (Figure 4.2). Deformation rates were measured across individual structures by spatially joining a DSInv—-polygons outlining the spatial extent of all buildings located within Los Angeles County (LAR-IAC 2008) -with the PSI results (Figure 4.3). Temporal monitoring was conducted at the individual structure level using a displacement-time series graph (Figure 4.4). Deformation rates on structures were successfully measured and monitored using spatial and temporal analyses of 40 radar 
images from the COSMO-SkyMed satellite (July 2012 through September 2014) with a combination of PSI data and GIS application through structure mapping. The methodology used to obtain these results were discussed in a step-by-step fashion, with the hopes that those interested in the asset management approach may utilize the multi-dimensional process of structure mapping to analyze their relevant datasets.

\subsection{Acknowledgements}

This project was funded by the US Department of Transportation (USDOT) through the Office of the Assistant Secretary for Research and Technology (Cooperative Agreement No. RI-TARS-14-H-MTU). COSMO-SkyMed imagery were provided by ESA under the Category-1 Proposal ID 31684. Optical imagery used were the 'World Imagery' and 'World Topographic Map' basemaps within the ArcGIS ${ }^{\circledR}$ software by Esri and cited as Esri et al. 2016a and Esri et al. 2016b.

\subsection{Disclaimer}

The views, opinions, findings, and conclusions reflected in this paper are the responsibility of the authors only and do not represent the official policy or position of the USDOT/OST-R or any state or other entity. 


\title{
Chapter 5: Monitoring India's Dams from Space: A Cost-Effective Approach using Sentinel-1 Radar Images ${ }^{15}$
}

\author{
El Hachemi Bouali ${ }^{16}$; Thomas Oommen, Ph.D., A.M.ASCE ${ }^{17}$; \\ and KS SajinKumar, Ph.D. ${ }^{18}$
}

\subsection{Abstract}

Interferometric synthetic aperture radar (InSAR) provides a cost-effective approach for long-term deformation monitoring of dams against the routine pre- and post-monsoon inspections for dam safety in India. This state-of-the-art technique can be used to supplement repeated field inspections and target structures at risk. Here we show three case studies from southern India - Idamalayar Dam, Malankara Dam, and Upper Sholayar Dam - and this study demonstrates the capabilities of InSAR to indirectly monitor dam health. 23 Sentinel-1 radar images during 2016-2017 were processed using Persistent Scatterer Interferometry (PSI). Idamlayar Dam is found to be relatively stable (possible point-source deterioration), while Malankara Dam and Upper Sholayar Dam are experiencing various amounts of subsidence.

${ }^{15}$ The material contained in this chapter was previously published in the International Dam Safety Conference 2018 Proceedings.

16 Department of Geological and Mining Engineering and Sciences, Michigan Technological Univ., 1400 Townsend Dr., Houghton, MI 49931 (corresponding author). E-mail: eybouali@mtu.edu

17 Department of Geological and Mining Engineering and Sciences, Michigan Technological Univ., 1400 Townsend Dr., Houghton, MI 49931. E-mail: toommen@mtu.edu

18 Department of Geology, University of Kerala, Thiruvananthapuram, India, sajinks@gmail.com 


\subsection{Dam Safety Procedures in India}

Ministry of Water Resources and Central Water Commission Dam Safety Organisation, Government of India, released a Report on Dam Safety Procedures (CWC 1986) that, based on several meetings of the International Congress on Large Dams, suggest recommendations for safe dam procedures from the pre-construction planning through post-construction monitoring and maintenance stages. The report specifically notes that instruments (e.g., strain transmitters, thermometers, stress meters, uplift pressure, and inclination transmitters) are to be installed on "concrete and masonry dams more than 30 metres in height" (p. 15). Safety inspections by experienced engineers are to be performed twice each year (pre- and post-monsoon) to assess dam health and a comprehensive, holistic dam examination should be conducted once per decade (Kumar 2007). The Dam Rehabilitation and Improvement Project (DRIP) in India was established to enhanced performance and increase safety of chosen dams. DRIP will cost $\$ 437.50$ million USD through 2020. The purpose of this study is to show that InSAR techniques can provide a cost-effective approach and supplement repeated safety inspections. The result will be a reduction of overall costs of dam maintenance and a more objective evaluation of the dam using accessible remote sensing data (Escobar-Wolf et al. 2015; Mazzanti 2017).

\subsection{Satellite InSAR and SAR Data}

Interferometric synthetic aperture radar (InSAR) is a remote sensing technique that utilizes the phase component of multiple synthetic aperture radar (SAR) images for obtaining information about how coherent targets change. InSAR enables the user to monitor ground deformation on or near assets, and across $\mathrm{km}^{2}$-scale areas over many years (Bouali et al. 2016a; Bouali et al. 2017a). Based on InSAR results, assets can be organized by hazard (e.g., assets undergoing greatest ground deformation exhibit highest hazard) and engineers can be dispatched for traditional field investigations.

Sentinel-1 is a dual satellite constellation launched by the European Space Agency (ESA) on 3 April 2014 (Sentinel-1A) and 25 April 2016 (Sentinel-1B). Sentinel-1 operates 
in the C-band (5.331 GHz; $5.6 \mathrm{~cm}$ wavelength). Twenty-three Sentinel-1 radar images acquired in Stripmap mode between 21 February 2016 and 3 June 2017 at a spatial resolution of $22 \mathrm{~m}$ - were processed using Persistent Scatterer Interferometry (PSI) using ENVI SARscape ${ }^{\mathrm{TM}}$ software. PSI is an InSAR stacking technique with many benefits: it reduces atmospheric noise, allows for displacement monitoring, and can measure ground velocity at an accuracy of $1 \mathrm{~mm} / \mathrm{year}$ (Ferretti et al. 2000). PSI measures ground deformation in the line-of-sight (LOS) direction $\left(\mathrm{N} 85^{\circ} \mathrm{W}, \sim 23^{\circ}\right.$ from nadir) at every image pixel (Ferretti et al. 2001). PSI excels in urbanized areas, which makes this technique a promising cost-effective approach for dam monitoring.

\subsection{Case Studies: Three Dams in Southern India}

Three dams in southern India are investigated: Idamalayar Dam, Malankara Dam, and Upper Sholayar Dam (Figure 5.1). The sub-sections below include the following information for each dam: brief history and description, PSI results, and discussion. PSI results are shown as velocity measurements: negative values indicate deformation away from the satellite while positive values indicate deformation towards the satellite.

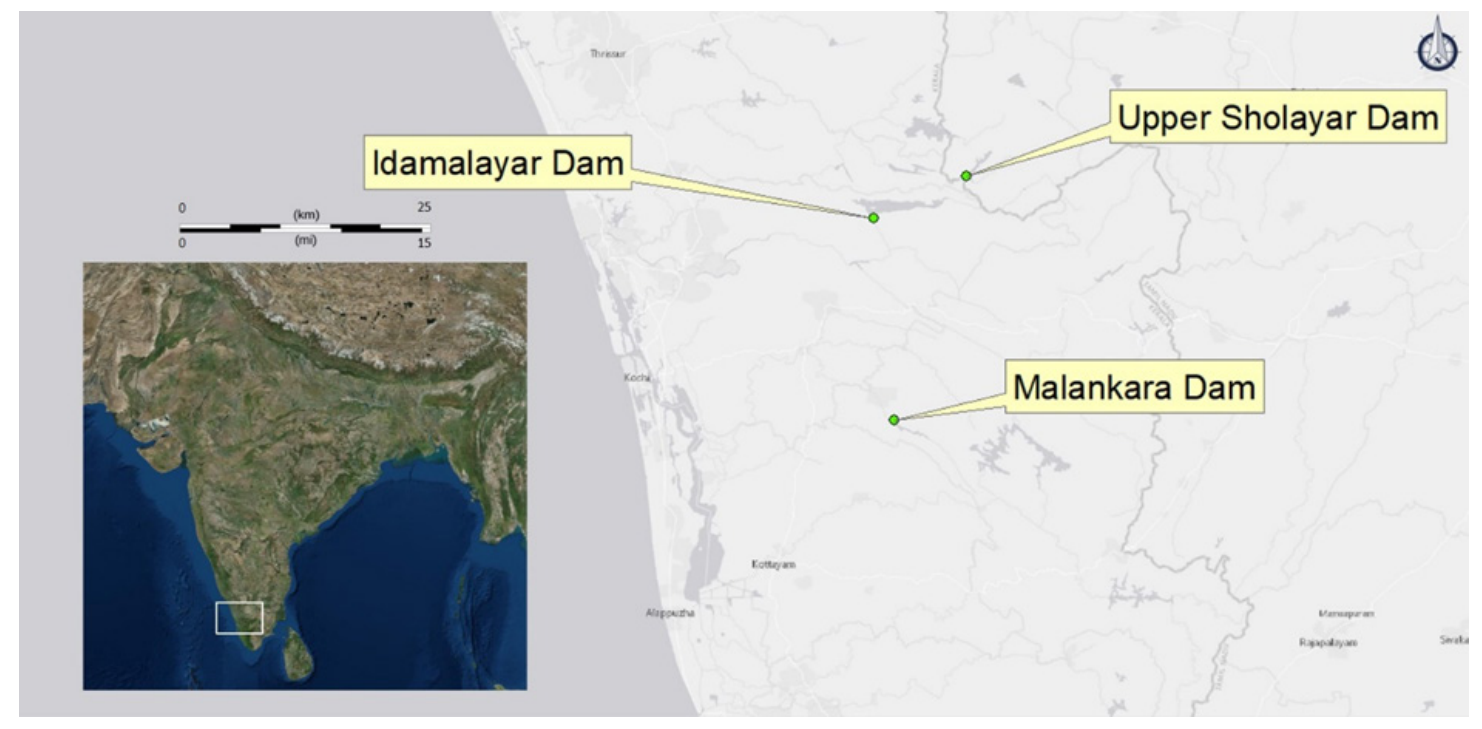

Figure 5.1: Idamalayar Dam, Malankara Dam, and Upper Sholayar Dam are in southern India. 


\subsubsection{Idamalayar Dam}

Idamalayar Dam is a multipurpose concrete gravity dam located in the Ernakulam District in Kerala, India (Figure 5.2). The structure was completed in 1985 and has a length of $373 \mathrm{~m}$ and height of $102.8 \mathrm{~m}$. The dam creates the $28.3 \mathrm{~km}^{2}$ Idamalayar reservoir used for power generation and a proposed irrigation program.
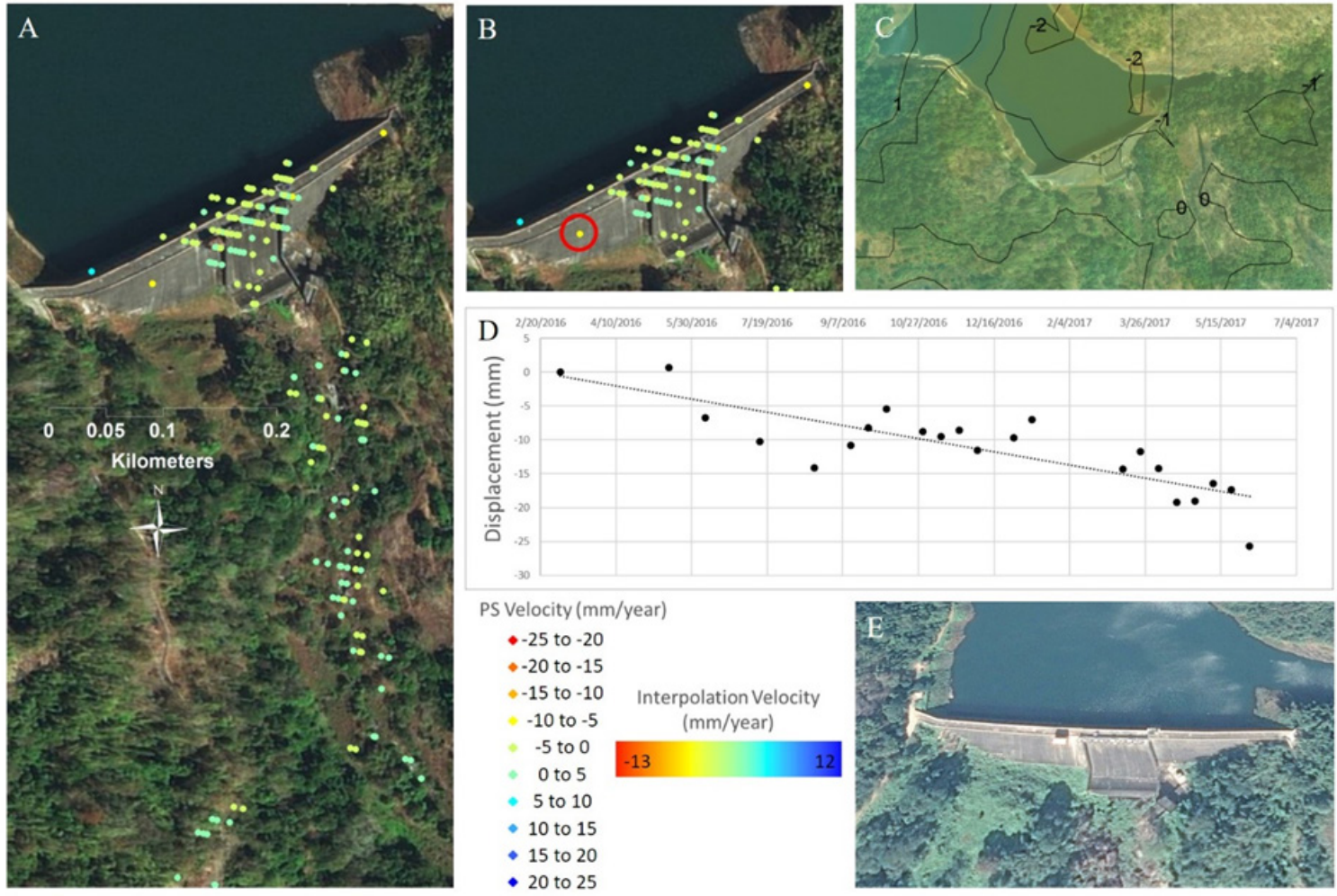

Figure 5.2: Idamalayar Dam. (A) Results from PSI technique. Persistent scatterers (PS) are individual points measuring velocity ( $\mathrm{mm} /$ year) ranging from $-25 \mathrm{~mm} /$ year (red) to 25 mm/year (blue). (B) Close-up of PS points on Idamalayar Dam. (C) Kriging interpolation of PSI results (contour interval $=1 \mathrm{~mm} /$ year). Interpolation velocity ranges from -13 mm/year (red) to $12 \mathrm{~mm} /$ year (blue). (D) Displacement-time series of PS point in red circle from (B). (E) Google Earth view of the Idamalayar Dam.

One hundred twelve PS points are identified on the Idamalayar Dam, of which 103 are located within the middle, tallest portion of the dam (Figure 5.2A-B). Deformation rates 
across the concrete structure range from $7 \mathrm{~mm} /$ year to $-10 \mathrm{~mm} /$ year (Figure 5.2D shows $10 \mathrm{~mm}$ /year persistent scatterer, PS, point), with the greatest velocities measured along the dam flanks. A Kriging interpolation of the PS velocity (Figure 5.2C) demarks the reservoir side of Idamalayar Dam as undergoing slight subsidence (-2 mm/year contour located north of the east flank) and south side as relatively stable $(0 \mathrm{~mm} /$ year contour located south of the structure). Although three PS points along the dam flanks measure cm-scale movements, most of the data show the dam is relatively stable. 109 PS points measure velocities at $<5 \mathrm{~mm} /$ year in either direction. The Kriging interpolation also indicates the dam is moving at an average velocity of $-1 \mathrm{~mm} /$ year (the $-1 \mathrm{~mm} /$ year contour line is parallel to the length of the dam). PS points such as that shown in Figure 5.2(D) should not be dismissed, however, as this displacement-time series implies there may be a localized structural health issue (e.g., Kang et al. 2017).

\subsubsection{Malankara Dam}

Malankara Dam is a gravity dam built in 1994 across the Thodupuzha River with a height of $42 \mathrm{~m}$ and length of $460 \mathrm{~m}$ in Thodupuzha, Kerala, India (Figure 5.3). The dam was built to provide irrigation to the region but is also a tourist destination because it is open year-round and the $153.5 \mathrm{~km}^{2}$ artificial lake supports boating and fishing activities.

One hundred eleven PS points are obtained within the Malankara Dam region (Figure 5.3A): 77 PS points on the gravity dam itself and 34 PS points within the building complex on the property to the northwest. One hundred seven PS points exhibit downward deformation; the remaining four PS points measure ground movements between $0 \mathrm{~mm} /$ year and $2 \mathrm{~mm} /$ year. The Malankara Dam is experiencing variable rates of subsidence. The 53 PS points located on the middle crest and berm portion of the dam indicate an average velocity of $-3 \mathrm{~mm} / \mathrm{year}$. The southwest embankment is moving at a velocity as high as -16 $\mathrm{mm} /$ year (red circle in Figure 5.3B; Figure 5.3D) and the north embankment is moving between $-5 \mathrm{~m} / \mathrm{year}$ and $-9 \mathrm{~mm} /$ year. Figure $5.3 \mathrm{C}$ provides the Kriging interpolation of the PS velocity, which shows the entire Malankara Dam lies between the $-2 \mathrm{~mm} /$ year and -7 $\mathrm{mm} /$ year contours, with subsidence rates increasing towards the northwest. Presence of regional subsidence - and not exclusively on Malankara Dam - may mean the structure is 
not failing. Instead there may be geological factors (e.g., sediment compaction or tectonic activity) or other anthropogenic factors (e.g., subsurface groundwater extraction) causing apparent subsidence near Malankara Dam.
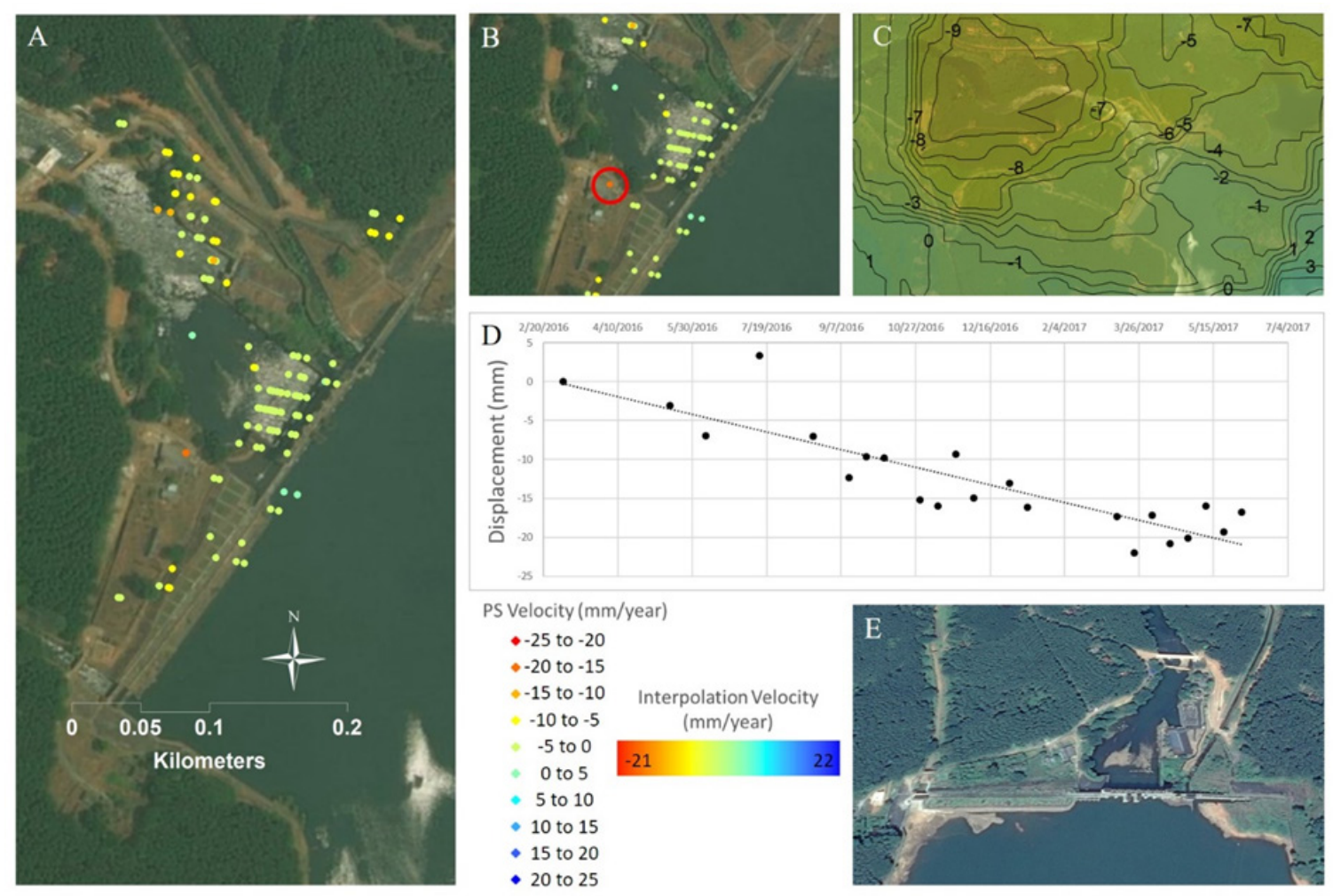

Figure 5.3: Malankara Dam. (A) Results from PSI technique. PS are individual points measuring velocity (mm/year) ranging from -25 mm/year (red) to $25 \mathrm{~mm} /$ year (blue). (B) Close-up or PS points on Malankara Dam. (C) Kriging interpolation of PSI results (contour interval $=1 \mathrm{~mm} /$ year). Interpolation velocity ranges from $-21 \mathrm{~mm} /$ year $(\mathrm{red})$ to $22 \mathrm{~mm} /$ year (blue). (D) Displacement-time series of PS point in red circle from (B). (E) Google Earth view of the Malankara Dam.

\subsubsection{Upper Sholayar Dam}

Upper Sholayar Dam is a concrete masonry dam built in 1965 to aid in the generation of hydroelectric power (Figure 5.4). The dam has a height of $66 \mathrm{~m}$, a length of $430.6 \mathrm{~m}$, and creates a $71.3 \mathrm{~km}^{2}$ reservoir. 
Since reservoir levels were relatively low in 2016 and 2017, 918 PS points were identified on the Upper Sholayar Dam, mostly on the two large embankments flanking the concrete dam (Figure 5.4A). The entire structure is experiencing subsidence. Velocity values on both the north and south embankments range between $5 \mathrm{~mm} /$ year and $-10 \mathrm{~mm} /$ year (Figures 5.4A-C), and deformation on the concrete structure is as high as $-7 \mathrm{~mm}$ /year (Figures 5.4A-D). Kriging interpolation shows small subsidence bowls on each embankment and due west of the concrete dam. The most dramatic subsidence bowl (northwest corner of Figure 5.4C) covers a small neighborhood in Sholayar Dam City. Presence of these subsidence bowls - indicating no background deformation in the surrounding area, unlike around Malankara Dam—also implies the occurrence of subsidence on the Upper Sholayar Dam. 

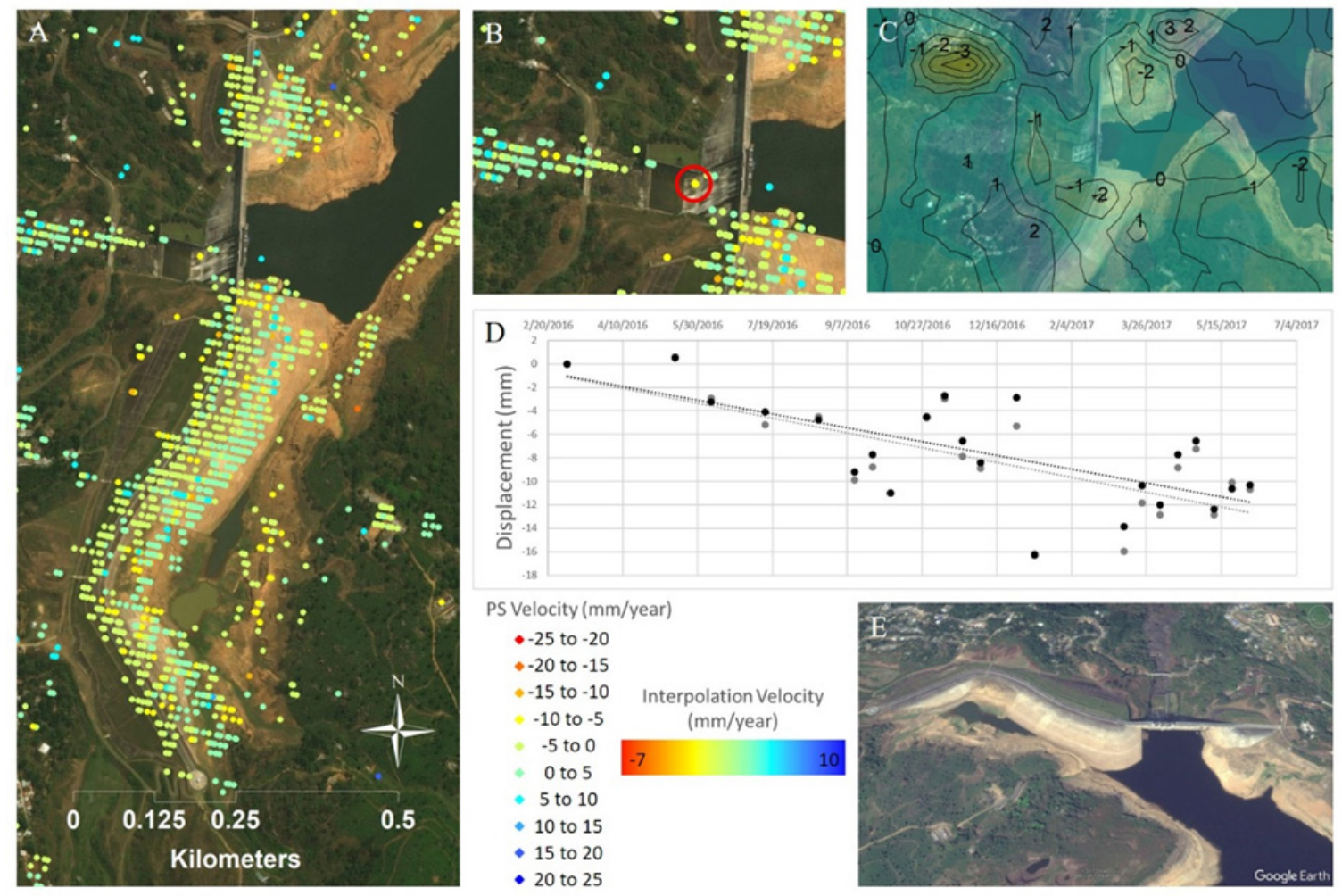

Figure 5.4: Upper Sholayar Dam. (A) Results from PSI technique. PS are individual points measuring velocity (mm/year) ranging from $-25 \mathrm{~mm} /$ year (red) to $25 \mathrm{~mm} /$ year (blue). (B) Close-up of PS points on Upper Sholayar Dam. (C) Kriging interpolation of PS results (contour interval $=1 \mathrm{~mm} /$ year). Interpolation velocity ranges from $-7 \mathrm{~mm} /$ year (red) to $10 \mathrm{~mm} /$ year (blue). (D) Displacement-time series of two PS points in red circle from (B). (E) Google Earth view of Upper Sholayar Dam.

\subsection{Conclusions}

InSAR is a remote sensing technique that presents opportunities to measure regional-scale ground deformation on critical assets. Idamalayar Dam, Malankara Dam, and Upper Sholayar Dam (Figure 5.1) are monitored using 23 Sentinel-1 radar images during 2016-2017. Results reveal a relatively stable Idamalayar Dam that may have localized deterioration (Figure 5.2), regional instability around Malankara Dam (Figure 5.3), and subsidence of Upper Sholayar Dam embankments (Figure 5.4). A high density of PS points proximal to assets allow agencies to utilize this technology for 
supplementation of in situ instruments. Therefore, InSAR can be used as a cost-effective method for long-term dam monitoring together with in situ instrumentation to understand structural and regional stability.

\subsection{Acknowledgements}

The first author acknowledges the support received through the NASA Earth and Space Science Fellowship Program (proposal: 16-EARTH16F-0086). The third author acknowledges the University Grants Commission, Government of India, for providing the UGC-Raman Fellowship for carrying out Post-Doctoral Research at Michigan Technological University. 


\section{Chapter 6: Monitoring the Casitas Dam in Ventura County, California with Satellite InSAR $^{19}$}

\subsection{History of the Casitas Dam}

Casitas Dam is an embankment dam in Ventura County, California, about 100 miles northwest of Los Angeles and is operated by the United States Bureau of Reclamation (USBR 2018). The Ventura River Project authorization bill was proposed to the United States Congress in 1955 and included construction of the Casitas Dam to create a reservoir, Lake Casitas, which would distribute water for agricultural, municipal, and industrial use through $33 \mathrm{mi}(53 \mathrm{~km})$ of pipeline (Figure 6.1). The bill was approved. Construction of Casitas Dam began in July 1956 and concluded in March 1959.

In the late 1990s, the USBR recommended reinforcement construction take place because Casitas Dam was vulnerable to liquefaction if a major earthquake (magnitude $>6.5$ ) occurred in the area (Green 1998). The agreed upon solution was to widen the dam crest and construct a 130-ft berm at the base of the Casitas Dam, as seen in the schematic in Figure 6.2 and the aerial photograph in Figure 6.3. The project ended up costing $\sim \$ 42$ million and was completed in 2000 (Surman 2000). Specifications of the Casitas Dam and Lake Casitas are provided in Figure 6.3.

${ }^{19}$ The material contained in this chapter is in preparation for future publication. 


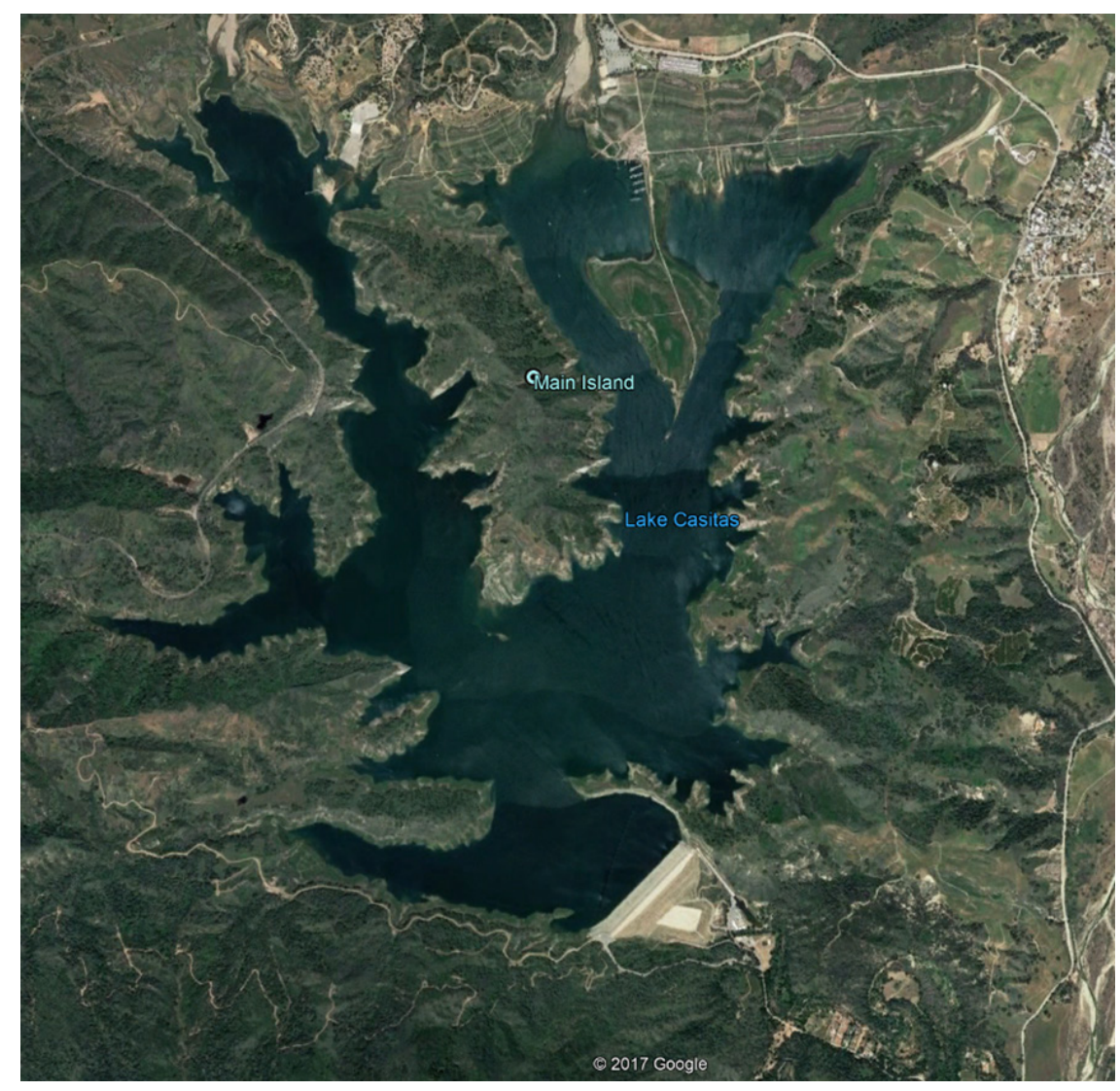

Figure 6.1: Google Earth image of the Casitas Dam placement at the southern end of Lake Casitas.

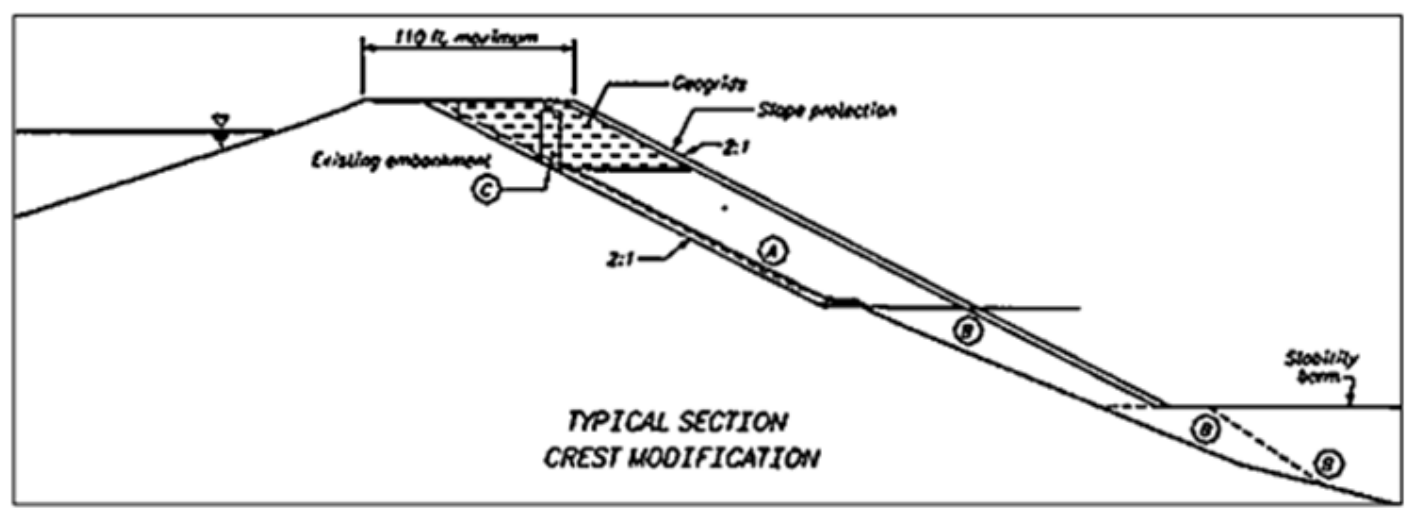

Figure 6.2: Construction plan schematic of Casitas Dam bolstering project in 1999 and 2000. The Casitas Dam crest was widened, and a stability berm was added at the base. Image taken from USBR (2015). 


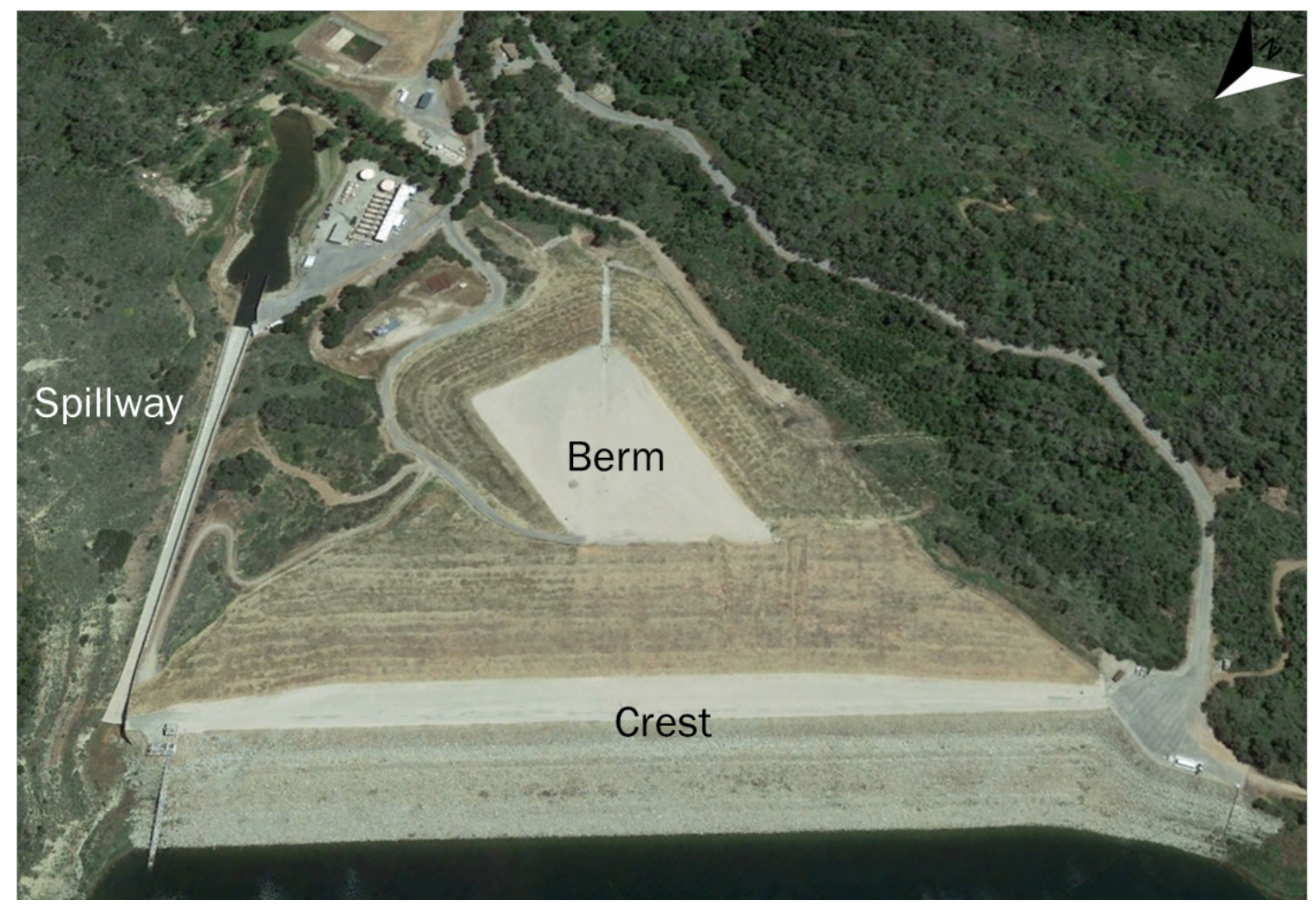

Figure 6.3: Casitas Dam and Reservoir Specifications. Crest length $=2,000 \mathrm{ft}(610 \mathrm{~m})$. Crest height $=335 \mathrm{ft}(102 \mathrm{~m})$. Crest elevation $=585 \mathrm{ft}(178 \mathrm{~m})$ above sea level. Spillway Crest elevation $=567 \mathrm{ft}(173 \mathrm{~m})$ above sea level. Berm height $=130 \mathrm{ft}(40 \mathrm{~m})$ and was constructed in 1999 and 2000. Lake Casitas is 254,000 acre-ft (313,000,000 $\left.\mathrm{m}^{3}\right)$ in area and was created from the damming of Coyote Creek and diverted water from Ventura River.

\subsection{Dam Monitoring Recommendations}

The Division of Dam Safety and Inspections (DDSI) established a list of minimum recommended factors to observe at dams that may pose a significant or high hazard (DSSI 2006). Based on these recommendations, embankment dams that pose such a hazard should include long-term monitoring of reservoir level, tailwater level, drain flow/seepage/leakage, pore and uplift pressure, seismic loads, surface settlement, surface alignment, and foundation movement. DSSI (2006) provide examples of deformation that may indicate a "developing problem," including "settlement of the crest ...bulging of the 
slopes, and ...horizontal and vertical surface movement" (p29 and p34). Recommended embankment dam monitoring strategies include measuring deformation along the length of the crest, with the "measurement points... spaced sufficiently close to allow measurement of all significant deformation" (p29, DSSI 2006).

\subsection{Data}

Persistent Scatterer Interferometry (PSI) is a remote sensing approach that can measure ground deformation across embankment dams at the DSSI (2006) recommended resolution. The merit of PSI for use in deformation monitoring across anthropogenic structures has been established in Chapters 3, 4, 5, 7, and 8, and in the myriad of references therein. Twenty-three descending ENVISAT Advanced Synthetic Aperture Radar (ASAR) images, acquired at a wavelength of $5.6 \mathrm{~cm}$ (C-Band) between September 4, 2005 and January 23, 2010 by the European Space Agency (ESA), were used in this study. ENVISAT ASAR images have a spatial resolution of $20 \mathrm{~m}$. The images were provided by the ESA from a written proposal (ID 82169). PSI measures average velocity in $\mathrm{mm} / \mathrm{year}$ (or displacement in $\mathrm{mm})$ in the line-of-sight direction $\left(\sim 23^{\circ}\right.$ from nadir, $\left.\mathrm{N} 85^{\circ} \mathrm{W}\right)$. These measurements are shown as persistent scatterer (PS) points. Negative values indicate ground movement away from the satellite (subsidence or westward movement); positive values indicate ground movement towards the satellite (uplift or eastward movement).

\subsection{Long-Term Monitoring Results and Discussion}

PSI results are shown in Figures 6.4. Over 100 PS points were obtained on the crest and berm, especially on the southern-facing slopes of the structure. In general, the Casitas Dam was moving in a downward direction (yellow, orange, and red PS) while the dam facilities were moving in an upward direction (blue PS). Since each PS point contains temporal deformation information (e.g., average velocity, displacement at each acquisition

date, etc.) and the relatively high-density spatial distribution of PS across the dam allows for multiple deformation measurements, PSI are sufficiently spaced to monitor all significant deformation (Ferretti et al. 2000; Ferretti et al. 2001). 


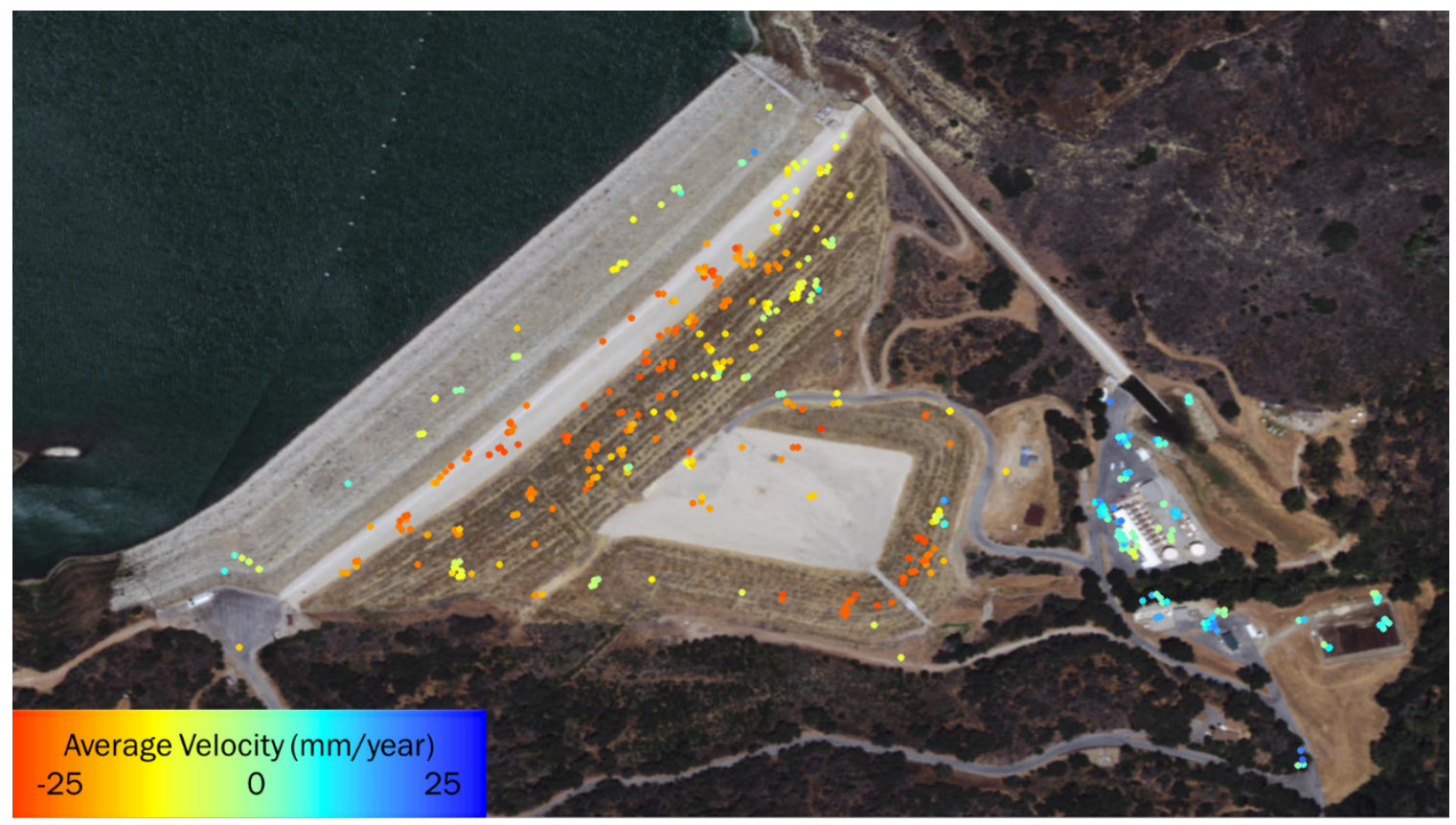

Figure 6.4: PS points on the Casitas Dam measured between September 4, 2005 and January 23, 2010.

Between 2005 and 2010, the Casitas Dam crest experienced differential deformation. A displacement-time series at four locations (numbered Series1, Series2, Series3, and Series4 on the plot) along the length of the crest is shown in Figure 6.5. The displacement-time series shows that, in general, the crest underwent downward deformation of varying degrees: $-42 \mathrm{~mm}$ at location $2,-16 \mathrm{~mm}$ at location $3,-12 \mathrm{~mm}$ at location 1 , and $-5 \mathrm{~mm}$ at location 4 . There is evidence for two potential causes of dam deformation. The first is the Casitas Dam underwent a general tilting of the dam crest is observed - the north side is relatively stable (location 4) and the south side settled at a rate up to $\sim 10 \mathrm{~mm} /$ year (at location 2). Tilting is based entirely on PSI results. The second potential cause incorporates surficial erosion and slumping viewable from aerial photographs (Figure 6.6). Slumping on the crest appears shallow but extends to $\sim 336 \mathrm{ft}$ $(\sim 102 \mathrm{~m})$ in two areas, which is measurable using PSI. It is possible the Casitas Dam crest may have undergone both slumping and settlement. Slumping may account for relatively high deformation at location $2(-42 \mathrm{~mm})$ and settlement may be attributable to deformation 
at locations 1, 3, and 4, with more slumping in the middle of the crest (-16 mm) and less near the edges (-12 mm on south side; $-5 \mathrm{~mm}$ on north side near spillway).

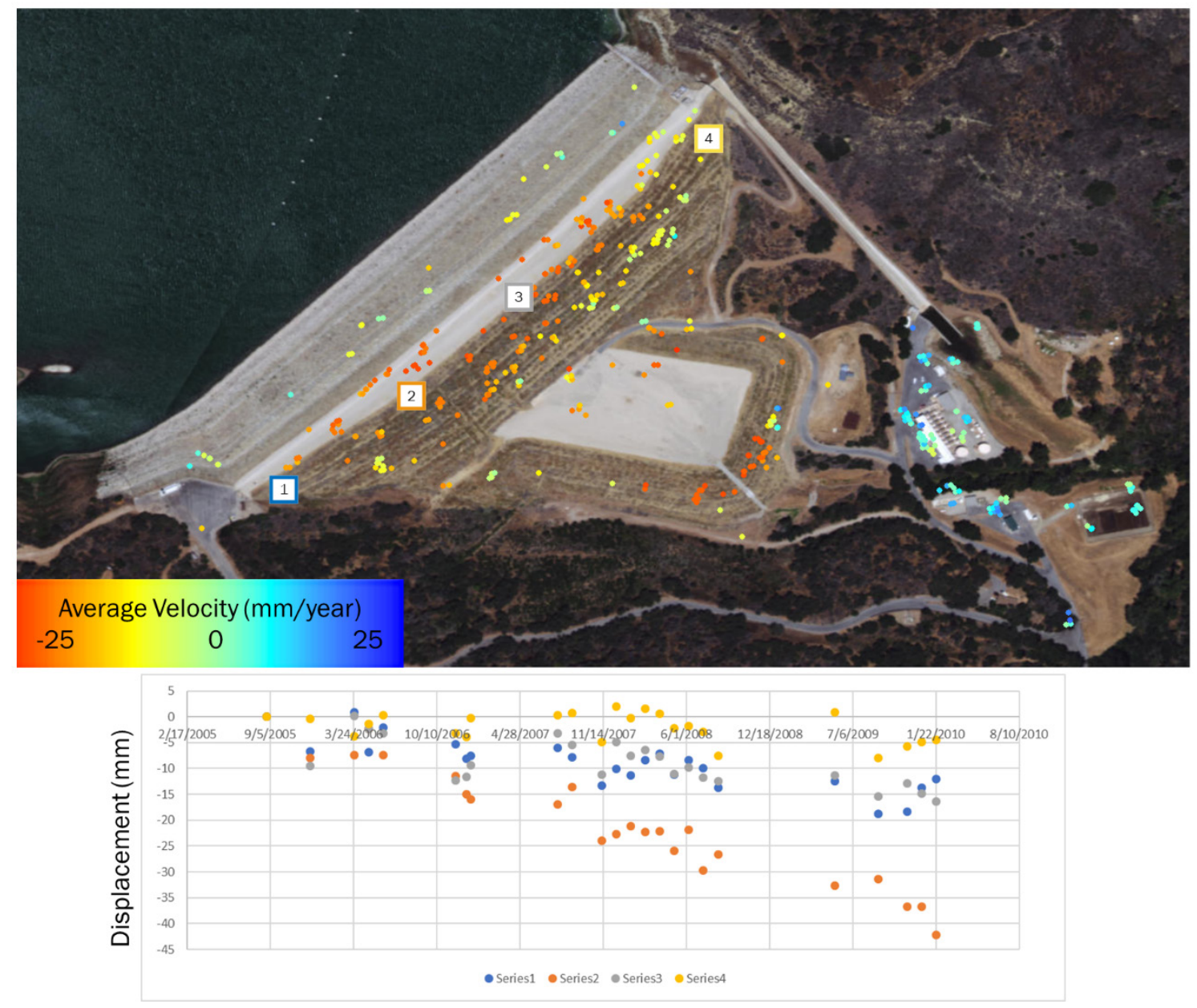

Figure 6.5: Displacement-time series at four locations across the Casitas Dam crest. Series\# at bottom of plot corresponds to location, e.g., Series1 (blue dots on plot) shows displacement-time series of location 1 (blue box). 


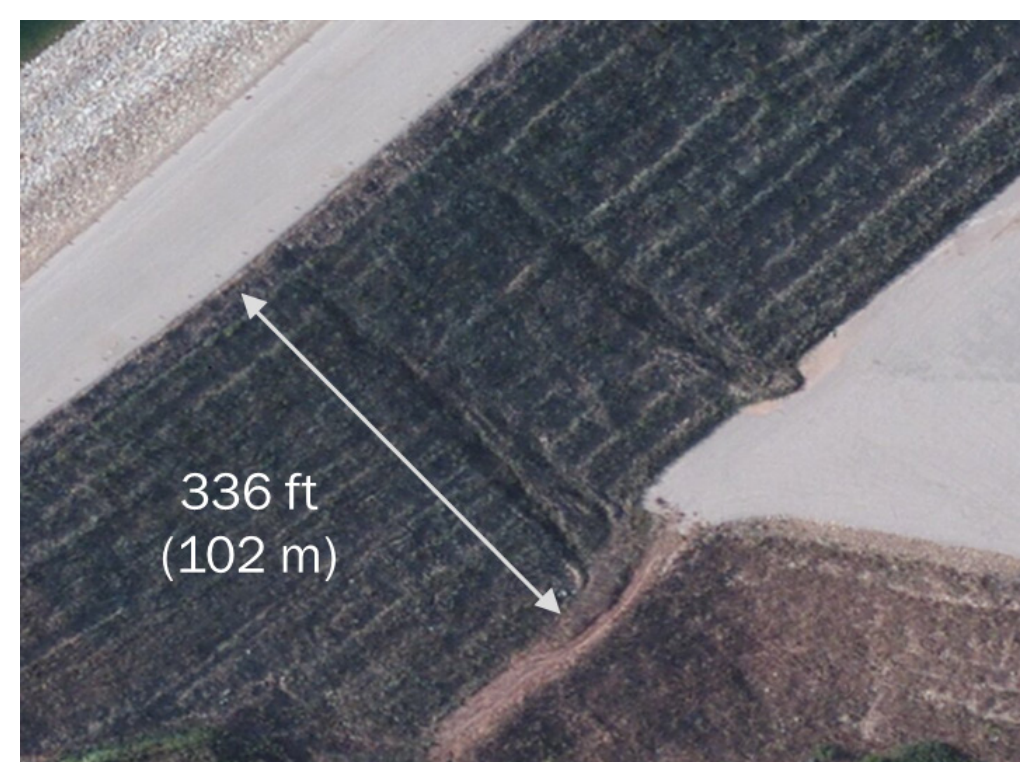

Figure 6.6: Close-up view of surface erosion and slumping on the crest.

Geospatial Kriging interpolation of PSI results is shown in Figure 6.6. The interpolation underestimates total displacement $(\mathrm{mm})$, but aids in visualization of the spatial distribution of significant deformation. Two areas of significant deformation are enhanced in the interpolation map: (1) linear deformation along length of crest, as discussed with displacement-time series analysis (Figure 6.5), and (2) deformation on the south side of the berm, which was not easily identifiable with PS points in Figure 6.4. The berm experienced greater downward deformation - as much as $-32 \mathrm{~mm}$ in the Kriging interpolation (as compared to $-22 \mathrm{~mm}$ on the crest). In addition, the berm shows no surficial evidence of deformation (Figure 6.7). This may be evidence of internal deformation, such as natural surface or foundational settlement, at a scale that is not visible to the human eye and may be below the measurement threshold of in situ instrumentation (e.g., mm-scale). 


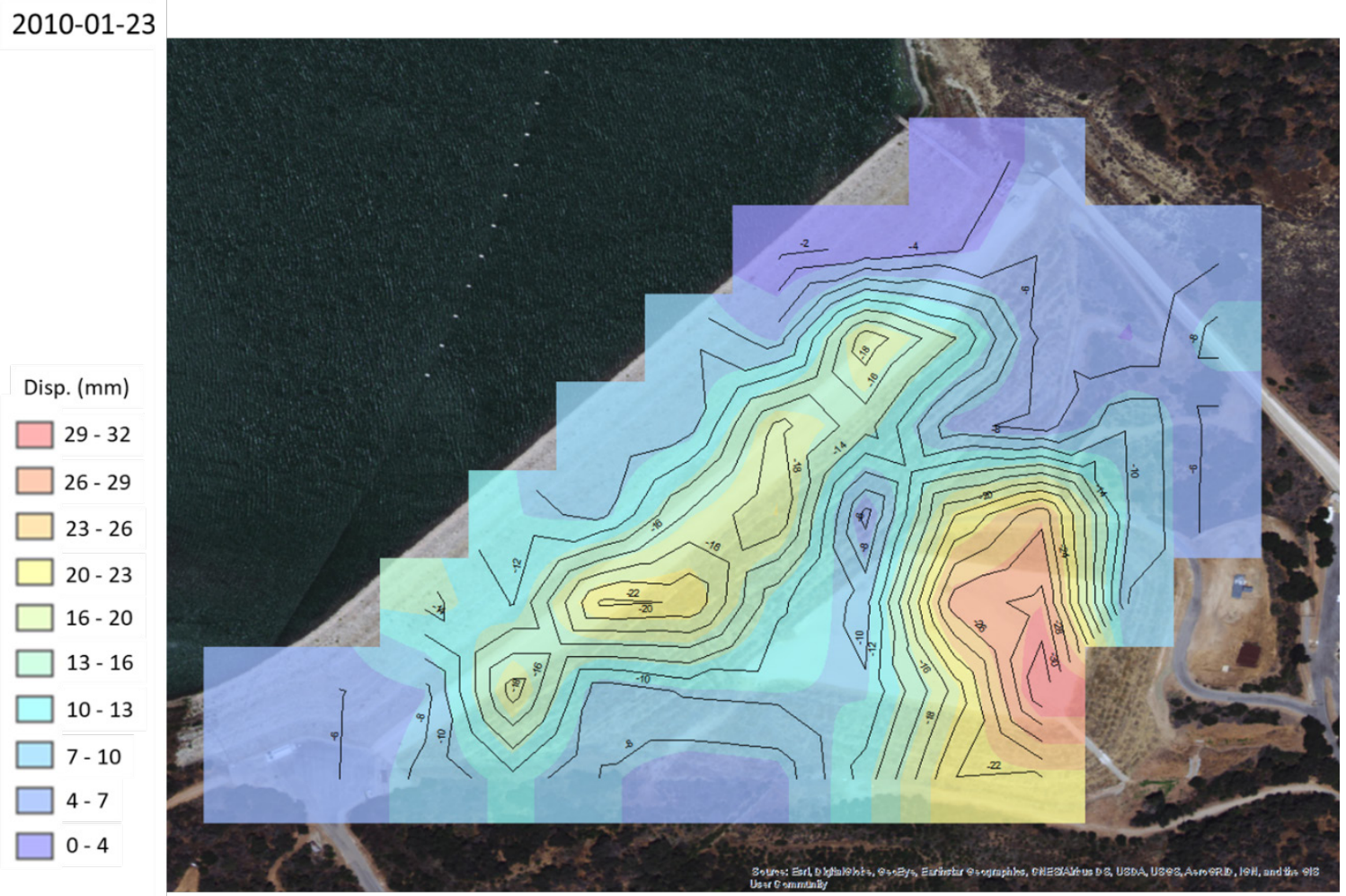

Figure 6.7: Kriging interpolation and contours of total displacement (mm) between September 4, 2005 and January 23, 2010. Contour intervals $=2 \mathrm{~mm}$. 


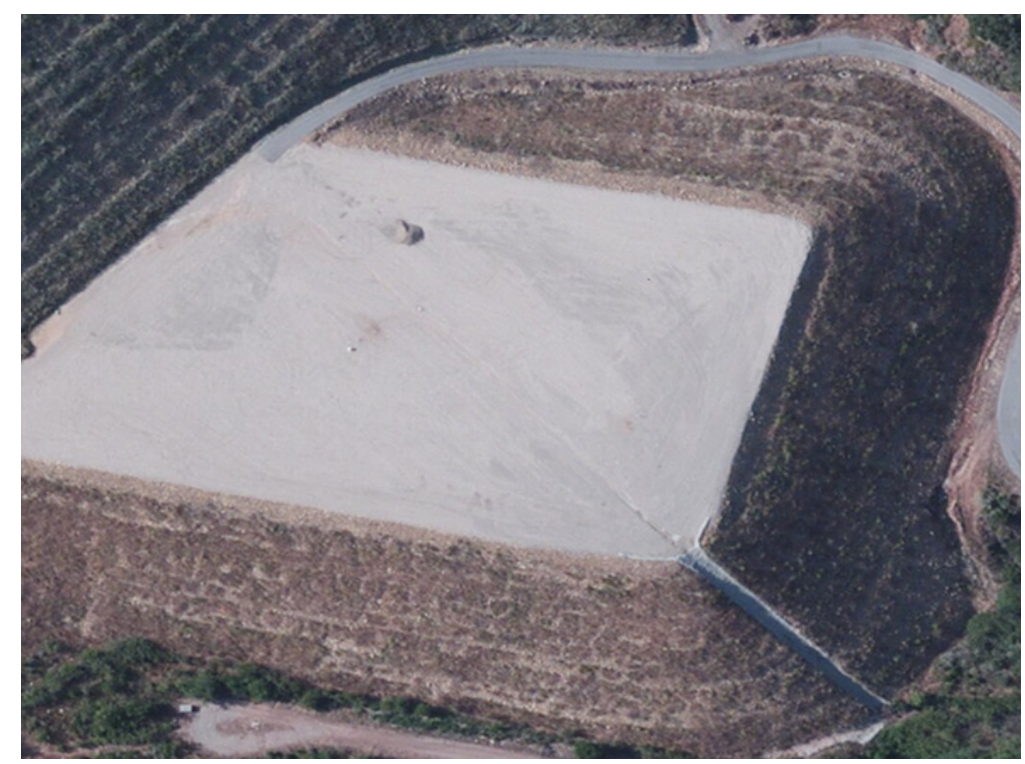

Figure 6.8: Close-up view of berm. There is no surface expression or indication of observed deformation.

\subsection{Future Work}

Embankment and berm settlement is a natural process that occurs over a dam's lifespan, as the fill material consolidates with time. Settlement may also be a portent indicating leakage or seepage (Sherard \& Dunnigan 1985). Dam settlement is heavily monitored and modeled during construction and shortly thereafter (Zhu et al. 2009; Wei \& Sun 2010). Dams should also be monitored throughout their life-cycle. The Federal Energy Regulatory Commission (FERC) Division of Dam Safety and Inspections recommend long-term embankment dam monitoring includes, among others, measurements on surface settlement, surface alignment, and foundation movement, which are all deformation variables (FERC 2006). Applications in remote sensing provide a perfect opportunity for long-term, post-construction dam monitoring. Interferometric Synthetic Aperture Radar (InSAR) has been successfully used to monitor deformation across many dam structures around the world (Grenerczy \& Wegmüller 2011; Chen et al. 2013; Tomás et al. 2013; Di Martire et al. 2014; Emadali et al. 2017). Therefore, the next step is to determine whether the deformation (measured using InSAR) at the Casitas Dam in California is attributable to material consolidation or if there is potential risk for future failure. 
Future research will focus on assessing the potential for using satellite-based radar imagery toward overall embankment and berm life-cycle monitoring. This includes inverse modeling and numerical analysis of InSAR measurements to help determine whether deformation observed on the Casitas Dam is due to natural settlement or other causes (e.g., foundation movement or internal erosion from piping). Different modeling approaches will be used to investigate potential causes of deformation and are listed as research objectives below:

Objective 1. Model three-dimensional embankment and berm consolidation using Rocscience RS3 and Settle3D software.

Objective 2. Model dam stability using three-dimensional finite element analysis (Rocscience RS3 and Slide software).

Objective 3. Model influences of Casitas Reservoir using transient state groundwater models (Rocscience RS3 software).

Objective 4. Combine the results from Objectives 1-3 and compare with InSAR deformation measurements. This will allow for the source of embankment and berm displacement to be isolated between natural settlement/consolidation, slope instability, and groundwater seepage.

\subsection{Conclusion}

PSI is a remote sensing technique that may supplement in situ measurements for long-term ground monitoring across embankment dams. There are many sensors currently available with better capabilities than presented in this chapter. High-resolution satellite imagery with a spatial resolution at $3 \mathrm{~m}$ (or better) is available from COSMO-SkyMed (see Chapters 7 and 8) and TerraSAR-X. High-resolution ground-based interferometry is a viable option as well (Monserrat et al. 2014) but requires base station installation. Current satellites also offer sub-weekly revisit periods and ground-based set-ups can yield hourly data measurements. Combined with traditional field methods, remote sensing offers a wonderful opportunity for long-term dam monitoring and the development of a deformation early warning system, e.g., deformation greater than a predetermined threshold will warrant additional, detailed field investigations. 


\title{
Chapter 7: Mapping of Slow Landslides on the Palos Verdes Peninsula using the California Landslide Inventory and Persistent Scatterer Interferometry ${ }^{20}$
}

\author{
El Hachemi Bouali ${ }^{21}$; Thomas Oommen, Ph.D., A.M.ASCE ${ }^{22}$; \\ and Rüdiger Escobar-Wolf, Ph.D. ${ }^{23}$
}

\subsection{Abstract}

Extremely slow landslides, those with a displacement rate $<16 \mathrm{~mm} / \mathrm{year}$, may be imperceptible without proper instrumentation. These landslides can cause infrastructure damage on a long-term timescale. The objective is to identify these landslides through the combination of information from the California Landslide Inventory (CLI) and ground displacement rates using results from Persistent Scatterer Interferometry (PSI), an interferometric synthetic aperture radar (InSAR) stacking technique, across the Palos Verdes Peninsula in California. A total of 34 ENVISAT radar images (acquired between 2005 and 2010) and 40 COSMO-SkyMed radar images (acquired between 2012 and 2014) were processed. An InSAR Landslide Inventory (ILI) is created using four criteria: minimum persistent scatterer (PS) count, average measured ground velocity, slope angle, and slope aspect. The ILI is divided into four categories: long term slides (LTSs),

\footnotetext{
${ }^{20}$ The material contained in this chapter was previously published in Landslides.

21 Department of Geological and Mining Engineering and Sciences, Michigan Technological Univ., 1400 Townsend Dr., Houghton, MI 49931 (corresponding author). E-mail: eybouali@mtu.edu

22 Department of Geological and Mining Engineering and Sciences, Michigan Technological Univ., 1400 Townsend Dr., Houghton, MI 49931. E-mail: toommen@mtu.edu

23 Department of Geological and Mining Engineering and Sciences, Michigan Technological Univ., 1400 Townsend Dr., Houghton, MI 49931. E-mail: rpescoba@mtu.edu
} 
potentially active slides (PASs), relatively stable slides (RSSs), and unmapped extremely slow slides (UESSs). These categories are based on whether landslides were previously mapped on that slope (in the CLI), if PSs are present, and whether PSs are unstable or stable. The final inventory includes 263 mapped landslides across the peninsula, of them 67 landslides were identified as UESS. Although UESS exhibit low velocity and are relatively small (average area of $8,865 \mathrm{~m}^{2}$ per slide), their presence in a highly populated area such as the Palos Verdes Peninsula could lead to destruction of infrastructure and property over the long term.

\subsection{Introduction}

Each landslide event has the potential to affect human lives in significant ways. The United States Geological Survey (USGS) estimates that landslides annually cause 25-50 deaths, $\$ 3.5$ billion in damages, reduced property values, loss of productivity, and destruction to natural environments in the United States alone (USGS 2005). The power release of a landslide is proportional to the product of its areal extent and velocity (Cruden and Varnes 1996). Many of these catastrophic landslides are large, exhibit rapid deformation, or both (Parise 2001; Hungr 2007; Lu et al. 2011). Slow landslides can also cause concern and raise long-term issues for residents and those who own property on the affected area. Terzaghi (1950) used the term "creep" to define landslides with a velocity $<30 \mathrm{~mm} / \mathrm{year}$. Cruden and Varnes (1996) developed a velocity scale, with "extremely slow" describing a velocity $<16 \mathrm{~mm} /$ year. These landslides are imperceptible without accurate instrumentation, and some structural damage may occur over a relatively prolonged period (e.g., longer than 10 years). Terminology from the Cruden and Varnes (1996) velocity scale is preferred for two reasons: (1) the term creep more recently took on a meaning that implies a variety of trigger mechanisms (e.g., USGS 2005) and (2) the velocity scale differentiates between extremely slow and "very slow" landslides, at a velocity of $16 \mathrm{~mm} / \mathrm{year}$, which is comparable to the velocity of slides investigated in this study. Extensive field research has laid the foundation for detailed landslide life-cycle management, which incorporates topics such as landslide characterization (Cruden 1991;

Cruden and Varnes 1996; Leroueil et al. 1996), hazard/risk evaluation and mapping 
(Carrara et al. 1991; Fell 1994; Finlay 1996; Fell and Hartford 1997; Morgenstern 1997; Parise 2001; Dai et al. 2002; Bouali et al. 2016b), long-term monitoring (Kousteni et al. 1999; Parise 2003), and failure prediction and modeling (Scheideggar 1973; van Westen et al. 1997; Chung and Fabbri 1999).

Remote sensing - specifically interferometric synthetic aperture radar (InSAR) techniques such as Persistent Scatterer Interferometry (PSI) - have become more widespread, especially in the last 15 years, in approaches for landslide life-cycle management (Catani et al. 2005; Colestanti and Wasowski 2006; Mazzanti et al. 2012; Bianchini et al. 2013; Tofani et al. 2013) with some studies emphasizing slow-moving landslide management (Cascini et al. 2013; Lu et al. 2014). Recent InSAR applications include the quantification of landslide activity (Cigna et al. 2013; Calvello et al. 2017), characterization of landslides in urbanized areas (Gullà et al. 2017), landslides along volcanic margins (Schaefer et al. 2015; Schaefer et al. 2016; Schaefer et al. 2017), identification of landslides with small areal extent (Zhao et al. 2016), and the creation of landslide inventory (Casagli et al. 2017; Novellino et al. 2017). The purpose of this paper is to demonstrate an approach to update a preexisting landslide inventory of extremely slow landslides by incorporating PSI results obtained from recent InSAR data acquired from satellites between 2005 and 2014. The final output is an updated landslide inventory that includes these previously unmapped landslides which can be verified through targeted field inspections as part of a recurring landslide life-cycle management procedure.

\subsection{Study Site}

The Palos Verdes Peninsula is in the southwestern corner of Los Angeles County, California, west of the Port of Los Angeles (Figure 7.1). Geology of the peninsula can be

divided into five general rock types: Franciscan Complex metamorphic rocks (KJf), intrusive igneous rocks (Ti5), marine sedimentary rocks (MI), alluvium (Q), and landslide deposits (Q1s). These rock types are shown in Figure 7.1 and described in further detail in Table 7.1 using information originally from the Geologic Map of California (Jennings et al. 1977). 
A variety of tectonic and natural hazard activities have been documented on the Palos Verdes Peninsula (geological features discussed are shown in Figure 7.1). The basement rock of the peninsula is composed of schist and volcanic rock that has undergone various degrees of metamorphism (Merriam 1960). Regional uplift of this basement rock is evidenced by 13 wave-cut marine terraces located on the peninsula above sea level (Kayen et al. 2002). Two major faults, striking northwest-southeast, cross the peninsula: the Cabrillo Fault and Palos Verdes Fault. The Wilmington Anticline axis trends northwestsoutheast and, along with the major faults, creates the southwest boundary of the Los Angeles Basin (Woodring et al. 1946; Wright 1991; Fisher et al. 2004). Surface lineaments throughout the peninsula correspond with subsurface faulting (Stephenson et al. 1995). The Monterey Formation overlies the basement rock, and the lowest member is the Altamira Shale which is several hundred feet thick (Merriam 1960; Vonder Linden and Lindvall 1982). Many landslides occur within this member. These slides generally exhibit translational movement when strata, composed of Altamira Shale and younger material on top, slide along seaward dipping bedding planes that are surrounded by bentonite clay (Merriam 1960; Vonder Linden and Lindvall 1982; CRPV 2012). Secondary slumping is propagating upslope behind these slides (CRPV 2012). Although several landslides have been individually identified across the Palos Verdes Peninsula, all landslides on the peninsula will be collectively referred to as the Palos Verdes Hills Landslide Complex, or PVHLC, for simplicity. 


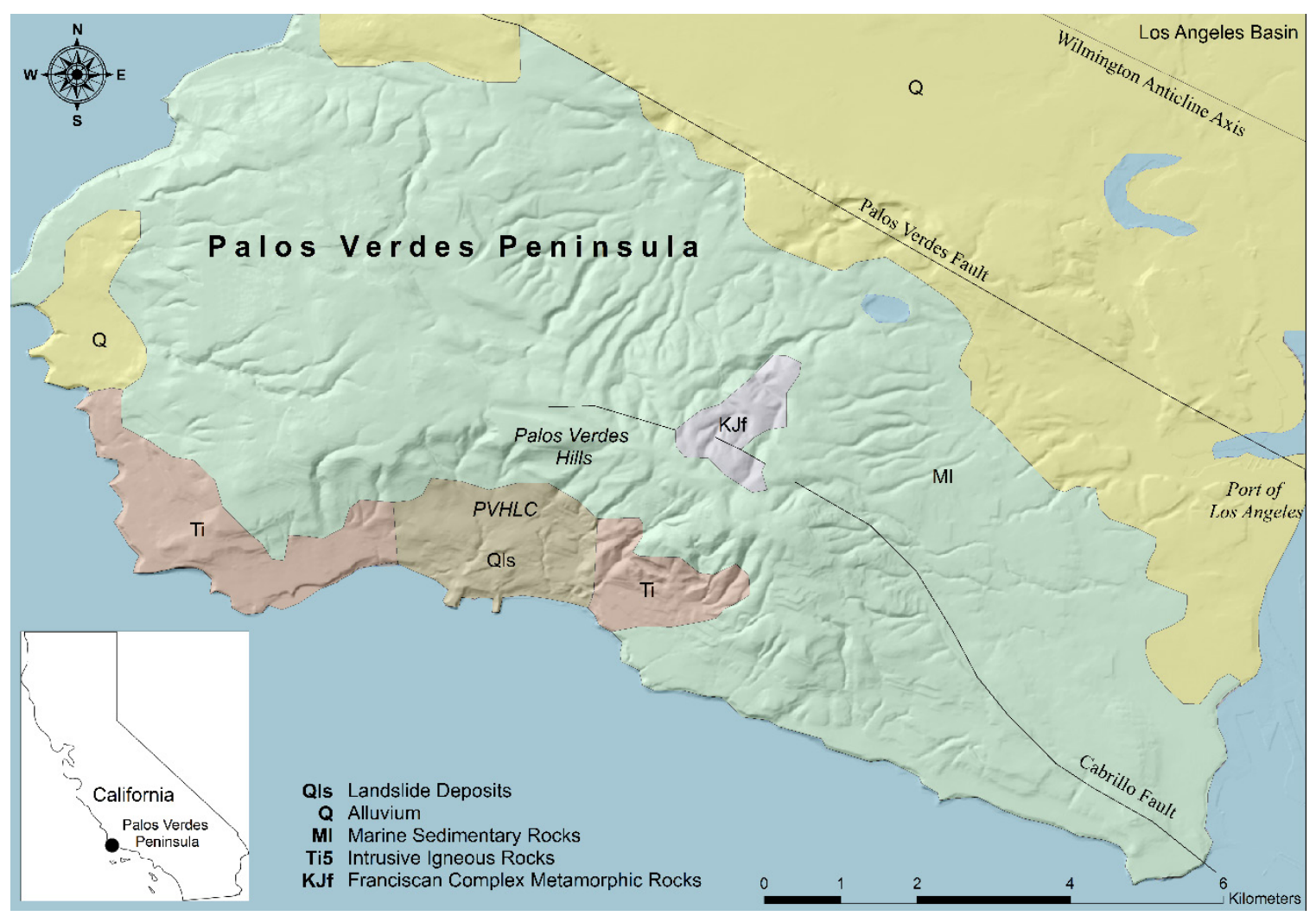

Figure 7.1: Geologic (Jennings et al. 1977) and hillshade map (USGS 2017) of the Palos Verdes Peninsula in California. The hillshade map is derived from a 10-m NED DEM with illumination azimuth of $315^{\circ}$ and altitude of $45^{\circ}$. 
Table 7.1: Descriptions of geological units on the Palos Verdes Peninsula.

\begin{tabular}{|c|c|c|c|c|}
\hline $\begin{array}{l}\text { Map } \\
\text { Symbol }\end{array}$ & Unit Name & $\begin{array}{l}\text { Unit Age } \\
\text { (Epoch) }\end{array}$ & Unit Description & $\begin{array}{l}\text { Number of } \\
\text { Formations }\end{array}$ \\
\hline Q1s & $\begin{array}{l}\text { Landslide } \\
\text { Deposits }\end{array}$ & $\begin{array}{l}\text { Holocene to } \\
\text { Pleistocene }\end{array}$ & Select large landslides & --- \\
\hline Q & Alluvium & $\begin{array}{l}\text { Holocene to } \\
\text { Pliocene }\end{array}$ & $\begin{array}{l}\text { Alluvium, lake, playa, and } \\
\text { terrace deposits; unconsolidated } \\
\text { and semi-consolidated. Mostly } \\
\text { non-marine, but includes marine } \\
\text { deposits near coast }\end{array}$ & 34 \\
\hline MI & $\begin{array}{l}\text { Marine } \\
\text { Sedimentary } \\
\text { Rocks }\end{array}$ & $\begin{array}{l}\text { Pliocene to } \\
\text { Oligocene }\end{array}$ & $\begin{array}{l}\text { Sandstone, shale, siltstone, } \\
\text { conglomerate, and breccia that } \\
\text { underwent blueschist-grade } \\
\text { metamorphism }\end{array}$ & 21 \\
\hline Ti5 & $\begin{array}{l}\text { Intrusive Igneous } \\
\text { Rocks }\end{array}$ & $\begin{array}{l}\text { Miocene(?) } \\
\text { to Late } \\
\text { Cretaceous }\end{array}$ & $\begin{array}{l}\text { Intrusive rocks, mostly shallow, } \\
\text { hypabyssal plugs and dikes }\end{array}$ & --- \\
\hline KJf & $\begin{array}{l}\text { Franciscan } \\
\text { Complex } \\
\text { Metamorphic } \\
\text { Rocks } \\
\end{array}$ & $\begin{array}{l}\text { Early to } \\
\text { Late } \\
\text { Cretaceous }\end{array}$ & $\begin{array}{l}\text { Sandstone with some shale, } \\
\text { chert, limestone, and } \\
\text { conglomerate }\end{array}$ & 1 \\
\hline
\end{tabular}

Geomorphological evidence of ancient landslides abounds the Palos Verdes Peninsula (Merriam 1960). Recently, portions of the PVHLC were reactivated due to infrastructure construction in 1956 (Ehlig 1982) and shortly thereafter began moving centimeters per day (Vonder Linden 1989). Landslide movement accelerated due to heavy rainfall in 1978 (Ehlig and Bean 1982) and lead to the installation of pumping wells, which were turned on to reduce groundwater levels in specified areas of the PVHLC (Kayen et al. 2002). Calabro et al. (2010) measured seasonal displacement rates across the PVHLC from 1995 through 2000 using InSAR and Global Positioning System (GPS) techniques, calculating an average summer displacement rate of $\sim 1 \mathrm{~m} / \mathrm{year}$ using InSAR and $1.17 \mathrm{~m} /$ year using GPS. The average winter deformation rate was above $2.6 \mathrm{~m} /$ year (measured using InSAR). The increase in PVHLC movements correlates with the timing of the wet season. In 2011, the cities of Rancho Palos Verdes and Los Angeles required roads by the sea to be repaired, replaced, or rerouted due to landslide activity (CRPV 2012; CLA 2016). 


\subsection{Data}

\subsubsection{California Landslide Inventory}

The California Geological Survey (CGS) is compiling and digitizing landslide maps to form a statewide database called the California Landslide Inventory (CLI). The CLI includes many landslides mapped by the CGS and other sources since the 1960s. The objective is to make California landslide data available to the public. The CLI database displays the spatial extent and individual records for each landslide, including landslide type, known event date(s) and current activity status, direction of movement, confidence level of landslide interpretations, and citations to the original source material. Figure 7.2 shows landslide locations mapped on the Palos Verdes Peninsula. The beta version of the CLI is available on a web-based GIS and is continuously updated (CGS 2017, see citation for URL).

\subsubsection{Satellite Radar Imagery}

PSI is an InSAR stacking technique where at least 20 single look complex (SLC) synthetic aperture radar (SAR) images are processed to measure ground deformation on relatively stable scatterers (Ferretti et al. 2000; Ferretti et al. 2001; Constantini et al. 2008; Crosetto et al. 2008). Extremely slow landslides, those moving less than $16 \mathrm{~mm} /$ year (Cruden and Varnes 1996), are detectable using PSI because their extremely slow nature allows the algorithm to identify individual persistent scatterers (PSs). PS may include anthropogenic structures (e.g., buildings, transportation infrastructure, pipelines) and natural features (e.g., rock outcrops with no or light vegetation). PSI can measure ground deformation at an accuracy of $1 \mathrm{~mm} /$ year (Ferretti et al. 2000; Ferretti et al. 2001; Crosetto et al. 2016). SLC SAR image stacks acquired from two satellites, ENVISAT and COSMOSkyMed, are processed separately through identical PSI steps using ENVI SARscape ${ }^{\mathrm{TM}}$ software (Sarmap 2009). Two satellites are chosen to increase landslide observation time (Table 7.2). PSI works well over urban areas, which aids in the identification of extremely 
slow landslides in regions of heavy infrastructure where they may be difficult to detect (Bouali et al. 2016a).

ENVISAT, operated by the European Space Agency (ESA), was launched on March 1, 2002 and was active until May 9, 2012. It followed a Sun-synchronous polar orbit and had a revisit time of 35 days. The ASAR instrument operated at a frequency of 5.331 GHz (5.6 cm wavelength in C-band). 34 SLC SAR images, acquired in descending direction between November 11, 2005 and October 14, 2010 (Table 7.2) in image mode at a resolution of $\sim 20 \mathrm{~m}$, were obtained from the ESA.

COSMO-SkyMed, the Constellation of small Satellites for the Mediterranean basin Observation, is a group of four identical satellites, COSMO-1, -2, -3, and -4, launched on June 8, 2007, December 9, 2007, October 25, 2008, and November 5, 2010, respectively. Operated by the Italian Space Agency (ASI), all satellites are currently active and follow a Sun-synchronous polar orbit with individual revisit times of 16 days and a collective revisit time of less than 15 days. The SAR antennas operate at a frequency of $9.6 \mathrm{GHz}(3.1 \mathrm{~cm}$ wavelength in X-band). 40 SLC SAR images, acquired in the descending direction between July 19, 2012 and September 27, 2014 (Table 7.2) in STRIPMAP HIMAGE mode at a resolution of $3 \mathrm{~m}$, were obtained from the ESA. 


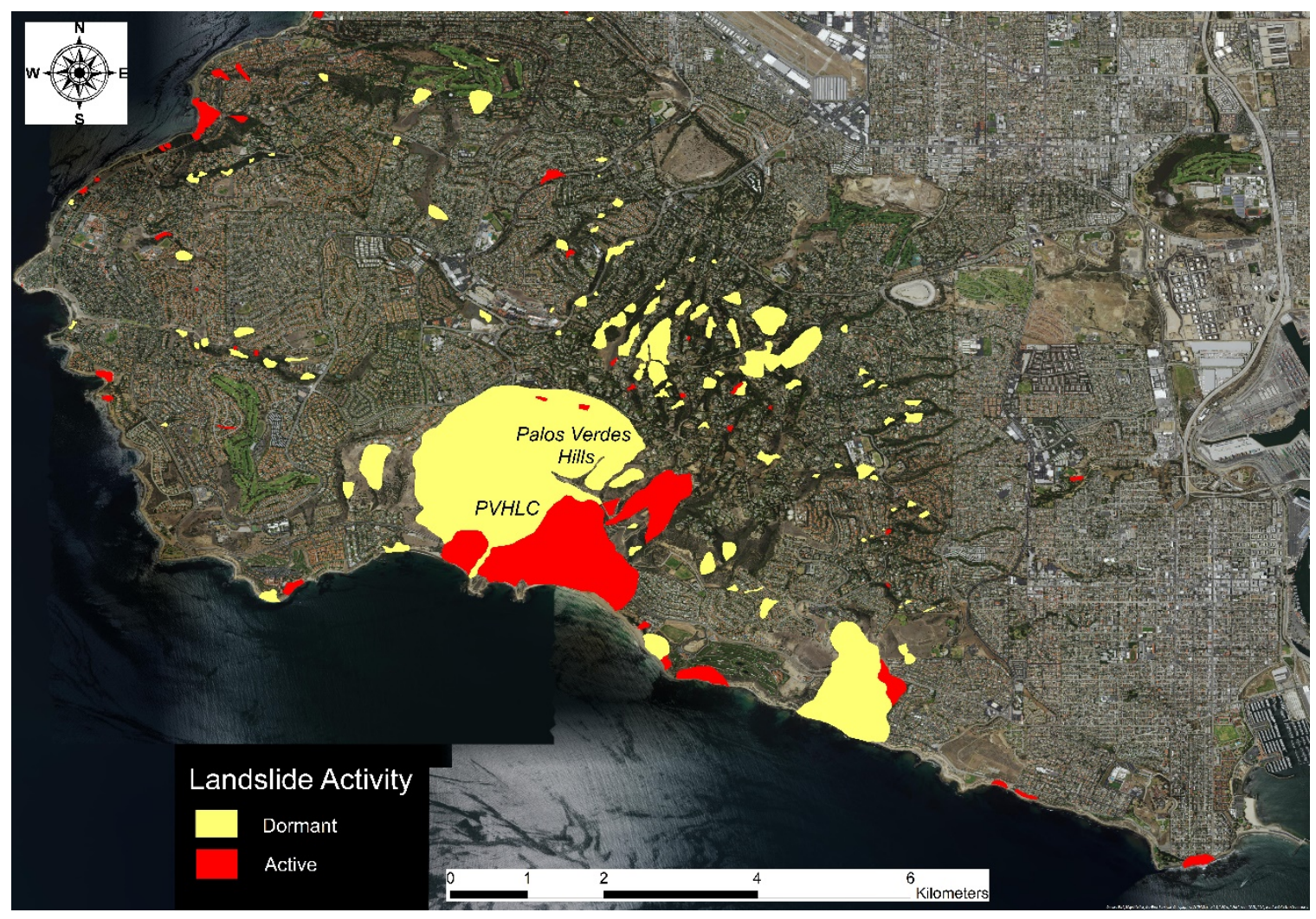

Figure 7.2: Dormant (yellow) and active (red) landslides mapped in the CLI across the Palos Verdes Peninsula (same areal extent as Figure 7.1). The landslides on the Palos Verdes Peninsula are all categorized as 'rock slides' in the CLI (CGS 2017). 
Table 7.2: A complete list of acquisition dates for the 34 ENVISAT (descending) and 40 COSMO-SkyMed (descending) SLC images used in this study.

\begin{tabular}{|c|c|}
\hline $\begin{array}{l}\text { ENVISAT } \\
\text { Acquisition Dates }\end{array}$ & $\begin{array}{l}\text { COSMO-SkyMed } \\
\text { Acquisition Dates }\end{array}$ \\
\hline Nov 24,2005 & Jul 19, 2012 \\
\hline Mar 09, 2006 & Aug 04, 2012 \\
\hline May 18,2006 & Aug 20, 2012 \\
\hline Jun 22, 2006 & Sep 04, 2012 \\
\hline Oct 05,2006 & Oct 07,2012 \\
\hline Nov 09, 2006 & Oct 23,2012 \\
\hline Jul 12, 2007 & Nov 08,2012 \\
\hline Aug 16, 2007 & Nov 24,2012 \\
\hline Sep 20, 2007 & Dec 10,2012 \\
\hline Nov 29, 2007 & Dec 26,2012 \\
\hline Feb 07, 2008 & Jan 01, 2013 \\
\hline Mar 13, 2008 & Jan 27, 2013 \\
\hline Apr 17,2008 & Feb 12, 2013 \\
\hline May 22,2008 & Feb 28, 2013 \\
\hline Jun 26,2008 & Mar 16, 2013 \\
\hline Jul 31, 2008 & Apr 17, 2013 \\
\hline Sep 04, 2008 & May 03, 2013 \\
\hline Dec 18, 2008 & May 19,2013 \\
\hline Jan 22, 2009 & Jun 20,2013 \\
\hline Apr 02, 2009 & Jul 06, 2013 \\
\hline May 07, 2009 & Jul 22, 2013 \\
\hline Jun 11, 2009 & Aug 27, 2013 \\
\hline Aug 20, 2009 & Sep 24, 2013 \\
\hline Sep 24, 2009 & Oct 10,2013 \\
\hline Oct 29,2009 & Nov 11,2013 \\
\hline Dec 03, 2009 & Nov 27,2013 \\
\hline Jan 07, 2010 & Dec 13, 2013 \\
\hline Feb 11,2010 & Dec 29, 2013 \\
\hline Apr 22, 2010 & Jan 30, 2014 \\
\hline May 27,2010 & Feb 15,2014 \\
\hline Jul 01, 2010 & Mar 19, 2014 \\
\hline Aug 05, 2010 & Apr 04, 2014 \\
\hline Sep 09,2010 & Apr 20, 2014 \\
\hline \multirow[t]{7}{*}{ Oct 14,2010} & May 06, 2014 \\
\hline & May 22,2014 \\
\hline & Jun 07, 2014 \\
\hline & Jul 25, 2014 \\
\hline & Aug 10, 2014 \\
\hline & Sep 11, 2014 \\
\hline & Sep 27, 2014 \\
\hline
\end{tabular}




\subsubsection{Direction and Magnitude of Deformation Rate}

Deformation rate, a velocity vector, is defined by direction and magnitude components. Velocity can only be measured in the line-of-sight (LOS) direction (Ferretti et al. 2000), which is described by two variables: (1) incidence angle - the angle between vertical (normal) and the transmitted radar beam $\left(0^{\circ}=\right.$ vertical; $90^{\circ}=$ horizontal $)$, and (2) azimuth angle - the compass direction the radar beam is transmitted from the satellite. Local LOS for ENVISAT is $\sim 21^{\circ}$ incidence at $N 85^{\circ} \mathrm{W}$ and for COSMO-SkyMed is $\sim 27^{\circ}$ incidence at $\mathrm{N} 85^{\circ} \mathrm{W}$. Positive average velocity $(\bar{V}>0)$ indicates ground movement in a direction toward the satellite, such as uplift (vertical component) or relatively large eastward direction (horizontal component); negative average velocity $(\bar{V}<0)$ indicates ground movement in a direction away from the satellite, such as a landslide/subsidence (vertical component) or relatively large westward deformation (horizontal component).

One-dimensional LOS measurement is a limiting factor when the goal is to create/update a landslide inventory along slopes of variable orientations and geometries. It is important to acknowledge that not all landslides may be identified using a stack of satellite imagery from one LOS direction-for example, west facing slopes on steep topography may not be viewable using ENVISAT and COSMO-SkyMed incidence and azimuth angles — and thus, field investigations may be necessary to create a more complete inventory (e.g., CLI). Many recent studies have demonstrated various methodologies used to overcome the LOS limitation for various steps in the landslide life-cycle management procedure (Notti et al. 2010; Bianchini et al. 2013; Cascini et al. 2013; Cigna et al. 2013; Herrara et al. 2013; Tofani et al. 2013; Lu et al. 2014; Zhao et al. 2016; Calvello et al. 2017; Casagli et al. 2017; Gullà et al. 2017; Schulz et al. 2017).

\subsection{Methodology}

The methodology follows the workflow provided in Figure 7.3. ENVISAT and COSMO-SkyMed radar images are acquired and processed. The processing results are then combined to generate the InSAR Landslide Inventory (ILI). Four criteria are used to identify slopes prone to landslides: PS number, average velocity, slope angle, and slope aspect. The methodology workflow is described in greater detail below. 


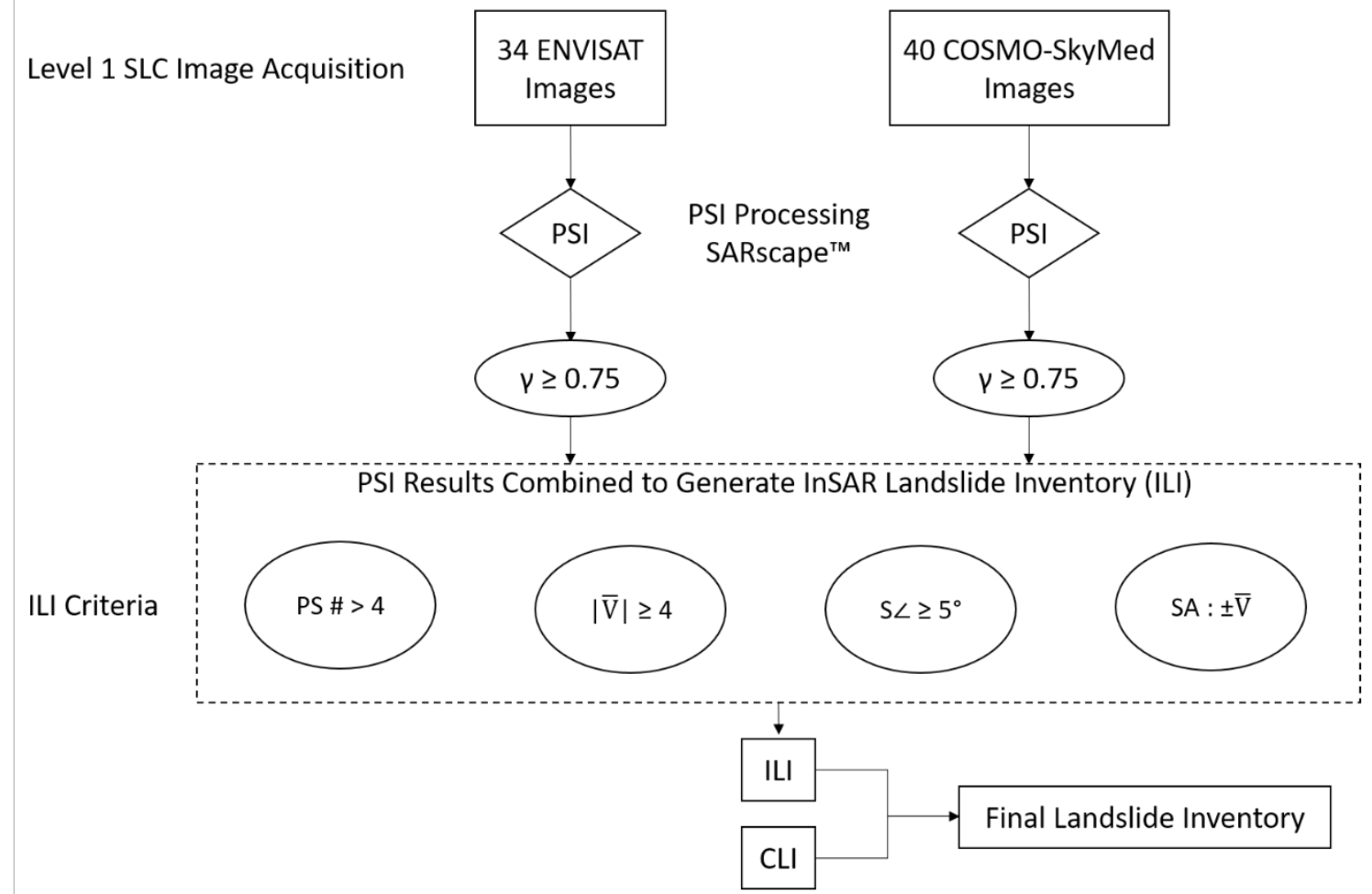

Figure 7.3: Workflow of methodological approach (see text for description of each step). Data and deliverables are shown in rectangles, processing steps in diamonds, and filtering criteria - which include coherence $(\gamma)$, PS number (PS \#), average velocity $(|\bar{V}|$, in mm/year), slope angle $(S \angle)$, and slope azimuth $(S A)$ - are displayed in ovals.

The level 1 SLC radar images acquired from ENVISAT and COSMO-SkyMed are processed in separate stacks using the interferometric stacking PSI workflow in ENVI SARscape $^{\mathrm{TM}}$ (Sarmap 2009). The ENVI SARscape ${ }^{\mathrm{TM}}$ workflow is built to process radar images with algorithms created by previous studies (Gatelli et al. 1994; Göblirsch and Pasquali 1996; Holecz et al. 1997; Reigber and Moreira 1997; Constantini 1998; Goldstein and Werner 1998; Ferretti et al. 2000; Ferretti et al. 2001; Berardino et al. 2002; Baran et al. 2003; Guarnieri et al. 2003; Hooper et al. 2004; Ghulam et al. 2010). PSI results are filtered to only include PS with a coherence $(\gamma) \geq 0.75 . \gamma$, the value of which is assigned to each PS and ranges between 0 (high noise or decorrelation) and 1 (no noise), quantifies the quality of the displacement measurement and is indirectly proportional to "systemic spatial 
decorrelation, additive noise, and the scene decorrelation that takes place between the acquisitions" (Sarpmap 2009, p. 163). Other studies considered coherence values reliable at $\gamma>0.50$ (Zhao et al. 2016), $\gamma \geq 0.60$ (Bianchini et al. 2013; Jones et al. 2016), and $\gamma \geq 0.65$ (Novellino et al. 2017); thus, the threshold of $\gamma \geq 0.75$ used in this study can be considered relatively strict.

The PSI results from both stacks (ENVISAT and COSMO-SkyMed) are combined, and potential landslides - to be included in the ILI — are identified based on four criteria: PS number, average velocity, slope angle, and slope aspect.

- Criterion 1. There must be more than four PS on a slope to be considered for further analysis (PS \# > 4; Figure 7.3). Bianchini et al. (2013) compared the number of landslides with PS \# $\geq 1$ and PS \# $>4$ and noticed a decrease of $1 / 2$ in the number of landslides identified when using the increased PS number requirement.

- Criterion 2. The PS identified from criterion 1 must exhibit an average velocity $\geq 4 \mathrm{~mm} /$ year - the minimum velocity required for the extremely slow landslide classification by Cruden and Varnes (1996) — with $\operatorname{sign}(\bar{V} \geq 4 \mathrm{~mm} /$ year, Figure 7.3) depending on the slope aspect (see criterion 4).

- Criterion 3. The PS identified from criterion 1 must also be located on a slope with a surface angle greater than $5^{\circ}$ from horizontal ( $\angle \geq 5^{\circ}$; Figure 7.3). Both the NED DEM and the ASTER global DEM were used to calculate surface angles of the topography across the Palos Verdes Peninsula. A slope angle of $5^{\circ}$ was chosen as the threshold for two reasons: (1) there exist many portions of the active PVHLC with a $6.3^{\circ}$ slope angle and a material friction angle of $6^{\circ}$ (Calabro et al. 2010) and (2) the dip of PVHLC rupture surfaces range from $5^{\circ}$ to $10^{\circ}$ toward the ocean (McNulty 2010).

- Criterion 4. Slopes that pass the previous three criteria are considered landslides if the slope aspect (SA), defined as the azimuth direction the slope dips, matches the sign of PS average velocity (SA: $\pm \bar{V}$; Figure 7.3). PS on west facing slopes must have a negative average velocity, which indicates ground movement away from the 
satellite. PS on east facing slopes must have a positive average velocity, which indicates ground movement toward the satellite.

The spatial extent of potential landslides from the ILI is then compared to the mapped landslides from the CLI. A final landslide inventory is created by merging the CLI and ILI. Landslide regions are then separated into four categories. (1) Long term slides (LTS) are those identified in both CLI and ILI. (2) Potentially active slides (PAS) are those identified only in CLI and no PSs were measured in the area, indicating decorrelation due to rapid ground movement or radiometric characteristics of the ground (Simons and Rosen 2007). (3) Relatively stable slopes (RSS) are those identified only in CLI and the presence of stable PS $(|\bar{V}|<4 \mathrm{~mm} /$ year) indicate a relatively stable slope. (4) Unmapped extremely slow slides (UESS) are those identified only in the ILI.

\subsection{Results and Discussion}

PSI results from ENVISAT and COSMO-SkyMed SLC SAR image stacks are shown in Figures 7.4 and 7.5, respectively. Of the PSs, 82,085 were located using the ENVISAT stack, and 808,010 PSs were located using the COSMO-SkyMed stack. The order of magnitude difference is likely due to spatial resolution ( $3 \mathrm{~m}$ for COSMO-SkyMed and $20 \mathrm{~m}$ for ENVISAT) and temporal image density (1 image every 20 days for COSMO-SkyMed and $\sim 53$ days for ENVISAT). More PSs were found in vegetated regions using the ENVISAT stack compared to the COSMO-SkyMed stack, which is a function of wavelength since decorrelation is more common in vegetation for short-wavelength sensors. For example, no PSs were found in the north-central section of the study area (region of decorrelation in Figure 7.5). The PSI technique underperformed in this region due to temporal decorrelation from dense vegetation and short X-band wavelength, as described by Wei and Sandwell (2010). In contrast, the COSMO-SkyMed stack obtained very high PS density ( $>500 \mathrm{PS} / \mathrm{km}^{2}$ ) in urban areas (both east and west portions of Figure 7.5). The ENVISAT stack obtained an average PS density $\left(\sim 100-200 \mathrm{PS} / \mathrm{km}^{2}\right)$ in urban areas. 


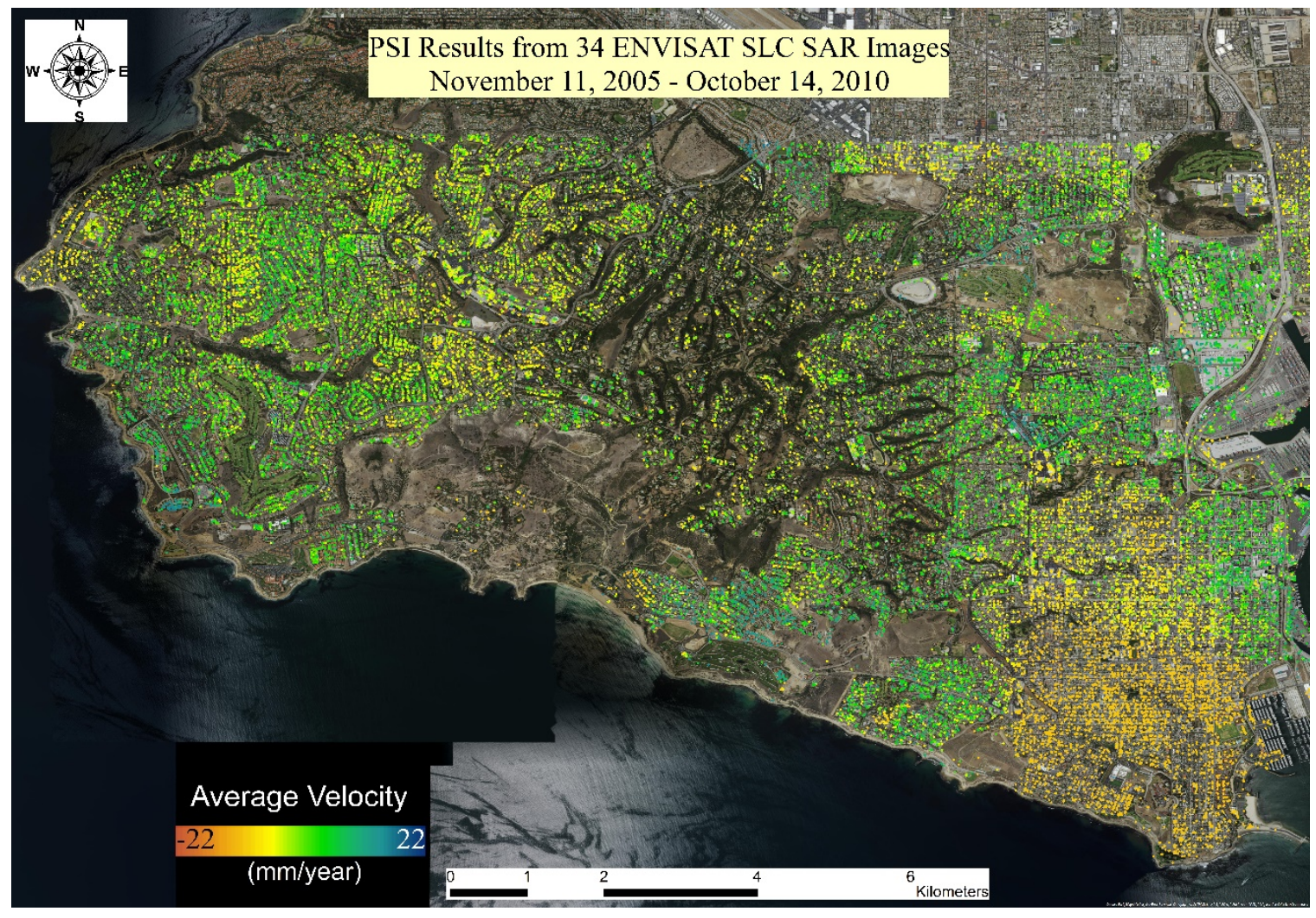

Figure 7.4: PSI results across the Palos Verdes Peninsula from 34 ENVISAT SLC SAR images (same areal extent as Figure 7.1). Average velocity values range from -22 mm/year (away from the satellite; red) to $22 \mathrm{~mm} /$ year (toward the satellite; blue), with yellow-green indicating stable PS. 


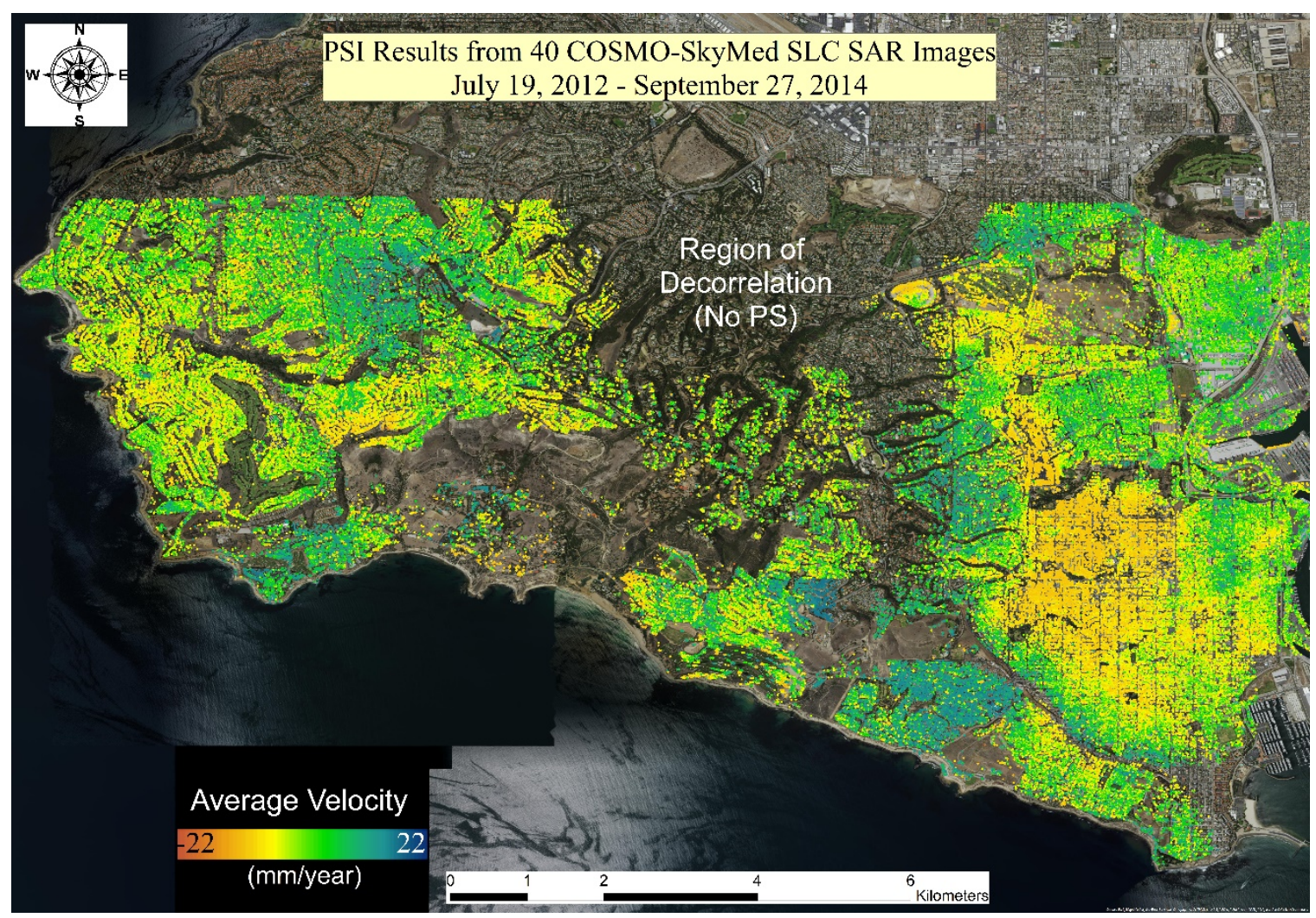

Figure 7.5: PSI results across the Palos Verdes Peninsula from 40 COSMO-SkyMed SLC SAR images (same areal extent as Fig 7.1). Average velocity values range from $-22 \mathrm{~mm} /$ year (away from the satellite; red) to $22 \mathrm{~mm} /$ year (toward the satellite; blue), with yellow-green indicating stable PS. No PS are measurable in the 'Region of Decorrelation' because of PSI limitations using a short X-band wavelength in a vegetated region.

Displacement time series from four continuous GPS stations on the Palos Verdes Peninsula - PVRS, PVHS, PVE3, and VTIS - were used to validate PSI results. GPS data were downloaded from UNAVCO's Digital Archive Interface (version 2). Each GPS time series is compared to the times series of the nearest PS from each satellite (Figure 7.6). GPS and PS locations are provided in Table 7.3. Three-component GPS measurements (vertical, north, and east) are converted to satellite $\operatorname{LOS}\left(\sim 23^{\circ}\right.$ from vertical in the $\mathrm{N} 85^{\circ} \mathrm{W}$ azimuth direction). Tectonic trends were subtracted from the north and east GPS components. Displacement time series from COSMO-SkyMed PS fall within GPS timeseries range at all four stations, while there is less correlation between ENVISAT PS and 
GPS (Table 7.4). If the GPS time series is considered the baseline, PSI results from COSMO-SkyMed are more accurate than ENVISAT. This could be caused by two factors. First, more COSMO-SkyMed SLC SAR images were acquired over a shorter period (greater temporal image density), which increases the coherence and signal-to-noise ration of the processing stack. Second, COSMO-SkyMed PSs tend to be more proximal to respective GPS stations; the average distance between COSMO-SkyMed PS and GPS stations is $36.25 \mathrm{~m}$, while the average distance between ENVISAT PS and GPS stations is $86.25 \mathrm{~m}$ (values averaged from Table 7.3). There is a possibility that PS and GPS measure dissimilar sources of displacement if they are too far apart.

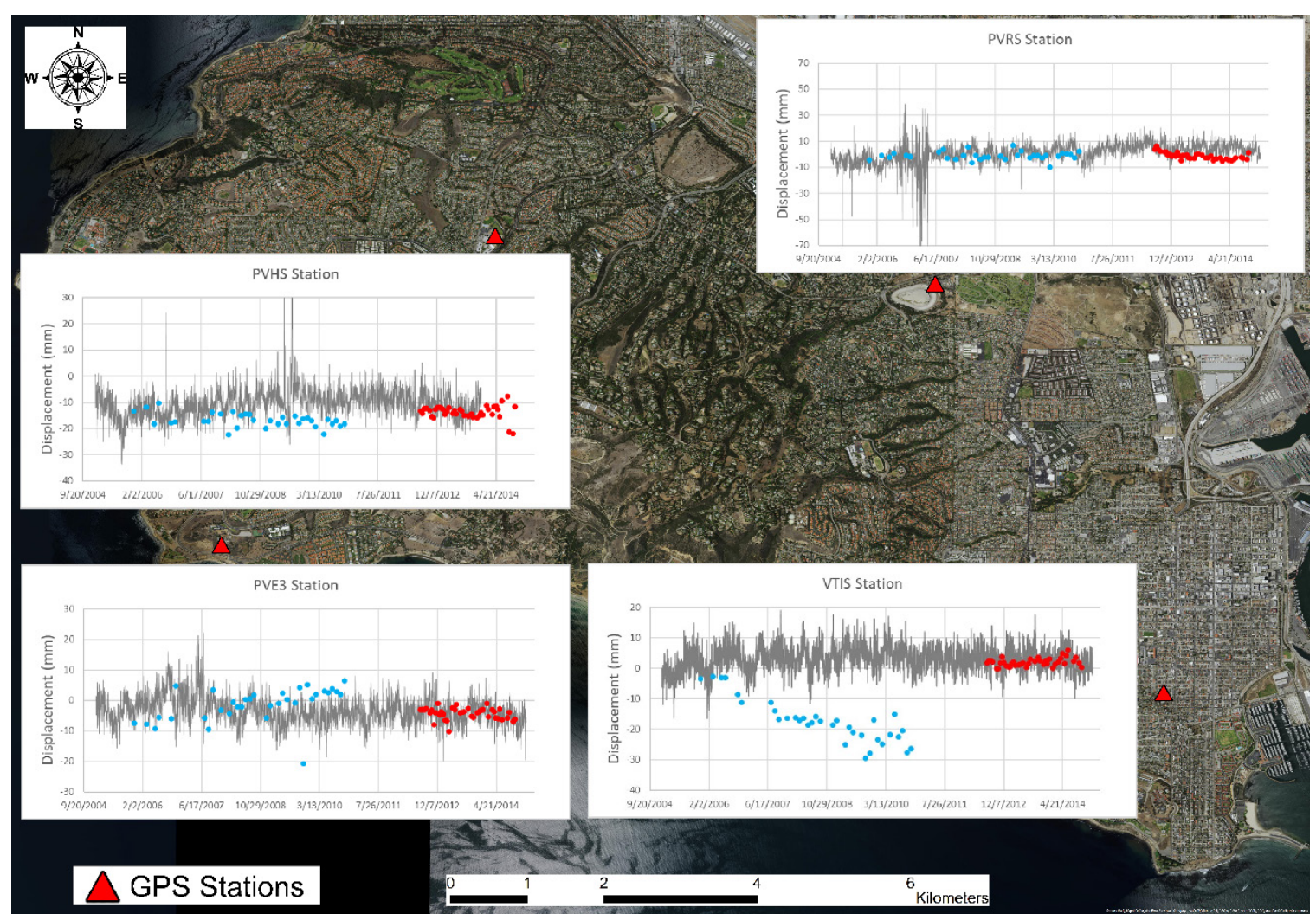

Figure 7.6: Displacement-time series of four GPS stations (continuous gray lines) projected in the satellite $\operatorname{LOS}\left(\sim 23^{\circ}\right.$ from vertical at $N 85^{\circ} \mathrm{W}$ azimuth) with the nearest detectable ENVISAT PS (blue points) and COSMO-SkyMed PS (red points). Locations of GPS stations are denoted with red triangles (same areal extent as Figure 7.1) and the distances from the GPS stations to each respective nearest PS are provided in Table 7.3. 
Table 7.3: Locations of GPS and nearest PS used in displacement comparison (Figure 7.6).

\begin{tabular}{|c|c|c|c|c|}
\hline \multirow{2}{*}{$\begin{array}{l}\text { GPS } \\
\text { Station } \\
\end{array}$} & \multicolumn{2}{|c|}{ GPS Coordinates } & \multirow{2}{*}{$\begin{array}{l}\text { Distance to } \\
\text { ENVISAT PS }\end{array}$} & \multirow{2}{*}{$\begin{array}{l}\text { Distance to } \\
\text { COSMO-SkyMed PS }\end{array}$} \\
\hline & Latitude & Longitude & & \\
\hline PVRS & $33.7739^{\circ}$ & $-118.3206^{\circ}$ & $\sim 82 \mathrm{~m}$ & $\sim 44 \mathrm{~m}$ \\
\hline PVHS & $33.7795^{\circ}$ & $-118.3722^{\circ}$ & $\sim 13 \mathrm{~m}$ & $\sim 12 \mathrm{~m}$ \\
\hline PVE3 & $33.7433^{\circ}$ & $-118.4043^{\circ}$ & $\sim 200 \mathrm{~m}$ & $\sim 82 \mathrm{~m}$ \\
\hline VTIS & $33.7260^{\circ}$ & $-118.2938^{\circ}$ & $\sim 50 \mathrm{~m}$ & $\sim 7 \mathrm{~m}$ \\
\hline
\end{tabular}

Table 7.4: Comparison of average displacement readings between LOS GPS and ENVISAT PS (11/24/2005 - 10/14/2010) and between LOS GPS and COSMO-SkyMed $\operatorname{PS}(7 / 19 / 2012-9 / 27 / 2014)$.

\begin{tabular}{|l|l|l|l|l|}
\hline \multirow{2}{*}{$\begin{array}{l}\text { GPS } \\
\text { Station }\end{array}$} & \multicolumn{2}{|l|}{$\begin{array}{l}\text { Average Displacement Reading } \\
\mathbf{1 1 / 2 4 / 2 0 0 5}-\mathbf{1 0} / \mathbf{1 4} / \mathbf{2 0 1 0}\end{array}$} & \multicolumn{2}{l|}{$\begin{array}{l}\text { Average Displacement Reading* } \\
\mathbf{7 / 1 9} / \mathbf{2 0 1 2}-\mathbf{9} / \mathbf{2 7} / \mathbf{2 0 1 4}\end{array}$} \\
\cline { 2 - 5 } & GPS & PS & GPS & PS \\
\hline PVRS & $-0.74 \mathrm{~mm}$ & $-1.16 \mathrm{~mm}$ & $4.43 \mathrm{~mm}$ & $-1.48 \mathrm{~mm}$ \\
\hline PVHS & $-10.15 \mathrm{~mm}$ & $-16.80 \mathrm{~mm}$ & $-10.95 \mathrm{~mm}$ & $-13.42 \mathrm{~mm}$ \\
\hline PVE3 & $-2.56 \mathrm{~mm}$ & $-1.41 \mathrm{~mm}$ & $-4.13 \mathrm{~mm}$ & $-4.30 \mathrm{~mm}$ \\
\hline VTIS & $3.76 \mathrm{~mm}$ & $-17.35 \mathrm{~mm}$ & $3.06 \mathrm{~mm}$ & $1.96 \mathrm{~mm}$ \\
\hline
\end{tabular}

*Period of average displacement reading for GPS Station PVHS is 7/19/2012 - 12/18/2013.

The final landslide inventory is provided in Figure 7.7. All landslides mapped in the CLI and ILI are merged. Landslides are classified into four categories (Figure 7.7): RSS (brown), PAS (yellow), LTS (green), and UESS (red).

RSS are considered historic or dormant slides. Stable PSs were identified within the boundaries of these slides that are mapped in the CLI. The adjective "relatively" is used because some RSS may exhibit $|\bar{V}|<4 \mathrm{~mm}$ /year but are considered stable since this rate is below the extremely slow landslide threshold. A total of 68 RSS with an average area of $112,873 \mathrm{~m}^{3}$ are identified.

PAS are mapped in the CLI, but no PS data are available within the slide boundaries. A stable slope experiences decorrelation if the geometry of objects on the slope's surface change (e.g., dense vegetation) or if material properties change (e.g., dielectric constant or moisture content) drastically between images. A moving slope experiences temporal decorrelation if movements exceed PSI measurement capabilities, 
which are $\sim 14.7$ and $\sim 25.7 \mathrm{~cm} /$ year in optimal conditions for ENVISAT and COSMOSkyMed, respectively (Crosetto et al. 2016). These slopes are labeled as potential slides due to the inherent uncertainty of the cause of decorrelation. More information is needed to accurately define whether these slopes are in motion; this issue can be resolved with field investigations. Of the PAS with an average area of 10,142 $\mathrm{m}^{2}, 114$ are identified.

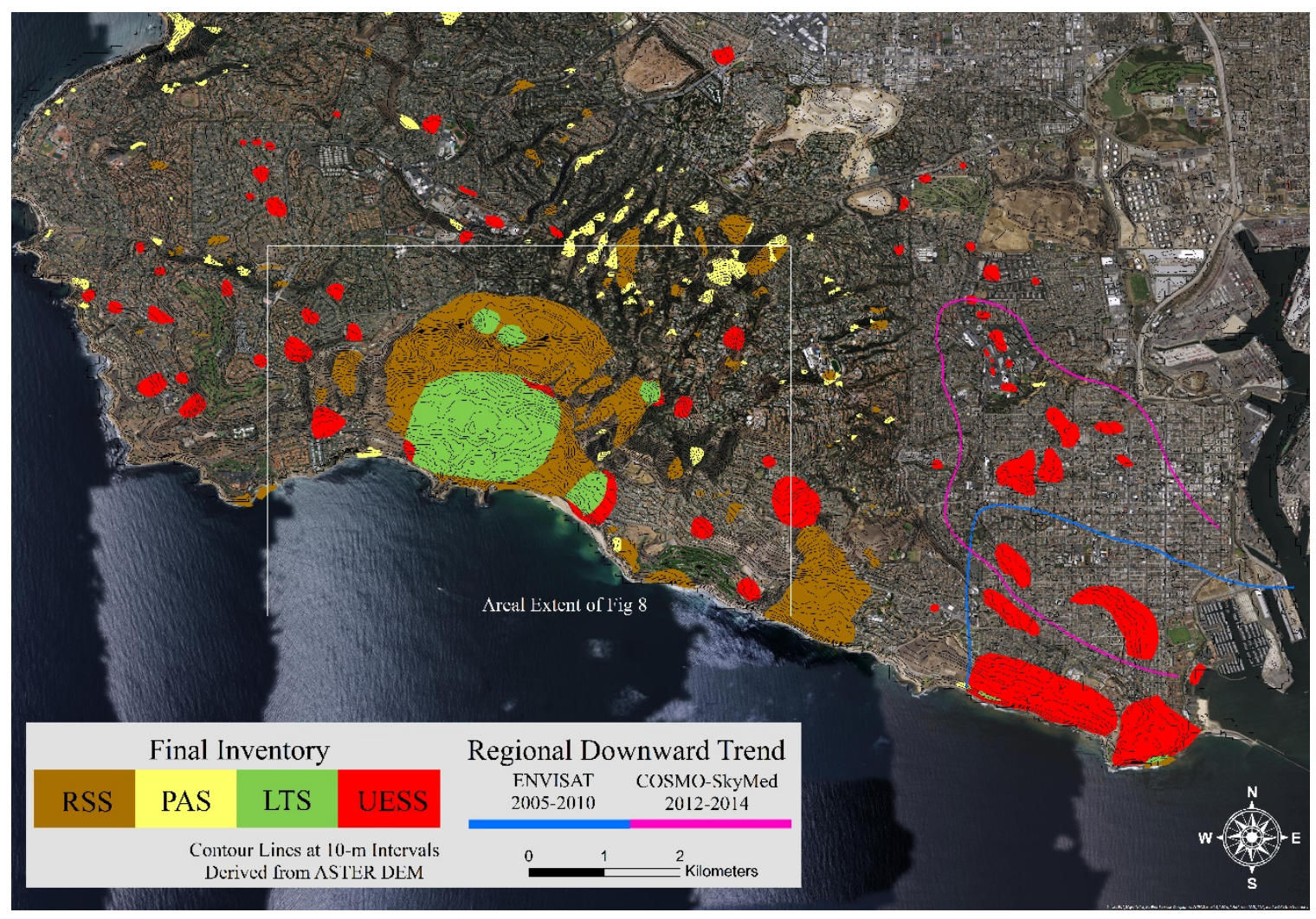

Figure 7.7: Final landslide inventory created from CLI and ILI (Figure 7.3). Landslide types include RSS (brown), PAS (yellow), LTS (green), and UESS (red). Outlines of the RDT identified by ENVISAT (blue line) and COSMO-SkyMed (magenta line) are in the southeast corner of the Palos Verdes Peninsula. Contour lines with 10-m intervals (black lines) are derived from the ASTER GDEM. The background image shows the same areal extent as Figure 7.1. The white rectangle outlines the extent of Figure 7.8. 
LTS are mapped in both the CLI and ILI, indicating protracted slope deformation. These slides exhibit $|\bar{V}|>4 \mathrm{~mm} /$ year between 2005 and 2014. A total of 14 LTS with an average area of $169,576 \mathrm{~m}^{2}$ are identified.

UESS are unmapped in the CLI but mapped in the ILI. Most UESS are in urban settings, which is probably due to the facts that (1) private property and infrastructure obstruct geological investigations and (2) PSI excels in urbanized regions, allowing the technique to measure slow displacement rates, which has been successfully accomplished in recent studies (Gullà et al. 2017; Peduto et al. 2017). 67 UESS are mapped in total and are by far the smallest, with an average area of $8,865 \mathrm{~m}^{2}$.

A regional downward trend (RDT), a relatively large area of downward ground motion detectable by both ENVISAT and COSMO-SkyMed satellites, is present in the southeast corner of the Palos Verdes Peninsula (Figure 7.4 and 7.5 in PSI results; outlined in Figure 7.7). The mean velocity of the RDT was measured to be $-4 \mathrm{~mm} /$ year between 2005 and 2010 (via ENVISAT) and -5 mm/year between 2012 and 2014 (via COSMOSkyMed). The center of the RDT appears to shift north, either indicating a migration in the triggering mechanism or evidence of two separate events (Figures 7.4, 7.5, and 7.7). Regional subsidence caused by oil, natural gas, and groundwater extraction in the Los Angeles Basin has been well documented (Mayuga and Allen 1970; CDWR 2014). Per the GPS displacement time series at VTIS station (Figure 7.6), the average velocity between 2005 and 2010 is $-1 \mathrm{~mm}$ every two years. The geometry of the RDT does allow for the potential of segmented movement of a large, slow-moving landslide (Figure 7.7). One can envision downward motion in the southeast direction, parallel to slope dip direction in the area, encroaching the sea. Only three slides within the RDT have been mapped in the CLI. Many UESS have been identified in this region, but difficulty arises when trying to join them into an $\sim 18 \mathrm{~km}^{2}$ landslide using point-source PSI data (as mentioned above). Further field investigation, which is recommended practice for InSAR remote sensing validation in general (Cigna et al. 2013), is needed to determine the existence of this potential landslide.

The final landslide inventory combines the original field notes included in the CLI with numerical displacement data from PSI results. Four different landslide types within e 
PVHLC, labeled I-IV in Figure 7.8, were chosen to illustrate the type of information incorporated in the final landslide inventory, which is provided in Table 7.5. Slides I, II, and III were originally mapped in the CLI and, therefore, are described in greater detail than Slide IV. A common feature of all four slides is the presence of anthropogenic structures and private property within the slide boundaries. An entire residential neighborhood is encompassed by Slides III and IV. Slide III, previously mapped as part of PVHLC, has 155 unstable PS ( $23 \%$ of total PS count) and a maximum average velocity measured at $-10.34 \mathrm{~mm} /$ year. Slide IV, previously unmapped, has 90 unstable PS, $\sim 2 \%$ of total PS count, spanning 15-20 houses at a maximum average velocity of $-9.17 \mathrm{~mm} / \mathrm{year}$. This slow movement will not cause catastrophic destruction but could cause structural damage over an extended period. 


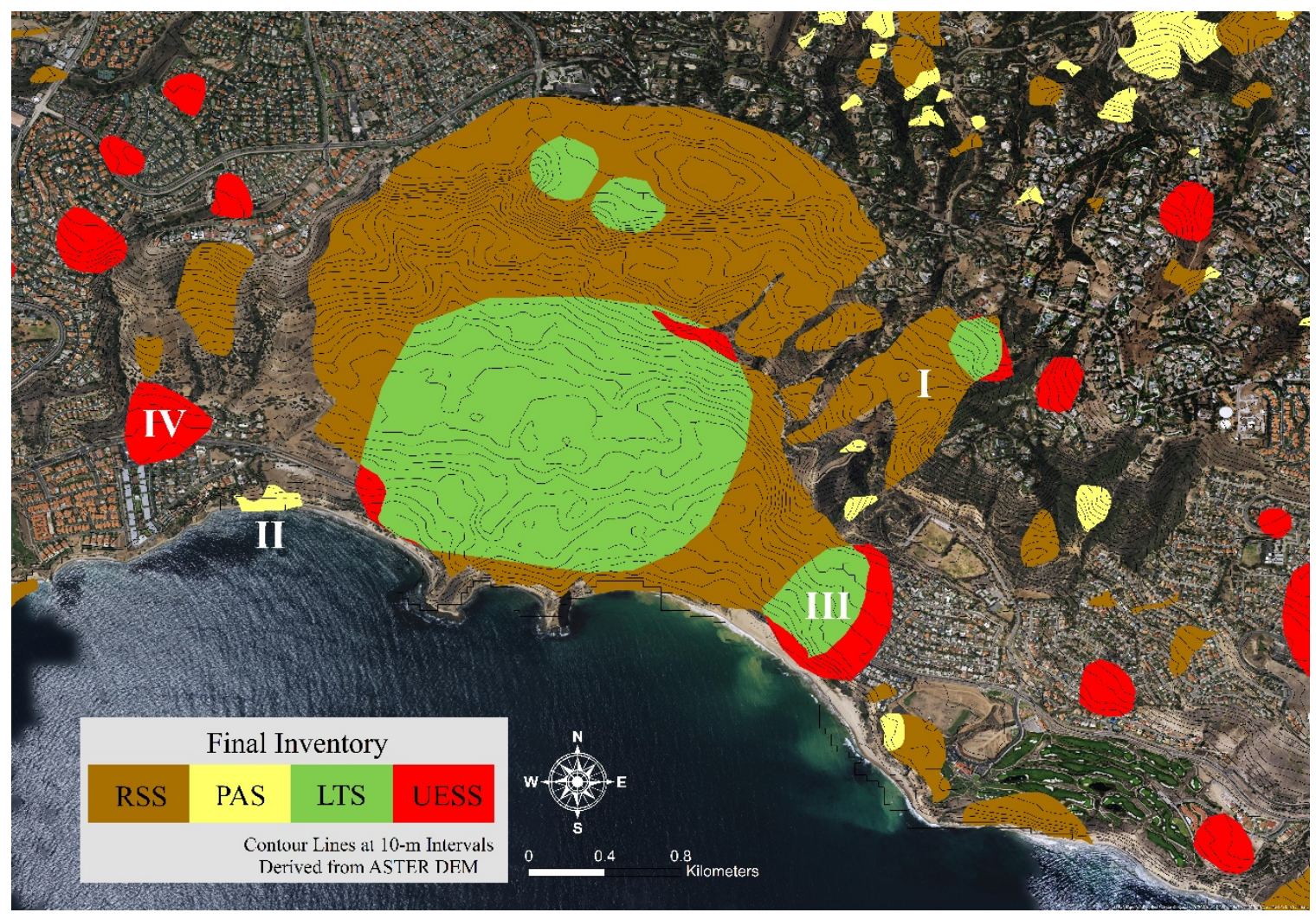

Figure 7.8: View of the final landslide inventory at the PVHLC. An example of CLI and ILI data integration is shown for the four slopes labeled I-IV, representing each landslide type, in Table 7.5. Contour lines with 10-m intervals (black lines) are derived from the ASTER GDEM. 
Table 7.5: Integration of CLI and ILI data for four slopes, labeled I-IV, in the PBLC (Figure 7.8).

\begin{tabular}{|l|l|l|l|l|}
\hline Slide Number & I & II & III & IV \\
\hline Slide Type & RSS & PAS & LTS & UESS \\
\hline Slide Area & $357,905 \mathrm{~m}^{2}$ & $19,665 \mathrm{~m}^{2}$ & $271,720 \mathrm{~m}^{2}$ & $203,790 \mathrm{~m}^{2}$ \\
\hline Slide Thickness & Deep $(>15 \mathrm{~m})$ & Shallow $(<3 \mathrm{~m})$ & Deep $(>15 \mathrm{~m})$ & Unknown \\
\hline Max. Slope & $33.22^{\circ}$ & $29.45^{\circ}$ & $24.96^{\circ}$ & $10.57^{\circ}$ \\
\hline $\begin{array}{l}\text { Number of } \\
\text { Unstable PS }\end{array}$ & 0 & 0 & 155 & 90 \\
\hline $\begin{array}{l}\text { Number of } \\
\text { Stable PS }\end{array}$ & 12 & 0 & 531 & 5,111 \\
\hline $\begin{array}{l}\text { Max. Downslope } \\
\text { Velocity }\end{array}$ & $-0.98 \mathrm{~mm} /$ year & Unknown & $-10.34 \mathrm{~mm} /$ year & $-9.17 \mathrm{~mm} /$ year \\
\hline $\begin{array}{l}\text { Location of } \\
\text { Max. Velocity }\end{array}$ & Southeast Toe & Not Applicable & Head & Southeast Flank \\
\hline $\begin{array}{l}\text { Direction of } \\
\text { Movement }\end{array}$ & $230^{\circ}$ & $170^{\circ}$ & $220^{\circ}$ & $\begin{array}{l}\text { Probably } \\
220^{\circ}-230^{\circ}\end{array}$ \\
\hline $\begin{array}{l}\text { Originally } \\
\text { Mapped }\end{array}$ & 1998 & 1998 & 1998 & $\begin{array}{l}\text { 2017 } \\
\text { (Previously } \\
\text { Unmapped) }\end{array}$ \\
\hline $\begin{array}{l}\text { CLI } \\
\text { Interpretation } \\
\text { Confidence }\end{array}$ & Definite & Definite & Definite & $\begin{array}{l}\text { Uncertain, } \\
\text { Field Inspection } \\
\text { Required }\end{array}$ \\
\hline
\end{tabular}

${ }^{\alpha}$ An unstable PS exhibits $|\overline{\mathrm{V}}|>4 \mathrm{~mm} /$ year in either direction.

${ }^{\beta}$ A stable PS exhibits $|\overline{\mathrm{V}}|<4 \mathrm{~mm} /$ year in either direction.

\subsubsection{PSI Limitations for Landslide Mapping}

Limitations of the PSI technique have already been alluded to in this study, but it is worth discussing three PSI limitations for landslide mapping in detail: sensor LOS direction, temporal decorrelation due to vegetation, and temporal decorrelation due to rapid deformation.

Landslide detection and deformation measurements are limited to the sensor LOS direction; this is inherent to the technique (Colesanti and Wasowski 2006; Bianchini et al. 2013; Cigna et al. 2013; $\mathrm{Hu}$ et al. 2014). Some landslides may not be detectable from certain LOS directions, e.g., steep slopes dipping parallel and away from the LOS direction (a steep, west facing slope may not reflect radar waves back to the ENVISAT and COSMOSkyMed sensors). This is the shadow problem that occurs with slant-range radar systems (Sarmap 2009). Landslide displacement perpendicular to the LOS direction (north or south) 
is also not detectable (Casagli et al. 2017). A work-around of the LOS limitation would be to acquire and process multiple SAR SLC image stacks with different fields of view over the same area, e.g., descending and ascending.

Temporal decorrelation due to the presence of vegetation may effectively hide landslides from PSI detection (Wei and Sandwell 2010; Mazzanti et al. 2012). This may be the case in the region of decorrelation in Figure 7.5 - the stack of short-wavelength (Xband) COSMO-SkyMed radar images was unable to correlate properly when subset around this region, while in contrast, the stack of (relatively) longer-wavelength (C-band) ENVISAT radar images can obtain PS in this region, albeit at a low PS density. Longer wavelengths are more likely to penetrate vegetation and, thus, L-band (wavelength $\sim 23 \mathrm{~cm}$ ) performs better in vegetated regions than C-band (wavelength $\sim 5.6 \mathrm{~cm}$ ) which performs better than X-band (wavelength $\sim 3.1 \mathrm{~cm}$ ), and so forth.

It is well documented that rapid landslides cause temporal decorrelation for the PSI technique (Crosetto et al. 2016; Casagli et al. 2017). Cigna et al. 2013 list the maximum velocities measurable with the PSI technique for satellites with different wavelengths and revisit periods; they range from $\sim 15 \mathrm{~cm} /$ year (ERS-1/-2 and ENVISAT at C-band) to $\sim 45 \mathrm{~cm} /$ year (ALOS and JERS at L-band). Crosetto et al. 2016 calculate the maximum velocities to be $\sim 14.7 \mathrm{~cm} /$ year (ENVISAT) and $\sim 25.7 \mathrm{~cm} /$ year (COSMO-SkyMed). Presence of these relatively quick landslides may be why there are 114 PAS (Figure 7.7), which were mapped in the CLI but may be moving too rapidly for PSI detection. This limitation may also be why many mapping studies focus on slow landslides when using PSI (Colesanti and Wasowski 2006; Mazzanti et al. 2012; Antronico et al. 2013; Cascini et al. 2013; Cigna et al. 2013; Tofani et al. 2013; Lu et al. 2014; Bouali et al. 2016a; Gullà et al. 2017; Peduto et al. 2017).

\subsubsection{PSI Advantages for Landslide Mapping}

Despite inherent limitations of PSI, many advantages make this remote sensing technique a quality supplemental landslide mapping approach. In general, PSI is a low cost/benefit ratio technique that allows for the detection of ground motion at any time of the day or night with an accuracy of $1 \mathrm{~mm} /$ year over wide areal coverage with a large 
archive of satellite imagery, beginning with ERS-1 in 1992 (Ferretti et al. 2000; Ferretti et al. 2001; Hooper et al. 2004; Colesanti and Wasowski 2006; Crosetto et al. 2016; Casagli et al. 2017). More specifically to slow landslide mapping, PSI excels in urban areas.

Anthropogenic structures (e.g., buildings) and infrastructure (e.g., bridges, pipelines, tunnels, and assets along transportation corridors) in urban settings are coherent targets that yield PSI results with high PS density. This is evident in Figures 7.4 and 7.5, where PS density is greater in urban areas (east and west portions of the peninsula) compared to the more rural, vegetated areas (middle of the peninsula). PS density may be high enough such that multiple PS are detected on each structure. This is beneficial because heavily urbanized areas may hinder traditional field-based landslide mapping, and as a proxy, PSI can be used to pinpoint neighborhoods, city blocks, or even individual buildings experiencing anomalous movements (Antronico et al. 2013; Tofani et al. 2013; Bouali et al. 2017b; Gullà et al. 2017; Wang et al. 2017).

\subsection{Conclusion}

The purpose of this paper is to update the CLI with satellite-based remote sensing data-PSI technique with 34 ENVISAT and 40 COSMO-SkyMed SLC SAR images-to include extremely slow landslides, defined as experiencing $|\bar{V}|>4 \mathrm{~mm} /$ year. The landslideprone Palos Verdes Peninsula is chosen as the study site (Figures 7.1 and 7.2). Only PS with $\gamma \geq 0.75$ are included in PSI results (Figures 7.4 and 7.5). PS derived from both satellites are then merged to generate the ILI based on four criteria: PS number, average velocity, slope angle, and slope aspect. The ILI is then merged with the CLI to generate a final landslide inventory (Figures 7.7 and 7.8). Landslides are separated into four categories: LTS, PAS, RSS, and UESS. These categories are based on whether they were previously mapped, if PS are present, and whether the PS are unstable or stable. The final inventory includes 263 mapped landslides across the peninsula: 68 RSS, 114 PAS, 14 LTS, and 67 UESS.

Constructing a near real-time landslide monitoring methodology using PSI would be a powerful supplemental approach for landslide life-cycle management. InSAR is already being used for near-real-time emergency response for natural hazards (Ramsey et 
al. 2009; Salvi et al. 2012; Nascetti et al. 2015). Near-real-time reprocessing of SAR SLC radar image stacks would allow for updates to landslide inventories at a frequency much higher than any current traditional approach, and fortunately, there are many current (Sentinel-1, ALOS-2, COSMO-SkyMed, PAZ, and KOMPSAT-5) and upcoming (RADARSAT constellation, NISAR, SAOCOM, and COSMO-SkyMed SG) SAR satellite missions for this to be feasible.

\subsection{Acknowledgements}

The study was funded through the NASA Earth and Space Science Fellowship Program (proposal: 16-EARTH16F-0086). Data were provided by many agencies and organizations. COSMO-SkyMed radar images were originally acquired by the Italian Space Agency and provided to the authors by the European Space Agency (proposal ID 31684). ENVISAT radar images were acquired and provided by the European Space Agency (proposal ID 82169). The California Landslide Inventory GIS shapefile for the Palos Verdes Peninsula was provided by the California Geological Survey, a division of the California Department of Conservation. Three digital elevation models were used: Shuttle Radar Topography Mission model is a product of the Jet Propulsion Laboratory; Advanced Spaceborne Thermal Emission and Reflection Radiometer model is a product of National Aeronautics and Space Administration (NASA) and Ministry of Economy, Trade, and Industry; a $1 / 3$ arc-second $(10 \mathrm{~m})$ NED DEM from the USGS (2017). Threecomponent (vertical, north, and east) displacement time-series composing the four GPS time-series were downloaded from the UNAVCO Data Archive Interface Version 2. The background image displayed in Figures 7.2, 7.4, 7.5, 7.6, and 7.8 were provided by the USGS, NASA, Google, and Digital Globe. The authors would finally like to thank the Landslide editors and two reviewers for their comments and assistance.

\subsection{Compliance with Ethical Standards}

Disclaimer. Maps throughout this paper were created using ArcGIS ${ }^{\circledR}$ software by Esri. ArcGIS ${ }^{\circledR}$ and $\operatorname{ArcMap}^{\mathrm{TM}}$ are the intellectual property of Esri and are used herein 
under license. Copyright $\left(\mathcal{C}\right.$ Esri. All rights reserved. For more information about Esri ${ }^{\circledR}$ software, please visit www.esri.com. 


\title{
Chapter 8: Evidence of Instability in Previously-mapped Landslides as Measured using GPS, Optical, and Radar Data between 2007 and 2017: A Case Study in the Portuguese Bend Landslide Complex, California $^{24}$
}

\author{
El Hachemi Bouali ${ }^{25}$; Thomas Oommen, Ph.D., A.M.ASCE ${ }^{26}$; \\ and Rüdiger Escobar-Wolf, Ph.D. ${ }^{27}$
}

\subsection{Abstract}

Velocity dictates the destructive potential of a landslide. A combination of radar, optical, and GPS data were used to maximize spatial and temporal coverage to monitor continuously-moving portions of the Portuguese Bend landslide complex on the Palos Verdes Peninsula in southern California. Forty radar images from the COSMO-SkyMed satellite, acquired between 19 July 2012 and 27 September 2014, were processed using Persistent Scatterer Interferometry (PSI). Eight optical images from the WorldView-2 satellite, acquired between 20 February 2011 and 16 February 2016, were processed using the Co-registration of Optically Sensed Images and Correlation (COSI-Corr) technique. Displacement measurements were taken at GPS monuments between September 2007 and

\footnotetext{
${ }^{24}$ The material contained in this chapter has been submitted for publication.

25 Department of Geological and Mining Engineering and Sciences, Michigan Technological Univ., 1400 Townsend Dr., Houghton, MI 49931 (corresponding author). E-mail: eybouali@mtu.edu

26 Department of Geological and Mining Engineering and Sciences, Michigan Technological Univ., 1400 Townsend Dr., Houghton, MI 49931. E-mail: toommen@mtu.edu

27 Department of Geological and Mining Engineering and Sciences, Michigan Technological Univ., 1400 Townsend Dr., Houghton, MI 49931. E-mail: rpescoba@mtu.edu
} 
May 2017. Incremental and average deformations across the landslide complex were measured using all three techniques. Velocity measured within the landslide complex ranges from slow ( $>1.6 \mathrm{~m} /$ year) to extremely slow $(<16 \mathrm{~mm} /$ year $)$. COSI-Corr and GPS provide detailed coverage of $\mathrm{m} /$ year-scale deformation while PSI can measure extremely slow deformation rates (mm/year-scale), which COSI-Corr and GPS cannot do reliably. This case study demonstrates the applicability of radar, optical, and GPS data synthesis as a complimentary approach to repeat field monitoring and mapping to changes in landslide activity through time.

\subsection{Introduction}

Destructive capabilities of a landslide depend on its velocity and proximity to assets deemed valuable to human livelihood (Hungr 2007). Unfortunately, many landslides occur in areas that put human life and societal assets (e.g., homes, infrastructure, transportation networks, etc.) at risk (Dai et al. 2002; Petley 2012). It is important that communities identify areas susceptible to landslides and perform necessary preventative measures, which may in some form include spatial identification (e.g., landslide inventory) and temporal monitoring (e.g., displacement measurements), to establish a community landslide mitigation plan (Ge and Lindell 2016; Scolobig et al. 2016). Observational landslide identification and monitoring can take many forms: repeat mapping expeditions with qualitative descriptions, quantitative field assessments and installation of in situ monitoring equipment (e.g., inclinometers or GPS monuments), and remote sensing surveys (terrestrial, aerial, or satellite-based).

The authors utilize similar data - the California landslide inventory (McMillian and Haydon 1998a, 1998b, and 1998c; Haydon 2007), annual displacement measurements at GPS monuments (McGee 2007-2017), and two satellite-based remote sensing techniques: Persistent Scatterer Interferometry (PSI) and Co-registration of Optically Sensed Images and Correlation (COSI-Corr) - to map the extent of recent landslide activity within a landslide complex and create a landslide activity map based on the Cruden and Varnes (1996) landslide velocity scale. PSI, COSI-Corr, and GPS measurements are used together to maximize spatial and temporal coverage but also, as shown in Table 8.1, to make sure 
any limitations of a single technique are surmounted by the others. For example, COSICorr and GPS can reliably measure ground deformation rates in the $\mathrm{cm} / \mathrm{year}$ to $\mathrm{m} / \mathrm{year}$ range, but neither have the accuracy to measure sub-cm/year velocity; PSI is capable of $\mathrm{mm}$ /year-scale measurements. Direct use of long-term radar, optical, and GPS monitoring of landslide activity mapping at three orders of magnitude (m/year to mm/year) has not been done previously.

Table 8.1: Variables to consider prior to mapping and monitoring of landslides using PSI, COSI-Corr, and GPS.

\begin{tabular}{|c|c|c|c|}
\hline & PSI & COSI-Corr & GPS \\
\hline $\begin{array}{c}\text { Spatial } \\
\text { Distribution of } \\
\text { Data Points }\end{array}$ & $\begin{array}{l}\text { Unknown until } \\
\text { processing complete }\end{array}$ & $\begin{array}{l}\text { Gridded across spatial } \\
\text { extent of input } \\
\text { imagery }\end{array}$ & $\begin{array}{l}\text { Installed; must be } \\
\text { placed in areas where } \\
\text { not disturbed by } \\
\text { external factors }\end{array}$ \\
\hline $\begin{array}{c}\text { Temporal } \\
\text { Distribution of } \\
\text { Data } \\
\end{array}$ & $\begin{array}{l}\text { Spans acquisition period } \\
\text { of sensor }\end{array}$ & $\begin{array}{l}\text { Spans acquisition } \\
\text { period of sensor }\end{array}$ & $\begin{array}{l}\text { Spans acquisition } \\
\text { period post- } \\
\text { installation } \\
\end{array}$ \\
\hline $\begin{array}{l}\text { Range of } \\
\text { Measurable } \\
\text { Deformation } \\
\text { Rates }\end{array}$ & $\begin{array}{c}<2.5 \mathrm{~cm} / \text { year (threshold } \\
\text { changes based on data } \\
\text { quality, number of } \\
\text { images, and radar } \\
\text { wavelength) }\end{array}$ & $\mathrm{cm} /$ year to $\mathrm{m} /$ year & $\mathrm{cm} /$ year to $\mathrm{m} /$ year \\
\hline $\begin{array}{l}\text { Direction(s) of } \\
\text { Measurements }\end{array}$ & $\begin{array}{l}\text { 1-dimensional, sensor } \\
\text { line-of-sight }\end{array}$ & $\begin{array}{c}\text { 2-dimensional, } \\
\text { horizontal (north- } \\
\text { south and east-west) }\end{array}$ & $\begin{array}{c}\text { 3-dimensional, } \\
\text { horizontal and } \\
\text { vertical }\end{array}$ \\
\hline Accuracy & $1 \mathrm{~mm} /$ year & $5-10 \mathrm{~cm} /$ year & $1-2 \mathrm{~cm} /$ year \\
\hline $\begin{array}{l}\text { Sources of } \\
\text { Noise }\end{array}$ & $\begin{array}{c}\text { Ionospheric effects, snow } \\
\text { cover, precipitation, } \\
\text { changes in dielectric } \\
\text { properties of materials, } \\
\text { vegetation, systematic } \\
\text { noise }\end{array}$ & $\begin{array}{l}\text { Cloud cover, snow } \\
\text { cover, vegetation, } \\
\text { drastic changes in } \\
\text { ground surface (e.g., } \\
\text { construction), } \\
\text { systematic noise }\end{array}$ & $\begin{array}{c}\text { Rapid ground } \\
\text { deformation } \\
\text { (destruction of } \\
\text { monuments), external } \\
\text { factors (e.g., humans } \\
\text { and animals) } \\
\end{array}$ \\
\hline $\begin{array}{l}\text { Measurements } \\
\text { Unavailable } \\
\text { (Decorrelation) } \\
\text { or Unreliable } \\
\end{array}$ & $\begin{array}{l}\text { Dense vegetation, } \\
\text { topographic shadow } \\
\text { zones, areas with rapid } \\
\text { ground deformation }\end{array}$ & $\begin{array}{c}\text { Areas beneath clouds, } \\
\text { dense vegetation, } \\
\text { topographic shadow } \\
\text { zones }\end{array}$ & $\begin{array}{l}\text { If impacted by } \\
\text { sources of noise } \\
\text { listed above }\end{array}$ \\
\hline Validation & $\begin{array}{l}\text { GPS and other ground- } \\
\text { truthing methods }\end{array}$ & $\begin{array}{l}\text { GPS and other } \\
\text { ground-truthing } \\
\text { methods }\end{array}$ & $\begin{array}{l}\text { Other ground- } \\
\text { truthing methods } \\
\text { (e.g., surveys) }\end{array}$ \\
\hline
\end{tabular}




\subsection{Study Area}

An active landslide complex is located on the south-central coast of the Palos Verdes Peninsula in California. Residential neighborhoods of Rancho Palos Verdes, Rolling Hills, and Rolling Hills Estates delineate the perimeter of previously mapped landslides. At least eight major landslides form this complex (Figure 8.1), including Ancient Portuguese Bend (AnPB), Active Portuguese Bend (AcPB), Valley View Graben (VVG), Parcel 4 (P4), Abalone Cove (AC), Klondike Canyon (KC), Beach Club (BC), and Flying Triangle (FT), as mapped by the California Geological Survey (Haydon 2007). Landslide mapping was originally performed through analysis of aerial photographs and then validated through field reconnaissance and topographic map interpretations (McMillian \& Haydon 1998a, 1998b, \& 1998c). Landslides were classified based on specific characteristics using terminology from Varnes (1978), Wieczorek (1984), Keaton and DeGraff (1996), and Cruden and Varnes (1996). Characteristics include landslide type, thickness, activity (as shown in Figure 8.1), movement direction, and confidence of interpretation (Haydon 2007); see Table 8.2 for characteristics of notable landslides.

The landslide complex is sliding south-southwest down the Palos Verdes Hills, a northwest-southeast trending ridge located north of Rolling Hills and Rolling Hills Estates. All major landslides are classified as rock slides (Haydon 2007) where the moving mass includes bedrock and younger alluvium, the main body generally stays intact, and movement can be described as either translational or rotational, although larger landslides exhibit complex movements (both translational and rotational). The basal surface of rupture on these deep-seated landslides (>15 $\mathrm{m}$ in thickness) typically occurs along bedding planes of the tuffaceous unit of the Altamira Shale, the oldest member of the middle to upper Miocene Monterey Formation, parts of which have been altered to bentonite and montmorillonite (Woodring et al. 1946; Merriam 1960). Relatively impermeable tuff beds rest between clay-altered, highly absorbent bedding planes that act as a conduit for groundwater (the basal surface of rupture) and studies have observed a direct correlation between precipitation and landslide activity (Ehlig and Bean 1982; Kayen et al. 2002; Haydon 2007; Calabro et al. 2010). Landslide activity (Figure 1 and Table 2) was defined by the California Geological Survey using aerial photographs from 1952-1959 
and 1994, and field work in the 1990s (Haydon 2007); it is based on the terminology proposed by Keaton and DeGraff (1996). Dormant slides are those that have not moved for at least 100 years - old/relict slides have not moved in the last 10,000 years. They show evidence of erosion and are covered with vegetation. Active/Historic slides are those that have occurred recently (since the 1950s) or "within historic time," defined as occurring within the last 100 years.

The landslide complex was dormant prior to reactivation in 1956 and possibly caused by two anthropogenic factors that may have increased groundwater pore pressure (although Kayen et al. (2002) acknowledge a lack of hydrologic data to support this hypothesis). First, Rancho Palos Verdes approved the construction of Palos Verdes Drive South, a road running perpendicular to the coastline, which cut through the slope toe. Material and fill used for construction were piled nearby, potentially causing rapid loading. Second, irrigation practices from nearby neighborhoods may have contributed to elevated groundwater levels (Ehlig 1992). The 1956 reactivation occurred within portions of AcPB. In February 1974, southern AC also began moving (Proffer 1992). Heavy rainfall in early 1978 accelerated deformation within the entirety of both AcPB and AC landslides (Ehlig and Bean 1982). A 1979 field investigation by Proffer (1992) concluded that short-term instability of $\mathrm{AC}$ was caused by increased groundwater levels and long-term instability by wave erosion of the toe. Eight dewatering wells were installed within the AC landslide boundary in 1980, significantly mitigating landslide hazard (Proffer 1992). In 1984, dewatering wells were also installed in the AcPB landslide (Ehlig 1992; Kayen et al. 2002; Zeiser Kling Consultants Inc. 2006). Other active landslides in the area were moving by the early- to mid-1980s (Ehlig 1992; Proffer 1992) and have been continuously moving since, exhibiting accelerated deformation rates $(>2.6 \mathrm{~m} / \mathrm{year})$ during rainy months and decelerated deformation rates $(<1 \mathrm{~m} /$ year) during dry months (Kayen et al. 2002; Calabro et al. 2010). In recent years, coastline roads (including Palos Verdes Drive South) had to be repaired, replaced, or rerouted (City of Rancho Palos Verdes 2012) and mitigation of the landslide complex is a continued topic of debate (Osier 2018). 


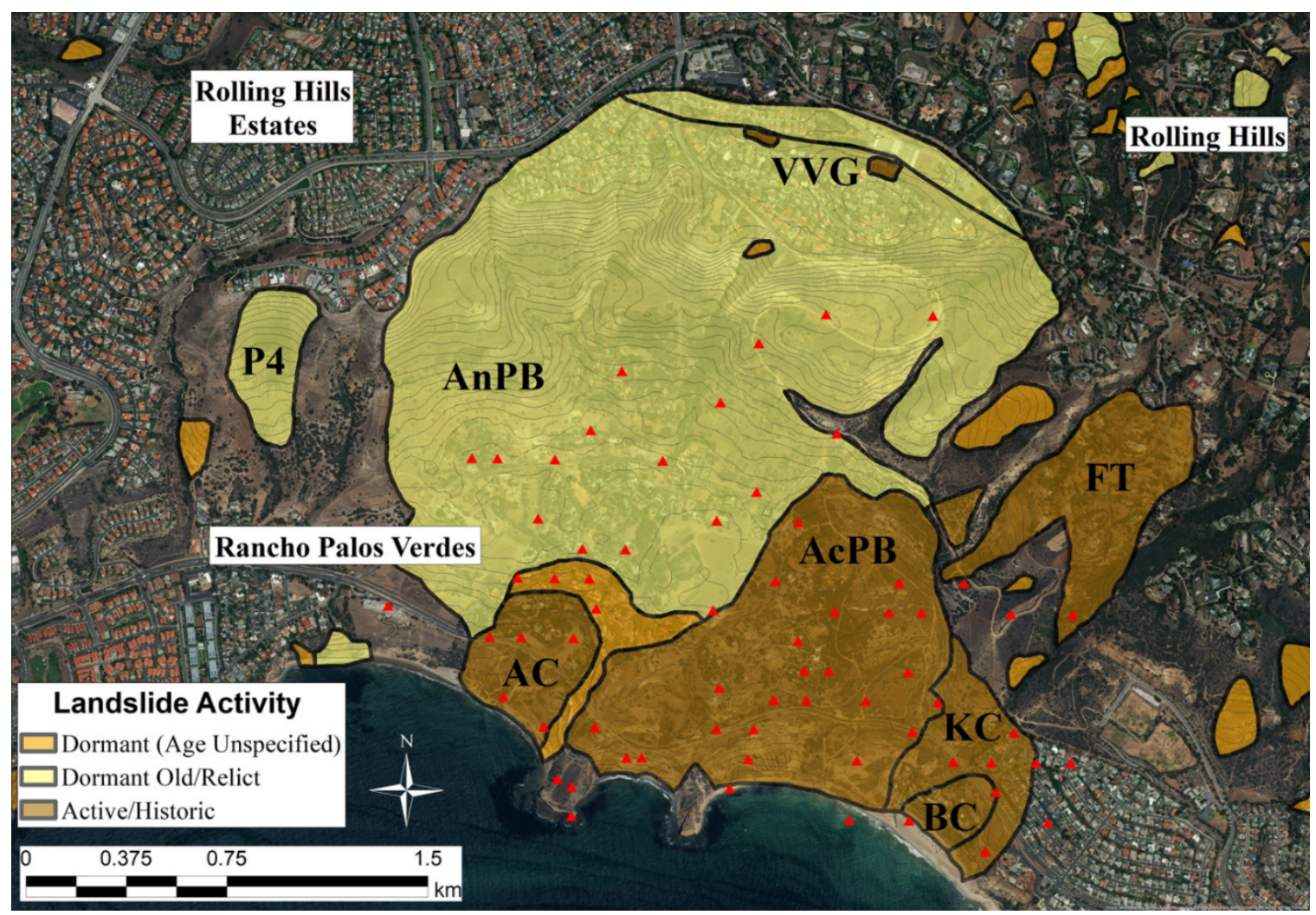

Figure 8.1: Study area. Major landslides, colored based on landslide activity (Haydon 2007), are Ancient Portuguese Bend (AnPB), Active Portuguese Bend (AcPB), Valley View Graben (VVG), Parcel 4 (P4), Abalone Cove (AC), Klondike Canyon (KC), Beach Club (BC), and Flying Triangle (FT). Contour intervals are $10 \mathrm{~m}$. GPS monuments are displayed as red triangles. 
Table 8.2: Landslide characteristics.

\begin{tabular}{|c|c|c|c|c|c|}
\hline Landslide & Type & $\begin{array}{c}\text { Thickness } \\
\mathbf{( f t}, \mathbf{m})\end{array}$ & Activity & $\begin{array}{c}\text { Movement } \\
\text { Direction } \\
\text { (azimuth) }\end{array}$ & $\begin{array}{c}\text { Interpretation } \\
\text { Confidence } \\
\text { Level }\end{array}$ \\
\hline AnPB & $\begin{array}{c}\text { Rock } \\
\text { Slide }\end{array}$ & $\begin{array}{c}>50, \\
>15.24\end{array}$ & $\begin{array}{c}\text { Dormant } \\
\text { Old/Relict }\end{array}$ & 180 & Definite \\
\hline AcPB & $\begin{array}{c}\text { Rock } \\
\text { Slide }\end{array}$ & $\begin{array}{c}>50, \\
>15.24\end{array}$ & Active/Historic & 180 & Definite \\
\hline VVG & $\begin{array}{c}\text { Rock } \\
\text { Slide }\end{array}$ & $\begin{array}{c}>50, \\
>15.24\end{array}$ & $\begin{array}{c}\text { Dormant } \\
\text { Old/Relict }\end{array}$ & 180 & Definite \\
\hline P4 & $\begin{array}{c}\text { Rock } \\
\text { Slide }\end{array}$ & $\begin{array}{c}10-50, \\
3.05-15.24\end{array}$ & $\begin{array}{c}\text { Dormant } \\
\text { Old/Relict }\end{array}$ & 180 & Definite \\
\hline AC & $\begin{array}{c}\text { Rock } \\
\text { Slide }\end{array}$ & $>50$, & Active/Historic & 220 & Definite \\
\hline KC & $\begin{array}{c}\text { Rock } \\
\text { Slide }\end{array}$ & $\begin{array}{c}>50, \\
>15.24\end{array}$ & Active/Historic & 220 & Definite \\
\hline BC & $\begin{array}{c}\text { Rock } \\
\text { Slide }\end{array}$ & $\begin{array}{c}>50, \\
>15.24\end{array}$ & Active/Historic & 220 & Definite \\
\hline Rock & $\begin{array}{c}>50, \\
\text { Slide }\end{array}$ & \multicolumn{1}{|c|}{ Active/Historic } & 230 & Definite \\
\hline
\end{tabular}

\subsection{Data and Methodology}

\subsubsection{GPS}

GPS surveys were conducted by Michael McGee, of McGee Surveying Consulting, on behalf of the City of Rancho Palos Verdes. Sixty-six GPS monuments were placed in a $\sim 4 \mathrm{~km} 2$ area, with a focus on the more active AcPB, KC, BC, and $\mathrm{AC}$ landslides, and partial coverage of AnPB and FT (Figure 8.1). This GPS survey was a continuation of an original survey which began in 1994 and included 149 monuments, but 89 monuments were lost or destroyed, some due to rapid landslide deformation mainly in AcPB (McGee 2007). McGee resumed annual monitoring of all GPS monuments (60 found from 1994 survey and six new) in September 2007, and continued through May 2017 (most recent dataset available). A subset of monuments (about 30) were chosen for semiannual monitoring beginning February 2012 and triannual monitoring beginning April 2014. All the information for this project, entitled 'Portuguese Bend Landslide Monitoring Surveys,' including project history, datums and reference system, data collection, equipment and 
processing, Global Navigation Satellite System (GNSS) network diagram and description, accuracy, and quality control/quality assurance may be found in a series of reports from the City of Rancho Palos Verdes (McGee 2007-2017). These GPS measurements are accurate to $1 \mathrm{~cm}$ (in relatively stable areas) and $2 \mathrm{~cm}$ (in active areas) between annual readings (McGee 2007-2017).

\subsubsection{COSI-Corr}

Co-registration of Optically Sensed Images and Correlation (COSI-Corr) is an optical remote sensing technique and ENVI software module (Leprince et al. 2004; Leprince et al. 2007). It was originally created to measure ground deformation from seismic activity with satellite or aerial optical image pairs - a pre-event image and post-event image (Ayoub et al. 2017). COSI-Corr measures two-dimensional (horizontal) ground deformation between image pairs, with displacement vectors in the north/south and east/west directions. Although designed to measure earthquake-induced deformation, COSI-Corr has been successfully used to measure geomorphological and surficial processes (Vermeesch and Drake 2008; Necsoiu et al. 2009; Bridges et al. 2012; Lucieer et al. 2014; Turner et al. 2015).

Eight WorldView-2 high resolution $(50 \mathrm{~cm})$ panchromatic optical images were acquired between 20 February 2011 and 16 February 2016. Images were obtained at an incidence angle of $20^{\circ}$ in the $450-800 \mathrm{~nm}$ spectral range. Operated by DigitalGlobe, images were processed to the map scale 1:12,000 orthorectified level. Full-size WorldView-2 images were cut to only include the spatial extent covered by the landslides identified in Figure 8.1 and Table 8.2 and distributed by ESA through a written proposal (ID 36617). The final output to COSI-Corr processing is a deformation map which includes twodimensional horizontal displacement measurements (north/south and east/west components) and a signal-to-noise ratio (SNR) at each pixel. SNR values range from 0 (all noise) to 1 (no noise). This procedure was then repeated for all image pairs and yielded nine deformation maps, which were then summed to produce a total deformation map. 


\subsubsection{PSI}

Persistent Scatterer Interferometry (PSI) is a remote sensing technique that measures geophysical and geometric changes of ground targets using radar image stacks (Ferretti et al. 2000; Ferretti et al. 2001). Coherent points, known as persistent scatterers (PS), are identified in every image to produce a point cloud, and each PS within the point cloud includes sufficient data to create a displacement-time series. PSI has been widely used for long-term monitoring of dynamic processes, with many recent studies focusing on landslides (Bianchini et al. 2015; Oliveira et al. 2015; Piacentini et al. 2015; Sara et al. 2015; Sun et al. 2015; Xue et al. 2015; Carlà et al. 2016; Ciampalini et al. 2016; Bayer et al. 2017; Béjar-Pizarro et al. 2017; Bianchini et al. 2017; Bouali et al. 2017; Rosi et al. 2018).

Forty descending COSMO-SkyMed radar images (level 1A: single-look complex slant products) were initially acquired between 19 July 2012 and 27 September 2014 by the Italian Space Agency (ASI). Images were acquired at a frequency of $9.6 \mathrm{GHz}-$ corresponding wavelength of $3.1 \mathrm{~cm}$ (X-band) - in STRIPMAP HIMAGE mode $\left(\sim 26^{\circ}\right.$ incidence angle) with a spatial resolution of $3 \mathrm{~m}$. Images were provided by the European Space Agency (ESA) through a written proposal (ID 31684). Level 1A products arrive as focused data in slant range, complex form with no Doppler projection, and include the following pre-processing steps (performed by ASI from Level 0 RAW products): gain receiver compensation, internal calibration, data focusing, statistics estimation of the output data, and data formatting into output (Italian Space Agency 2009). COSMOSkyMed radar images were processed with the ENVI + SARscape PSI software package (Sarmap 2017). The result is a PS point cloud. Every PS in the point cloud contains the following information: displacement $(\mathrm{mm})$ at each acquisition; average velocity (mm/year); coherence; location within three-dimensional, geocoded coordinate system $(\mathrm{x}, \mathrm{y}, \mathrm{z})$; line-of-sight incidence angle and azimuth direction of radar signal; original location within slant range coordinate system (azimuth, range); precision estimates of height $(\mathrm{m})$ and velocity ( $\mathrm{mm} /$ year). 


\subsection{Results and Discussion}

Maps illustrating the spatial extent of incremental displacement as measured by 66 GPS stations (McGee 2007) between 24 September 2007 and 3 May 2017 are provided in Figure 8.2. A maximum displacement $>20 \mathrm{~m}$ (average velocity $>2 \mathrm{~m} /$ year) was measured at the toe of AcPB. The most active region of the landslide complex is within the AcPB landslide block, which experienced incremental displacements $>1.5 \mathrm{~m}$ between annual surveys (orange and red arrows in Figure 8.2). Other regions of the landslide complex that experienced displacements between $1 \mathrm{~m}$ and $1.5 \mathrm{~m}$ (light green and yellow arrows in Figure 8.2) include AC (Figures 8.2A, 8.2C, 8.2D, and 8.2I), FT (Figures 8.2A-8.2E), and AnPB (Figures 8.2A and 8.2D) although the latter is mapped as dormant old/relict (Figure 8.1).

Average horizontal downslope velocity maps, as measured between eight chronological WorldView-2 images between 20 February 2011 and 16 February 2016 using COSI-Corr, are provided in Figure 8.3. The chronological maps show average horizontal velocity values ranging from $0.5 \mathrm{~m} /$ year to $6.2 \mathrm{~m} / \mathrm{year}$. Areas with an average horizontal velocity $<0.5 \mathrm{~m} /$ year are transparent and are either stable or fall within the noise range. These average horizontal velocity results are draped over a $3 \mathrm{~m}$ digital elevation model (LAR-IAC 2006) to illustrate that deformation occurs in the downslope direction.

Widespread deformation occurred throughout the Portuguese Bend landslide complex between 20 February 2011 and 29 May 2011 (Figure 8.3A); this timeframe is also encapsulated in GPS displacement measurements between 25 October 2010 and 3 October 2011 (Figure 8.2D). These widespread, relatively high rates of deformation in early 2011 correlate with a wet rainy season (December 2010 through March 2011). As shown in Figure 8.4, precipitation during this period was well above average in neighboring Los Angeles, California, with a total of 15.15 inches of rain.

GPS, COSI-Corr, and precipitation data can be combined to create a unique, descriptive timeline of annual deformation in and around the Portuguese Bend landslide complex. 

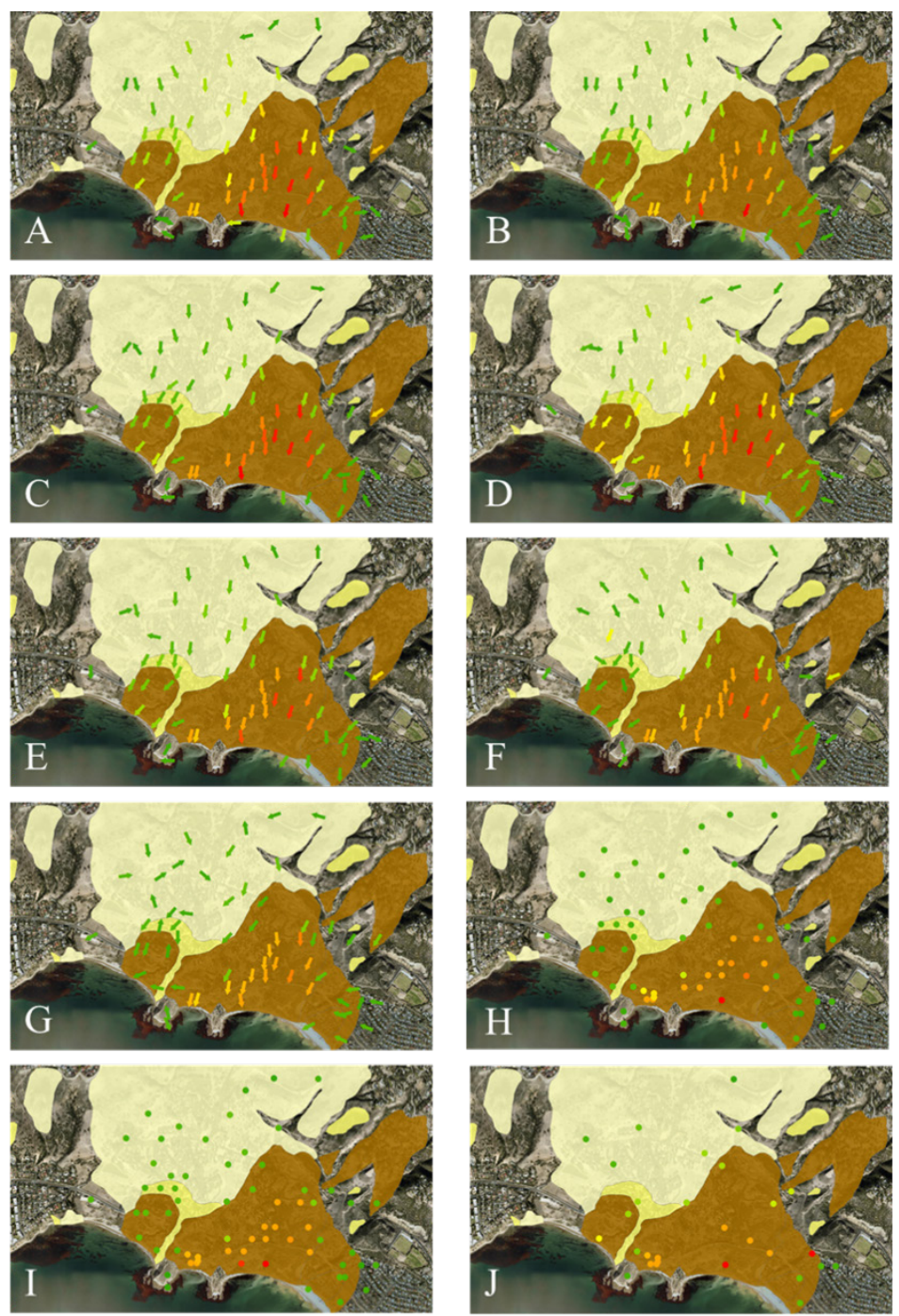

Displacement (m)
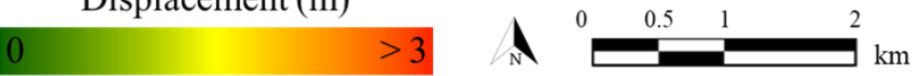

Figure 8.2: Incremental displacement (m) measured through annual GPS surveys from McGee (2007): (A) 24 September 2007 - 10 December 2008; (B) 10 December 2008 18 November 2009; (C) 18 November 2009 - 25 October 2010; (D) 25 October 2010 3 October 2011; (E) 3 October 2011 - 14 September 2012; (F) 14 September 2012 4 October 2013; (G) 4 October 2013 - 19 September 2014; (H) 19 September 2014 8 October 2015; (I) 8 October 2015 - 5 October 2016; (J) 5 October 2016-3 May 2017. Displacement magnitude shown using color scale (green to red). Displacement direction shown using arrows (displacement direction unavailable for $H, I$, and J). 

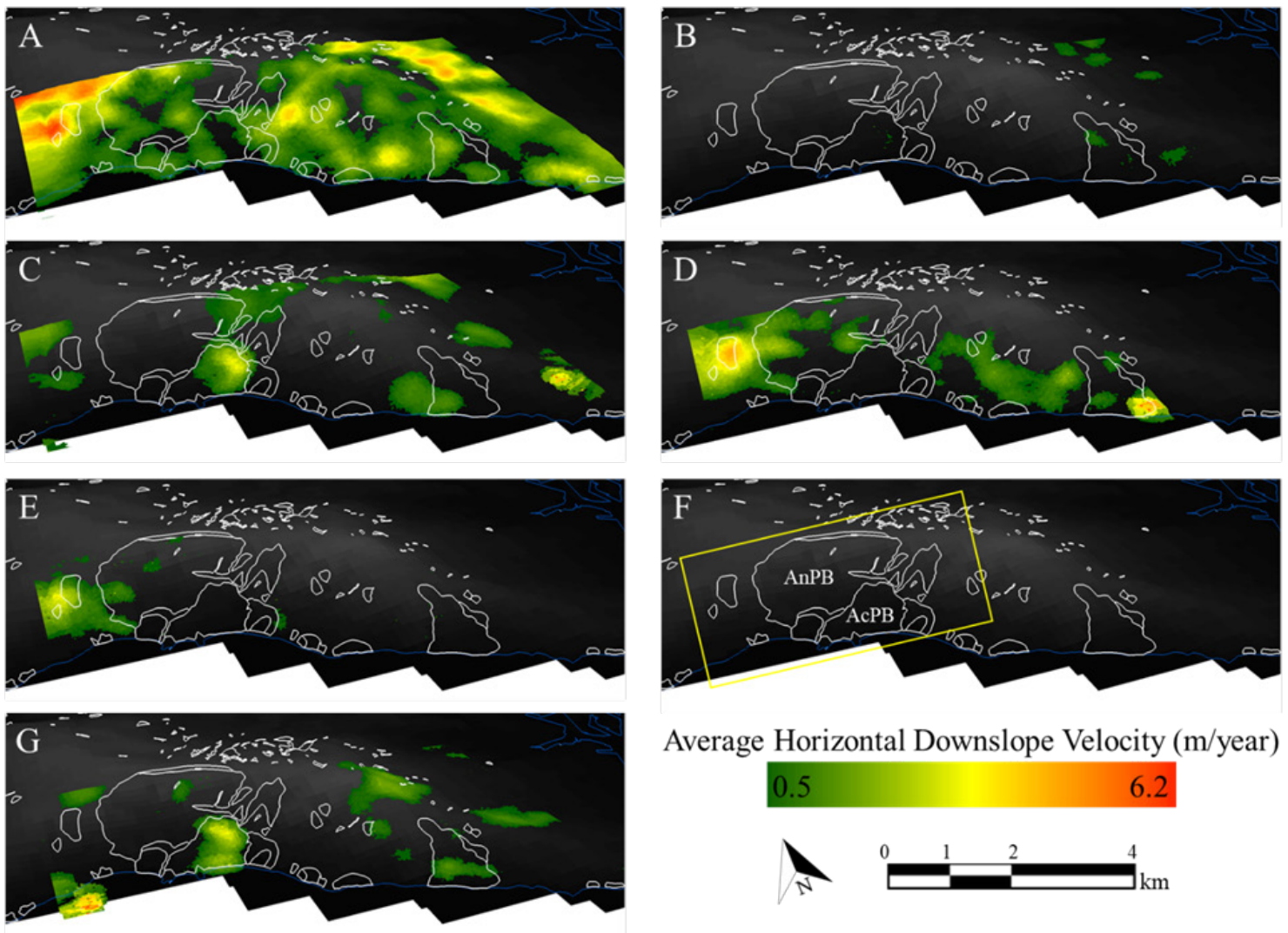

Average Horizontal Downslope Velocity (m/year)

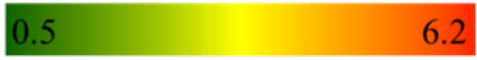

Figure 8.3: Incremental average horizontal downslope velocity (m/year) between chronological Worldview-2 image pairs. (A) 20 February 2011 - 29 May 2011; (B) 29 May 2011 - 17 February 2012; (C) 17 February 2012 - 9 November 2012; (D) 9 November 2012 - 15 September 2013; (E) 15 September 2013 - 29 March 2014; (F) 29 March 2014 - 17 September 2015; (G) 17 September 2015 - 16 February 2016. $A n P B$ and $A c P B$ are referenced in $(F)$ and the yellow rectangle delineates the approximate extent of the reference map provided in Figure 8.1. 


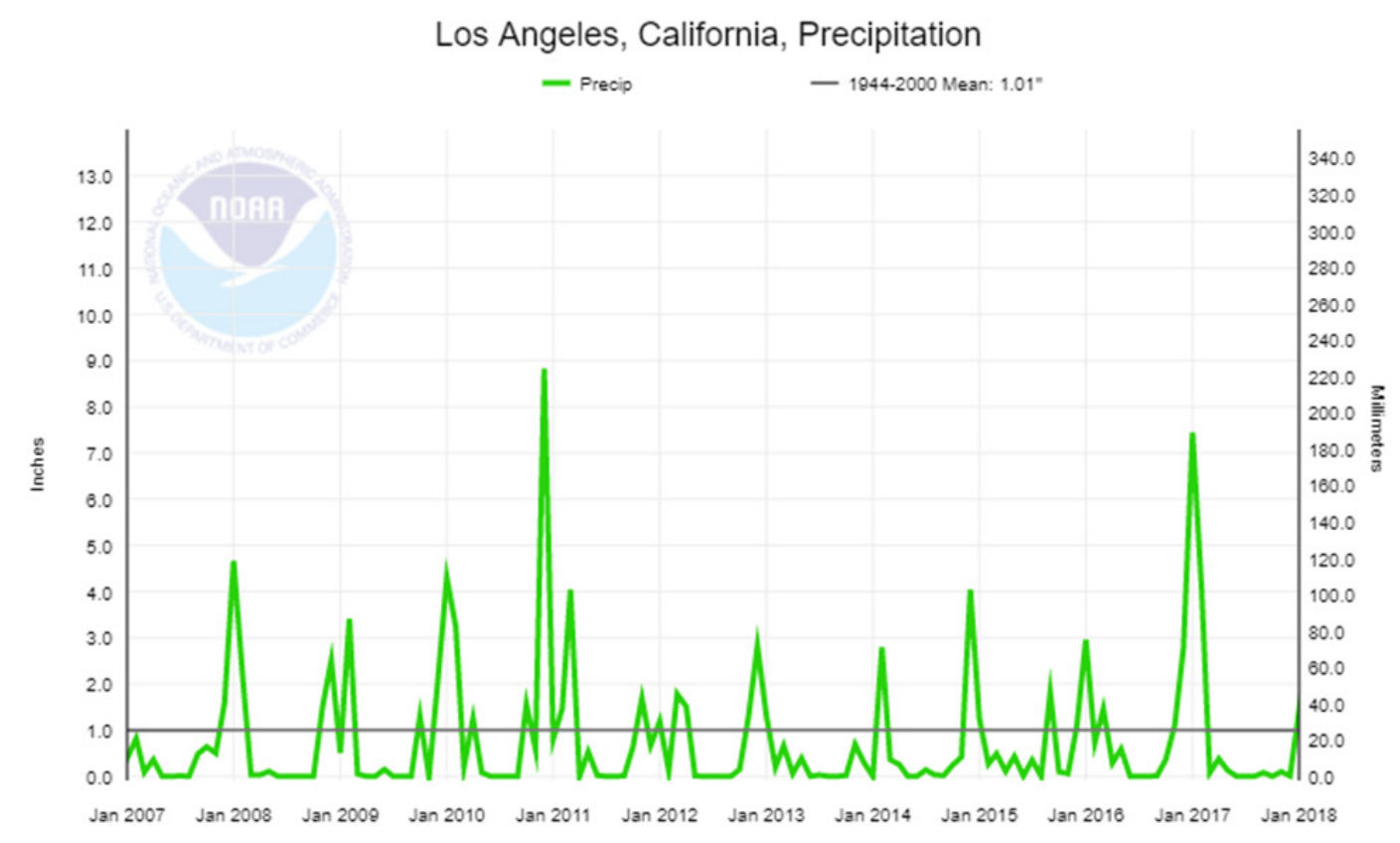

Figure 8.4: Precipitation time series for Los Angeles, California between January 2007 and January 2018 (NOAA 2018).

2007 and 2008. GPS survey begins 24 September 2007. Landslide deformation $>1.5 \mathrm{~m}$ occurs within the western and central regions of AcPB and FT (orange and red arrows in Figure 8.2A). Deformation between $1 \mathrm{~m}$ and $1.5 \mathrm{~m}$ is measured in the southeastern region of AnPB and northern/northwestern regions of AcPB (yellow arrows in Figure 8.2A). $\mathrm{KC}$ and $\mathrm{BC}$ are relatively stable.

2009. Deformation across $\mathrm{AcPB}$, although similar in extent to previous years, decreases slightly (there are more orange arrows in the central region of AcPB, Figure 8.2B). Eastern toe of FT still measures $\sim 1 \mathrm{~m}$ displacement. AnPB and AC are more stable. $\mathrm{KC}$ and $\mathrm{BC}$ are still stable.

2010. Central region of $\mathrm{AcPB}$ remains the most active and deformation has increased since 2009 (more red arrows, Figure 8.2C). Activity levels of other landslides remain the same as in 2009.

2011. Deformation increases within and around the Portuguese Bend landslide complex (Figures 8.2D and 8.3A) and correlates with rainy season (December 2010 through March 2011) with well above-average precipitation (Figure 8.4). GPS-measured 
displacements exceed $1 \mathrm{~m}$ in western and central AcPB, AC, and FT (Figure 8.2D). Average horizontal downslope velocity measurements by COSI-Corr show widespread instability, including areas not mapped as landslides, between February and May 2011 (Figure $8.3 \mathrm{~A}$ ). The study area experiences little significant deformation (none in the landslide complex) for the remainder of the year (Figure 8.3B).

2012. AcPB remains active throughout the year as shown by both GPS (Figure 8.2E) and COSI-Corr (Figure 8.3C). Adjacent slides also experience activity, such as FT and AnPB. Slides outside the Portuguese Bend landslide complex undergo movement as well.

2013. Most active landslide during this year is $P 4$. Average horizontal downslope velocity in P4 peaks at $\sim 4 \mathrm{~m} /$ year through September (Figure 8.3D) before decreasing to $\sim 3 \mathrm{~m} /$ year for the remainder of the year (Figure 8.3E). AcPB remains active, although appears to be dominated by vertical deformation since three-dimensional GPS measurements indicate $>1.5 \mathrm{~m}$ displacement (Figure 8.2F) while two-dimensional (horizontal) COSI-Corr measurements do not capture significant deformation (Figures $8.3 \mathrm{D}$ and $8.3 \mathrm{E})$.

2014 and 2015. No significant horizontal deformation measured by COSI-Corr (Figure 8.3F) until September 2015 (Figure 8.3G). GPS measurements continue to show activity throughout AcPB while adjacent landslides are stable (Figures $8.2 \mathrm{G}$ and $8.2 \mathrm{H}$ ).

2016. Average horizontal downslope velocity within AcPB ranges from $0.5 \mathrm{~m}$ (throughout landslide) to $3 \mathrm{~m}$ (near head of landslide) between September 2015 and February 2016 (Figure 8.3G). Although GPS coverage at head of AcPB is sparse, measurements indicate $>3 \mathrm{~m}$ displacement at the two of AcPB (Figure 8.2I).

2017. GPS measurements continue to show relatively high displacements $(>2 \mathrm{~m})$ across AcPB through May (Figure 8.2J).

GPS and COSI-Corr measurements can also be directly compared to analyze temporal changes at a single location in the landslide complex. A velocity time series from the $\mathrm{AcPB}$ toe is provided in Figure 8.5. AcPB toe maintains a deformation rate between 0.8 and $1.0 \mathrm{~m} /$ year from late 2007 through early 2009. Deformation then accelerates to a peak velocity $>1.6 \mathrm{~m} /$ year in June 2010. The toe then experiences a prolonged 
deceleration. After peak acceleration in June 2010 the toe steadily decelerates to a minimum velocity of $\sim 0.2 \mathrm{~m} /$ year in July 2014. GPS and COSI-Corr data show a deceleration trend, although the latter shows a semi-cyclical fluctuation with a period of $\sim 18$ months. The final GPS and COSI-Corr average velocity point indicates another period of acceleration. Both datasets provide the greatest discrepancy in velocity measurements: $\sim 0.8 \mathrm{~m} /$ year (GPS) and $\sim 1.5 \mathrm{~m} /$ year (COSI-Corr).

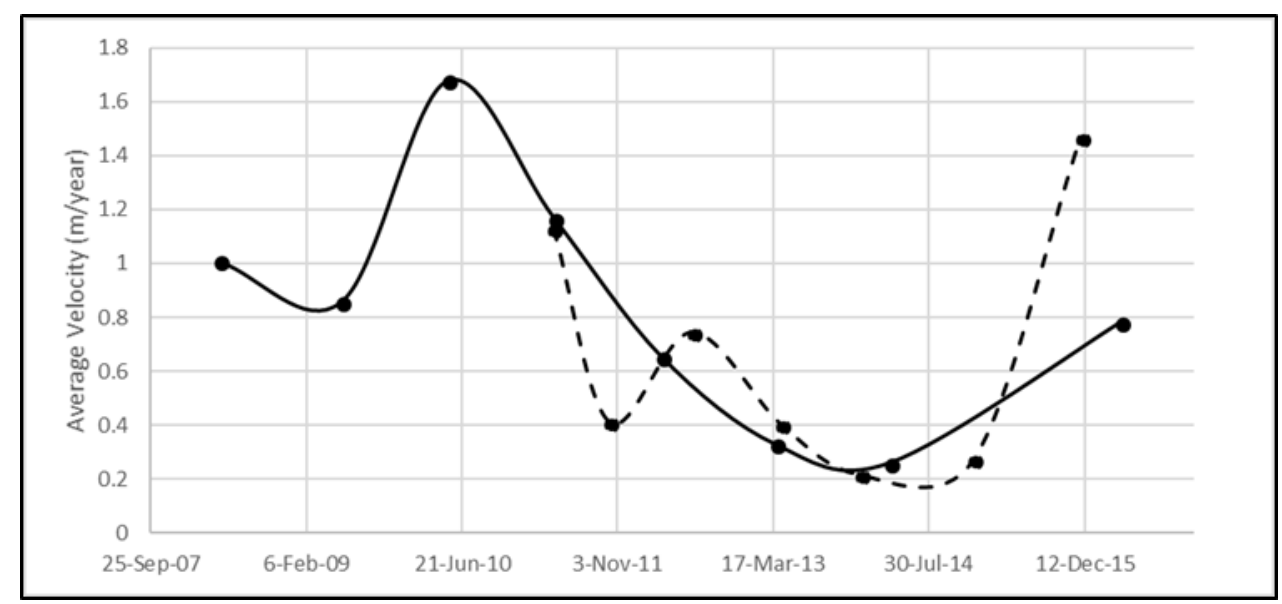

Figure 8.5: Average velocity time series with GPS (solid curve) and COSI-Corr (dashed curve) at GPS station UB-2 located at the toe of AcPB (the most active region of the Portuguese Bend landslide complex).

Neither GPS nor COSI-Corr can accurately measure extremely slow deformation of $<16 \mathrm{~mm} /$ year (Cruden \& Varnes 1996), so PSI is required for these measurements. Figure 8.6 shows PSI average velocity measurements between 19 July 2012 and 27 September 2014 across the Portuguese Bend landslide complex. PSI average velocity is measured in the line-of-sight direction $\left(26^{\circ}\right.$ from nadir, $\left.\mathrm{N} 85^{\circ} \mathrm{W}\right)$, with negative values indicating ground movement away from the satellite (which corresponds to downward and/or westward directions). There are five areas of interest that stand out when comparing PSI results with GPS and COSI-Corr.

AcPB Body. As mentioned before, this is one of the more active areas within the landslide complex. A lack of PS suggest decorrelation due to rapid deformation (which 
occurs at a velocity $>2.5 \mathrm{~cm} /$ year). PS that border AcPB exhibit velocity around $-8 \mathrm{~mm} /$ year. PS presence within AcPB appear to act as a boundary around high landslide activity areas, which are approximated well by GPS displacement measurements (yellow, orange, and red arrows in Figure 8.2).

AC and AcPB Toe. This region also shows high landslide activity (Figures 8.2 and 8.3). However, presence of PS suggests there is no decorrelation due to rapid deformation and, instead, high landslide activity is localized (e.g., GPS stations are placed in areas with local instability and nearby areas may not be as unstable, hence PS presence). In fact, there are no PS along the coast (Figure 8.6), which is where most GPS monuments are located (see Figures 8.1 and 8.2). PS presence in this region once again act as a boundary to the high landslide activity occurring along the coast.

KC. Houses in a residential neighborhood in Rancho Palos Verdes were built on the $\mathrm{KC}$ landslide, which was mapped as an active slide (Figure 8.1). These houses appear to be moving with $\mathrm{KC}$ at a velocity between -6 and $-8 \mathrm{~mm} / \mathrm{year}$ (red PS in Figure 8.6). PSI velocity values follow a general trend through this neighborhood: houses undergoing greatest velocity are in the west (atop $\mathrm{KC}$, red PS), toward the southeast are houses with moderate velocity (approximately $-4 \mathrm{~mm} /$ year, yellow PS), and further east are stable houses (green PS).

AnPB and VVG Scarp Reactivation. A region of red and yellow PS highlights a possible reactivation near the scarp of AnPB and VVG (Figure 8.6), which has been mapped as a dormant slide. Previous mapping efforts (Haydon 2007) have interestingly identified three small, historic soil slides (shallow, $<3 \mathrm{~m}$ deep) within AnPB and VVG (small brown areas, Figure 8.1). PSI results indicate the possibility of a larger, slow-moving landslide with a triangular shape that mirrors the location of the historic soil slides. The historic soil slides may be small, surficial slides caused by relatively slow movement of a larger block. PSI results give a reason to believe there may be an extremely slow reactivation near the historic scarp of the AnPB and VVG landslides.

P4. This landslide was previously mapped as a dormant slide (Haydon 2007) and has not been studied in any recent landslide analysis of the Palos Verdes Peninsula. P4 is home to the $0.40-\mathrm{km} 2$ Three Sisters Reserve, one of ten reserves that make up the Palos 
Verdes Nature Preserve. COSI-Corr total horizontal displacement measurements indicate the entire region surrounding $\mathrm{P} 4$ is undergoing significant deformation: an average velocity of 1.20 m/year (2011-2016) and peak velocities exceeding $4 \mathrm{~m} /$ year in early 2011 and between November 2012 and March 2014. PSI results support the general assessment of P4 instability (Figure 8.6): there are few PS within the P4 (except for relatively stable points in the south and west), and there is a large areal swath of relatively high-velocity PS (red and orange, between -5 and $-8 \mathrm{~mm} /$ year) in the residential neighborhood to the north.

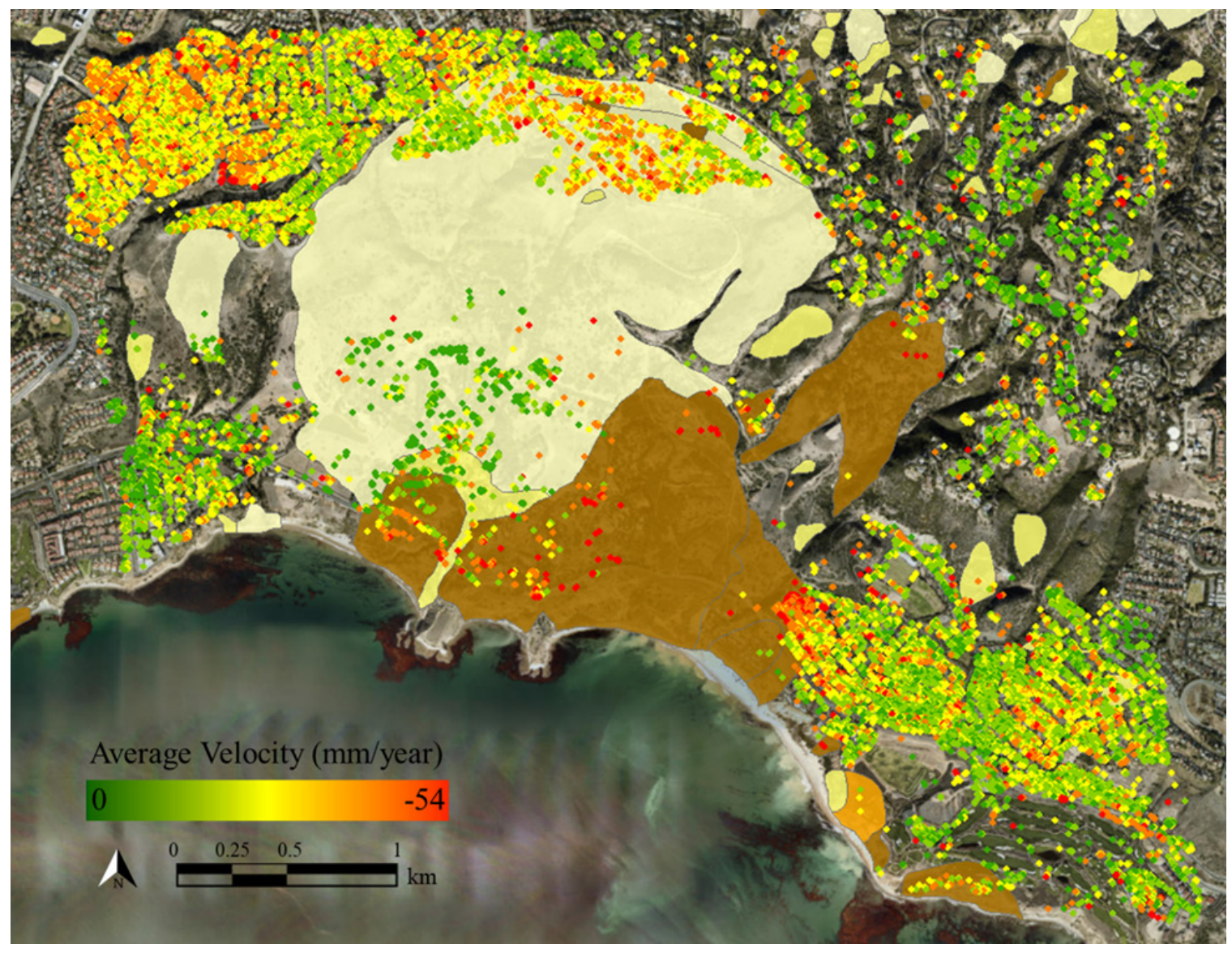

Figure 8.6: Average velocity (mm/year) between 19 July 2012 and 27 September 2014 measured using 40 COSMO-SkyMed images with PSI processing. Negative velocity values measure deformation away from the satellite. 


\subsection{Final Landslide Deformation Map}

A final landslide deformation map is provided in Figure 8.7. This map, which segments landslide activity based on Cruden and Varnes (1996) landslide velocity scale, is divided as follows: slow (velocity $>1.6 \mathrm{~m} /$ year), very slow (velocity between $16 \mathrm{~mm} /$ year and $1.6 \mathrm{~m} /$ year), and extremely slow (velocity $<16 \mathrm{~mm} /$ year). Stable areas, those with no sustained deformation throughout the study period, are not labeled. Below are listed additional notes on how PSI, COSI-Corr, and GPS deformation data were converted into the final landslide deformation map.

Slow Landslides. No location within the landslide complex moved at an average velocity $>1.6 \mathrm{~m} /$ year over the entire span of GPS or COSI-Corr observations. However, 14 GPS monuments experienced a velocity $>1.6 \mathrm{~m} /$ year for a portion of the study period. The areal extent of these 14 GPS monuments cover the slow landslide area in Figure 8.7.

Very Slow Landslides. These are portions of the landslide complex that were consistently moving, as measured by COSI-Corr and GPS. There was typically a lack of PS presence in these areas since a velocity of $16 \mathrm{~mm} /$ year is near the maximum PS velocity threshold of $25 \mathrm{~mm} /$ year.

Extremely Slow Landslides. Velocity $<16 \mathrm{~mm} /$ year is below the accuracy of COSI-Corr and GPS measurements and, therefore, mapping of these areas relied exclusively on PSI results.

Stable Areas. Areas were considered stable if (1) COSI-Corr and GPS measurements were below the accuracy threshold and (2) PS with a velocity of $\sim 0 \mathrm{~mm} /$ year were present. 


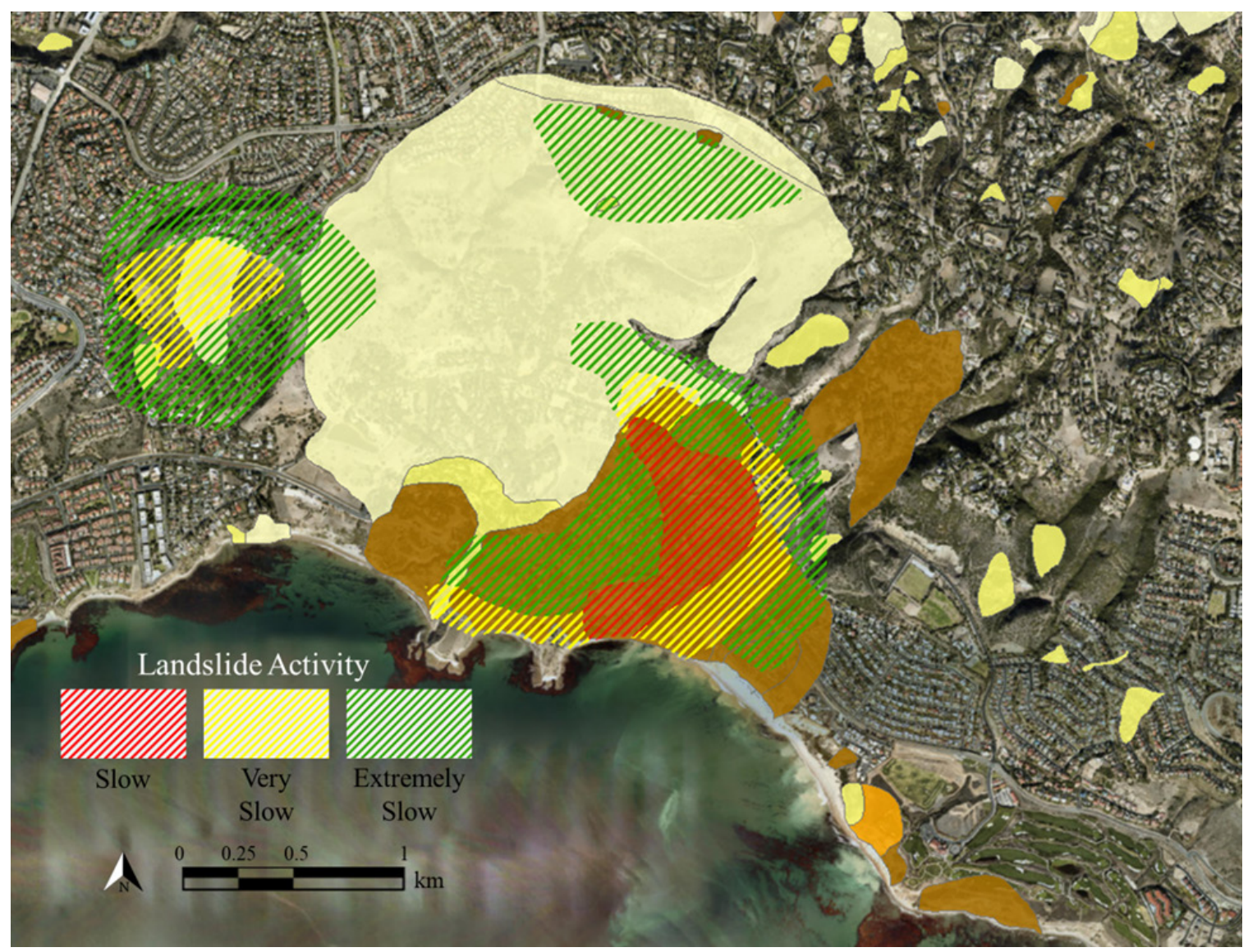

Figure 8.7: Activity within landslide complex based on Cruden and Varnes (1996) landslide velocity scale. Slow landslide area (velocity $>1.6 \mathrm{~m} / \mathrm{year}$ ) denoted by red diagonal hashes. Very slow landslide area (velocity between $16 \mathrm{~mm} /$ year and $1.6 \mathrm{~m} /$ year) denoted by orange horizontal hashes. Extremely slow landslide area (velocity $<16$ mm/year) denoted by yellow diagonal hashes. Landslide activity, as previously mapped (McMillan \& Haydon 1998a, 1998b, \& 1998c; Haydon 2007), same as Figure 8.1.

\subsection{Conclusion}

Continuously-moving landslides, such as the Portuguese Bend landslide complex on the Palos Verdes Peninsula in southern California, are ideal locations for multi-sensor monitoring. The premise is that each technique (PSI, COSI-Corr, and GPS), when analyzed together, provides an advantage where the others might be limited (see Table 8.1). Forty COSMO-SkyMed radar images (2012-2014) were processed using PSI to measure average 
velocity, eight WorldView-2 (2011-2016) optical images were processed using COSI-Corr to measure average horizontal downslope velocity, and 66 GPS monuments (2007-2017) were used to measure incremental displacement. This approach allowed for delineation of active zones within the landslide complex (during the study period between 2007 and 2017). A final landslide deformation map was produced (Figure 8.7), which divides the landslide complex into three activity categories based on the Cruden \& Varnes (1996) velocity scale: slow (>1.6 m/year), very slow (between $16 \mathrm{~mm} /$ year and $1.6 \mathrm{~m} / \mathrm{year}$ ), extremely slow ( $<16 \mathrm{~mm} /$ year), and stable. Average velocity measurements obtained in this study match those of previous studies (Calabro et al. 2010; City of Rancho Palos Verdes 2012) and older observations (Ehlig 1992; Proffer 1992; Kayen et al. 2002; Haydon 2007).

\subsection{Acknowledgements}

This study was funded by the NASA Earth and Space Science Fellowship Program (proposal 16-EARTH16F-0086). COSMO-SkyMed images were acquired by the Italian Space Agency and provided by the European Space Agency (ESA, proposal ID 31684). ENVISAT images were acquired and provided by ESA (proposal ID 82169). WorldView2 images were acquired by Digital Globe and provided by ESA (proposal ID 36617). California landslide inventory shapefile was provided by the California Geological Survey and the California Department of Conservation. GPS survey reports were provided by the City of Rancho Palos Verdes, California. Digital elevation models were provided by the Jet Propulsion Laboratory and the United States Geological Survey. Precipitation data for Los Angeles, California were provided by the National Oceanic and Atmospheric Administration. 


\section{Chapter 9: Future Work in Landslide Prediction}

\subsection{Introduction}

The consequences of slope instability (e.g., landslides, rockfalls, debris flows) are severe across the world. United States Geological Survey (USGS) estimated a cost of $\$ 3.5$ billion annually was required to repair slope instability damages in US, 25-50 deaths annually, reduced real estate values, loss of productivity, and damage to natural environments (USGS 2005). A 2012 study in Geology found that loss of life is usually underestimated and between 2004 and 2010 a total of 2,620 fatal landslides caused 32,322 deaths globally, which is an order of magnitude greater than previously calculated (Petley 2012). A recent example, the Oso, Washington mudslide which occurred on March 22, 2014 covered an area of approximately 1 square mile, killed 43 people and caused approximately $\$ 42 \mathrm{M}$ in damage and clean-up according to Governor Inslee of Washington state (AP 2014; BBC 2014), and cost \$28.1M to rebuild highway SR 530 (WSDOT 2015). The complexity and confusion surrounding predicting when landslides occur can be summed up by the responses of officials and academics during the two days after the Oso slide: John Pennington (Snohomish County Department of Emergency Management Director) claimed the slide was "completely unforeseen" and "came out of nowhere," yet Daniel Miller (geomorphologist at the Earth Systems Institute) wrote a report in 1997 basically predicting this landslide (Green et al. 2014) having knowledge of the unstable geology of the region (Haugerud 2014). The Oso mudslide only partially illustrates the difficulties in dealing with landslides: not only are they frequent, seemingly unpredictable, and can cause heavy damage, but the myriad of landslide triggers and mechanisms (Highland \& Bobrowsky 2008) can result in unstable slopes in all 50 states (Radbruch-Hall et al. 1982). Types of landslides differ widely by region, including mountainous avalanches and slides (Radbruch-Hall et al. 1976), alluvial fan slides (Blair 
and McPherson 1994), or unstable bluffs along lakeshore environments (Chase and Kehew 2000). A common complaint after devastating landslides of any sort is the lack of forewarning. This has led research into the study of landslide forecasting.

\subsection{Future Work in Landslide Prediction}

Conventional monitoring techniques require the installation of invasive, in situ instrumentation such as inclinometers, piezometers, and/or accelerometers to measure rotational displacement, ground water levels (convert to pore pressure), and the change in displacement rates, respectively. The installation of this instrument suite, although exceptionally useful (e.g., inclinometers alone can measure landslide movement direction, magnitude, rate, and depth), does have some downsides, including requiring upfront cost of installation and continued upkeep of the instruments, the common accidental improper installation resulting in the underachievement of actual slope monitoring (Stark and Choi 2008), and alteration of the environment in and on top of the slope. Regardless, much progress has been made in the way of in situ data analysis toward landslide monitoring and slope failure prediction.

Fukuzono (1985) and Voight (1989b) developed a relationship between a material's time of failure and its strain rate. This relationship has been successfully applied to the prediction of slope failure using in situ data. Voight (1989a), Kilburn and Voight (1998), and Petley et al. (2002) applied the relationship proposed by Voight (1989b). The authors quantified a relation between the strain rate applied to a material and it's time of failure between metals (e.g., aluminum, nickel, and titanium) and soils (e.g., mixed mineral soil, Haney clay). The relationship is as follows:

$$
\dot{\Omega}^{-\alpha} \ddot{\Omega}-A=0
$$

where $\alpha$ and $\mathrm{A}$ are constants and $\Omega$ is the strain of the deforming material (equation 1 from Voight 1989b). Time of failure may be approximated by plotting the inverse velocity $\left(\dot{\Omega}^{-\alpha}\right)$ or acceleration $(\ddot{\Omega})$, on the $y$-axis, with respect to time. Material failure occurs when the inverse velocity approaches zero $\left(\dot{\Omega}^{-\alpha} \rightarrow 0\right)$ or, likewise, when the acceleration 
asymptotically approaches infinity $(\ddot{\Omega} \rightarrow \infty)$. The approximate time at which $\dot{\Omega}^{-\alpha} \rightarrow 0$ or $\ddot{\Omega} \rightarrow \infty$ occurs is the time at which the material has failed.

Figure 9.1 shows two example plots by Petley et al. (2002) where two sets of readings from inclinometers located within the Selborne landslide were converted into $\Lambda$ measurements (with units of days/millimeter). Since $1 / \mathrm{v}=0$ is impossible, applying a basic best-fit trend line in the form of $\Lambda=\mathrm{mt}+\mathrm{b}$ (for a linear $\Lambda$-t relationship), where $\mathrm{m}$ is the slope and $\mathrm{b}$ is the $\Lambda$-intercept, and solving for $\mathrm{t}$ yields a predicted time for slope failure. A linear $\Lambda$-t relationship has been observed in cases where brittle deformation or failure along pre-existing planes of weakness (e.g., shear zones, faults, scarps) occurs (Petley et al. 2002; Kilburn and Petley 2003; Petley 2004). Nonlinear $\Lambda$-t relationships have also been observed and have been interpreted as landslides exhibiting a ductile failure mechanism (Angeli et al. 1989; Petley et al. 2002; Petley and Petley 2004; Federico et al. 2012; Wartman \& Malasavage 2013). A time integration of the model from Voight (1989b) allows for the calculation of the landslide velocity, $V(t)$ :

$$
V(t)=\left[A(\alpha-1)\left(t_{f}-t\right)+V_{f}^{1-\alpha}\right]^{\frac{1}{1-\alpha}}
$$

where $V_{f}$ is the velocity at the time of failure $\left(t_{f}\right)$. Wartman \& Malasavage (2013) found that predicting slope failures using linear regression works better "with data collected closer to failure... but at the cost of reduced warning time" while nonlinear models "produce an excellent fit over the full time range of observed displacements" but requires "back-fit empirical parameters" (p747) which limits its application for landslide failure predictions. 

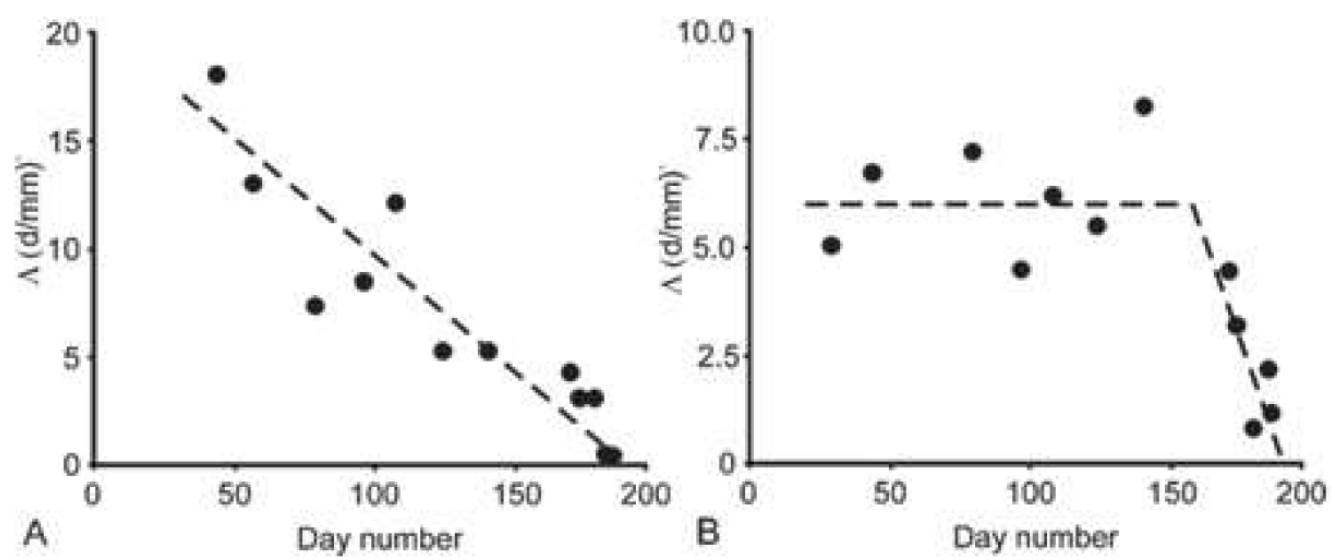

Figure 9.1: 1-t plots for two inclinometers experiencing different deformation rates at separate times. (A) This inclinometer experienced linear acceleration (slope of trend line) until failure at day 180. (B) This inclinometer experienced steady-state creep (horizontal trend line) until day 152 when a sudden increase in acceleration was observed until failure on day 180. Image taken from Petley et al. (2002).

Unfortunately, in situ instrumentation is costly and not practical to use for comprehensive monitoring and prediction of largescale landslides. Remote sensing (satellite-based optical and radar imagery) has proven to be a nonintrusive and costeffective alternative option for the long-term monitoring of landslides (Mantovani et al. 1996; Temesgen et al. 2001; Metternicht et al. 2005; Tralli et al. 2005). There are a few advantages that remote sensing has over in situ measurements: (1) the ability to repeatedly cover large swaths of land over relatively short periods of time, (2) the capability of acquiring data over an entire slope as opposed to point-source data, and (3) the fact that remote sensing is noninvasive and does not impact the environment or geotechnical infrastructure in any way. Many studies have demonstrated the advantage of satellite remote sensing techniques for landslide monitoring (Rathje et al. 2006; Raspini et al. 2013; Suncar et al 2013; Schaefer et al. 2015; Schlögel et al. 2015). Rathje et al. (2006) found that satellite-based optical imagery allowed researchers to "capture the extent of damage" and "to consider fully the context of failure" (p841). Suncar et al. (2013) later showed that deformation rates calculated from high resolution optical imagery correlated well with GPS 
ground stations. Schlögel et al. (2015) were able to use satellite-based radar imagery to map displacement patterns to infer geomorphological structure and landslide deformation type (e.g., rotational slide, translational slide, and complex slide). Even with successful application of satellite-based techniques towards landslide monitoring, there have been no studies utilizing the satellite derived data toward landslide prediction, like that of in situ measurements plotted in $\Lambda$-t space, as described by Voight (1989a).

Information gained from landslide prediction will also benefit landslide hazard and risk assessments. Landslide hazard assessment determines the probability of landslide occurrence within a specific period. Landslide risk is the product of its hazard, the potential outcomes, and the elements (e.g., infrastructure, people, etc.) at risk. An example risk assessment workflow, recreated from Dai et al. (2002), is provided in Figure 9.2. Most of the data required for landslide hazard and risk assessment (Triggering Factors, Preparatory Factors, Landslide Inventory, Land Use, and Elements at Risk) can be obtained through geographic information systems (GIS) layers from various sources. Probability of Landslide and Runout Behavior can utilize results from the inverse velocity method and slope stability models. The Vulnerability Assessment, Hazard Assessment, and Risk Assessment can be performed like previously published geotechnical and landslide assessments (Dai et al. 2002; Dilger and Halstead 2005; Pantelidis 2011 and citations therein; Anderson \& Rivers 2013; Metzger et al. 2014; Hutchinson et al. 2015). 


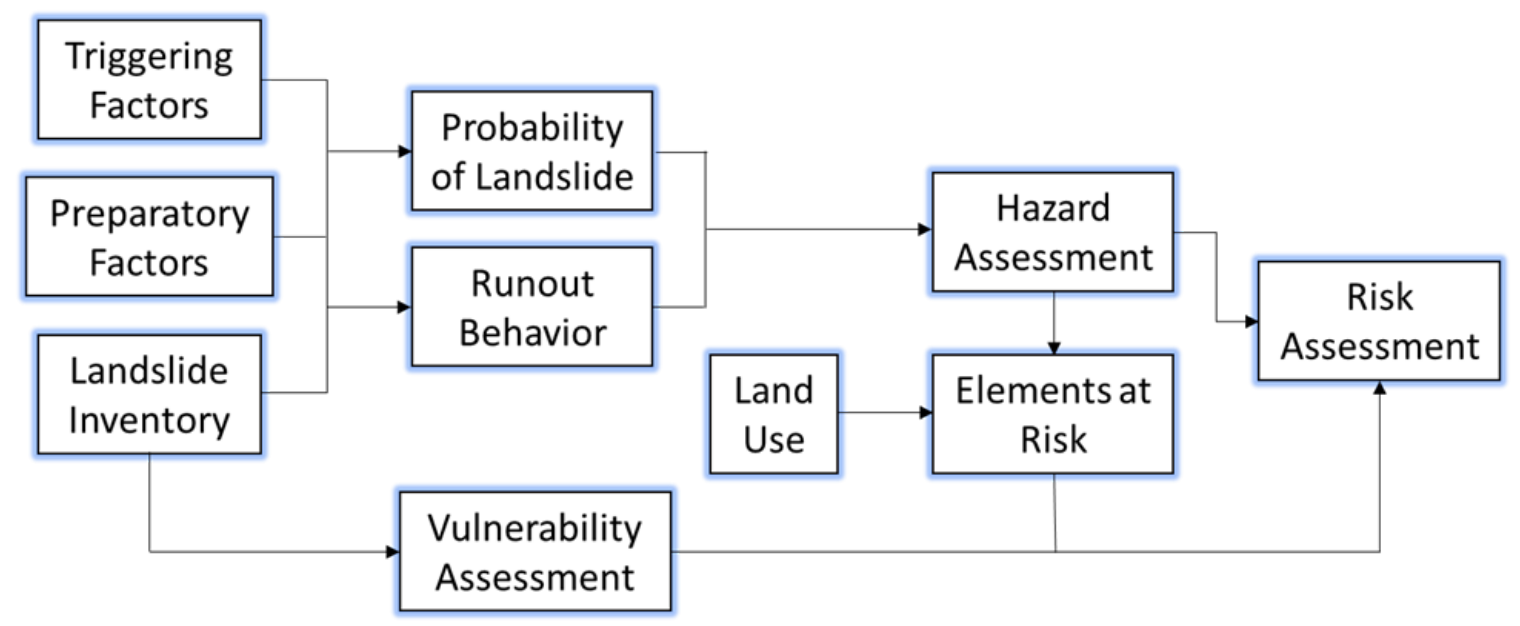

Figure 9.2: Landslide hazard and risk assessment framework (recreated from Dai et al. 2002).

\subsection{Preliminary Results in Landslide Prediction}

The first preliminary test of applying displacement time-series and $\Lambda$-t plots toward slope monitoring and prediction have been conducted on a rock slope in southeastern Nevada (slope studied in Chapters 2 and 3). The slope in question has experienced two forms of slope instability since blasting occurred in January 2005: (1) occasional rockfalls, and (2) rotational ( $\sim 2-5 \mathrm{ft}$ ) and extensional displacements (up to $20 \mathrm{ft}$ ) concentrated along the scarp. The objective of this test was to examine whether the use of SB-InSAR could (1) identify the large, unstable portion of the slope, and (2) monitor the deformation experienced on the slope, mainly the fact that the slope was stable prior to January 2005 and unstable afterwards.

Although the slope has yet to fail, a $\Lambda$-t plot (Figure 9.3) was generated for one of the three DS points exhibiting relatively high displacement along the slope face (Figure 3.7). The $\Lambda$-t plot illustrates the variable amounts of deformation and displacement mechanism types experienced by the slope between 1992 and 2011. The slope appears to become more stable from 1992 to 2001, where the inverse velocity increases from 100 days $/ \mathrm{mm}$ to almost 1,000 days $/ \mathrm{mm}$. Figure 9.3(B) shows the zoomed-in portion of the $\Lambda$-t plot from 2003 to 2010, where the overall $\Lambda$-t trend appears to be nonlinear (ductile). Figure 9.3(C) then shows the portion of the $\Lambda$-t plot from 2009 to 2010 , where the overall $\Lambda$-t plot 
has changed to a linear (brittle) inverse velocity curve. This indicates a potential change in displacement regime (e.g., a transition from extensional displacement to rotational sliding?). Further investigation is required.

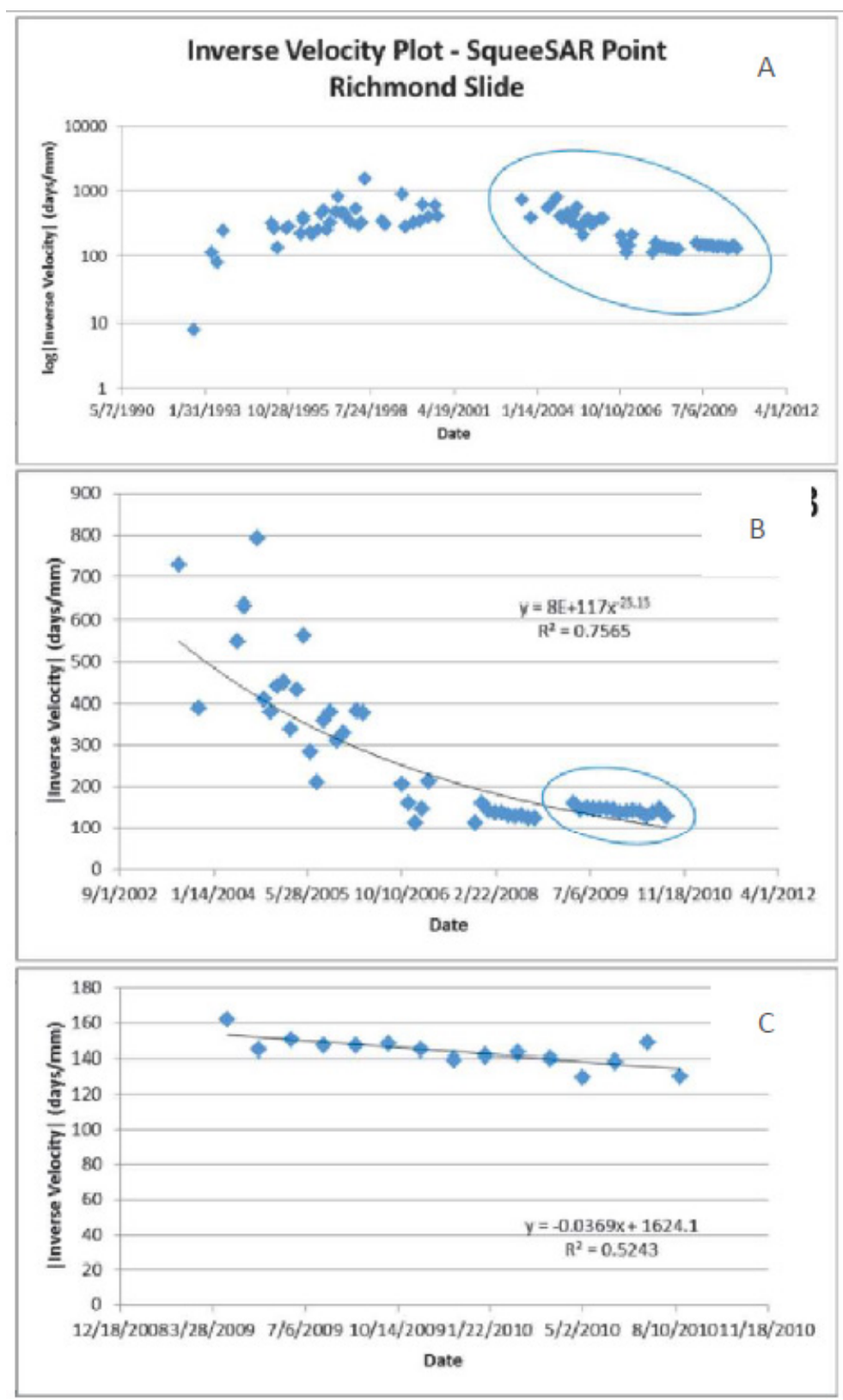

Figure 9.3: Inverse velocity plots of one DS point generated from the SqueeSAR ${ }^{\mathrm{TM}}$ technique at slope S-1 (aka Richmond Slide) from Figure 3.7. 
The second preliminary result continues the work on the Palos Verdes Peninsula landslide complex discussed in Chapter 8. In additional to the spatial analysis of Persistent Scatterer Interferometry (PSI), Co-registration of Optically Sensed Images and Correlation (COSI-Corr), and global positioning system (GPS) displacement and velocity data, a temporal analysis of these data at specific locations within a landslide can yield results on landslide history (e.g., periods of acceleration and deceleration). A velocity-time series from measurements at a GPS monument located on the toe of AcPB (Figure 8.1), along with corresponding COSI-Corr horizontal velocity calculated from Kriging interpolation (from Figure 8.6), is provided in Figure 9.4. Average velocity $(\bar{V})$ is calculated with the following equation:

$$
\bar{V}=\frac{d_{T}}{\left(i_{n+1}-i_{n}\right)}
$$

where $d_{T}$ is the total displacement (GPS) or total horizontal displacement (COSI-Corr) and $\left(i_{n+1}-i_{n}\right)$ is the timespan between image pairs. Landslide activity at the AcPB toe can be divided into three temporal activity states.

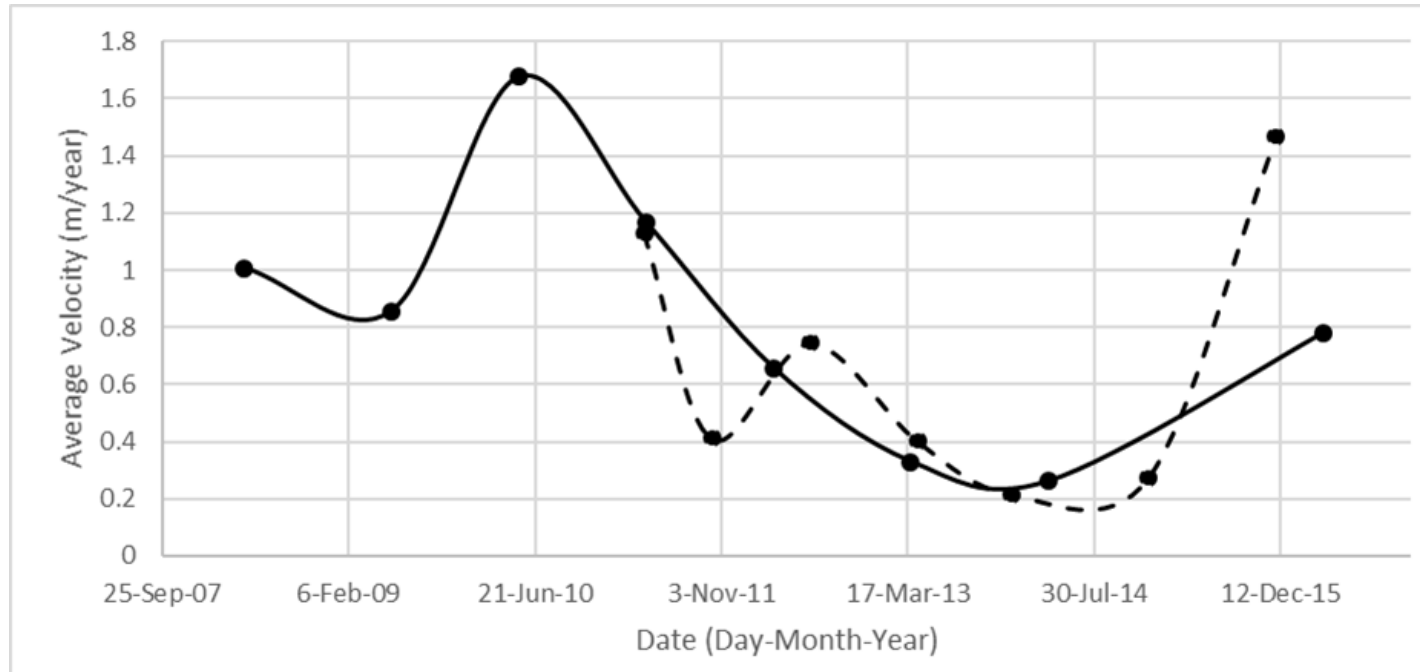

Figure 9.4: Velocity-time series of GPS monument (Figure 8.1) and COSI-Corr in m/year. Each point is plotted at the middle date within image pairs (e.g., average velocity between February 20, 2011 and May 29, 2011 is plotted on April 10, 2011). 
September 2007 - June 2010. AcPB toe maintained a deformation rate between 0.8 and $1.0 \mathrm{~m} /$ year from late 2007 through early 2009. Rate of deformation then accelerated to a peak $>1.6 \mathrm{~m} /$ year in June 2010. Only GPS data are available for this period.

June 2010 - July 2014. The toe then experienced a prolonged deceleration. Postpeak acceleration in June 2010, the toe steadily decelerated to a minimum deformation rate of $\sim 0.2 \mathrm{~m} /$ year in July 2014. GPS and COSI-Corr data show a deceleration trend, although the latter shows a semi-cyclical fluctuation with a period of $\sim 18$ months.

July 2014 - December 2015. The final GPS and COSI-Corr average velocity point indicates another period of acceleration occurred. Unfortunately, neither dataset extends past January 2016. Both datasets also provide the greatest difference in deformation rates: GPS at $\sim 0.8 \mathrm{~m} /$ year and COSI-Corr at $\sim 1.5 \mathrm{~m} /$ year.

This is an example of preliminary temporal analysis of GPS, COSI-Corr, and PSI data within the landslide complex on the Palos Verdes Peninsula. The remainder of this paper focuses on spatial analysis of velocity measurements, but future work in temporal analysis includes spatial representation of acceleration/deceleration periods (e.g., annual maps that show which areas of acceleration, deceleration, or constant velocity across the landslide complex) and the possibility of landslide prediction (e.g., Inverse Velocity Method). 


\section{Chapter 10: Conclusions}

\subsection{Introduction}

The motivation of research presented in this dissertation is on the use of remote sensing to monitor ground deformation across assets (e.g., stable and unstable slopes, dams, and urban infrastructure) as an efficient and cost-effective geotechnical asset management approach. Previous chapters have focused on outputs of remote sensing techniques, mainly spatial and temporal distribution of ground deformation (in terms of displacement, velocity, or acceleration). In contrast, this chapter provides brief concluding thoughts on the remote sensing techniques themselves through a series of comparisons. Section 10.2 examines how differences in various parameters (e.g., radar wavelength, spatial resolution, coherence, etc.) influence deformation results from radar sensors. Section 10.3 compares the performance of radar and optical sensors. The remaining sections look at recent and future research in combining radar, optical, and Global Positioning System (GPS) datasets (Section 10.4) and use of unmanned aerial vehicles (UAVs) for high-resolution data collection (Section 10.5).

\subsection{Synthetic Aperture Radar Sensors}

Many satellites include synthetic aperture radar (SAR) sensors (Table 10.1). Optimal application of SAR data depends on a variety of parameters. A discussion and comparison of these parameters is provided below, including radar wavelength (Section 10.2.1), spatial resolution (Section 10.2.2), and coherence (Section 10.2.3). 
Table 10.1: Historic, present, and future satellites with SAR sensors.

\begin{tabular}{|c|c|c|c|}
\hline Satellite & $\begin{array}{c}\text { Acquisition } \\
\text { Period }\end{array}$ & Operator & $\begin{array}{c}\text { Radar } \\
\text { Wavelength } \\
\text { (Band) }\end{array}$ \\
\hline ERS-1 & $1991-2000$ & $\begin{array}{c}\text { European Space } \\
\text { Agency (ESA) }\end{array}$ & C-Band \\
\hline JERS-1 & $1992-1998$ & $\begin{array}{c}\text { Japan Aerospace } \\
\text { Exploration Agency } \\
\text { (JAXA) }\end{array}$ & L-Band \\
\hline ERS-2 & $1995-2011$ & ESA & C-Band \\
\hline Radarsat-1 & $1995-2013$ & $\begin{array}{l}\text { Canadian Space } \\
\text { Agency (CSA) }\end{array}$ & C-Band \\
\hline ENVISAT & $2002-2012$ & ESA & C-Band \\
\hline ALOS-1 & $2006-2011$ & JAXA & L-Band \\
\hline $\begin{array}{l}\text { COSMO- } \\
\text { SkyMed }\end{array}$ & $2007-$ present & $\begin{array}{l}\text { Italian Space Agency } \\
\text { (ASI) }\end{array}$ & X-Band \\
\hline TerraSAR-X & & $\begin{array}{l}\text { Deutsches Zentrum } \\
\text { für Luft- und } \\
\text { Ramfahrt e.V. (DLR) }\end{array}$ & X-Band \\
\hline Radarsat-2 & 2007 - present & CSA & C-Band \\
\hline TanDEM-X & 2010 - present & DLR & X-Band \\
\hline RISAT-1 & $2012-$ present & $\begin{array}{c}\text { Indian Space } \\
\text { Research } \\
\text { Organization (ISRO) }\end{array}$ & C-Band \\
\hline KOMPSAT-5 & 2013 - present & $\begin{array}{l}\text { Korean Areospace } \\
\text { Research Institute } \\
\text { (KARI) }\end{array}$ & X-Band \\
\hline ALOS-2 & 2014 - present & JAXA & L-Band \\
\hline Sentinel-1A & 2014 - present & ESA & C-Band \\
\hline Sentinel-1B & 2016 - present & ESA & C-Band \\
\hline PAZ & 2018 & $\begin{array}{c}\text { Instituto National de } \\
\text { Técnica Aeroespacial } \\
\text { (INTA) }\end{array}$ & X-Band \\
\hline $\begin{array}{l}\text { COSMO- } \\
\text { SkyMed SG }\end{array}$ & 2018 & ASI & X-Band \\
\hline $\begin{array}{l}\text { RADARSAT } \\
\text { Constellation }\end{array}$ & 2018 & CSA & C-Band \\
\hline SAOCOM-1a, b & 2018, 2019 & $\begin{array}{c}\text { Comision Nacional de } \\
\text { Actividades } \\
\text { Espaciales } \\
\end{array}$ & L-Band \\
\hline NISAR & 2020 & $\begin{array}{l}\text { ISRO and National } \\
\text { Aeronautics and }\end{array}$ & L-Band \\
\hline
\end{tabular}




\begin{tabular}{|c|c|c|c|}
\hline & & $\begin{array}{c}\text { Space Administration } \\
\text { (NASA) }\end{array}$ & \\
\hline TanDEM-L & 2022 & DLR & L-Band \\
\hline
\end{tabular}

\subsubsection{Radar Wavelength}

The wavelength of a transmitted radar wave is one of the most important parameters for a satellite sensor. Radar wavelength $(\lambda)$ defines the modulo- $2 \pi$ phase change scale and is inversely proportional to the phase change $(\phi)$, as shown in Figure 10.1 and displayed in the following equation:

$$
\phi=2 R \frac{2 \pi}{\lambda}
$$

where $\mathrm{R}$ is the slant-range distance is doubled to incorporate the two-way travel distance. Since $\lambda$ is an engineered parameter in the radar sensor (e.g., an independent variable) and $\mathrm{R}$ is directly proportional to $\phi, \lambda$ determines the maximum $\mathrm{R}$ that can be measured with one full $\phi$-cycle. This can be quantified by setting $\phi=2 \pi$ (one $\phi$-cycle) and solving the previous equation for R:

$$
R=\frac{\lambda}{2}
$$

Therefore, the maximum $\mathrm{R}$ measurable by any radar sensor (without repeating phase values) is $\lambda / 2$. For example, ERS-1, ERS-2, and ENVISAT used radar sensors with $\lambda \approx 5.6 \mathrm{~cm}$, resulting in a maximum $\mathrm{R} \approx 2.8 \mathrm{~cm}$ (between image pairs without phase ramps). 


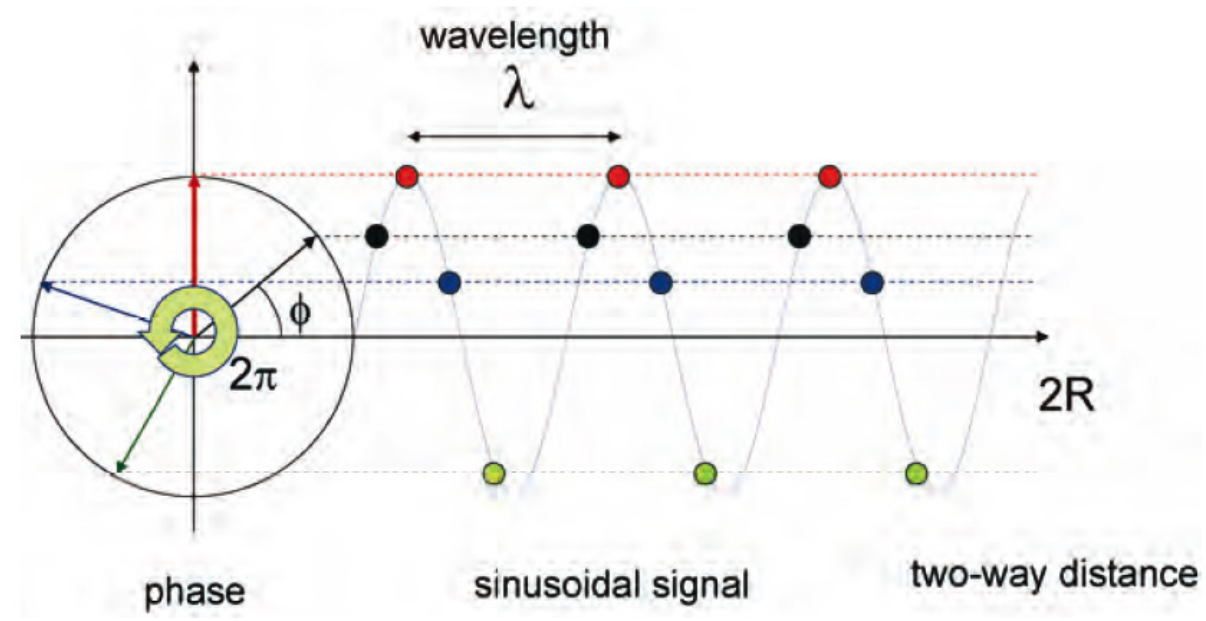

Figure 10.1: Radar wave shown as a sinusoidal function with period of $2 \pi$ radians. Identically-colored points (black, red, blue, and green) correspond to a respective phase change value between 0 and $2 \pi$. Image taken from Part A of the European Space Agency InSAR Users Guide (Ferretti et al. 2007a).

Radar sensors that transmit different wavelengths may also record different phase changes due to radar interaction with ground targets that have experienced physical changes from various sources (Ferretti et al. 2007b), including vegetation (random geometric changes) and irrigation, flooding, or precipitation (changes in moisture content, electrical conductivity, and volume of swelling soils). For example, radar sensors using longer wavelengths are less affected by random geometric changes (e.g., decorrelation) caused by vegetation; thus, L Band performs better than $\mathrm{C}$ Band which performs better than X band and has been shown in previous studies (Kellndorfer et al. 2004; Garestier et al. 2008; Bergen et al. 2009; Wei and Sandwell 2010; Ahmed et al. 2011).

Based on the intrinsic wavelength-phase change-slant range distance relationship, radar sensors perform better at certain study sites. Short wavelength (e.g., X Band) sensors are useful in urban areas and human-made structures and would be beneficial in areas like San Pedro, California (Chapter 4) and dams (Chapters 5 and 6). Long wavelength (e.g., L and P Band) sensors are useful in rural and vegetated regions and would be beneficial in areas like the Portuguese Bend Landslide Complex (Chapters 7 and 8) or in regions with cm-scale deformation like the slides along the railroad complex in Nevada 
(Chapters 2 and 3). Medium wavelength (e.g., C Band) sensors are the most common (see Table 10.1) and perform adequately in many regions, which is why these sensors were used in many studies (Chapters 2, 3, 5, 6, and 7).

\subsubsection{Spatial Resolution}

SAR dimensions are defined as azimuth (parallel to satellite flight path) and range (perpendicular to satellite flight path) as shown in Figure 10.2 (Dzurisin and Lu 2007). The best range resolution $\left(\Delta \mathrm{R}_{\mathrm{g}}\right)$ attainable with $\mathrm{SAR}$ is

$$
\Delta R_{g}=\frac{c}{2 B \sin \theta}
$$

where $\mathrm{c}$ is the speed of light, B is the frequency bandwidth of a transmitted radar pulse, and $\theta$ is the incidence angle. Range resolution “...is controlled by the type of frequency modulated waveform and the way in which the return signal is compressed" (Dzurisin and Lu 2007, p162). The best azimuth resolution ( $\Delta \mathrm{Ag}_{\mathrm{g}}$ - also shown as $\delta \mathrm{x}$ in Figure 10.2) attainable with SAR is

$$
\Delta A_{g}=\delta x=\frac{L}{2}
$$

where $\mathrm{L}$ is the antenna length. Azimuth resolution is only controlled by the antenna length: a shorter antenna results in an improved azimuth resolution. However, although a smaller antenna results in better azimuth resolution, data from a small antenna will result in a poor signal-to-noise (SNR) ratio due to issues with the pulse repetition frequency and energy output from the sensor - see Dzurisin and Lu (2007) for further discussion on this subject. 


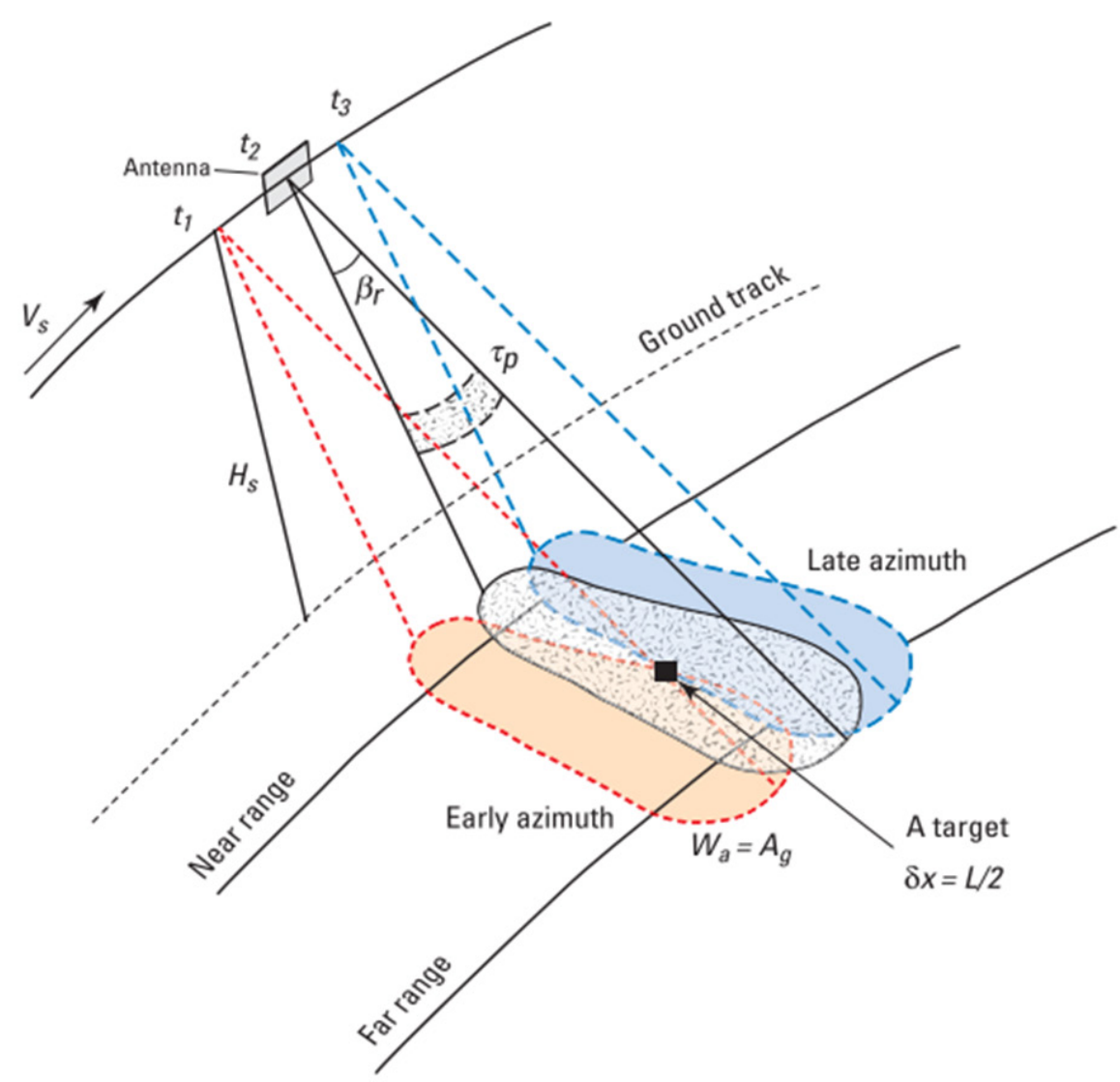

Figure 10.2: Azimuth resolution is parallel to satellite flight path; range resolution is perpendicular to satellite flight path. Variables in the image are defined as follows: $V_{s}$ is the satellite velocity; $t_{1}, t_{2}$, and $t_{3}$ are chronological points in time; $H_{s}$ is the satellite height; $\beta_{r}$ is the angular beam width in range direction; $\tau_{p}$ is the pulse duration; $W_{a}$ is the footprint width in the azimuth direction; $A_{g}$ is the azimuth resolution; $\delta x$ is the focused azimuth resolution; L is the antenna length. Image provided by Dzurisin \& Lu (2007).

The relationship between antenna length and spatial resolution can be seen with actual SAR sensors. TerraSAR-X antenna has a length of $5 \mathrm{~m}$ and a spatial resolution of $1.1 \mathrm{~m}$, ALOS PALSAR antenna has a length of $8.9 \mathrm{~m}$ and offers a $10 \mathrm{~m}$ spatial resolution, and Sentinel-1 has an antenna length of $12.3 \mathrm{~m}$ with a spatial resolution of $20 \mathrm{~m}$. 


\subsubsection{Coherence}

Coherence $(\gamma)$ is an estimation of the phase noise (or SNR) from an interferogram generated by a SAR image pair $\left(\mathrm{u}_{1}\right.$ and $\left.\mathrm{u}_{2}\right)$ and ranges in value from 0 (presence of complete phase noise) to 1 (absence of phase noise). Phase noise between SAR image pairs may occur from various sources, including physical changes of ground targets, misregistration of SAR images, geometric decorrelation, and systematic noise (Rodriguez and Martin 1992). Coherence is calculated over a small-pixel window as follows:

$$
\gamma=\frac{u_{1} u_{2}^{*}}{\sqrt{u_{1}^{2} u_{2}^{2}}}
$$

where ${ }^{*}$ is the complex conjugate (Ferretti et al. 2007c). Ferretti et al. (2007b) came up with five generalizations about expected coherence between SAR image pairs.

1. Areas with high coherence include urban settings and exposed rock.

2. Coherence is inversely proportional to temporal resolution in areas with sparse vegetation - that is, less time between SAR image pairs will result in relatively high coherence.

3. Areas with dense vegetation (e.g., forests) exhibit low coherence.

4. Foreshortening will result in areas with no coherence $(0)$ if the perpendicular baseline between SAR image pairs exceeds a few meters (more likely than not).

5. Slopes facing toward the radar sensor will have higher coherence than slopes facing away from the radar sensor.

Coherence may also be used to determine interferogram quality through the generation of coherence maps (Goodman 1963; Prati and Rocca 1992; Rodriquez and Martin 1992; Rocca et al. 1994). As described in the list above, coherence can measure changes in scattering properties of ground targets. Ferretti et al. (2007b) provide a few examples as to how coherence maps can measure and monitor changes of different ground features; these examples are provided in Table 10.2. 
Table 10.2: Typical coherence values of ground targets.

\begin{tabular}{|c|c|c|}
\hline Ground Target & Coherence & Explanation \\
\hline Water bodies & Near zero & $\begin{array}{c}\text { Calm water bodies reflect all } \\
\text { radar waves away from sensor; } \\
\text { turbulent water bodies change } \\
\text { scattering properties constantly }\end{array}$ \\
\hline Vegetation & $\begin{array}{c}\text { Ranges from near zero } \\
\text { (dense) to medium } \\
\text { (short) depending on } \\
\text { vegetation type }\end{array}$ & $\begin{array}{c}\text { Dense vegetation is in constant } \\
\text { motion (e.g., wind through } \\
\text { trees); shrubbery and short } \\
\text { vegetation may not randomly } \\
\text { scatter radar waves as much }\end{array}$ \\
\hline $\begin{array}{c}\text { Human-Made Structures } \\
\text { and Bare/Exposed Rock }\end{array}$ & High & $\begin{array}{c}\text { Unless these ground targets are } \\
\text { moving rapidly (destroyed), } \\
\text { coherence will remain high } \\
\text { since scattering properties do } \\
\text { not change much over time }\end{array}$ \\
\hline
\end{tabular}

\subsection{Radar vs Optical Sensors}

Radar (active) and optical (passive) sensors each provide a set of pros and cons when processing satellite-based remote sensing data. These pros and cons have been covered extensively, are taught in introductory remote sensing courses, and are inherent to each system. In general, satellite-based radar sensors excel over optical sensors in terms of data acquisition flexibility (radar can obtain data when cloudy and, as an active system, at night), deformation measurement accuracy ( $1 \mathrm{~mm} /$ year for radar and multiple $\mathrm{cm} /$ year for optical), and ground property measurements (e.g., geometry, dielectric constant and conductivity, surface roughness, and moisture content). Satellite-based radar sensors suffer in certain aspects where optical sensors do not, including experiencing reduction in SNR and coherence (especially over long time periods), geometric effects from topography that require precise processing (e.g., layover, foreshortening), and data loss due to topographic shadowing or snow cover.

The remainder of this section will include concise discussions on effectiveness of radar and optical sensors at study sites discussed in previous chapters. These include: (1) benefits of using both sensors for a Rockfall Hazard Rating System (RHRS) and for geotechnical asset management (GAM) purposes within a railroad corridor in southeastern 
Nevada (Chapters 2 and 3), and (2) use of persistent scatterer interferometry (PSI) and coregistration of optically sensed images and correlation (COSI-Corr) for landslide mapping and monitoring on the Palos Verdes Peninsula in California (Chapters 7 and 8).

\subsubsection{Rockfall Hazard Rating System and Geotechnical Asset Management}

A railroad corridor through a canyon system is the study site at which the RHRS (Chapter 2) and GAM (Chapter 3) projects were performed. Terrestrial-, UAV-, and satellite-based optical imagery were utilized for the RHRS project, while terrestrial- and satellite-based optical imagery and satellite-based radar imagery were used for the GAM project. In both cases, it was highly beneficial to use a combination of imagery: optical images were used for geotechnical site characterization and radar images for deformation measurements. Below are a few take-aways regarding the practicality and effectiveness of combining optical and radar images for RHRS and GAM projects:

1. It is helpful to collect optical imagery from various look angles (line-of-sight, LOS) to fully capture unstable slopes and rockfall hazards, especially on slopes with a wide range of dip angles. For example, vertical slopes will not be seen in optical images taken from sensors with LOS at nadir ( $0^{\circ}$ incidence angle). The optimal LOS direction is perpendicular to the slope dip direction. Vertical images are useful at observing potential hazards above the slope and at locations that may be unobservable from the ground (e.g., railroad tracks at the bottom of a slope).

2. Resolution of optical images is vital. Resolution is directly proportional to the effectiveness of optical images for RHRS purposes. Coarse resolution imagery led to an underestimation of RHRS scores when compared to high-resolution imagery. This is because coarse resolution imagery limits the user's ability to 'see' slope characteristics that may indicate instability (e.g., rock blocks, faults, surface erosion, etc.) if the spatial extent of these characteristics is less than pixel resolution. For example, a 4 x $4 \mathrm{~m}$ boulder on a $45^{\circ}$ slope, which can cause immense damage during a rockfall, will be unobservable in optical images with a resolution of $10 \mathrm{~m}$. 
3. Deformation measurements from radar images provide a proxy for condition assessment. High rates of deformation, or presence of substantial differential deformation (e.g., shearing), indicate possible deterioration in an asset's condition.

4. The archival SAR image library spans from 1992 to present with radar data obtained from many agencies (see Table 10.1). This resource provides data useful for long-term asset monitoring.

\subsubsection{Landslide Mapping and Monitoring}

Chapter 7 provides a case study for the use of radar images for mapping extremely slow landslides on the Palos Verdes Peninsula. Chapter 8 focuses on the Portuguese Bend Landslide complex (also on the Palos Verdes Peninsula) to demonstrate a novel approach for combining results from radar and optical images, along with GPS data, to monitor continually-moving landslides. The chapters incorporate remote sensing stacking techniques - PSI with radar data (Chapters 7 and 8) and COSI-Corr with optical data (Chapter 8) - to measure ground deformation. Here are some thoughts on the utility of both radar and optical data for measuring landslide deformation at various magnitudes:

1. Extremely slow landslides are those with a velocity less than $16 \mathrm{~mm} /$ year (Cruden and Varnes 1996). Assuming the study site is adequate for PSI analysis (see Section 10.2.3), this radar technique works well for extremely slow landslide monitoring. PSI velocity measurements have an accuracy of $1 \mathrm{~mm} / \mathrm{year}$ and can measure deformation up to $\sim 2-3 \mathrm{~cm} /$ year (Ferretti et al. 2000; Ferretti et al. 2001; Crosetto et al. 2016). These highly accurate measurements limit the range of landslides observable with PSI and, in the presence of faster landslides, another technique should be used.

2. COSI-Corr and GPS are capable of measuring landslide velocity on the $\mathrm{cm} /$ yearand m/year-scales. Neither COSI-Corr nor GPS are stacking techniques; instead, long-term measurements are obtained through the summation of chronological acquisitions (e.g., comparison of chronological optical image pairs with COSI-Corr and continuous or repeat measurements with GPS). Summation of chronological acquisitions results in greater noise (lower SNR) when compared with stacking 
techniques (e.g., PSI) and, therefore, COSI-Corr and GPS are unable to discern $\mathrm{mm} /$ year-scale deformation rates.

\subsection{Combining Radar, Optical, and GPS}

As demonstrated in previous chapters and by myriad references provided throughout, there exist a variety of remote sensing and geodetic approaches for the measurement of surface deformation. Remote sensing approaches include optical (photography, photogrammetry, and LiDAR) and radar from various platforms, including stationary and moving terrestrial, airborne via airplane or UAV, and satellite-based. The most common ground-based geodetic approach is GPS. Each approach has inherent strengths and weaknesses. One common way to work around this approach is to employ a methodology that incorporates multiple remote sensing and/or geodetic datasets. For example, we utilize satellite-based radar, satellite-based optical, and terrestrial GPS to monitor landslide activity of the Portuguese Bend Landslide complex (Chapter 8). Unfortunately, however, comparing results from various sensors is like comparing apples to oranges - how can we compare $\mathrm{mm} /$ year-scale PSI results measured in a specific lineof-sight (LOS) direction ( $\mathrm{N} 85^{\circ} \mathrm{W}$, about $23^{\circ}$ from vertical) with $\mathrm{cm} /$ year to $\mathrm{m} / \mathrm{year}$ COSICorr results measured in the horizontal plane? The following sections focus on the

difficulties with comparing radar, optical, and GPS results (Section 10.4.1) and discuss a few ideas to work around these difficulties (Section 10.4.2).

\subsubsection{Difficulty with Comparing Radar, Optical, and GPS Results}

As alluded to in the previous section, the major difficulty with comparing deformation measurements from different remote sensing and geodetic datasets is coping with the apparent deformation magnitude, which differs from the absolute deformation magnitude. The absolute deformation magnitude is the actual or "true" deformation; if we could measure deformation in all directions, the absolute deformation magnitude would be measured in the direction of greatest deformation. For example, if $2 \mathrm{~m}$ of vertical subsidence was occurring in our area of interest, the absolute deformation magnitude would 
be $2 \mathrm{~m}$. If we were to measure this same subsidence event with a remote sensor with a LOS oblique from vertical (the direction of greatest deformation), we would measure subsidence displacement at $<2 \mathrm{~m}$, depending on the LOS incidence angle. Finally, if we were to measure this subsidence with COSI-Corr - which only measures horizontal deformation (e.g., incidence angle at $90^{\circ}$ vertical), we would not detect any subsidence at all. These last two scenarios demonstrate apparent deformation magnitudes where, since we are not collecting data in the actual subsidence direction (the direction of greatest deformation in this case), we do not capture the full impact of the subsidence event.

In addition to this LOS difficulty, each remote sensing and geodetic technique measures ground deformation across different magnitude ranges. PSI can measure ground deformation between $1 \mathrm{~mm} /$ year and 2-3 cm/year. Radar interferograms can generally measure $\mathrm{cm} /$ year and $\mathrm{m} /$ year deformation rates, depending strongly on coherence and lack of decorrelation. COSI-Corr can measure $\mathrm{cm} /$ year and $\mathrm{m} / \mathrm{year}$ deformation rates, depending on temporal resolution and cloud cover. GPS can also measure $\mathrm{cm} /$ year and $\mathrm{m} /$ year deformation rates but suffer from data loss if rapid deformation occurs and the instrument is destroyed (as happened at Portuguese Bend Landslide complex). Radar interferograms, COSI-Corr, and GPS cannot resolve $\mathrm{mm} /$ year deformation due to noise.

\subsubsection{How to Resolve LOS and Magnitude Differences}

The only way to compare radar, optical, and GPS deformation results is to make sure each result is measuring the same thing. Of the two difficulties discussed above-LOS and magnitude differences - only the first can be resolved directly while the second may be indirectly helpful.

LOS differences can be resolved using trigonometry so that all deformation measurements are in the same direction. Thus, if we use the scenario from Chapter 8 where radar, optical, and GPS data were acquired over the Portuguese Bend Landslide complex, we can decide which LOS direction we need to solve for by assigning a degree of freedom number to each technique. Degree of freedom is equal to the number of spatial dimensions a technique uses for deformation measurements. GPS has a degree of freedom of three because it measures ground deformation in three dimensions: up/down, north/south, and 
east/west. COSI-Corr (optical) has a degree of freedom of two: north/south and east/west. PSI (radar) has a degree of freedom of one: satellite LOS direction. Thus, in theory, we should recompute GPS and COSI-Corr deformation measurements to match PSI measurements, since PSI is the most limited in terms of degree of freedom. However, an issue arises between PSI and COSI-Corr: PSI measurements include a vertical component while COSI-Corr does not and, so, they cannot be compared. One workaround is to perform PSI processing using two stacks - one descending and one ascending over the same area of interest - so that two-dimensional deformation measurements can be resolved, allowing direct mathematical comparisons between PSI, COSI-Corr, and GPS. Unfortunately, ascending COSMO-SkyMed radar images were not available for the study in Chapter 8. How can we resolve this issue?

One idea is to use three-dimensional GPS results as a bridge between PSI and COSI-Corr. GPS results can be independently compared to both PSI and COSI-Corr and if GPS matches well with each we can then assume PSI and COSI-Corr would be comparable too. This forms a PSI to GPS to COSI-Corr bridge, but there may be another problem: deformation magnitude. GPS and COSI-Corr deformation results are too noisy for $\mathrm{mm} /$ year-scale measurements and, for the most part, maximum C-Band PSI results are approximately 2-3 cm/year. The only plausible solution to this problem (other than using a different technique than PSI) is to use a radar sensor with a longer wavelength (e.g., LBand or P-Band). Processing long wavelength radar data with PSI allows for a greater deformation (velocity) threshold. For example, the ALOS PALSAR sensor emits a radar wavelength of $\sim 23.62 \mathrm{~cm}$; potential future P-band satellites would have a wavelength between $60 \mathrm{~cm}$ and $1.2 \mathrm{~m}$, which would greatly increase the deformation range measurable using PSI. For now, and with the wavelengths used in this dissertation (X-Band and CBand), directly comparing GPS and PSI results is limited unless used like in Chapter 8: PSI is used for very slow measurements and COSI-Corr and GPS used for more rapid measurements. 


\subsection{Utilizing Unmanned Aerial Vehicles (UAVs)}

It is worth mentioning the potential of UAVs as a platform for interferometric synthetic aperture radar (InSAR). Like the progression optical photogrammetry took satellite to terrestrial to UAV - InSAR is presently used on satellite and terrestrial platforms and, so naturally, the next step is to deploy a high-resolution UAV with a SAR sensor. A few issues that need to be resolved include:

1. Antenna Length and Weight Restrictions. Azimuth resolution is indirectly proportional to antenna length: shorter antennas yield higher resolution. Satellites must sacrifice azimuth resolution and carry longer antennas so that enough radar echoes return and are captured by the antenna. UAVs may not suffer from a similar issue since they will be flying much closer to the ground. Due to weight restrictions and battery life, UAVs would most likely be limited to very small, light-weight antennas.

2. Flight Path. Flight paths can be mapped using computer software. InSAR would be possible if flight paths were designed to be horizontally offset by an amount less than the perpendicular baseline. Here is an example:

a. Acquisition 1: UAV is flown in one direction (e.g., north to south) over area of interest.

b. Acquisition 2: Later, the UAV follows a flight path identical to Acquisition 1 (and in the same north-to-south direction) but the flight path is now offset by $1 \mathrm{~m}$ to the east.

The offset flight path during Acquisition 2 will allow for the generation of an interferogram.

3. Other Engineering Variables. Many components would have to be newly designed (basically miniaturized satellite components). Another big limitation is data storage because high-resolution InSAR would accrue a lot of data during a brief period. Data would either need to be uploaded during acquisition, which would require communication with a ground base station, or stored on an external hard drive device, which would increase instrument weight on the UAV. Other 
variables to consider are battery life, flight time, and maneuverability (especially if the UAV is carrying a lot of equipment).

Overall, the future for UAV-based InSAR is bright and appears to be under development by some research groups (Nitti et al. 2015), although few (if any) case studies have been published. 


\section{References}

AASHTO: American Association of State Highways and Transportation Officials (1993) Guide for Design of Pavement Structures. AASHTO, GDPS-4, Washington, D.C., $624 \mathrm{p}$.

AASHTO: American Association of State Highways and Transportation Officials (2001) Pavement Management Guide. AASHTO, Washington, D.C., 254 p.

AASHTO: American Association of State Highways and Transportation Officials (2011) An Overview of the Guide. In: U.S. Department of Transportation Federal Highway Administration, editors. AASHTO Transportation Asset Management Guide: A Focus on Implementation. Washington, D.C., 1.1-24.

AASHTO: American Association of State Highways and Transportation Officials (2013) AASHTO Transportation Asset Management Guide: A Focus on Implementation. Publication No. FHWA-HIF-10-023, 1-48.

Abellán A, Calvet J, Vilaplana J M, and Blanchard J (2010) Detection and spatial prediction of rockfalls by means of terrestrial laser scanner monitoring. Geomorphology, 119(3-4):162-171.

Abellán A, Jaboyedoff M, Oppikofer T, Vilaplana JM (2009) Detection of millimetric deformation using a terrestrial laser scanner: experiment and application to a rockfall event. Natural Hazards and Earth System Sciences, 9:365-372.

Ahmed R, Siqueira P, Hensley S, Chapman B, and Bergen K (2011) A survey of temporal decorrelation from spaceborne L-Band repeat-pass InSAR. Remote Sensing of Environment, 115(11):2887-2896.

Anderson SA, Alzamora D, and DeMarco MJ (2009) Asset Management Systems for Retaining Walls. In: Geo-Velopment: The Role of Geological and Geotechnical Engineering in New and Redevelopment Projects, 162-177. 
Anderson SA and Rivers BS (2013) Corridor Management: A Means to Elevate Understanding of Geotechnical Impacts on System Performance. Transportation Research Record: Journal of the Transportation Research Board, 2349:9-15.

Angeli M-G, Gasparetto P, Pasuto A, and Silvano S (1989) Examples of landslide instrumentation (Italy). Proceedings of the 12th International Conference on Soil Mechanics and Foundation Engineering, Rio de Janeiro, 3:1531-1534.

Antronico L, Borrelli L, Peduto D, Fornaro G, Gullà G, Paglia L, Zeni G (2013) Conventional and innovative techniques for the monitoring of displacements in landslide affected area. In: Landslide science and practice, Springer Berlin Heidelberg, 125-133.

AP: Associated Press (2014) Last body found in Washington mudslide. MyNorthwest. http://mynorthwest.com/174/2570325/Last-body-found-in-Washington-mudslide.

ASI: Italian Space Agency (2009) COSMO-SkyMed SAR Products Handbook, Rev. 2. Italian Space Agency, $105 \mathrm{p}$.

Austroads (1997) Strategy for improving asset management practices. Austroads Incorporated, Sydney, Australia.

Ayoub F, Leprince S, and Avouac J-P (2017) User's Guide to COSI-CORR: Coregistration of Optically Sensed Images and Correlation. California Institute of Technology, http://www.tectonics.caltech.edu/slip_history/spot_coseis/pdf_files/CosiCorrGuide2017.pdf.

Baran I, Stewart MP, Kampes BM, Perski Z, and Lilly P (2003) A modification to the Goldstein radar interferogram filter. IEEE Transactions on Geoscience and Remote Sensing, 41(9):2114-2118.

Bauer A, Paar G, and Kaltenböck A (2005) Mass movement monitoring using terrestrial laser scanner for rock fall management. In: Geo-information for disaster management, Springer Berlin Heidelberg, 393-406.

Bayer B, Simoni A, Schmidt D, and Bertello L (2017) Using advanced InSAR techniques to monitor landslide deformations induced by tunneling in the Northern Apennines, Italy. Engineering Geology, 226:20-32. 
BBC: British Broadcasting Corporation (2014) Oso mudslide: Washington state disaster site yields more dead. BBC News, http://www.bbc.com/news/world-us-canada26855649.

Béjar-Pizarro M, Notti D, Mateos RM, Ezquerro P, Centolanza G, Herrera G, Bru G, Sanabria M, Solari L, Duro J, and Fernández J (2017) Mapping Vulnerable Urban Areas Affected by Slow-Moving Landslides Using Sentinel-1 InSAR Data. Remote Sensing, 9(9):876.

Berardino P, Frnaro G, Lanari R, and Sansosti E (2002) A new algorithm for surface deformation monitoring based on small baseline differential SAR interferograms. IEEE Transactions on Geoscience and Remote Sensing, 40(11):2375-2383.

Bergen KM, Goetz SJ, Dubayah RO, Henebry GM, Hunsaker CT, Imhoff ML, Nelson RF, Parker GG, Radeloff VC (2009) Remote sensing of vegetation 3-D structure for biodiversity and habitat: Review and implications for lidar and radar spaceborne missions. Biogeosciences, 114(G2), 13 p.

Bianchini S, Ciampalini A, Raspini F, Bardi F, Di Traglia F, Moretti S, and Casagli N (2015) Multi-Temporal Evaluation of Landslide Movements and Impacts on Buildings in San Fratello (Italy) By Means of C-Band and X-Band PSI Data. Pure and Applied Geophysics, 172(11):3043-3065.

Bianchini S, Herrera G, Mateos RM, Notti D, Garcia I, Mora O, and Moretti S (2013) Landslide activity maps generation by means of persistent scatterer interferometry. Remote Sensing, 5(12):6198-6222.

Bianchini S, Solari L, and Casagli N (2017) A GIS-Based Procedure for Landslide Intensity Evaluation and Specific Risk Analysis Supported by Persistent Scatterers Interferometry (PSI). Remote Sensing, 9(11):1093.

Blair TC and McPherson JG (1994) Alluvial Fan Processes and Forms. Geomorphology of Desert Environments, V:354-402.

Bouali EH, Oommen T, and Escobar-Wolf R (2016a) Interferometric Stacking toward Geohazard Identification and Geotechnical Asset Monitoring. Journal of Infrastructure Systems, 22(2) 05016001. 
Bouali EH, Oommen T, Vitton S, Escobar-Wolf R, and Brooks C (2016b) Rockfall hazard rating system: benefits of utilizing remote sensing. Environmental and Engineering Geoscience, 23(3):165-177.

Bouali EH, Oommen T, and Escobar-Wolf R (2017a) Mapping of slow landslides on the Palos Verdes Peninsula using the California landslide inventory and persistent scatterer interferometry. Landslides, 1-14.

Bouali EH, Oommen T, and Escobar-Wolf R (2017b) Structure mapping through spatial and temporal deformation monitoring using persistent scatterer interferometry and geographic information systems. Geotechnical Frontiers 2017, 278:509-519.

Brawner CO (1994) Rockfall Hazard Mitigation Methods - Participant's Workbook, NHI Course No. 13219. U.S. Department of Transportation, Federal Highway Administration, Publication No. FHWA SA-93-085.

Brawner CO and Wyllie DC (1975) Rock Slope Stability on Railway Projects. Proceedings of the American Railway Engineering Association Regional Meeting, Vancouver, British Columbia, Canada, 8 p.

Bridges NT, Ayoub F, Avouac J-P, Leprince S, Lucas A, and Mattson S (2012) Earth-like sand fluxes on Mars. Nature, 485:339-342.

Brutus O and Tauber G (2009) Guide to asset management of earth retaining structures. U.S. Department of Transportation, Federal Highway Administration, Office of Asset Management, Washington, D.C., 120 p.

Calabro MD, Schmidt DA, and Roering JJ (2010) An examination of seasonal deformation at the Portuguese Bend landslide, Southern California, using radar interferometry. Journal of Geophysical Research: Earth Surface, 115(F2):1-10.

Calvello M, Peduto D, and Arena A (2017) Combined use of statistical and DInSAR data analyses to define the state of activity of slow-moving landslides. Landslides, 14(2):473-489.

Cambridge Systematics Inc., Applied Research Associates Inc., Arora and Associates, KLS Engineering, PB Consult Inc., Lambert L (2009) An Asset-Management Framework for the Interstate Highway System. Transportation Research Board, Washington, D.C., 82 p. 
Cambridge Systematics Inc., Parsons Brinckerhoff Quade and Douglas Inc., Roy Jorgensen Associates Inc., and Thompson PD (2002) Transportation Asset Management Guide, Task 1 - Synthesis of Asset Management Practice. Phase 1 Report, NCHRP Web Document 41 (Project SP20-24[11]): Contractor's Final Report, 1-84.

Carlà T, Raspini F, Intrieri E, and Casagli N (2016) A simple method to help determine landslide susceptibility from spaceborne InSAR data: the Montescaglioso case study. Environmental Earth Sciences, 75(24):1492.

Carrara A, Cardinali M, Detti R, Guzzetti F, Pasqui V, and Reichenbach P (1991) GIS techniques and statistical models in evaluating landslide hazard. Earth Surface Processes and Landforms, 16(5):427-445.

Casagli N, Frodella W, Morelli S, Tofani V, Ciampalini A, Intrieri E, Raspini F, Rossi G, Tanteri L, and Lu P (2017) Spaceborne, UAV and ground-based remote sensing techniques for landslide mapping, monitoring and early warning. Geoenvironmental Disasters, 4.1(9):1-23.

Cascini L, Peduto D, Pisciotta G, Arena L, Ferlisi S, and Fornaro G (2013) The combination of DInSAR and facility damage data for the updating of slow-moving landslide inventory maps at medium scale. Natural Hazards and Earth System Sciences, 13(6):1527-1549.

Catani F, Casagli N, Ermini L, Righini G, and Menduni G (2005) Landslide hazard and risk mapping at catchment scale in the Arno River basin. Landslides, 2(4):329-342.

CDWR: California Department of Water Resources (2014) Summary of Recent, Historical, and Estimated Potential for Future Land Subsidence in California. State of California Department of Water Resources, 23 p.

CGS: California Geological Survey (2017) California landslide inventory [web-based GIS]. California Department of Conservation, http://maps.conservation.ca/gov/cgs/lsi.

Chase RB and Kehew AE (2000) Slope stability analysis and ground-water hydrology in heterogeneous glacial material: Elements for prediction of bluff erosion. U.S. Army Research Office Grant 34767-GS Final Progress Report, 20 p. 
Chen B, Deng K, Fan H, and Hao M (2013) Large-scale deformation monitoring in mining area by D-InSAR and 3D laser scanning technology integration. International Journal of Mining Science and Technology, 23(4):555-561.

Chou C, Chen A, Ling H, and Change C-M (2006) Development of the Maintenance Rating Program for City Roadway Networks in Taiwan. Airfield and Highway Pavement Specialty Conference, Atlanta, Georgia, April 30-May 3, 924-935.

Ciampalini A, Raspini F, Lagomarsino D, Catani F, and Casagli N (2016) Landslide susceptibility map refinement using PSInSAR data. Remote Sensing of Environment, 184, 302-315.

Cigna F, Bianchini S, and Casagli N (2013) How to assess landslide activity and intensity with persistent scatterer interferometry (PSI): the PSI-based matrix approach. Landslides, 10(3):267-283.

Chung CF and Fabbri AG (1999) Probabilistic prediction models for landslide hazard mapping. Photogrammetric Engineering and Remote Sensing, 65(12):1389-1399.

CLA: City of Los Angeles (2016) White Point landslide: project summary. http://eng.lacity.org/whitepoint/whitepointlandslide.htm.

Colesanti C and Wasowski J (2006) Investigating landslides with space-borne synthetic aperture radar (SAR) interferometry. Engineering Geology, 88(3):173-199.

Constantini M (1998) A novel phase unwrapping method based on network programming. IEEE Transactions on Geoscience and Remote Sensing, 36(3):813-821.

Constantini M, Falco S, Malvarosa F, and Minati F (2008) A new method for identification and analysis of persistent scatterers in series of SAR images. IEEE International Geoscience and Remote Sensing Symposium, 2:449-452.

Crafford AEJ (2007) Geologic Map of Nevada. U.S. Geological Survey Data Series 249, 1: 250,000 scale.

Crosetto M, Biescas E, and Duro J (2008) Generation of advanced ERS and Envisat interferometric SAR products using the stable point network technique. Photogrammetric Engineering \& Remote Sensing, 74(4):443-450. 
Crosetto M, Monserrat O, Cuevas-González M, Devanthéry N, and Crippa B (2016) Persistent scatterer interferometry: a review. Journal of Photogrammetry and Remote Sensing, 115:78-89.

Crosetto M, Monserrat O, Iglesias R, and Crippa B (2010) Persistent scatterer interferometry: Potential, limits and initial $\mathrm{C}$ - and $\mathrm{X}$-band comparison. Photogrammetric Engineering and Remote Sensing, 76(9):1061-1069.

Crosetto M, Monserrat O, Jungner A, and Crippa B (2009) Persistent scatterer interferometry: Potential and limits. Proceedings of the 2009 ISPRS Workshop on High-Resolution Earth Imaging for Geospatial Information, 25, 6 p.

CRPV: City of Rancho Palos Verdes (2012) Landslide Workshop. http://www.rpvca.gov/documentcenter/view/5564.

Cruden DM (1991) A simple definition of a landslide. Bulletin of Engineering Geology and the Environment, 43(1):27-29.

Cruden DM and Varnes DJ (1996) Landslide types and processes. In: Turner KA, Schuster RL (eds) Landslides: Investigation and Mitigation (Chapter 3), Transportation Research Board Special Report 247:36-75.

CWC: Central Water Commission (1986) Report on Dam Safety Procedures. Government of India, Ministry of Water Resources, Central Water Commission am Safety Organisation, $103 \mathrm{p}$.

Dai FC, Lee CF, Ngai YY (2002) Landslide risk assessment and management: an overview. Engineering Geology, 64(1):65-87.

DDSI: Division of Dam Safety and Inspections (2006) Chapter IX: Instrumentation and Monitoring. In: Engineering Guidelines for the Evaluation of Hydropower Projects, Federal Energy Regulatory Commission, https://www.ferc.gov/industries/hydropower/safety/guidelines/engguide/chap9.pdf, 86 p.

Di Crescenzo G and Santo A (2007) High-resolution mapping of rock fall instability through the integration of photogrammetric, geomorphological and engineeringgeological surveys. Quaternary International, 171-172:118-130. 
Di Martire D, Iglesias R, Monells D, Centolanza G, Sica S, Ramondini M, Pagano L, Mallorqui JJ, and Calcaterra D (2014) Comparison between differential SAR interferometry and ground measurements data in the displacement monitoring of the earth-dam of Conza della Campania (Italy). Remote Sensing of Environment, 148:58-69.

Dilger F and Halstead RJ (2005) Integrating hazards assessment and impact assessment: the case of the Caliente rail corridor to Yucca Mountain. 32nd annual Waste Management Symposium, 1 March, Tucson, Arizona, 14 p.

Dzurisin D and Lu Z (2007) Interferometric synthetic-aperture radar (InSAR). In: Dzurisin D (ed) Volcano Deformation: Geodetic Monitoring Techniques, Springer, Berlin, Heidelberg, 153-194.

Ehlig PL (1982) The Palos Verdes Peninsula: its physiography, land use and geologic setting. In: Cooper JD (ed) Volume and Guidebook: Landslides and Landslide Abatement, Geological Society of America, Palos Verdes Peninsula, Southern California, Cordilleran Section, 78th Annual Meeting, 3-6.

Ehlig PL (1992) Evolution, mechanics and mitigation of the Portuguese Bend landslide, Palos Verdes Peninsula, CA. In: Pipkin BW and Proctor RJ (eds.) Engineering Geology Practice in Southern California. Special Publication No. 4, Associations of Engineering Geology.

Ehlig PL and Bean RT (1982) Dewatering of the Abalone Cove landslide, Rancho Palos Verdes County, CA. In: Cooper JD (ed) Volume and Guidebook: Landslides and Landslide Abatement, Geological Society of America, Palos Verdes Peninsula, Southern California, Cordilleran Section, 78th Annual Meeting, 67-79.

Emadali L, Motagh M, and Haghighi MH (2017) Characterizing post-construction settlement of the Masjed-Soleyman embankment dam, Southwest Iran, using TerraSAR-X SpotLight radar imagery. Engineering Structures, 143:261-273.

Emmett M, Strikis A, Etherington T, and Eastoe N (2015) Asset Management Plan Vegetation. Tasmanian Networks, $30 \mathrm{p}$.

Escobar-Wolf R, Bouali EH, Oommen T, Brooks C, and Vitton SJ (2015) Cost benefit analysis of a proactive geotechnical asset management system using remote 
sensing. Deliverable 6-A, US Department of Transportation, USDOT Cooperative Agreement No. RITARS-14-H-MTU, 42 p.

Esri, DigitalGlobe, GeoEye, Earthstar Geographics, CNES/Airbus DS, USDA, USGS, AEX, Getmapping, Aerogrid, IGN, IGP, swisstopo and the GIS User Community (2016a) World Imagery Basemap, ArcMap® software.

Esri, HERE, DeLorme, Intermap, increment P Corp., GEBCO, USGS, FAO, NPS, NRCAN, GeoBase, IGN, Kadaster NL, Ordnance Survey, Esri Japan, METI, Esri China (Hong Kong), swisstopo, MapmyIndia, () OpenStreetMap contributors and the GIS User Community (2016b) World Topographic Map Basemap, ArcMap ${ }^{\circledR}$ software.

FDOT: Florida Department of Transportation (2013) Florida Department of Transportation Maintenance Rating Program Handbook Computer Based Training, http://wbt.dot.state.fl.us/ois/MRPHandbook/index.htm.

FERC: Federal Energy Regulatory Commission (2006) Engineering Guidelines for the Evaluation of Hydropower Projects, Chapter IX: Instrumentation and Monitoring. Division of Dam and Safety Inspections, https://www.ferc.gov/industries/hydropower/safety/guidelines/engguide/chap9.pdf, 86 p.

Federico A, Popescu M, Elia G, Fidelibus C, Internò G, and Murianni A (2012) Prediction of time to slope failure: a general framework. Environmental Earth Science, $66: 245-256$.

Fell R (1994) Landslide risk assessment and acceptable risk. Canadian Geotechnical Journal, 31(2):261-272.

Fell R and Hartford D (1997) Landslide risk management. In: Cruden D, Fell R (eds) Landslide Risk Assessment. Balkema, Roterdam, 51-109.

Ferretti A, Fumagalli A, Novali F, Prati C, Rocca F, and Rucci A (2011) A New Algorithm for Processing Interferometric Data-Stacks: SqueeSAR. IEEE Transactions on Geoscience and Remote Sensing, 49(9):3460-3470. 
Ferretti A, Monti-Guarnieri A, Prati C, Rocca F, and Massonnet D (2007a) Part A: InSAR Principles: Guidelines for SAR Interferometry Processing and Interpretation. Fletcher K (ed.), European Space Agency, TM-19, ESA Publications, 48 p.

Ferretti A, Monti-Guarnieri A, Prati C, Rocca F, and Massonnet D (2007b) Part B: InSAR Processing: A Practical Approach. Fletcher K (ed.), European Space Agency, TM19, ESA Publications, $71 \mathrm{p}$.

Ferretti A, Monti-Guarnieri A, Prati C, Rocca F, and Massonnet D (2007c) Part C: InSAR Processing: A Mathematical Approach. Fletcher K (ed.), European Space Agency, TM-19, ESA Publications, $115 \mathrm{p}$.

Ferretti A, Prati C, and Rocca F (2000) Nonlinear subsidence rate estimation using permanent scatterers in differential SAR interferometry. IEEE Transactions on Geoscience and Remote Sensing, 38(9):2202-2212.

Ferretti A, Prati C, and Rocca F (2001) Permanent Scatterers in SAR Interferometry. IEEE Transactions on Geoscience and Remote Sensing, 39(1):8-20.

FHWA: Federal Highway Administration (1991) An Advanced Course in Pavement Management Systems. Federal Highway Administration, Washington, D.C., 184 p.

FHWA: Federal Highway Administration (1999) Asset Management Primer. U.S. Department of Transportation, Washington, D.C., 1-30.

FHWA: Federal Highway Administration (2007) Asset Management Overview. U.S. Department of Transportation, Washington, D.C., 52 p.

FHWA: Federal Highway Administration (2013) Selection Procedure for Reference and Cluster Bridges, http://www.fhwa.dot.gov/multimedia/research/infrastructure/bridges/ltbp/index.cf $\mathrm{m}$

FHWA: Federal Highway Administration (2014) Program Overview, http://www.fhwa.dot.gov/research/tfhrc/programs/infrastructure/structures/ltbp/ab out.cfm

Finlay PJ (1996) The risk assessment of slopes. University of New South Wales, School of Civil Engineering, PhD Dissertation. 
Fisher MA, Normark WR, Langenheim VE, Calvert AJ, Sliter R (2004) The offshore Palos Verdes Fault Zone near San Pedro, Southern California. Bulletin of the Seismological Society of America, 94(2):506-530.

Flintsch GW and Bryant Jr. JW (2006) Asset management data collection for supporting decision processes. U.S. Department of Transportation, Washington, D.C., 97 p.

Fukuzono T (1985) A new method for predicting the failure time of a slope. Proceedings from the IV International Conference and field Workshop on Landslides, Tokyo, Japan, 145-150.

Galehouse L, Mouthrop JS, and Hicks RG (2006) Principles of pavement preservation. In Pavement preservation compendium II, Federal Highway Administration report no. FHWA-IF-06-049, Washington, D.C., 67-73.

Garestier F, Dubois-Fernandez PC, and Champion I (2008) Forest height inversion using high-resolution P-band Pol-InSAR data. IEEE Transactions on Geoscience and Remote Sensing, 46(11), 3544-3559.

Gatelli F, Guamieri AM, Parizzi F, Pasquali P, Prati C, and Rocca F (1994) The wave number shift in SAR interferometry. IEEE Transactions on Geoscience and Remote Sensing, 32(4):855-865.

Ge YG and Lindell MK (2016) County planners' perceptions of land-use planning tools for environmental hazard mitigation: A survey in the US Pacific states. Environment and Planning B: Planning and Design, 43(4):716-736.

Ghulam A, Amer R, and Ripperdam R (2010) A filtering approach to improve deformation accuracy using large baseline, low coherence DInSAR phase images. Geoscience Remote Sensing Symposium (GARSS), 2010 I.E. International, Honolulu, Hawaii, 3494-3497.

Glendinning S, Hall J, and Manning L (2009) Asset-management strategies for infrastructure embankments. Proceedings of the Institution of Civil EngineersEngineering Sustainability, 162(2):111-120.

Göblirsch W and Pasquali P (1996) Algorithms for calculation of digital surface models from the unwrapped interferometric phase. Remote sensing - a scientific vision for sustainable development 1997. IEEE International, 1:656-658. 
Goldstein RM and Werner CL (1998) Radar interferogram filtering for geophysical applications. Geophysical Research Letters, 25(21):4035-4038.

Goodman NR (1963) Statistical analysis based on a certain multivariate complex Gaussian distribution (an introduction). The Annals of Mathematical Statistics, 34(1):152177.

Green N (1998) Federal Agency Urges Bolstering of Casitas Dam. Los Angeles Times, written June 24, 1998, http://articles.latimes.com/1998/jun/24/local/me-63010.

Green SJ, Brunner J, Rosenthal BM, Armstrong K, and Carter M (2014) Risk of slide 'unforeseen'? Warnings go back decades. The Seattle Times. Originally published March 24 , 2014 , http://old.seattletimes.com/html/localnews/2023218573_mudslidewarningsxml.ht $\mathrm{ml}$.

Grenerczy G and Wegmüller U (2011) Persistent scatterer interferometry analysis of the embankment failure of a red mud reservoir using ENVISAT ASAR data. Natural Hazards, 59(2):1047.

Guarnieri AM, Guccione P, Pasquali P, and Desnos YL (2003) Multi-mode ENVISAT ASAR interferometry: techniques and preliminary results. IEE Proceedings-Radar, Sonar and Navigation, 150(3):193-200.

Gullà G, Peduto L, Antronico L, and Fornaro G (2017) Geometric and kinematic characterization of landslides affecting urban areas: the Lungro case study (Calabria, southern Italy). Landslides, 14:171-188.

Gutkowski RM and Arenella ND (1998) Investigation of PONTIS - A bridge management software, http://www.mountain-plains.org/pubs/pdf/MPC98-95.pdf, 43 p.

Haas R and Hudson WR (2015) Pavement Asset Management. John Wiley and Sons, 432 p.

Harris Geospatial Solutions (2018) RPC Orthorectification Tool. http://www.harrisgeospatial.com/docs/rpcorthotutorial.html.

Haugerud RA (2014) Preliminary Interpretation of Pre-2014 Landslide Deposits in the Vicinity of Oso, Washington. US Geological Survey Open-File Report 2014-1065, 4 p., http://dx.doi.org/10.3133/ofr20141065. 
Hawkins N and Smadi O (2013) Use of Transportation Asset Management Principles in State Highway Agencies: A Synthesis of Highway Practice. Transportation Research Board, Washington, D.C., 98 p.

Haydon WD (2007) Landslide Inventory Map of the Palos Verdes Peninsula, Los Angeles

County, California. California Geological Survey, Geologic Information and Publications, $\quad$ Sacramento, CA 95814, www.conservation.ca/gov/cgs/geologic_hazards/landslides/.

Herrera G, Gutierrez F, Garcia-Davalillo JC, Guerrero J, Notti D, Galve JP, FernandezMerodo JA, and Cooksley G (2013) Multi-sensor advanced DInSAR monitoring of very slow landslides: the Tena Valley case study (central Spanish Pyrenees). Remote Sensing of Environment, 128:31-43.

Highland LM and Bobrowsky P (2008) The landslide handbook A guide to understanding landslides. US Geological Survey Circular 1325, 129 p.

Holecz F, Moreira J, Pasquali P, Voight S, Meier E, and Nuesch D (1997) Height model generation, automatic geocoding and a mosaicking using airborne AeS-1 InSAR data. Remote sensing — a scientific vision for sustainable development 1997. IEEE International, 4:1929-1931.

Hooper A, Zebker P, Segall P, and Kampes B (2004) A new method for measuring deformation on volcanoes and other non-urban areas using InSAR persistent scatterers. Geophysical Research Letters, 31(23):1-5.

Hu J, Li ZW, Ding XL, Zhu JJ, Zhang L, and Sun Q (2014) Resolving three-dimensional surface displacements from InSAR measurements: a review. Earth-Science Reviews, 133:1-17.

Huang SL, Darrow MM, and Calvin P (2009) Unstable Slope Management Program: Background Research and Program Inception - Phase I Final Report. Alaska Department of Transportation and Public Facilities, 90 p.

Hungr O (2007) Dynamics of rapid landslides. In: Fukuoka H (ed) Progress of landslide science. Springer, Berlin Heidelberg, 47-57.

Hutchinson JD, Lato M, Gauthier D, Kromer R, Ondercin M, MacGowan T, and Edwards T (2015) Rock Slope Monitoring and Risk Management for Railway Infrastructure 
in the White Canyon, British Columbia, Canada. Engineering Geology for Society and Territory, 2:435-439.

Jennings CW, Strand RG, and Rogers TH (1977) Geologic map of California. California Division of Mines and Geology.

Jones CE, An K, Blom RG, Kent JD, Ivins ER, and Bekaert D (2016) Anthropogenic and geologic influences on subsidence in the vicinity of New Orleans, Louisiana. Journal of Geophysical Research: Solid Earth, 121(5):3867-3887.

Jonsson B (2010) Transportation Asset Management: Quality-Relating Accounting, Measurements and use in Road Management's Processes, Report 92. Department of Real Estate and Construction Management, Royal Institute of Technology (Kungliga Tekniska Högskolan), 1-214.

Justice SM (2015) Application of a hazard rating system for rock slopes along a transportation corridor using remote sensing. Master's Report, Michigan Technological University, 86 p.

Kang F, Liu J, Li J, and Li S (2017) Concrete dam deformation prediction model for health monitoring based on extreme learning machine. Journal of the International Association for Structural Control and Monitoring, 24:1-11.

Kayen RE, Lee HJ, and Hein JR (2002) Influence of the Portuguese Bend landslide on the character of the effluent-affected sediment deposit, Palos Verdes margin, Southern California. Continental Shelf Research, 22(6):911-922.

Keaton JR and DeGraff JV (1996) Chapter 9: Surface observation and geologic mapping. In: Turner AK and Schuster RJ (eds.) Landslides: Investigation and Mitigation, Special Report 247, Transportation Research Board, National Research Council, Washington, D.C., 178-230.

Kellndorfer J, Walker W, Pierce L, Dobson C, Fites JA, Hunsaker C, Vona J, and Clutter M (2004) Vegetation height estimation from Shuttle Radar Topography Mission and National Elevation Datasets. Remote Sensing of Environment, 93:339-358.

Kilburn CRJ and Petley DN (2003) Forecasting giant, catastrophic slope collapse: lessons from Vajont, Northern Italy. Geomorphology, 54:21-32. 
Kilburn CRJ and Voight B (1998) Slow rock fracture as a precursor at Soufriere Hills volcano, Montserrat. Geophysical Research Letters, 25:3665-3668.

Kousteni A, Hill R, Dixon N, and Kavanagh J (1999) Acoustic emission technique for monitoring soil and rock slope instability. In Yagi N, Yamagami T, Jiang JC (eds) Slope stability engineering. Balkema, Rotterdam, 150-156.

Kumar M (2017) Dam Safety in India. Government of India, Ministry of Water Resources, Central Water Commission Dam Safety Organisation, 69 p.

Lan H, Martin CD, Zhou C, and Lim CH (2010) Rockfall hazard analysis using LiDAR and spatial modeling. Geomorphology, 118(1-2):213-223.

LAR-IAC: Los Angeles Regional Imagery Acquisition Consortium (2006) 10-foot Digital Elevation Model (DEM), LAR-IAC Public Domain. https://egis3.lacounty.gov/dataportal/2011/01/26/2006-10-foot-digital-elevationmodel-dem-public-domain/.

LAR-IAC: Los Angeles Regional Imagery Acquisition Consortium (2008) Los Angeles Countywide Building Outlines. ArcMap ${ }^{\circledR}$ GIS Layer File available at http://egis3.lacounty.gov/dataportal/2011/04/28/countywide-building-outlines/.

Lato MJ, Diederichs MS, Hutchinson DJ, and Harrap R (2012) Evaluating roadside rockmasses for rockfall hazards using LiDAR data: optimizing data collection and processing protocols. Natural Hazards, 60(3):831-864.

Lato MJ, Hutchinson DJ, Diederichs MS, and Harrap R (2009) Engineering monitoring of rockfall hazards along transportation corridors: Using mobile terrestrial LiDAR. Natural Hazards and Earth System Sciences, 9(3):935-946.

Lee Merkhofer Consulting (2014) Technical Terms Used in Project Portfolio Management (Continued), http://www.prioritysystem.com/glossary2aa.html

Leprince S, Ayoub F, Lin J, Avouac J-P, Muse P, Barbot S, Michel R, Binet R, and Klinger Y (2004) COSI-Corr: Measuring ground deformation using optical satellite and aerial images. http://www.tectonics.caltech.edu/slip_history/spot_coseis/index.html.

Leprince S, Barbot S, Ayoub F, and Avouac J-P (2007) Automatic, precise, orthorectification and co-registration for satellite image correlation: Application to 
seismotectonics. IEEE Transactions in Geosciences and Remote Sensing, 45:15291558.

Leroueil S, Locat J, Vaunat J, Picarelli L, Lee H, and Faure R (1996) Geotechnical characterization of slope movements. In: Senneset K (ed) Landslides. Balkema, Rotterdam, 53-74.

Lindquist K and Wendt M (2012) Transportation Asset Management (TAM) Plans including Best Practices: Synthesis. Washington State Department of Transportation, $51 \mathrm{p}$.

Lu P, Catani F, Tofani V, and Casagli N (2014) Quantitative hazard and risk assessment for slow-moving landslides from persistent scatterer interferometry. Landslides, 11(4):685-696.

Lu P, Stumpf A, Norman K, and Casagli N (2011) Object-oriented change detection for landslide rapid mapping. IEEE Geoscience and Remote Sensing Letters, 8(4):701705.

Lucieer A, de Jong SM, and Turner D (2014) Mapping landslide displacements using Structure from Motion (SfM) and image correlation of multi-temporal UAV photography. Progress in Physical Geology, 1-20.

Maerz NH, Youssef A, and Fennessey TW (2005) New Risk-Consequence Rockfall Hazard Rating System for Missouri Highways Using Digital Image Analysis. Environmental \& Engineering Geoscience, XI(3):229-249.

Mantovani F, Soeters R, and Van Westen CJ (1996) Remote sensing techniques for landslide studies and hazard zonation in Europe. Geomorphology, 15(3-4):213-225.

Mayuga MN and Allen DR (1970) Subsidence in the Wilmington Oil Field, Long Beach, California, USA. Proceedings of Tokyo Symposium of Land Subsidence, 1:66-79.

Mazzanti P (2017) Toward transportation asset management: what is the role of geotechnical monitoring? Journal of Civil Structural Health Monitoring, 1-12.

Mazzanti P, Rocca A, Bozzano F, Cossu R, and Floris M (2012) Landslide forecasting analysis by displacement time series derived from satellite InSAR data: preliminary results. ESA SP-697:1-8. 
McGee M (2007-2017) Survey Report of the Portuguese Bend Landslide Monitoring Surveys for the City of Rancho Palos Verdes prepared by McGee Surveying Consulting. Series of Reports: 2007, 2008, 2009, 2010, 2011, 2012, 2013, 2014, 2015, 2016, and 2017, City of Rancho Palos Verdes, McGee Surveying Consulting, $234 \mathrm{p}$.

McMillan JR and Haydon WD (1998a) Earthquake-Induced Landslide Zones in the Torrance 7.5-Minute Quadrangle, Los Angeles County, California. California Geological Survey Seismic Hazard Zone Report 035, Section 2, 19-38.

McMillan JR and Haydon WD (1998b) Earthquake-Induced Landslides Zones in the San Pedro 7.5-Minute Quadrangle, Los Angeles County, California. California Geological Survey Open File Report 98-24, Section 2, 15-30.

McMillan JR and Haydon WD (1998c) Earthquake-Induced Landslide Zones in the Redondo Beach 7.5-Minute Quadrangle, Los Angeles County. California Geological Survey Seismic Hazard Zone Report 031, Section 2, 17-35.

McNulty B (2012) Geology of the Palos Verdes Peninsula, Los Angeles, CA: A Field Guide for the Non-Geologist. Department of Earth Science, California State University Dominguez Hills and CSUDH Presidential Creative Initiative Fund. http://www4.csudh.edu/earth/palos-verdes.

MDOT: Michigan Department of Transportation (2015) Asset Management at MDOT, http://www.michigan.gov/mdot/0,4616,7-151-9621_15757-25283--,00.html.

Merriam R (1960) Portuguese Bend landslide, Palos Verdes Hills, California. Journal of Geology, 68(2):140-153.

Metzger AT, Olsen M, Wartman J, Dunham L, and Stuedlein A (2014) A platform for proactive risk-based slope asset management - phase 1. Pacific Northwest Transportation Consortium, $97 \mathrm{p}$.

Mian JF, Whittlestone AP, Patterson D, and Rudrum DM (2011) A risk-based approach for the assessment and management of infrastructure assets. Asset Management Conference 2011 IET and IAM, London, United Kingdom, Nov 30-Dec 1, 1-6. 
Monserrat O, Crosetto M, and Luzi G (2014) A review of ground-based SAR interferometry for deformation measurement. ISPRS Journal of Photogrammetry and Remote Sensing, 93:40-48.

Morgenstern NR (1997) Toward landslide risk assessment in practice. In: Cruden D, Fell $\mathrm{R}$ (eds) Landslide risk assessment. Balkema, Rotterdam, 15-23.

Mosman Council (2013) Asset Management Buildings. Mosman Council, 80 p.

Nascetti A, Capaldo P, Porfini M, Pieralice F, Fratarcangeli F, Benenati L, and Crespi M (2015) Fast terrain modelling for hydrogeological risk mapping and emergency management: the contribution of high-resolution satellite SAR imagery. Geomatics, Natural Hazards and Risk, 6(5-7):554-582.

NCTA: North Carolina Turnpike Authority (2014) Maintenance Rating Program: Triangle Expressway 2014 Third Quarter Report (July-September), http://www.ncdot.gov/projects/triangleexpressway/download/mrp_q3_2014_final. pdf, $126 \mathrm{p}$.

Necsoiu M, Leprince S, Hooper DM, Dinwiddie CL, McGinnis RN, and Walter GR (2009) Monitoring migration rates of an active subarctic dune field using optical imagery. Remote Sensing of Environment, 113(11):2441-2447.

Nitti DO, Bovenga F, Chiaradia MT, Greco M, and Pinelli G (2015) Feasibility of Using Synthetic Aperture Radar to Aid UAV Navigation. Sensors, 15:18335.

Notti D, Davalillo JC, Herrera G, and More O (2010) Assessment of the performance of X-band satellite radar data for landslide mapping and monitoring: Upper Tena Valley case study. Natural Hazards and Earth System Sciences, 10(9):1865-1875.

Novellino A, Cigna F, Sowter A, Ramondini M, and Calcaterra D (2017) Exploitation of the intermittent SBAS (ISBAS) algorithm with COSMO-SkyMed data for landslide mapping in north-western Sicily, Italy. Geomorphology, 280:153-166.

Oliveira SC, Zèzere JL, Catalão J, and Nico G (2015) The contribution of PSInSAR interferometry to landslide hazard in weak rock-dominated areas. Landslides, 12(4):703-719. 
Osier V (2018) Rancho Palos Verdes mulling long-term fix for Portuguese Bend Landslide. Daily Breeze, January 27, https://www.dailybreeze.com/2018/01/27/rancho-palosverdes-mulling-long-term-fix-for-portuguese-bend-landslide/.

Pantelidis L (2011) A critical review of highway slope instability risk assessment systems. Bulletin of Engineering Geology and the Environment, 70:395-400.

Parise M (2001) Landslide mapping techniques and their use in the assessment of the landslide hazard. Physics and Chemistry of the Earth, Part C: Solar, Terrestrial \& Planetary Science, 26(9):697-703.

Parise M (2003) Observation of surface features on an active landslide, and implications for understanding its history of movement. Natural Hazards and Earth System Science, 3:569-580.

Peduto D, Ferlisi S, Nicodemo G, Reale D, Pisciotta G, and Gullà G (2017) Empirical fragility and vulnerability curves for buildings exposed to slow-moving landslides at medium and large scales. Landslides, 1-15.

Perry J, Pedley M, and Reid M (2003) Infrastructure Embankments: Condition Appraisal and Remedial Treatment, 2nd edition. Construction Industry Research and Information Association (CIRIA) Publication, 245 p.

Peterson DE (1987) Pavement Management Practices. NCHRP Synthesis 135, Transportation Research Board, Washington, D.C., 139 p.

Petley DN (2004) The evolution of slope failures: mechanisms of rupture propagation. Natural Hazards and Earth System Sciences, 4:147-152.

Petley DN (2012) Global patterns of loss of life from landslides. Geology, 40(10):927-930.

Petley DN and Petley DJ (2004) On the initiation of large rockslides: perspectives from a new analysis of the Vajont movement record. In: Large Rock Slope Failures (ed: Evans SG), Balkema, Rotterdam (NATO Science Series), 77-84.

Petley DN, Bulmer MH, and Murphy W (2002) Patterns of movement in rotational and translational landslides. Geology, 30(8):719-722.

Piacentini D, Devoto S, Mantovani M, Pasuto A, Prampolini M, and Soldati M (2015) Landslide susceptibility modeling assisted by Persistent Scatterer Interferometry 
(PSI): an example from the northwestern coast of Malta. Natural Hazards, 78(1):681-697.

Pierson LA, Davis SA, and Van Vickle R (1990) Rockfall Hazard Rating System Implementation Manual: Oregon Department of Transportation. Pub. No. FHWAOR-EG-90-01, 1-112.

Pierson LA (1991) Rockfall Hazard Rating System. Oregon State Highway Division, Federal Highway Administration, Report No. FHWA-OR-GT-92-05, 15 p.

Pierson LA (1992) Rockfall Hazard Rating System: Rockfall prediction and control and landslide case histories. Research Record 1343, Transportation Research Board, Washington, D.C., 6-13.

Pierson LA and Van Vickle R (1993) Rockfall Hazard Rating System - Participant's Manual, NHI Course No. 130220. U.S. Department of Transportation, Federal Highway Administration, Publication No. FHWA SA-93-057, 112 p.

POLA: Port of Los Angeles (2012) Facts and Figures Card. Port of Los Angeles, 2 p.

Prati C and Rocca F (1992) Range resolution enhancement with multiple SAR surveys combination. International Geoscience and Remote Sensing Symposium, 26-29 May, Houston, Texas, USA, 1576-1578.

Proffer KA (1992) Ground water in the Abalone Cover landslide, Palos Verdes Peninsula, southern California. Reviews in Engineering Geology, IX:69-82.

Radbruch-Hall DH, Colton RB, Davies WE, Lucchitta I, Skipp BA, and Varnes DJ (1982) Landslide Overview Map of the Conterminous United States. US Geological Survey Professional Paper 1183. Digital version of the map created by Godt JW and found as an Open-File Report 97-289: http://landslides.usgs.gov/hazards/nationalmap/.

Radbruch-Hall DH, Varnes DJ, and Savage WZ (1976) Gravitational spreading of steepsided ridges ("sacking") in western United States. Bulletin of the International Association of Engineering Geology, 14:23-35.

Ramsey E III, Werle D, Lu Z, Rangoonwala A, and Suzuoki Y (2009) A case of timely satellite image acquisitions in support of coastal emergency environmental response management. Journal of Coastal Research, 1168-1172. 
Raspini F, Moretti S, and Casagli N (2013) Landslide Mapping Using SqueeSAR Data: Giampilieri (Italy) Case Study. Landslide Science and Practice, 1:1-8.

Rathje E, Kayen R, and Woo K-S (2006) Remote Sensing Observations of Landslides and Ground Deformation from the 2004 Niigata Ken Chuetsu Earthquake. Soils and Foundations, 46(6):831-842.

Reigber A and Moreira J (1997) Phase unwrapping by fusion of local and global methods. Remote sensing - a scientific vision for sustainable development 1997. IEEE International, 2:869-871.

Rocca F, Prati C, Pasquali P, and Monti Guarnieri A (1994) ERS-1 SAR Interferometry techniques and applications. ESA Contract Report n.3-7439/92/HGE-1, 134 p.

Rodriguez E and Martin JM (1992) Theory and design of interferometric synthetic aperture radars. IEEE Proceedings F - Radar and Signal Processing, 139(2):147-159.

Rosi A, Tofani V, Tanteri L, Tacconi Stefanelli C, Agostini A, Catani F, and Casagli N (2018) The new landslide inventory of Tuscany (Italy) updated with PS-InSAR: geomorphological features and landslide distribution. Landslides, 15(1):5-19.

Salvi S, Tolomei C, Boncori JPM, Pezzo G, Atzori S, Antonioli A, Trasatti E, Giuliani R, Zoffoli S, and Coletta A (2012) Activation of the SIGRIS monitoring system for ground deformation mapping during the Emilia 2012 seismic sequence, using COSMO-SkyMed InSAR data. Annals of Geophysics, 55(4):797-802.

Sanford Bernhardt KL, Loehr JE, and Huaco D (2003) Asset management framework for geotechnical infrastructure. Journal of Infrastructure Systems, 9(3):107-116.

Sara F, Silvia B, and Sandro M (2015) Landslide inventory updating by means of Persistent Scatterer Interferometry (PSI): the Setta basin (Italy) case study. Geomatics, Natural Hazards and Risk, 6(5-7):419-438.

Sarmap (2009) Synthetic Aperture Radar and SARscape ${ }^{\circledR}$ Guidebook, 274 p.

$\begin{array}{llllll}\text { Sarmap } & \text { (2014) } & \text { PS } & \text { Tutorial } & \text { (Version } & \text { 0.9). }\end{array}$ http://www.sarmap.ch/tutorials/PS_Tutorial_V_0_9.pdf.

Sarmap (2017) SARscape v. 5.2 software.

Schaefer LN, Lu Z, and Oommen T (2015) Dramatic volcanic instability revealed by InSAR. Geology, 43(8):743-746. 
Schaefer LN, Lu Z, and Oommen T (2016) Post-eruption deformation processes measured using ALOS-1 and UAVSAR InSAR at Pacaya Volcano, Guatemala. Remote Sensing, 8(1), $15 \mathrm{p}$.

Schaefer LN, Wang T, Escobar-Wolf R, Oommen T, Lu Z, Kim J, Lundgren PR, and Waite GP (2017) Three-dimensional displacements of a large volcano flank movement during the May 2010 eruptions at Pacaya Volcano, Guatemala. Geophysical Research Letters, 44(1):135-142.

Scheidegger AE (1973) On the prediction of the reach and velocity of catastrophic landslides. Rock Mechanics and Rock Engineering, 5(4):231-236.

Schlögel R, Doubre C, Malet J-P, and Masson F (2015) Landslide deformation monitoring with ALOS/PALSAR imagery: A D-InSAR geomorphological interpretation method. Geomorphology, 231:314-330.

Schulz WH, Coe JA, Ricci PP, Smoczyk GM, Shurtleff BL, and Panosky J (2017) Landslide kinematics and their potential controls from hourly to decadal timescales: insights from integrating ground-based InSAR measurements with structural maps and longterm monitoring data. Geomorphology, 285:121-136.

Scolobig A, Thompson M, and Linnerooth-Bayer J (2016) Compromise not consensus: Designing a participatory process for landslide risk mitigation. Natural Hazards, 81(1):45-68.

Sherard JL and Dunnigan LP (1985) Filters and leakage control in embankment dams. In Seepage and leakage from dams and impoundments, ASCE, 1-30.

Simons M and Rosen PA (2007) Interferometric synthetic aperture radar geodesy. In: Treatise on Geophysics - Geodesy, Vol. 3, Elsevier, Amsterdam, Netherlands, 391446.

SSWD: Sacramento Suburban Water District (2011) Buildings and Structures Asset Management Plan: Draft. Sacramento Suburban Water District, 25 p.

Stanley DA and Pierson LA (2013) Geotechnical Asset Management of Slopes: Condition Indices and Performance Measures. Proc., Geo-Congress 2013: Stability and Performance of Slopes and Embankments III, Geotechnical Special Publication No. 231, American Society of Civil Engineers, New York, 1658-1667. 
Stark TD and Choi H (2008) Slope inclinometers for landslides. Landslides, 5:339-350.

Stephenson WJ, Rockwell TK, Odum JK, Shedlock KM, and Okaya DA (1995) Seismic reflection and geomorphic characterization of the onshore Palos Verdes Fault Zone, Los Angeles, California. Bulletin of the Seismological Society of America, 85(3):943-950.

Strouth A and Eberhardt E (2007) The use of LiDAR to overcome rock slope hazard data collection challenges at Afternoon Creek, Washington. In: Laser and Photogrammetric Methods for Rock Face Characterization, eds. Tonon, F. and Kottenstette, J. T., American Rock Mechanics Association in Conjunction with GoldenRocks 2006, Colorado School of Mines, 109-120.

Sun Q, Zhang L, Ding XL, Hu J, Li ZW, and Zhu JJ (2015) Slope deformation prior to Zhouqu, China landslide from InSAR time series analysis. Remote Sensing of Environment, 156:45-57.

Suncar O, Rathje E, and Buckley S (2013) Deformations of a Rapidly Moving Landslide from High-Resolution Optical Satellite Imagery. Geo-Congress 2013, 269-278.

Surman M (2000) \$42-Million Retrofit of Casitas Dam Mostly Done. Los Angeles Times, written on February 12, 2000, http://articles.latimes.com/2000/feb/12/local/me63600 .

Temesgen B, Mohammed MU, and Korme T (2001) Natural hazard assessment using GIS and remote sensing methods, with particular reference to the landslides in the Wondogenet Area, Ethiopia. Physics and Chemistry of the Earth, Part C: Solar, Terrestrial \& Planetary Science, 26(9):665-675.

Terzaghi K (1950) Mechanisms of landslides. In; Paige S (ed) Application of geology to engineering practice. Geological Society of America, New York, New York, 83123.

Tofani V, Raspini F, Catani F, and Casagli N (2013) Persistent scatterer interferometry (PSI) technique for landslide characterization and monitoring. Remote Sensing, 5:1045-1065. 
Tomás R, Cano M, Garcia-Barba J, Vicente F, Herrera G, Lopez-Sanchez JM, and Mallorqui JJ (2013) Monitoring an earthfill dam using differential SAR interferometry: La Pedrera dam, Alicante, Spain. Engineering Geology, 157:21-32.

Tralli DM, Blom RG, Zlotnicki V, Donnellan A, and Evans DL (2005) Satellite remote sensing of earthquake, volcano, flood, landslide and coastal inundation hazards. ISPRS Journal of Photogrammetry and Remote Sensing, 59(4):185-198.

TranSystems Corporation (2011) Asset Management Guide for Local Agency Bridges in Michigan. Michigan Transportation Asset Management Council, 78 p.

Turner D, Lucieer A, and de Jong SM (2015) Time series analysis of landslide dynamics using an unmanned aerial vehicle (UAV). Remote Sensing, 7(2):1736-1757.

UAM: Utility Asset Management (2013) Utility Asset Management Cutting Edge Skills and Service (brochure). Utility Asset Management, 2 p.

USBR: United States Bureau of Reclamation (2015) Chapter 13: Seismic Analysis and Design. In: Design Standards No. 13: Embankment Dams, U.S. Department of the Interior, $352 \mathrm{p}$.

USBR: United States Bureau of Reclamation (2018) Projects \& Facilities: Casitas Dam. https://www.usbr.gov/projects/index.php?id=276.

USDOT: U.S. Department of Transportation (1995) Recording and Coding Guide for the Structure Inventory and Appraisal of the Nation's Bridges. Federal Highway Administration, report no. FHWA-PD-96-001, 124 p.

USDOT: U.S. Department of Transportation (2007) Asset Management Overview. Federal Highway Administration Office of Asset Management, report no. FHWA-IF-08$008,52 \mathrm{p}$.

USDOT: U.S. Department of Transportation (2012) Achieving the Bridges of Tomorrow:

The Long-Term Bridge Performance Program, publication no. FHWA-HRT-12017, http://www.fhwa.dot.gov/publications/focus/12sep/12sep03.cfm.

USDOT: U.S. Department of Transportation (2013) Performance Management, http://www.fhwa.dot.gov/map21/factsheets/pm.cfm.

USDOT: U.S. Department of Transportation (2015) Moving Ahead for Progress in the 21st Century Act (MAP-21), http://www.dot.gov/map21. 
USGS: U.S. Geological Survey (1999) National Elevation Dataset, 10 m Digital Elevation Model.

USGS: U.S. Geological Survey (2005) Landslide hazards - a national threat. USGS Fact Sheet 2005-3156, Dec. 2005, 2 p.

USGS: U.S. Geological Survey (2015) High Resolution Orthoimagery (HRO). https://lta.cr.usgs.gov/high_res_ortho.

USGS: U.S. Geological Survey (2017) National Elevation Dataset, Hillshade Map, 10 m Digital Elevation Model. https://ta.cr.usgs.gov/NED.

USGS: U.S. Geological Survey (2018) The National Map. https://nationalmap.gov/index.html.

van Westen CJ, Rengers N, Terlien MTJ, and Soeters R (1997) Prediction of the occurrence of slope instability phenomena through GIS-based hazard zonation. Geologische Rundschau, 86(2):404-414.

Varnes DJ (1978) Slope movement types and processes. In: Special Report 176, Schuster RL and Krizek RJ (eds.), Landslides: Analysis and Control, Transportation Research Board, National Research Council, Washington, D.C., 11-33.

Vermeesch P and Drake N (2008) Remotely sensed dune celerity and sand flux measurements of the world's fastest barchans (Bodélé, Chad). Geophysical Research Letters, 35(24):L24404.

Vessely M (2013) Geotechnical Asset Management: Implementation Concepts and Strategies. United States Department of Transportation, Central Federal Lands Highway Division, Pub. No. FHWA-CFL/TD-13-003, 1-73.

Vessely M, Widmann B, Walters B, Collins M, Funk N, Ortiz T, and Liapply J (2015) Wall and Geotechnical Asset Management Implementation at the Colorado Department of Transportation. Transportation Research Board: Journal of the Transportation Research Board, 2529:27-36.

Voight B (1989a) A method for prediction of volcanic eruptions. Nature, 332:125-130.

Voight B (1989b) A Relation to Describe Rate-Dependent Material Failure. Science, New Series, 243(4888):200-203. 
Vonder Linden K (1989) The Portuguese Bend landslide. Engineering Geology, 27(14):301-373.

Vonder Linden K and Lindvall CE (1982) The Portuguese Bend landslide. In: Cooper JD (ed) Volume and Guidebook: Landslides and Landslide Abatement. Geological Society of America, Palos Verdes Peninsula, Southern California, Cordilleran Section, 78th Annual Meeting, 49-56.

Wang Y, Zhu XX, Zeisl B, and Pollefeys M (2017) Fusing meter-resolution 4-D InSAR point clouds and optical images for semantic urban infrastructure monitoring. IEEE Transactions on Geoscience and Remote Sensing, 55(1):14-26.

Wartman J and Malasavage NE (2013) Predicting Time-to-Failure in Slopes from Precursory Displacements: A Centrifuge Experiment. Geo-Congress 2013, 741749.

Wei M and Sandwell DT (2010) Decorrelation of L-band and C-band interferometry over vegetated areas in California. IEEE Transactions on Geoscience and Remote Sensing, 48(7):2942-2952.

Wei Y and Sun Y (2010) Study on modeling dam settlement by grey system method [J]. Journal of China Institute of Water Resources and Hydropower Research, 1:007.

Westoby MJ, Brasington J, Glasser NF, Hambrey MJ, and Reynolds JM (2012) 'Structurefrom-Motion' photogrammetry: A low-cost, effective tool for geoscience applications. Geomorphology, 179:300-314.

Wieczorek GF (1984) Preparing a detailed landslide-inventory map for hazard evaluation and reduction. Bulletin of the Association of Engineering Geologists, 21(3):337342.

Woodring WP, Bramlette MN, and Kew WSW (1946) Geology and paleontology of the Palos Verdes Hills, California. U.S. Geological Survey Professor Papers 207, 145 p.

Woodruff JM (2005) Consequence and likelihood in risk estimation: A matter of balance in UK health and safety risk assessment practice. Safety Science, 43:345-353. 
Wright TL (1991) Structural geology and tectonic evolution of the Los Angeles basin, California. In: Biddle KT (ed) Active margin basins. American Association of Petroleum Geologists memoir, 52:35-134.

WSDOT: Washington State Department of Transportation (2015) Rebuilding SR 530. http://www.wsdot.wa.gov/projects/SR530/Landslide/.

Wyllie DC (1980) Toppling rock slope failures: examples of analysis and stabilization. Rock Mechanics, 13:89-98.

Wyllie DC (1987) Rock slope inventory system. Proceedings of the Federal Highway Administration Rock Fall Mitigation Seminar, FHWA, Region 10, Portland, Oregon, $25 \mathrm{p}$.

Wyllie DC, McCammon NR, and Brumund WF (1979) Use of risk analysis in planning slope stabilization programs on transportation routes. Research Record 749, Transportation Research Board, Washington, D.C.

Xue YT, Meng XM, Li K, and Chen G (2015) Loess Slope Instability Assessment Based on PS-InSAR Detected and Spatial Analysis in Lanzhou Region, China. Advanced Materials Research, 1065:2342-2352.

Zeiser Kling Consultants, Inc. (2006) Evaluation of Recent Movement related to the Klondike Canyon Landslide, Rancho Palos Verdes, California. Correspondence with the City of Rancho Palos Verdes, PN 97082-1364, March 14, 10 p.

Zhao C, Zhang Q, He Y, Peng J, Yang C, and Kang Y (2016) Small-scale landslide monitoring with small baseline subsets interferometric synthetic aperture radar technique - case study of Xingyuan landslide, Shaanxi, China. Journal of Applied Remote Sensing, 10(2):1-14.

Zhu PY, Zhou Y, Thevenaz L, and Jiang GL (2009) Seepage and settlement monitoring for earth embankment dams using fully distributed sensing along optical fibers. In 2008 International Conference on Optical Instruments and Technology: Optoelectronic Measurement Technology and Applications, 7160:716013. 


\section{Appendix}

\section{A.1 Processing Workflows}

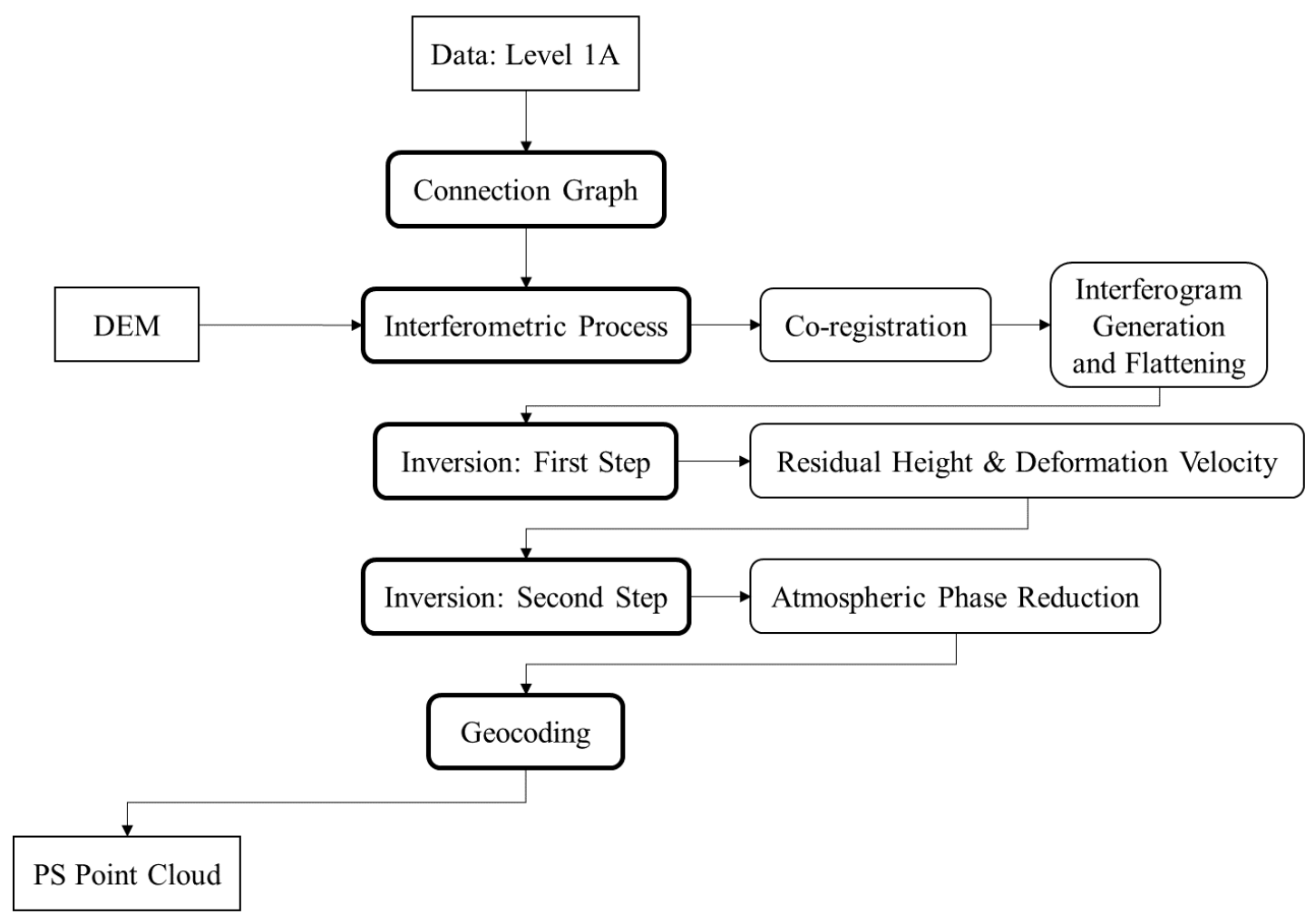

Figure A.1.1: PSI workflow. 


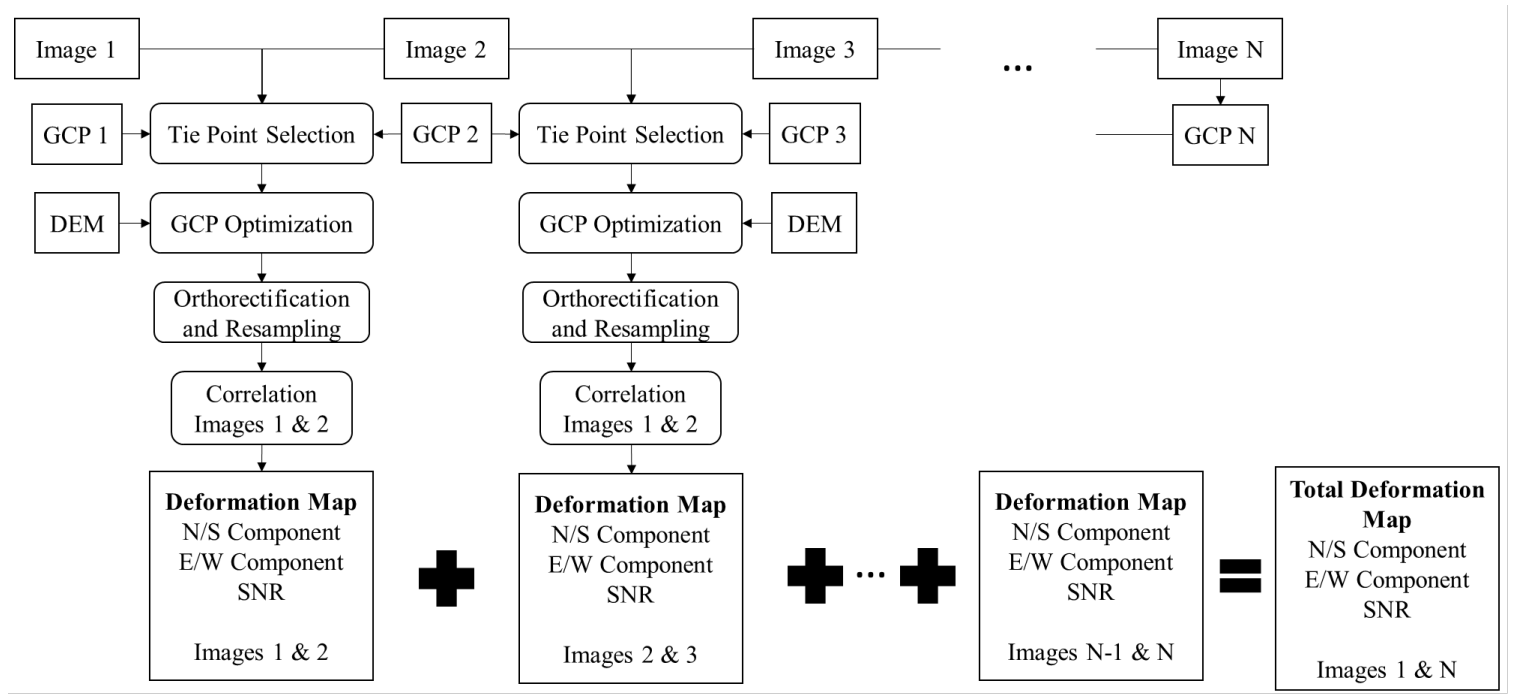

Figure A.1.2: COSI-Corr workflow. 


\section{A.2 Abstracts for Conference Presentations}

The abstracts for conference presentations given on the topic of remote sensing for geotechnical and natural hazard applications are listed below in chronological order. Subsections are titled by presentation name. The presenter is denoted with an asterisk $\left({ }^{*}\right)$.

\section{A.2.1 An Application of Interferometric Synthetic Aperture Radar in a Railroad Corridor}

El Hachemi Bouali ${ }^{1}$, Thomas Oommen ${ }^{1 *}$, Rüdiger Escobar-Wolf ${ }^{1}$, and Samuel C Douglas ${ }^{2}$ ${ }^{1}$ Department of Geological and Mining Engineering and Sciences, Michigan Technological University, 1400 Townsend Drive, Houghton, MI 49931

${ }^{2}$ Union Pacific Railroad, Omaha, NE 68179

Presented at the 2014 Annual Technical Forum for Geohazards Impacting Transportation, August 5-7, 2014 in Lexington, Kentucky.

The value of using the remote sensing technique Interferometric Synthetic Aperture Radar (InSAR) to detect ground movement has been recognized and is increasing in popularity over the last decade. InSAR has been widely used to detect surficial deformation due to natural hazards (e.g. landslides, subsidence, lava flows, etc.). Specialized InSAR techniques, such as Persistent Scatterer Interferometry (PSI), has allowed for millimeterscale detection of ground motion on coherent structures and landmarks, which are mainly found in urban areas. Therefore, applications of these InSAR techniques have been focused around ground deformation beneath anthropogenic structures, such as those found within the transportation environment.

The purpose of this project is to examine the use of InSAR within a specific and relatively complex transportation environment: a railroad corridor that passes through complex terrain. Two InSAR techniques are used to study the ground deformation along the railroad corridor. Both approaches use the same 51 single-look complex images (Level 1) from ENVISAT-ASAR (C-band SAR, $5.331 \mathrm{GHz}$ ) acquired between 2003 and 2010. The first approach is the generation of interferograms to view the phase change between 
chronological pairs of scenes. The second approach utilizes the PSI technique, an interferometric stacking method, which allows for quantitative results in the form of spatial ground velocity points and displacement time-series analyses. By using this multi-tiered approach, InSAR results allow for the generation of useful datasets, such as deformation hazard maps, which are beneficial in providing data for preventative transportation asset management.

\section{A.2.2 Interferometric Synthetic Aperture Radar Applied to Geotechnical Asset Management in Transportation Environments}

El Hachemi Bouali ${ }^{1 *}$, Rüdiger Escobar-Wolf ${ }^{1}$, and Thomas Oommen ${ }^{1}$

${ }^{1}$ Department of Geological and Mining Engineering and Sciences, Michigan Technological University, 1400 Townsend Drive, Houghton, MI 49931

Presented at the Association of Environmental \& Engineering Geologists $57^{\text {th }}$ Annual Meeting, September 20-28, 2014 in Scottsdale, Arizona.

The geotechnical assets that are common to various transportation environments include cut slopes, embankments, retaining structures, rock slopes, culverts, and pipelines. These geotechnical assets often provide the foundational building block that holds or supports other transportation assets. Monitoring and maintaining these assets along the transportation corridor is particularly challenging due to its vastness. Therefore, it has become a common practice for transportation agencies to approach asset maintenance with a worst first mindset: focus on the infrastructure in the worst, or failed condition prior to addressing any preventative measures. The high logistical expenses and labor costs required for field investigation to maintain all assets leads to this mindset. Therefore, developing an approach that would be cost effective, relatively easy to use, and would allow for data processing over a large swath of area over a short period of time could be an ideal approach for geotechnical asset management (GAM). Remote sensing techniques are capable of fulfilling these criteria. This project focuses on the application of Interferometric Synthetic Aperture Radar (InSAR) techniques to directly measure ground motion along 
and near geotechnical assets in four different transportation environments: (1) Alaskan highway through mountainous terrain; (2) a segment of the Trans-Alaska Pipeline System; (3) the Michigan 10 highway; (4) part of the Union Pacific Railroad. Applying InSAR to these differing environments will allow for a better understanding of the advantages and limitations of using this technique and, ultimately, to incorporate these methods for transportation assets and GAM. This project will illustrate the capabilities of InSAR usage over different transportation environments, discuss various calibration and validation efforts, and compare InSAR displacement results to field-derived displacement data as a measure of accuracy of this remote sensing application.

\section{A.2.3 Field Verification of Satellite-based Velocity Data}

El Hachemi Bouali ${ }^{1 *}$, Thomas Oommen ${ }^{1}$, and Rüdiger Escobar-Wolf ${ }^{1}$

${ }^{1}$ Department of Geological and Mining Engineering and Sciences, Michigan Technological University, 1400 Townsend Drive, Houghton, MI 49931

Presented at the Geological Society of America North-Central Section $49^{\text {th }}$ Annual Meeting, May 19-20, 2015, in Madison, Wisconsin.

Interferometric Synthetic Aperture Radar (InSAR) has become a popular satellitebased remote sensing technique used to measure many types of ground deformation, including subsidence/uplift, faulting, and landslides. InSAR stacking, such as the Persistent Scatterer Interferometry (PSI) algorithm, allows for pixel-scale velocity measurements as accurate as $1 \mathrm{~mm} / \mathrm{year}$. The purpose of this project is to assess the capabilities of PSI to identify hazard zones through field verification and validation.

The study area is a $30-\mathrm{km}$ railroad corridor that traverses a canyon system composed of volcanic sediments and rocks in southeastern Nevada. Since 2005, sporadic rockfalls have occurred along slopes near the railroad tracks, prompting an investigation of the capabilities of various remote sensing techniques to monitor slope movements and to identify additional, potentially unstable regions. With the use of PSI a total of 90 satellite 
images (ERS-1/-2 and ENVISAT), acquired over the railroad corridor from 1992 to 2011, were processed and results are in the form of persistent scatterer (PS) points.

Potential hazard zones were identified using qualitative criteria similar to those found in current slope management programs. Slopes were classified as hazardous if they displayed the following three criteria: (1) slope height $\geq 50$ feet, (2) located within 100 feet of railroad tracks, and (3) average downslope velocity $>2 \mathrm{~mm} /$ year. 13 potential hazard zones were identified. This presentation will discuss the capability of radar interferometry, coupled with basic slope management criteria, to accurately identify downslope movements along a transportation environment. Field verification will help solidify the benefits of utilizing InSAR techniques.

\section{A.2.4 Can We Extract Information Regarding Transportation Asset Condition from Satellite-based Radar Interferometric Data?}

El Hachemi Bouali ${ }^{1 *}$, Thomas Oommen ${ }^{1}$, and Rüdiger Escobar-Wolf ${ }^{1}$

${ }^{1}$ Department of Geological and Mining Engineering and Sciences, Michigan Technological University, 1400 Townsend Drive, Houghton, MI 49931

Presented at the Association of Environmental \& Engineering Geologists $58^{\text {th }}$ Annual Meeting, September 19-26, 2015 in Pittsburgh, Pennsylvania.

As many transportation agencies adopt asset management (AM) programs for preventative care and long-term maintenance purposes, it is becoming more apparent that the myriad of disparate asset types across large-scale transportation networks (e.g., statewide level) are difficult to adequately manage in a timely fashion. There seems to be a disconnect between the robust requirements for successful AM implementation, as described by various transportation agencies' AM frameworks, and the completion of these requirements in the field. For example, the recently-passed Moving Ahead from Progress in the $21^{\text {st }}$ Century Act (MAP-21) dictates that each State Department of Transportation is required to develop a risk-based AM plan and are encouraged "to include all infrastructure 
assets within the right-of-way corridor..." This is a daunting task if done entirely via fieldbased methods.

The authors investigate the use of radar interferometry, a remote sensing technique where all data are acquired via active microwave sensors attached to polar orbiting satellites, towards the condition assessment of various asset types (e.g., geotechnical, transportation, and pavement) within the transportation corridor. An analysis of different radar interferometry outputs - primary products such as interferograms, coherence maps, amplitude imagery, and persistent scatterer points - is explored to see if secondary products may be generated to further assist in the initial condition assessment and long-term monitoring steps of AM programs.

\section{A.2.5 A Multi-Sensor Approach to Monitor Slope Displacement}

El Hachemi Bouali ${ }^{1 *}$, Thomas Oommen ${ }^{1}$, and Rüdiger Escobar-Wolf ${ }^{1}$

${ }^{1}$ Department of Geological and Mining Engineering and Sciences, Michigan Technological University, 1400 Townsend Drive, Houghton, MI 49931

Presented at the American Geophysical Union Fall 2015 Meeting, December 14-18, 2015, in San Francisco, California.

The use of remote sensing toward slope monitoring and landslide detection has been widespread. Common techniques include interferometric synthetic aperture radar (InSAR), light detection and ranging (LiDAR), and optical photogrammetric methods. Each technique can measure ground motion when data over the same region are acquired through multiple acquisitions, with typical data outputs displayed in spatial form (e.g., displacement/velocity maps or two- and three-dimensional change detection models) or in temporal form (e.g., displacement time series).

The authors apply a multi-sensor approach - combining satellite-based InSAR, terrestrial LiDAR, and aerial optical photogrammetry - in order to optimize these remote sensing techniques based on their advantages and limitations. This application is conducted over a railroad corridor in southeastern Nevada. InSAR results include the calculation of 
displacement rates across many slopes over a long period of time. Two slopes, identified as potentially hazardous, are further analyzed in greater detail using LiDAR and optical photogrammetry. Slope displacements are measured using a point-cloud change detection analysis; the potential for stacking acquisitions to create displacement time-series is also explored. Overall, the goal is to illustrate the benefits of using a multi-sensor, remote sensing approach towards the monitoring of slope instability.

\section{A.2.6 Monitoring Slope Instability and Ground Deformation across the Palos Verdes Peninsula with COSMO-SkyMed Satellite Radar Imagery}

El Hachemi Bouali ${ }^{1 *}$

${ }^{1}$ Department of Geological and Mining Engineering and Sciences, Michigan Technological University, 1400 Townsend Drive, Houghton, MI 49931

Presented at the 2016 Graduate Research Colloquium at Michigan Technological University, February 24-25, 2016, in Houghton, Michigan.

The Palos Verdes Peninsula, located in southwestern Los Angeles County, California, experiences widespread slope instability and ground deformation due to many geologic and climatic factors. A majority of the landslides occur within the Palos Verdes Hills, a complex of ancient and modern mass movements atop the southward-dipping portion of an anticline. Landslides can be classified into two groups: (1) deep-seated translational slides with a slip surface usually adjacent to the Altamira Shale Formation, and (2) relatively shallow complex slides occurring on remnant deposits of past mass movements. Climatic factors, mainly precipitation, have been correlated to increased slope instability as the magnitude of landslides increases during the wet season (winter to spring). In order to understand the spatial and temporal variations in ground deformation across the peninsula, an interferometric synthetic aperture radar (InSAR) stacking technique (persistent scatterer interferometry, PSI) was used to process 40 COSMO-SkyMed satellite radar images acquired between July 2012 and September 2014. PSI allows for the conversion of single-look complex radar images, which measure the amplitude and phase 
of radar echoes, into ground deformation maps that show deformation rates (e.g., velocity) down to $1 \mathrm{~mm} /$ year at a spatial resolution of $3 \mathrm{~m}$. This presentation will illustrate the capabilities of InSAR to monitor slope instability in rural environments and the impacts of widespread ground deformation on anthropogenic structures in adjacent urban environments.

\section{A.2.7 Rockfall Hazard Analysis using Satellite, UAV, and Field Data: A Comparison of Techniques and RHRS Results}

El Hachemi Bouali ${ }^{1 *}$, Thomas Oommen ${ }^{1}$, Stanley Vitton ${ }^{2}$, Rüdiger Escobar-Wolf ${ }^{1}$, and Colin Brooks ${ }^{3}$

${ }^{1}$ Department of Geological and Mining Engineering and Sciences, Michigan Technological University, 1400 Townsend Drive, Houghton, MI 49931

${ }^{2}$ Department of Civil and Environmental Engineering, Michigan Technological University, 1400 Townsend Drive, Houghton, MI 49931

${ }^{3}$ Michigan Tech Research Institute, 3600 Green Court, Suite 100, Ann Arbor, MI 48105

Presented at the Association of Environmental \& Engineering Geologists $59^{\text {th }}$ Annual Meeting, September 18-24, 2016 in Kona, Hawaii.

Providing efficient and economically feasible assessment methods is an important component of a geotechnical asset management (GAM) program. Traditionally, the assessment method has been to collect field-based data and observations. This takes time, especially for large transportation corridors. The uses of satellites and unmanned aerial vehicles (UAVs) is presently becoming a more viable method for GAM programs. This study uses the Rockfall Hazard Rating System (RHRS) as the metric for assessing rock slope conditions along a railroad corridor in southeastern Nevada. RHRS values, a measure of potential future rock slope instability, were measured along 14 slopes using three data sources: (1) detailed field investigations (the traditional and most widespread approach), (2) historical optical satellite imagery, and (3) optical UAV imagery. RHRS values generated from these three data sets were compared and contrasted. As expected, the field- 
based RHRS approach is a more robust method when compared to remote sensing techniques. The study found, however, that satellite-based data can provide meaningful RHRS estimates when accounting for image resolution limits and UAV-based data can provide RHRS estimates that are within the statistical variance of traditional field-based data.

\section{A.2.8 Comparing the California Landslide Inventory to Ground Motion Detected by the COSMO-SkyMed Satellite across the Palos Verdes Peninsula}

El Hachemi Bouali ${ }^{1 *}$, Thomas Oommen ${ }^{1}$, and Rüdiger Escobar-Wolf ${ }^{1}$

${ }^{1}$ Department of Geological and Mining Engineering and Sciences, Michigan Technological University, 1400 Townsend Drive, Houghton, MI 49931

Presented at the Association of Environmental \& Engineering Geologists $59^{\text {th }}$ Annual Meeting, September 18-24, 2016 in Kona, Hawaii.

The California Landslide Inventory (CLI), prepared by the California Geological Survey, is a digital landslide map database. A landslide inventory map establishes the extent of historic ground deformation and aids in the identification of potential locations of future activity. Incorporating landslides that have occurred statewide over the past 50 years, the CLI documents the spatial, temporal, and geologic information, acquired from various field observations, of each mass movement. Interferometric Synthetic Aperture Radar (InSAR) techniques have become a widely-used remote sensing technique for the detection and monitoring of ground deformation. Forty COSMO-SkyMed synthetic aperture radar images, acquired between July 2012 and September 2014, were processed using the Persistent Scatterer Interferometry (PSI) InSAR technique. PSI allows for the pixel-scale $(3 \mathrm{~m})$ displacement rate calculations with an accuracy of $1 \mathrm{~mm} / \mathrm{year}$. A benefit of using InSAR is that the technique can detect very slow landslides, with velocities on the mm-scale, which may not be immediately detectable by field crews. The study area is the Palos Verdes Peninsula. Located southwest of the Los Angeles metropolitan area, the peninsula contains landslide-prone regions that experience significant ground deformation, 
especially during wet seasons. The goal of this project is to combine available resources (CLI, InSAR displacement rates, and InSAR displacement time-series) to determine whether areas of relatively high displacement rates (measured using InSAR) correspond to known, historic landslides or previously unnoticed landslides.

\section{A.2.9 Utilizing PSInSAR to Monitor Transportation Asset Conditions to Maintain Mobility Efficiency}

El Hachemi Bouali ${ }^{1 *}$ and Thomas Oommen ${ }^{1}$

${ }^{1}$ Department of Geological and Mining Engineering and Sciences, Michigan Technological University, 1400 Townsend Drive, Houghton, MI 49931

Presented at the Michigan Tech Mobility Summit, April 20, 2017 in Houghton, Michigan.

Many transportation agencies are adopting asset management programs for preventative care and long-term maintenance purposes. The condition of assets such as bridges, overpasses, retaining walls, and slopes directly influence mobility efficiency within the right-of-way corridor. Mobility, inversely proportional to the cost and time required for travel (high mobility occurs with low cost and travel time), decreases when transportation assets experience extreme degradation or failure. The development of an approach that can monitor changes to transportation asset conditions over time can be of great benefit to asset management programs at any scale. The authors demonstrate the capabilities of PSInSAR, a remote sensing technique that stacks radar signals from satellites, to measure ground deformation rates along transportation assets over a period of time.

\section{A.2.10 Evaluating the Integrity of Railway Corridor Using Remote Sensing}

El Hachemi Bouali ${ }^{1 *}$, Thomas Oommen ${ }^{1}$, Rüdiger Escobar-Wolf ${ }^{1}$, Colin Brooks ${ }^{2}$, and Pasi Lautala $^{3}$

${ }^{1}$ Department of Geological and Mining Engineering and Sciences, Michigan Technological University, 1400 Townsend Drive, Houghton, MI 49931 
${ }^{2}$ Michigan Tech Research Institute, 3600 Green Court, Suite 100, Ann Arbor, MI 48105

${ }^{3}$ Department of Civil and Environmental Engineering, Michigan Technological University, 1400 Townsend Drive, Houghton, MI 49931

Presented at the Rail Infrastructure and Vehicle Inspection Technology Conference, June 20-21, 2017 in Urbana, Illinois.

Abstract written by Thomas Oommen:

Slope instability related conditions often interrupt the integrity of the railway corridor in mountainous terrains. A pro-active monitoring of the railway corridor is necessary to reduce interruption, improve safety, and more appropriate allocation of limited maintenance funds. However, a corridor wide quantitative monitoring using traditional slope monitoring techniques is challenging and cost prohibitive. In recent studies, remote sensing methods have shown promise for monitoring slope instability along railway corridors. We present a recent application of remote sensors such as Interferometric Synthetic Aperture Radar (InSAR), Light Detection and Ranging (LiDAR), and photogrammetry from satellite, airborne, mobile, and terrestrial platforms to monitor a rail corridor in Nevada. The study showed that thee sensors provide high spatial and temporal resolution to quantitatively evaluate the integrity of the rail corridor. The InSAR results indicate that $\mathrm{mm}$ scale detection of ground movements can be achieved to pro-actively monitor slope instability before a failure occurs. Whereas, the photogrammetry provides a cost-effective approach to quantify ground displacements.

\section{A.2.11 Monitoring the Casitas Dam in Ventura County, California with Satellite InSAR}

El Hachemi Bouali ${ }^{1 *}$, Thomas Oommen ${ }^{1}$, and Rüdiger Escobar-Wolf ${ }^{1}$

${ }^{1}$ Department of Geological and Mining Engineering and Sciences, Michigan Technological University, 1400 Townsend Drive, Houghton, MI 49931 
Presented at the Association of Environmental \& Engineering Geologists $60^{\text {th }}$ Annual Meeting, September 10-16, 2017 in Colorado Springs, Colorado.

The Casitas Dam is an earthfill dam built in 1959 and operated by the Bureau of Reclamation in Ventura County, California. The dam is 2,000 feet long, 334 feet tall, and impounds Coyote Creek to form Lake Casitas, a reservoir with a volume of 254,000 acrefeet. An environmental report was released in 1998 labelling the dam at risk of rupture if a magnitude-7 earthquake occurs on the proximal Red Mountain Fault. A rupture would release a 300-foot wall of water down Coyote Creek, possibly killing 400 people and causing about $\$ 430$ million in property damage. This report prompted an effort to strengthen the dam, which began in May 1999 and concluded in December 2000, by replacing liquefaction-prone soils with firm earth and building a buttress behind the dam. Interferometric Synthetic Aperture Radar (InSAR) can be utilized for the measurement of structural displacement across the Casitas Dam. This allows for long-term monitoring of dam movements and quantification of the effectiveness of stabilization efforts in 2000. For example, 24 ENVISAT images (acquired between 2005 and 2010) were processed with the Persistent Scatterer Interferometry (PSI) algorithm and revealed that portions of the Casitas Dam underwent approximately five centimeters of displacement and the buttress experienced nine centimeters of displacement, both in the downward direction. Aerial images correlate some areas of dam displacement with surficial erosion. However, there are regions of centimeter-scale displacements with no evidence of erosion, possibly indicating internal deformation of the earthfill dam and buttress. The authors use PSI results, displacement-time series, and interpolation maps to demonstrate InSAR capabilities of monitoring the Casitas Dam.

\section{A.2.12 Slow Landslide Identification using InSAR to Update the California Landslide Inventory on the Palos Verdes Peninsula}

El Hachemi Bouali ${ }^{1 *}$, Thomas Oommen ${ }^{1}$, and Rüdiger Escobar-Wolf ${ }^{1}$

${ }^{1}$ Department of Geological and Mining Engineering and Sciences, Michigan Technological University, 1400 Townsend Drive, Houghton, MI 49931 
Presented at the Geological Society of America Annual Meeting, October 22-25, 2017 in Seattle, Washington.

Sudden, quick-moving landslides are well-documented natural hazard events that can cause extreme damage and loss of life. Slow landslides, those with displacement rates less than $16 \mathrm{~mm} /$ year, may be imperceptible without proper instrumentation, but can also damage infrastructure and require expensive reconstruction efforts, typically on a longterm timescale. The objective of this presentation is to update the California Landslide Inventory (CLI) with slow landslides information from the Palos Verdes Peninsula using the Interferometric Synthetic Aperture Radar (InSAR) technique known as Persistent Scatterer Interferometry (PSI). 34 ENVISAT (2005-2010) and 40 COSMO-SkyMed (2012-2014) radar images were processed. Slow landslides detected using InSAR comprise the InSAR Landslide Inventory (ILI), which was created using four criteria: a minimum PS count, average ground velocity, slope angle, and slope aspect. Landslides in the ILI are further divided into four categories: (1) long-term slides, (2) potentially active slides, (3) relatively stable slopes, and (4) unmapped extremely slow slides. The four categories were based on whether landslides were previously mapped on that slope (in the CLI), if persistent scatterers (PS) were present, and whether PS are stable or unstable. The final inventory included 263 mapped landslides across the Palos Verdes Peninsula, of them 67 landslides were identified as unmapped extremely slow slides.

\section{A.2.13 Landslide Life-Cycle Monitoring and Failure Prediction using Satellite Remote Sensing}

El Hachemi Bouali ${ }^{1 *}$, Thomas Oommen ${ }^{1}$, and Rüdiger Escobar-Wolf ${ }^{1}$

${ }^{1}$ Department of Geological and Mining Engineering and Sciences, Michigan Technological University, 1400 Townsend Drive, Houghton, MI 49931

Presented at the American Geophysical Union Fall Meeting, December 11-15, 2017 in New Orleans, LA. 
The consequences of slope instability are severe across the world: the US Geological Survey estimates that, each year, the United States spends $\$ 3.5 \mathrm{~B}$ to repair damages caused by landslides, 25-50 deaths occur, real estate values in affected areas are reduced, productivity decreases, and natural environments are destroyed. A 2012 study by D.N. Petley found that loss of life is typically underestimated and, between 2004 and 2010, 2,620 fatal landslides caused 32,322 deaths around the world. These statistics have led research into the study of landslide monitoring and forecasting. More specifically, this presentation focuses on assessing the potential for using satellite-based optical and radar imagery toward overall landslide life-cycle monitoring and prediction. Radar images from multiple satellites (ERS-1, ERS-2, ENVISAT, and COSMO-SkyMed) are processed using the Persistent Scatterer Interferometry (PSI) technique. Optical images, from the Worldview2 satellite, are orthorectified and processed using the Co-registration of Optically Sensed Images and Correlation (COSI-Corr) algorithm. Both approaches, process stacks of respective images, yield ground displacement rate values. Ground displacement information is used to generate 'inverse-velocity vs time' plots, a proxy relationship that is used to estimate landslide occurrence (slope failure) and derived from a relationship quantified by T. Fukuzono in 1985 and B. Voight in 1988 between a material's time of failure and the strain rate applied to that material. Successful laboratory tests have demonstrated the usefulness of 'inverse-velocity vs time' plots. This presentation will investigate the applicability of this approach with remote sensing on natural landslides in the western United States.

\section{A.2.14 Satellite InSAR as an Initial Health Assessment Tool for Dams and Reservoirs}

El Hachemi Bouali ${ }^{1 *}$, Thomas Oommen ${ }^{1}$, KS Sajinkumar ${ }^{2}$, and Rüdiger Escobar-Wolf ${ }^{1}$

${ }^{1}$ Department of Geological and Mining Engineering and Sciences, Michigan Technological University, 1400 Townsend Drive, Houghton, MI 49931

${ }^{2}$ Department of Geology, University of Kerala, Karyavattom, Thiruvananthapuram, Kerala 695581, India 
Presented at the U.S. Society on Dams Conference and Exhibition, April 30 - May 2, 2018 in Miami, Florida.

Worldwide, there are over 57,000 large dams ( $>15$ meters in height) —with China, the United States, India, Japan, and Brazil owning well over 32,000 large dams. Dams provide a range of benefits: flood control; water storage in reservoirs for agricultural, industrial, and municipal uses; hydropower; navigation; debris control; and recreation. Dams also pose an inherent risk, mainly to humans, wildlife, and infrastructure downstream, for example if a dam failure occurs. Dam failures may be caused by structural failure, settlement or cracking (concrete), piping or internal erosion (soil), movement of the dam foundation, or natural deterioration due to insufficient preventative maintenance and upkeep. This paper presents a demonstration of satellite Interferometric Synthetic Aperture Radar (InSAR) as an initial health assessment tool for dam and reservoir infrastructure through a series of case studies of dams in the United States and India. InSAR techniques, such as Persistent Scatterer Interferometry (PSI), can measure small, decadal displacement rates $(\sim 1 \mathrm{~mm} /$ year) on ground targets that experience relatively minimal geometric and dielectric variations, such as anthropogenic infrastructure. Dams in these case studies are monitored using satellite radar imagery from ERS-1, ESR-2, ENVISAT, Sentinel-1, and COSMO-SkyMed, collectively between 1992 and 2016. PSI results pinpoint areas of abnormal displacement, which may indicate early signs of dam instability. This paper illustrates a rapid monitoring approach for identifying dam instability and locations that may require further structural and geotechnical assessment.

\section{A.2.15 Landslide Monitoring at Three Orders of Magnitude: PSI, COSI-Corr, and GPS Measurements at the Portuguese Bend Landslide Complex in Southern California}

El Hachemi Bouali ${ }^{1}$, Thomas Oommen ${ }^{1}$, and Rüdiger Escobar-Wolf ${ }^{1 *}$

${ }^{1}$ Department of Geological and Mining Engineering and Sciences, Michigan Technological University, 1400 Townsend Drive, Houghton, MI 49931 
Presented at the joint Association of Environmental \& Engineering Geologists $61^{\text {st }}$ Annual Meeting and $113^{\text {th }}$ International Association of Engineering Geology and the Environment Congress, September 15-23, 2018 in San Francisco, California.

The destructive potential of a landslide is directly related to its peak velocity, cumulative displacement, and activity duration. A combination of radar, optical, and GPS data were used to monitor continually-moving portions of the Portuguese Bend Landslide complex on the Palos Verdes Peninsula in southern California. Forty radar images from COSMOSkyMed, acquired between July 19, 2012 and September 27, 2014, were processed using Persistent Scatterer Interferometry (PSI). Ten optical images from WorldView-2, acquired between February 20, 2011 and March 6, 2016, were processed using the Co-registration of Optically Sensed Images and Correlation (COSI-Corr) technique. Data from 66 GPS monuments were acquired between September 2007 and May 2017. PSI, COSI-Corr, and GPS allowed for deformation measurements spanning three orders of magnitude, from mscale to mm-scale. Each technique provides an advantage where the others might be limited. COSI-Corr and GPS provide detailed coverage of m-scale deformation. COSICorr is not prone to loss of data due to rapid movements (e.g., destruction of GPS monuments); GPS is not affected by systematic remote sensing noise (e.g., COSI-Corr signal-to-noise ratio). PSI can measure extremely slow deformation (e.g., mm-scale), which COSI-Corr and GPS cannot do reliably. PSI, COSI-Corr, and GPS results were combined to monitor peak velocity ( $>1.6 \mathrm{~m} /$ year), cumulative displacement $(>10 \mathrm{~m})$, and activity duration (some locations continuously active for over 12 years), allowing for detailed spatial and temporal analyses of landslide deformation across the Portuguese Bend Landslide complex. 


\section{A.3 Copyright Permission}

\section{ASCE Authorship, Originality, and Copyright Transfer Agreement}

Publication Title: Interferometric stacking toward geo-hazard identification and geotechnical asset monitoring

Manuscript Title: Interferometric stacking toward geo-hazard identification and geotechnical asset monitoring

Author(s) - Names, postal addresses, and e-mail addresses of all authors

El Hachemi Bouali, Michigan Technological University, 1400 Townsend Drive, Houghton, MI 49931, eybouali@mtu.edu

Thomas Oommen, Michigan Technological University, 1400 Townsend Drive, Houghton, MI 49931, toommen@mtu.edu

Rudiger Escobar-Wolf, Michigan Technological University, 1400 Townsend Drive, Houghton, MI 49931, rpescoba@mtu.edu

\section{Authorship Responsibility}

To protect the integrity of authorship, only people who have significantly contributed to the research or project and manuscript preparation shall be listed as coauthors. The corresponding author attests to the fact that anyone named as a coauthor has seen the final version of the manuscript and has agreed to its submission for publication. Doccascd pcrscns who meet the criteria for coauthorship shall be included, with a footnote reporting date of death. No fictitious name shall be given as an author or coauthor. An author who submits a manuscript for publication accepts responsibility for having properly included all, and only, qualified coauthors.

I, the corresponding author, confirm that the authors listed on the manuscript are aware of their authorship status and qualify to be authors on the manuscript according to the auidelines above

El Hachemi Bouali

Print Name

Signature

Date

\section{Originality of Content}

ASCE respects the copyright ownership of other publishers. ASCE requires authors to obtain permission from the copyright holder to reproduce any material that (1) they did not create themselves and/or (2) has been previously published, to include the authors' own work for which copyright was transferred to an entity other than ASCE. Each author has a responsibility to identify materials that require permission by including a citation in the figure or table caption or in extracted text. Materials re-used from an open access repository or in the public domain must still include a citation and URL, if applicable. At the time of submission, authors must provide verification that the copyright owner will permit re-use by a commercial publisher in print and electronic forms with worldwide distribution. For Conference Proceeding manuscripts submitted through the ASCE online submission system, authors are asked to verify that they have permission to re-use content where applicable. Written permissions are not required at submission but must be provided to ASCE if requested. Regardless of acceptance, no manuscript or part of a manuscript will be published by ASCE without proper verification of all necessary permissions to re-use. ASCE accepts no responsibility for verifying permissions provided by the author. Any breach of copyright will result in retraction of the published manuscript.

I, the corresponding author, confirm that all of the content, figures (drawings, charts, photographs, etc.), and tables in the submitted work are either original work created by the authors listed on the manuscript or work for which permission to reuse has been obtained from the creator. For any figures, tables, or text blocks exceeding 100 words from a journal article or 500 words from a book, written permission from the copyright holder has been obtained and supplied with the submission.

\section{El Hachemi Bouali}

Print name

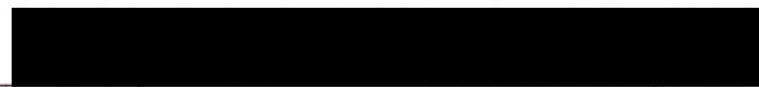

Signature
Date

\section{Copyright Transfer}

ASCE requires that authors or their agents assign copyright to ASCE for all original content published by ASCE. The author(s) warrant(s) that the above-cited manuscript is the original work of the author(s) and has never been published in its present form. 
The undersigned, with the consent of all authors, hereby transfers, to the extent that there is copyright to be transferred, the exclusive copyright interest in the above-cited manuscript (subsequently called the "work") in this and all subsequent editions of the work (to include closures and errata), and in derivatives, translations, or ancillaries, in English and in foreign translations, in all formats and media of expression now known or later developed, including electronic, to the American Society of Civil Engineers subject to the following:

- The undersigned author and all coauthors retain the right to revise, adapt, prepare derivative works, present orally, or distribute the work, provided that all such use is for the personal noncommercial benefit of the author(s) and is consistent with any prior contractual agreement between the undersigned and/or coauthors and their employer(s).

- No proprietary right other than copyright is claimed by ASCE.

- If the manuscript is not accepted for publication by ASCE or is withdrawn by the author prior to publication (online or in Fititity, this transfer will be null and void.

- Authors may post a PDF of the ASCE-published version of their work on their employers' Intranet with password protection. The following statement must appear with the work: "This material may be downloaded for personal use oniy. Any other use requires prior permission of the American Society of Civil Engineers."

- Authors may post the final draft of their work on open, unrestricted Internet sites or deposit it in an institutional repository when the draft contains a link to the published version at www.ascelibrary.org. "Final draft" means the version submitted to ASCE after peer review and prior to copyediting or other ASCE production activities; it does not include the copyedited version, the page proof, a PDF, or full-text HTML of the published version.

Exceptions to the Copyright Transfer policy exist in the following circumstances. Check the appropriate box below to indicate whether you are claiming an exception:

$\square$ U.S. GOVERNMENT EMPLOYEES: Work prepared by U.S. Government employees in their official capacities is not subject to copyright in the United States. Such authors must place their work in the public domain, meaning that it can be freely copied, republished, or redistributed. In order for the work to be placed in the public domain, ALL. AUTHORS must be official U.S. Government employees. If at least one author is not a U.S. Government employee, copyright must be transferred to ASCE by that author.

$\square$ CROWN GOVERNMENT COPYRIGHT: Whereby a work is prepared by officers of the Crown Government in their official capacities, the Crown Government reserves its own copyright under national law. If ALL AUTHORS on the manuscript are Crown Government employees, copyright cannot be transferred to ASCE; however, ASCE is given the following nonexclusive rights: (1) to use, print, and/or publish in any language and any format, print and electronic, the above-mentioned work or any part thereof, provided that the name of the author and the Crown Government affiliation is clearly indicated; (2) to grant the same rights to others to print or publish the work; and (3) to collect royalty fees. ALL AUTHORS must be official Crown Government employees in order to claim this exemption in its entirety. If at least one author is not a Crown Government employee, copyright must be transferred to ASCE by that author.

$\square$ WORK-FOR-HIRE: Privately employed authors who have prepared works in their official capacity as employees must also transfer copyright to ASCE; however, their employer retains the rights to revise, adapt, prepare derivative works, publish, reprint, reproduce, and distribute the work provided that such use is for the promotion of its business enterprise and does not imply the endorsement of ASCE. In this instance, an authorized agent from the authors' employer must sign the form below.

$\square$ U.S. GOVERNMENT CONTRACTORS: Work prepared by authors under a contract for the U.S. Government (e.g., U.S. Government labs) may or may not be subject to copyright transfer. Authors must refer to their contractor agreement. For works that qualify as U.S. Government works by a contractor, ASCE acknowledges that the U.S. Government retains a nonexclusive, paid-up, irrevocable, worldwide license to publish or reproduce this work for U.S. Government purposes only. This policy DOES NOT apply to work created with U.S. Government grants.

I, the corresponding author, acting with consent of all authors listed on the manuscript, hereby transfer copyright or claim exemption to transfer copyright of the work as indicated above to the American Society of Civil Engineers.

\section{El Hachemi Bouali}




\section{ASCE Authorship, Originality, and Copyright Transfer Agreement}

Publication Title: Geotechnical Frontiers 2017 Conference Proceedings

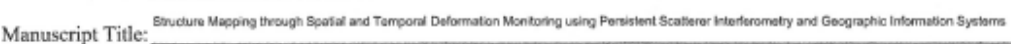

Author(s) - Names, postal addresses, and e-mail addresses of all authors

El Hachemi Y. Bouali, 1400 Townsend Dr., Houghton, MI 49931, eybouali@mtu.edu

Thomas Oommen, 1400 Townsend Dr., Houghton, MI 49931, toommen@mtu.edu

Rudiger Escobar-Wolf, 1400 Townsend Dr., Houghton, Ml 49931, rpescoba@mtu.edu

\section{Authorship Responsibility}

To protect the integrity of authorship, only people who have significantly contributed to the research or project and manuscript preparation shall be listed as coauthors. The corresponding author attests to the fact that anyone named as a coauthor has seen the final version of the manuscript and has agreed to its submission for publication. Deceased persons who meet the criteria for coauthorship shall be included, with a footnote reporting date of death. No fictitious name shall be given as an author or coauthor. An author who submits a manuscript for publication accepts responsibility for having properly included all, and only, qualified coauthors.

I. the corresponding author, confirm that the authors listed on the manuscript are aware of their authorship status and qualify to be authors on the manuscript according to the guidelines above.

El Hachemi Bouali

Print Name

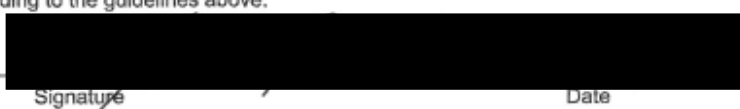

II. Originality of Content

ASCE respects the copyright ownership of other publishers. ASCE requires authors to obtain permission from the copyright holder to reproduce any material that (1) they did not create themselves and/or (2) has been previously published, to include the authors' own work for which copyright was transferred to an entity other than ASCE. Each author has a responsibility to identify materials that require permission by including a citation in the figure or table caption or in extracted text. Materials re-used from an open access repository or in the public domain must still include a citation and URL, if applicable. At the time of submission, authors must provide verification that the copyright owner will permit re-use by a commercial publisher in print and electronic forms with worldwide distribution. For Conference Proceeding manuscripts submitted through the ASCE online submission system, authors are asked to verify that they have permission to re-use content where applicable. Written permissions are not required at submission but must be provided to ASCE if requested. Regardless of acceptance, no manuscript or part of a manuscript will be published by ASCE without proper verification of all necessary permissions to re-use. ASCE accepts no responsibility for verifying permissions provided by the author. Any breach of copyright will result in retraction of the published manuscript.

I, the corresponding author, confirm that all of the content, figures (drawings, charts, photographs, etc.), and tables in the submitted work are either original work created by the authors listed on the manuscript or work for which permission to reuse has been obtained from the creator. For any figures, tables, or text blocks exceeding 100 words from a journal article or 500 words from a book, written permission from the copyright holder has been obtained and supplied with the submission.

El Hachemi Bouali

Print name

Signature

Date

III. Copyright Transfer

ASCE requires that authors or their agents assign copyright to ASCE for all original content published by ASCE. The author(s) warrant(s) that the above-cited manuscript is the original work of the author(s) and has never been published in its present form. 
The undersigned, with the consent of all authors, hereby transfers, to the extent that there is copyright to be transferred the exclusive copyright interest in the above-cited manuscript (subsequently called the "work") in this and all subsequent editions of the work (to include closures and errata), and in derivatives, translations, or ancillaries, in English and in foreign translations, in all formats and media of expression now known or later developed, including electronic, to the American Society of Civil Engineers subject to the following:

- The undersigned author and all coauthors retain the right to revise, adapt, prepare derivative works, present orally, or distribute the work, provided that all such use is for the personal noncommercial benefit of the author(s) and is
consistent with any prior contractual agreement between the undersigned and/or coauthors and their employer(s).

- No proprietary right other than copyright is claimed by ASCE.

- If the manuscript is not accepted for publication by ASCE or is withdrawn by the author prior to publication (online or in print), this transfer will be null and void.

- Authors may post a PDF of the ASCE-published version of their work on their employers' Intranet with password protection. The following statement must appear with the work: "This material may be downloaded for personal use only. Any other use requires prior permission of the American Society of Civil Engineers."

- Authors may post the final draft of their work on open, unrestricted Internet sites or deposit it in an institutional repository when the draft contains a link to the published version at www.ascelibrary.org. "Final draft" means the version submitted to ASCE after peer review and prior to copyediting or other ASCE production activities; it does not include the copyedited version, the page proof, a PDF, or full-text HTML of the published version.

Exceptions to the Copyright Transfer policy exist in the following circumstances. Check the appropriate box below to indicate whether you are claiming an exception:

$\square$ U.S. GOVERNMENT EMPLOYEES: Work prepared by U.S. Government employees in their official capacities is not subject to copyright in the United States. Such authors must place their work in the public domain, meaning that it can be freely copied, republished, or redistributed. In order for the work to be placed in the public domain, ALL AUTHORS must be official U.S. Government employees. If at least one author is not a U.S. Government employee, copyright must be transferred to ASCE by that author.

$\square$ CROWN GOVERNMENT COPYRIGHT: Whereby a work is prepared by officers of the Crown Government in their official capacities, the Crown Government reserves its own copyright under national law. If ALL AUTHORS on the manuscript are Crown Government employees, copyright cannot be transferred to ASCE; however, ASCE is given the following nonexclusive rights: (1) to use, print, and/or publish in any language and any format, print and electronic, the above-mentioned work or any part thereof, provided that the name of the author and the Crown Government affiliation is clearly indicated; (2) to grant the same rights to others to print or publish the work; and (3) to collect royalty fees. ALL AUTHORS must be official Crown Government employees in order to claim this exemption in its entirety. If at least one author is not a Crown Government employee, copyright must be transferred to ASCE by that author.

$\square$ WORK-FOR-HIRE: Privately employed authors who have prepared works in their official capacity as employees must also transfer copyright to ASCE; however, their employer retains the rights to revise, adapt, prepare derivative works, publish, reprint, reproduce, and distribute the work provided that such use is for the promotion of its business enterprise and does not imply the endorsement of ASCE. In this instance, an authorized agent from the authors' employer must sign the form below.

$\square$ U.S. GOVERNMENT CONTRACTORS: Work prepared by authors under a contract for the U.S. Government (e.g., U.S. Government labs) may or may not be subject to copyright transfer. Authors must refer to their contractor agreement. For works that qualify as U.S. Govemment works by a contractor, ASCE acknowledges that the U.S. Government retains a nonexclusive, paid-up, irrevocable, worldwide license to publish or reproduce this work for U.S. Government purposes only. This policy DOES NOT apply to work created with U.S. Government grants.

I, the corresponding author, acting with consent of all authors listed on the manuscript, hereby transfer copyright or claim exemption to transfer copyright of the work as indicated above to the American Society of Civil Engineers.

\section{El Hachemi Bouali}

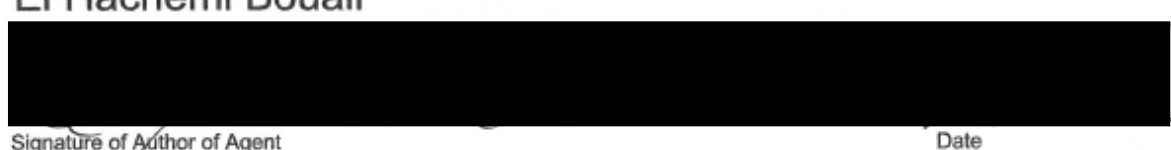

Signature of Adothor of Agent

Date

More information regarding the policies of ASCE can be found at http://www.asce.org/authorsandeditors 
EEG Manuscript Number

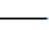

Manuscript Title:

Names of all Authors in manuscript order:

Corresponding Author Name, Address, phone, email:

Copyright Transfer Agreement

The undersigned, with the consent of all the co-authors, hereby transfers to the Association of Environmental \& Engineering

Geologists (AEG) the copyright for the above-cited manuscript ("article") including all tables, illustrations or other information submitted therewith that are intended for publication as part of the article in all forms and media, including electronic, throughout the world, in all languages, effective when and if the article is accepted for publication. The AEG's Policy Number II-12, Copyright Policy, is hereby considered part of this Agreement by reference.

Copyright is not claimed for author(s) who are U.S. Govemment employees and who contributed to the above-cited article as part of their professional employment. If any authors are in this category, check here 0 and insert names below;

Author's Rights

The authors retain the following rights without needing to seek permission from AEG:

1. use the article for personal use and within the employer's institution or company for educational or research purposes, including use in course packs;

2. revise, adapt, prepare derivative works, present orally, or distribute the arficle, provided that all such use is for the personal noncommercial benefit of the author(s) and is consistent with any prior contractual agreement between the undersigned and/or coauthors and their employer(s);

3. post the abstract of the article on his/her webpage and/or that of his/her employer but there must be a link to the AEG website for the full paper. Authors are not permitted to post the full published version of the EEG article online.

4. AEG claims no proprietary right, other than copyright; no rights in patents, trademarks or other intellectual property rights are transferred to the journal.

\section{Authors' Affirmations}

The undersigned, on behalf of all authors, affirms that:

1. the co-author(s) are aware that I am signing on their behalf and hereby transfer the copyright to the AEG

2. the above-cited manuscript is the original work of the author(s);

3. the article has not been published before;

4. the article is not being considered for publication elsewhere in either printed or electronic form;

5. the article contains no violation of any existing copyright or third party rights.

\section{SIGN HERE FOR COPYRIGHT TRANSFER}

[Corresponding Author]

Print Name: Signature

Date:

Note: If the manuscript is not accepted by EEG or is withdrawn prior to acceptance by EEG, this transfer will be null and void.

Please return this form to Abdul Shakoo

Department of Geology

Kent State University

Kent, $\mathrm{OH} 44242$

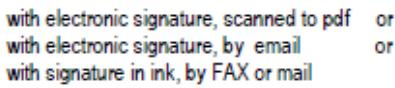

Ph: $330-672-2968$

Fax: $330-672-7949$ email: ashakoor@kent.edu

This article will not be published unless a Copyright Transfer Agreement has been signed and received by Environmental and Engineering Geoscience journal Editorial Office. 


\section{首 Springer}

\section{Self-archiving policy}

We are a 'green' publisher, as we allow self-archiving, but most importantly we are fully transparent about your rights.

Publishing in a subscription-based journal

By signing the Copyright Transfer Statement you still retain substantial rights, such as self-archiving

Author(s) are permitted to self-archive a pre-print and an author's accepted manuscript version of their Article.

a. a pre-print is the author's version of the Article before peer-review has taken place ("Pre-Print'). Prior to acceptance for publication,

Author(s) retain the right to make a Pre-Print of their Article available on any of the following: their own personal, self- maintained website;

legally compliant, non-commercial pre-print server such as but not limited to arXiv and bioRxiv. Once the Article has been published, the Author(s) should update the acknowledgement and provide a link to the definitive version on the publisher's website: 'This is a pre-print of

an article published in [insert jounal titeg The fing authenticated ver

b. An Author's Accepted Manuscript (AAM) is the version accepted for publication in a joumal following peer review but prior to copyediting and typesetting that can be made available under the following conditions:

a. Author(s) retain the right to make an AAM of their Article available on their own personal, self- maintained website immediately on acceptance,

b. Author(s) retain the right to make an AAM of their Article available for public release on any of the following 12 months after first

An acknowledgement in the following form should be included, together with a link to the published version on the publisher's website: "This is a post-peer-review, pre-copyedit version of an article published in [insert journal title]. The final authenticated version is available online

When publishing an article in a subscription journal, without open access, authors sign the Copyright Transfer Statement (CTS) which also details Springer's self-archiving policy.

See here for Springer Nature terms of reuse for archived author accepted manuscripts (AAMs) of subscription articles.

Publishing open access

If you publish your article open access, the final published version can be archived in institutional or funder repositories and can be made publicly accessible immediately.

Open Access at Springer 